University of Windsor

Scholarship at UWindsor

\title{
STUDY OF MOTOR OIL COOLING AT LOW REYNOLDS NUMBER IN MULTI-PORT NARROW CHANNELS
}

\author{
Mohammed Saadi \\ University of Windsor
}

Follow this and additional works at: https://scholar.uwindsor.ca/etd

\section{Recommended Citation}

Saadi, Mohammed, "STUDY OF MOTOR OIL COOLING AT LOW REYNOLDS NUMBER IN MULTI-PORT NARROW CHANNELS" (2012). Electronic Theses and Dissertations. 206.

https://scholar.uwindsor.ca/etd/206

This online database contains the full-text of PhD dissertations and Masters' theses of University of Windsor students from 1954 forward. These documents are made available for personal study and research purposes only, in accordance with the Canadian Copyright Act and the Creative Commons license-CC BY-NC-ND (Attribution, Non-Commercial, No Derivative Works). Under this license, works must always be attributed to the copyright holder (original author), cannot be used for any commercial purposes, and may not be altered. Any other use would require the permission of the copyright holder. Students may inquire about withdrawing their dissertation and/or thesis from this database. For additional inquiries, please contact the repository administrator via email (scholarship@uwindsor.ca) or by telephone at 519-253-3000ext. 3208. 
STUDY OF MOTOR OIL COOLING AT LOW REYNOLDS

\title{
NUMBER IN MULTI-PORT NARROW CHANNELS
}

\author{
by \\ Mohammed Saadi

\begin{abstract}
A Thesis
Submitted to the Faculty of Graduate Studies

through Mechanical, Automotive, and Materials Engineering in Partial Fulfillment of the Requirements for the Degree of Master of Applied Science at the University of Windsor
\end{abstract}

Windsor, Ontario, Canada

2012

(C) 2012 Mohammed Saadi 
STUDY OF MOTOR OIL COOLING AT LOW REYNOLDS

NUMBER IN MULTI-PORT NARROW CHANNELS

by

Mohammed Saadi

APPROVED BY:

Dr. Tirupati Bolisetti

Department of Civil and Environmental Engineering

Dr. Gary Rankin

Department of Mechanical, Automotive and Materials Engineering

Dr. Amir Fartaj, Advisor

Department of Mechanical, Automotive and Materials Engineering

Dr. Nader Zamani, Chair of Defense

Department of Mechanical, Automotive and Materials Engineering

June $11^{\text {th }}, 2012$ 


\section{DECLARATION OF ORIGINALITY}

I hereby certify that I am the sole author of this thesis and that no part of this thesis has been published or submitted for publication.

I certify that, to the best of my knowledge, my thesis does not infringe upon anyone's copyright nor violate any proprietary rights and that any ideas, techniques, quotations, or any other material from the work of other people included in my thesis, published or otherwise, are fully acknowledged in accordance with the standard referencing practices. Furthermore, to the extent that I have included copyrighted material that surpasses the bounds of fair dealing within the meaning of the Canada Copyright Act, I certify that I have obtained a written permission from the copyright owner(s) to include such material(s) in my thesis and have included copies of such copyright clearances to my appendix.

I declare that this is a true copy of my thesis, including any final revisions, as approved by my thesis committee and the Graduate Studies office, and that this thesis has not been submitted for a higher degree to any other University or Institution. 


\begin{abstract}
Mini and micro-scale channels have drawn researchers' attention in the past three decades. The use of these channels in a heat exchanger is due to the several advantages they provide. Motor oil was chosen as the working fluid since it is greatly utilized in automotive applications. In current investigations, experiments were performed to verify the aptness of cooling the oil through a cross-flow minichannel heat exchanger. The inlet temperature of the motor oil was kept constant at $75^{\circ} \mathrm{C}$, while the air inlet temperatures were varied within the range of $20^{\circ} \mathrm{C}-40^{\circ} \mathrm{C}$. The range of oil Reynolds number was found to be between 0.85 to 3.5 whereas the air velocities were between $6 \mathrm{~m} / \mathrm{s}$ and 18 $\mathrm{m} / \mathrm{s}$. Correlations were developed between the $\mathrm{Nu}_{\text {oil }}$ and $\mathrm{Re}_{\text {oil }}$ and $\operatorname{Pr}_{\text {oil }}$. The effect of $\operatorname{Re}_{\text {oil }}$ on the heat transfer coefficient, NTU, and effectiveness were investigated. The results were compared with the findings of another viscous fluid where a similar test specimen was used and same trends were observed.
\end{abstract}




\section{Dedicated to Allah Almighty}

\section{The Most Gracious and the Most Merciful, who all praise belongs to Him alone in this world and in the Hereafter.}




\section{ACKNOWLEDGEMENTS}

Alhamdulillah "Praise be to Allah", I was able to complete this research. Yet, this research could not have been completed without the guidance, encouragement and unconditional support from those who have been around me.

The author would like to express his deepest gratitude to his academic supervisor, Dr. Amir Fartaj, for providing unlimited support and encouragement. The author feels very privileged to be able to obtain scientific advice, expertise and insightful perspectives from Dr. Fartaj. This important research would not have been finalized without his mentoring, invaluable instructions, and enthusiasm.

The author is thankful to the committee members, Dr. Gary Rankin and Dr. Tirupati Bolisetti. Their useful suggestions and observations have elevated the quality of this thesis and made it more interesting and informative.

The author would like to recognize the secretarial help and support from Ms. Rose Gignac and Ms Barb Tattersall. They have both shown a friendly demeanour and always offered professional assistance to me throughout the masters program.

A heartfelt and sincere appreciation goes to the author's colleagues: Shahram Fotowat, Md Abdul Quaiyum, Serena Askar, and Mohammed Ismail. Exceptional appreciation goes to Shahram. Mr. Fotowat has always been extremely helpful and supportive, 
especially offering his help in running the experiments. A genuine thank you goes to Abdul for his consistent help and valuable input and comments that the author has greatly benefited from. Warm gratitude goes to Ms. Askar for her assistance in compiling the thesis and her helpful suggestions and remarks. Last but definitely not the least; the author is truly appreciative to Ismail for his insightful discussions and for his help during the experimental runs.

The author must express gratitude towards his parents who have provided him with a strong work ethic to achieve his goals and unconditional support. Thank you mother for your unconditional love and prayers. Also, eternal appreciation goes to my father whom I look up to in this life and whom I always get support from.

Finally, the author would like to express his profound thankfulness to his precious wife and daughter for their patience and understanding all the way through this research. He is eternally indebted to them. 
TABLE OF CONTENTS

DECLARATION OF ORIGINALITY ....................................................................... ii

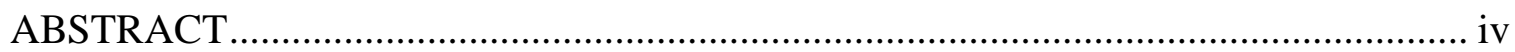

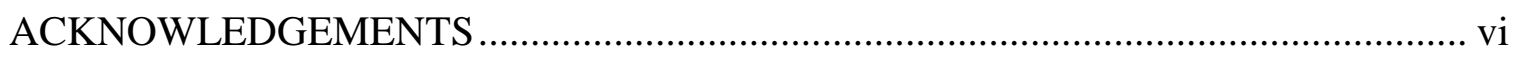

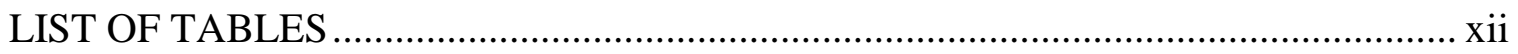

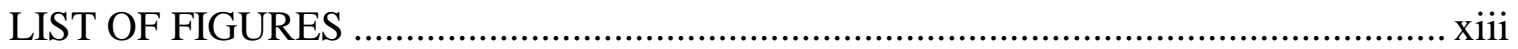

NOMENCLATURE / ABBREVIATIONS ………………....................................... xvi

\section{CHAPTER}

I. INTRODUCTION......................................................................................

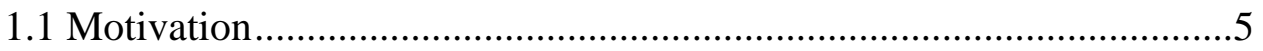

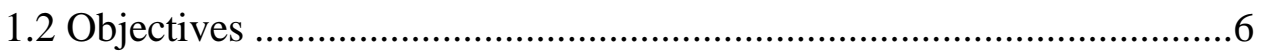

II. REVIEW OF LITERATURE.........................................................................8

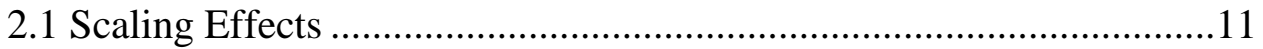

2.2 Axial Heat Conduction in Channel Wall ..............................................12

2.3 Literature Review on Axial Heat Conduction in Channel Wall ..........14

2.4 Axial Heat Conduction in Fluid...........................................................17

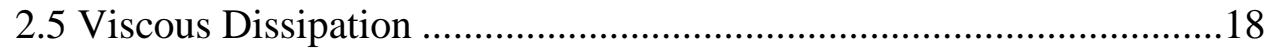

2.6 Literature Review on Viscous Dissipation .......................................18

2.7 Effects of Thermo-Physical Properties ................................................

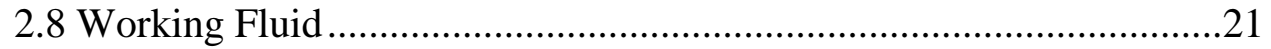

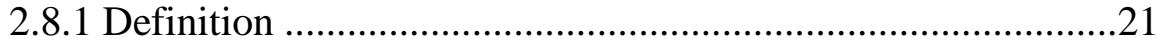

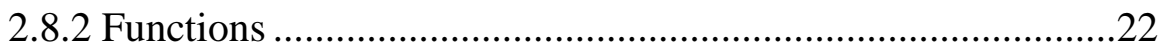

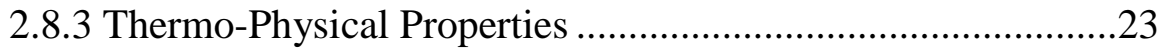

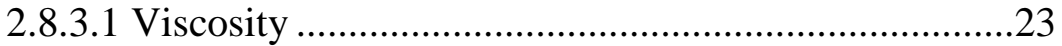

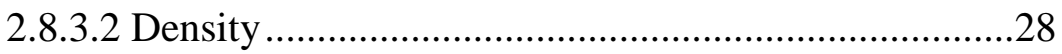

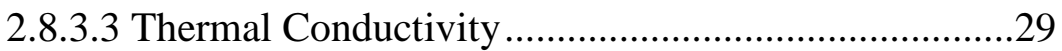

2.8.3.4 Specific Heat Capacity ..............................................29

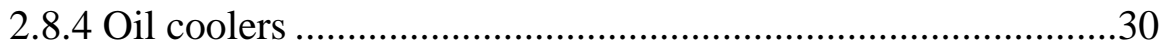

2.8.4.1 Liquid to air (tube-and-fin heat exchanger).................30

2.8.4.2 Liquid to liquid (shell-and-tube heat exchanger)........31

2.9 Scope of Current Investigation ............................................................ 
III. THEORETICAL BACKGROUND AND ANALYSIS......................33

3.1 Reference (Bulk) and Wall Temperatures .......................................34

3.2 Dimensionless Groups ................................................................36

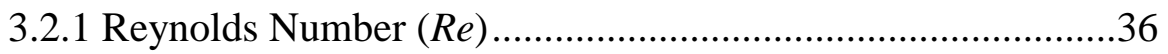

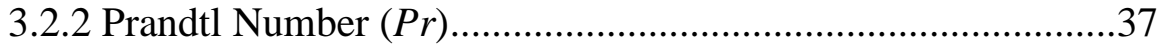

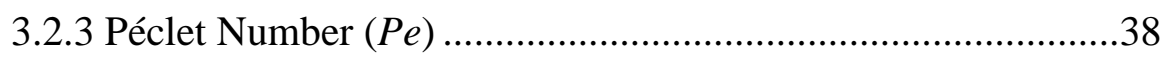

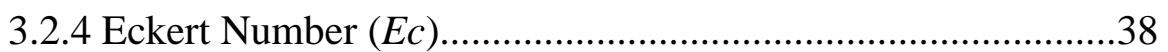

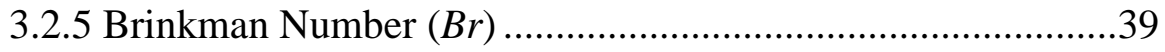

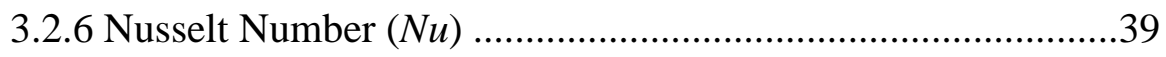

3.2.7 Axial Heat Conduction Number $(M)$..................................41

3.3 Fluid Flow Characteristics .............................................................42

3.3.1 Entrance Lengths .........................................................42

3.3.2 Motor Oil Flow Rate and Reynolds Number ........................44

3.3.3 Pressure Drop ................................................................45

3.3.4 Friction Factor ..................................................................46

3.4 Heat Transfer Characteristics.......................................................47

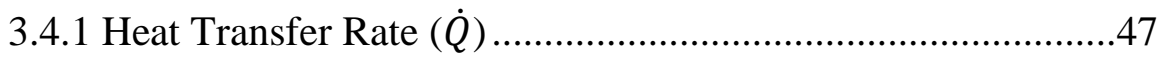

3.4.2 Heat Balance (HB) ............................................................4

3.4.3 Heat Transfer Coefficient $(h)$.............................................48

3.5 Heat Transfer Performance ..............................................................49

3.5.1 Overall Heat Transfer Conductance $(U A)$.............................49

3.5.2 Number of Transfer Unit $(N T U)$.......................................50

3.5.3 Heat Exchanger Effectiveness $(\varepsilon)$....................................51

IV. EXPERIMENTAL SET-UP AND PROCEDURE.............................53

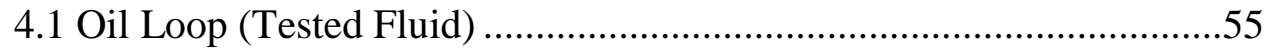

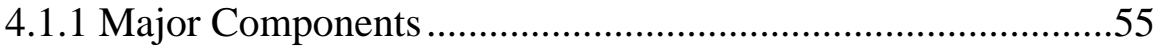

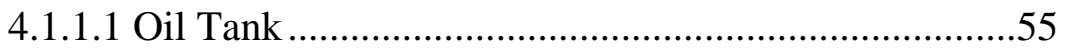

4.1.1.2 Gear Pump ..........................................................56

4.1.1.3 Electric Heater ....................................................57

4.1.2 Minor Components............................................................59

4.1.2.1 Flow Management Accessories ...............................59

4.1.2.2 Flow Monitoring Devices ........................................59

4.1.2.3 Flow Measurement Instruments .............................59

4.2 Air Loop (Cooling Fluid) ............................................................62

4.2.1 Thermal Wind Tunnel .........................................................62

4.2.2 Test Chamber ..............................................................64

4.2.3 Thermocouples ............................................................66 
4.2.4 Differential Pressure Transducers (DPTs) .............................68

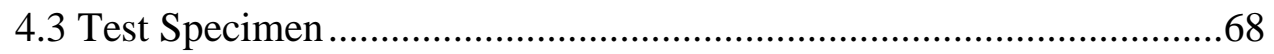

4.4 Data Acquisition System................................................................

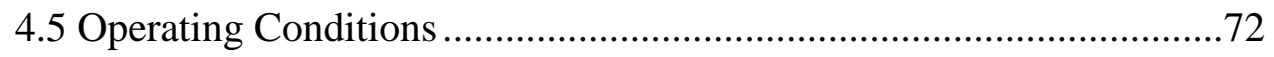

4.6 Data Collection Methodology …………………………………........75

v. RESULTS AND DISCUSSIONS.........................................................78

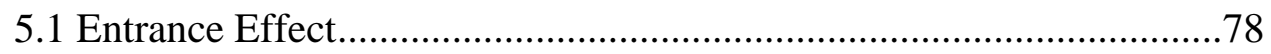

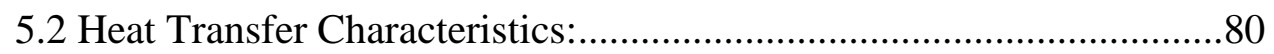

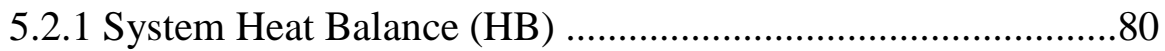

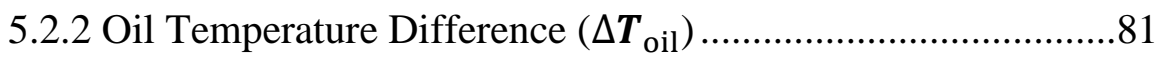

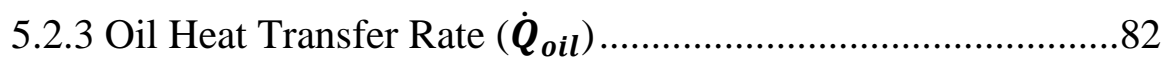

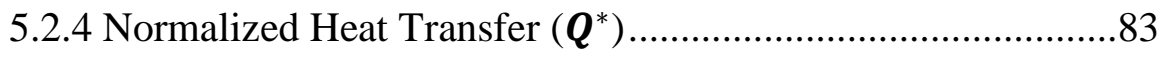

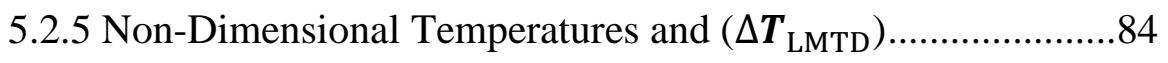

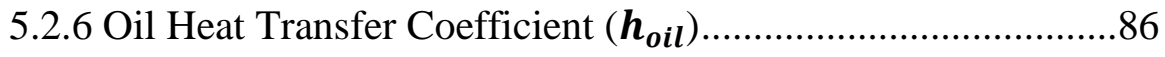

5.2.7 Oil Nusselt Number $\left(\boldsymbol{N} \boldsymbol{u}_{\boldsymbol{o i l}}\right)$ and Channel Non-dimensional

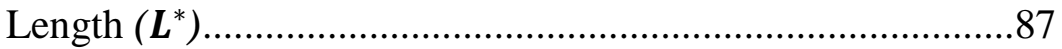

5.2.8 Oil Nusselt Number $\left(\boldsymbol{N} \boldsymbol{u}_{\text {oil }}\right)$ and Flow Mode ………...............89

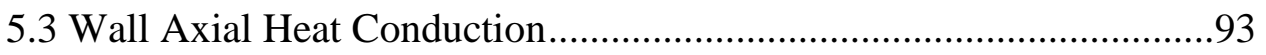

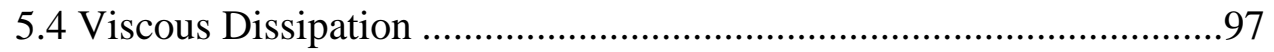

5.5 Pressure Drop and Friction Factor ………………….......................103

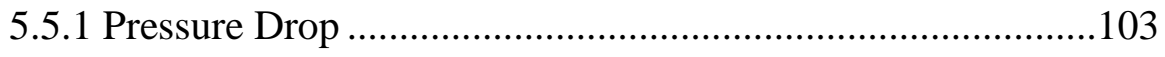

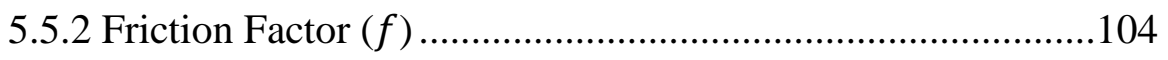

5.6 Heat Exchanger Performance ……………………….......................106

5.6.1 Overall Heat Exchanger Conductance $(U A)$.........................106

5.6.2 Number of Transfer Unit $(N T U)$............................................107

5.6.3 Heat Exchanger Effectiveness $(\varepsilon)$........................................109

VI. CONCLUSIONS AND RECOMMENDATIONS..................................110

6.1 Summary and Conclusion ...............................................................110

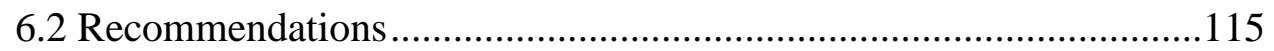

\section{APPENDICES}

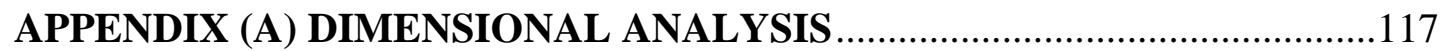

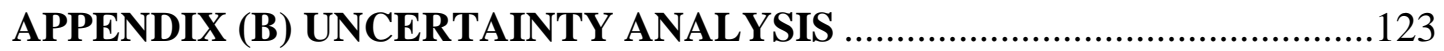

B.1 Uncertainty Analysis of Independent Parameters ..............................124

B.1.1 Uncertainties of Oil Inlet and Outlet Temperatures .............124

B.1.2 Uncertainties of Some Key Geometrical Parameters ............125 
B.2 Uncertainty Analysis of Dependent Parameters................................125

B.2.1 Uncertainty Analysis of Thermo-Physical Properties ..........125

B.2.2 Uncertainties of Oil Bulk Temperatures .................................126

B.2.3 Uncertainty of Oil Mass Flow Rate ....................................126

B.2.4 Uncertainty of Oil Mass Flux .............................................127

B.2.5 Uncertainty of Oil Velocity ................................................127

B.2.6 Uncertainty of Oil Reynolds Number..................................128

B.2.7 Uncertainty of Oil Prandtl Number ......................................128

B.2.8 Uncertainty of Oil Péclet Number ........................................129

B.2.9 Uncertainty of Oil Eckert Number .......................................129

B.2.10 Uncertainty of Oil Brinkman Number ................................129

B.2.11 Uncertainty of Oil Heat Transfer Rate ...............................130

B.2.12 Uncertainty of Oil Heat Transfer Coefficient.....................130

B.2.13 Uncertainty of Oil Nusselt Number....................................131

B.2.14 Uncertainty of Corrected Oil Nusselt Number ....................131

B.2.15 Uncertainty of Corrected Oil Nusselt Number Empirical

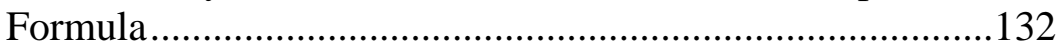

B.2.16 Uncertainty of Pressure Drop …………………...............132

B.2.17 Uncertainty of Friction Factor …………………...............133

B.2.18 Uncertainty of Corrected Friction Factor ……………….....133

B.2.19 Uncertainty of Normalized Heat Transfer ............................134

APPENDIX (C) TEST SPECIMEN GEOMETRICAL PARAMETERS ..........142 APPENDIX (D) SIMPLIFICATION OF AXIAL HEAT CONDUCTION

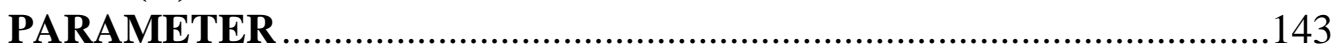

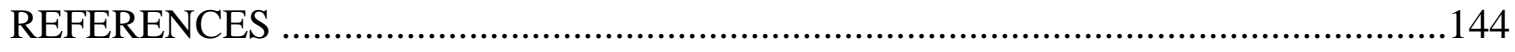

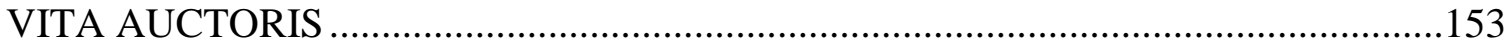




\section{LIST OF TABLES}

TABle 1.1: Micro-Scale Channel CATEgorization................................................... 3

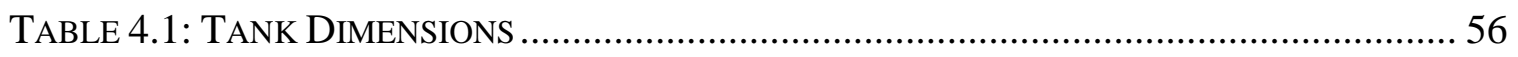

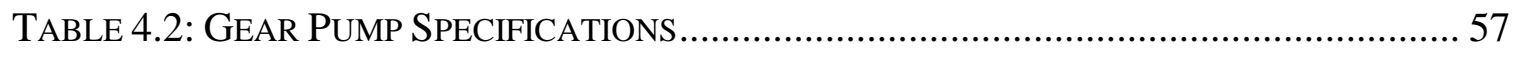

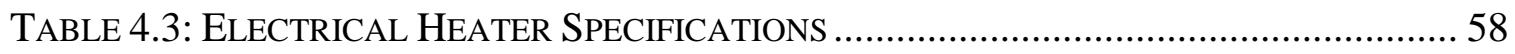

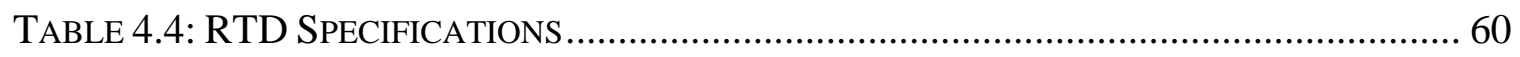

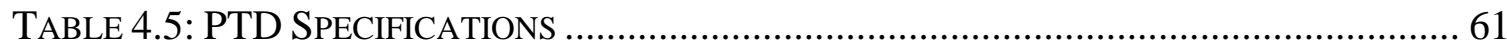

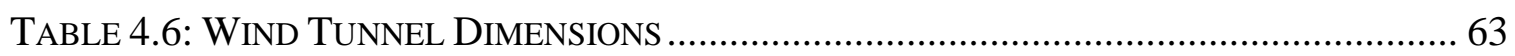

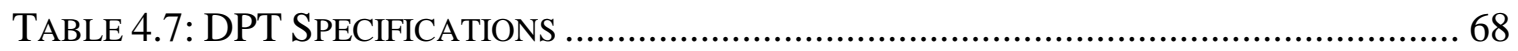

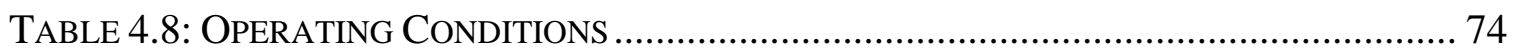

TABLE 4.9: PARAMETERS SHOWN IN DAQ ….................................................. 77

TABle B.1: UnCERTAinties VAlues For GEOMETRICAL PARAMETERS........................ 125

TABLE B.2: UnCERTAINTIES VALUES FOR CERTAIN PARAMETERS ............................... 135

TABle C.1: IMPortant Dimensions of THE TEST SPECIMEN .................................. 142 


\section{LIST OF FIGURES}

Figure 2.1: OiL DyNAMiC Viscosity VARIATION WITH TEMPERATURE ........................ 26

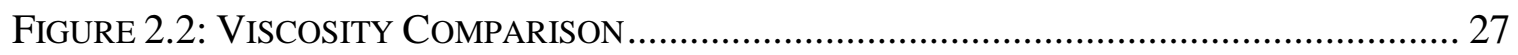

Figure 2.3: Oil DENSITY VARIATION WITH TEMPERATURE......................................... 28

FIgURE 2.4: OIL THERMAL CONDUCTIVITY VARIATION WITH TEMPERATURE................... 29

Figure 2.5: Oil SPECIFIC HEAT VARIATION with TEMPERATURE ................................ 30

FIGURE 3.1: OIL VISCOSITY INSIDE A FLOW PASSAGE .............................................. 41

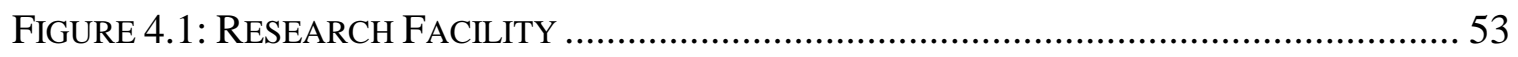

Figure 4.2: SchEMATIC DiAgRAM OF THE EXPERIMENTAL SET-UP .............................. 54

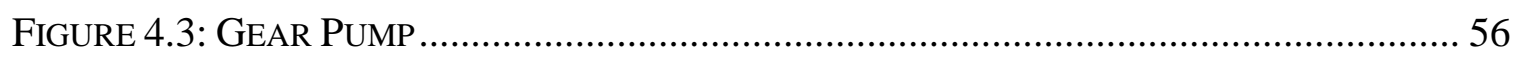

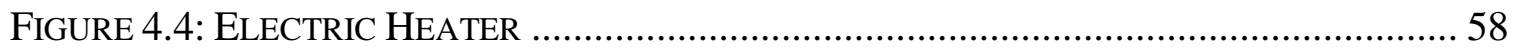

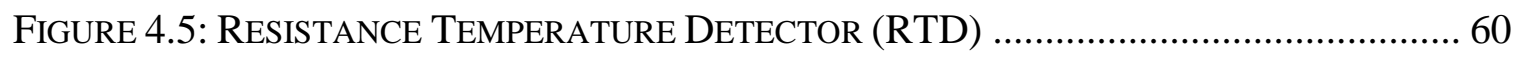

FIgURE 4.6: Pressure TRANSDUCER TRANSMITTER (PTD) ...................................... 61

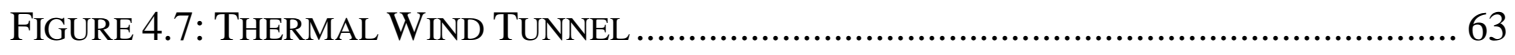

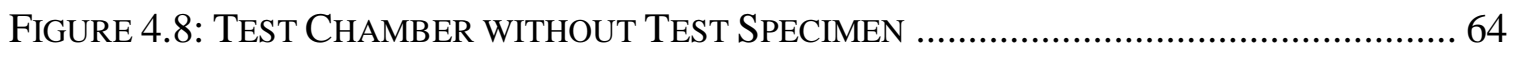

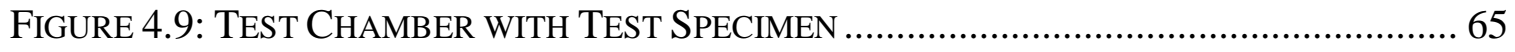

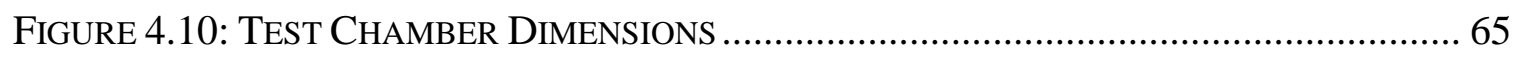

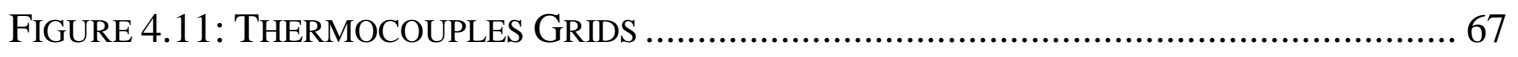

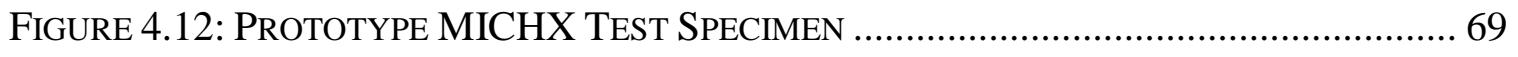

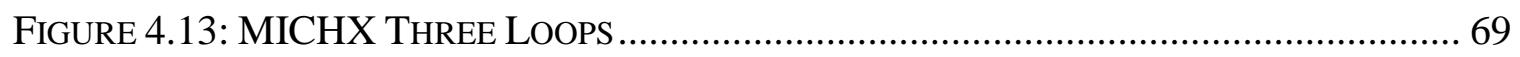

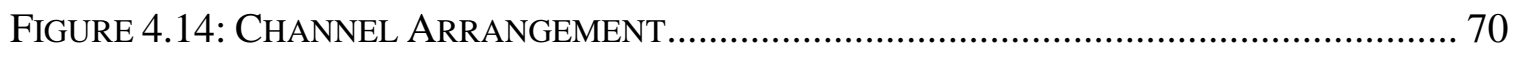

FIGURE 4.15: MICHX HEADER AND MANIFOLDS ................................................ 71 
FiguRE 5.1: HEAT BALANCE Vs OIL REYNOLDS NUMBER ............................................. 80

FiguRE 5.2: OIL TEMPERATURE DifFERENCE Vs OIL REYNoldS Number ......................... 81

Figure 5.3: Oil Heat Transfer Rate Vs Oil Reynolds Number ................................ 82

Figure 5.4: Normalized Heat Transfer QuANtity Vs Oil Reynolds Number ....... 83

Figure 5.5: Non-Dimensional TemPerature Vs Oil Reynolds Number .................... 84

Figure 5.6: Log Mean TemPerature DifFerence Vs Oil Reynolds NumBer ........... 85

Figure 5.7: Oil Heat TRANSFer CoefFicient Vs OIL Reynolds Number ..................... 86

Figure 5.8: Oil Heat Transfer Coefficient Vs Oil Péclet Number .......................... 87

Figure 5.9: Oil Nusselt Number Vs ChanNel Non-Dimensional Length ................ 88

FiguRE 5.10: OIL NuSSELt Number Vs OIL ReYNoldS NumbeR.................................... 90

Figure 5.11: EFFECT OF OIL REYNOLDS AND PRANDTL NuMBERS ON OIL NUSSELT

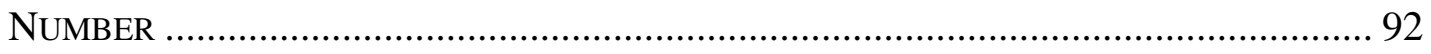

FigURE 5.12: CoMPARISON OF NU = F (RE, PR) OF Motor OIL AND ATF ......................... 93

Figure 5.13: Oil Nusselt Number Vs Axial Heat Conduction Parameter............. 95

Figure 5.14: Axial Heat Conduction Parameter Vs Oil Péclet Number ............... 96

FiguRe 5.15: OIL ECKERT NuMBer Vs OIL PÉCLET NuMBer........................................... 98

Figure 5.16: Oil NuSSELt Number Vs OIL ECKeRT Number ........................................ 99

Figure 5.17: Oil NusSelt Number Vs OIL ECKerT Number ......................................... 99

FiguRe 5.18: Oil Brinkman Number Vs OIL ReYNoldS Number .............................. 100

Figure 5.19: OIL BRinkMan Number Vs OIL PéClet Number..................................... 101

FiguRE 5.20: OIL NuSSELt Number Vs OIL BRINKMAN NuMBER ................................. 102

FIGURE 5.21: PRESSURE DRoP VS OIL REYNOLDS NuMBER............................................ 104

FigURE 5.22: Friction FACTOR Vs OIL REYNOLDS NUMBER ......................................... 105 
Figure 5.23: Overall Thermal CONDUCTANCE Vs Oil ReynOldS NuMBER

FIGURE 5.24: NTU VS OIL REYNOLDS NUMBER

FIGURE 5.25: EFFECTIVENESS VS NTU.......................................................... 108

FIGURE 5.26: EFFECTIVENESS Vs OIL REYNOLDS NUMBER.......................................... 109 


\section{NOMENCLATURE / ABBREVIATIONS}

$\begin{array}{ll}A_{c s} & \text { Cross-sectional Area, }\left(\mathrm{m}^{2}\right) \\ A_{c s, M C} & \text { Cross-Sectional Area of an Individual Channel, }\left(\mathrm{m}^{2}\right) \\ A_{\text {frontal }} & \text { Frontal Area of the Minichannel Heat Exchanger, }\left(\mathrm{m}^{2}\right) \\ A_{s, \text { oil side }} & \text { Total Inner Heat Transfer Surface Area of all minichannels, }\left(\mathrm{m}^{2}\right) \\ A_{\text {wall }} & \text { Cross-Sectional Area of the Wall, }\left(\mathrm{m}^{2}\right) \\ B r & \text { Brinkman Number } \\ \beta & \text { Heat Exchanger Area Density, }\left(\mathrm{m}^{2} / \mathrm{m}^{3}\right) \\ c p & \text { Specific Heat Capacity, }(\mathrm{J} / \mathrm{Kg}-\mathrm{K}) \\ c p_{\text {oil }} & \text { Oil Specific Heat Capacity, }(\mathrm{J} / \mathrm{Kg}-\mathrm{K}) \\ C_{\text {oil }} & \text { Oil Heat Capacity Rate },(\mathrm{W} / \mathrm{K}) \\ C_{\text {air }} & \text { Air Heat Capacity Rate },(\mathrm{W} / \mathrm{K}) \\ C_{\text {min }} & \text { Minimum Heat Capacity Rate },(\mathrm{W} / \mathrm{K}) \\ C_{\text {max }} & \text { Maximum Heat Capacity Rate },(\mathrm{W} / \mathrm{K}) \\ C^{*} & \text { Heat Capacity Rate Ratio } \\ D & \text { Channel Diameter, (m) } \\ D_{c} & \text { Serpentine Curvature Diameter, }(\mathrm{m}) \\ D_{h} & \text { Channel Hydraulic Diameter, }(\mathrm{m}) \\ D_{i} & \text { Channel Inside Diameter, }(\mathrm{m}) \\ D_{o} & \text { Channel Outside Diameter, }(\mathrm{m}) \\ E c & \end{array}$




\begin{tabular}{|c|c|}
\hline$f_{\text {bulk }}$ & Friction Factor Based on Constant Property \\
\hline$f_{c}$ & Friction Factor Corrected for Temperature with Variable Property Ratio \\
\hline$F$ & LMTD Correction Factor for Multi-pass and Cross-flow Heat Exchanger \\
\hline$G_{\text {oil }}$ & Oil Mass Flux, $\left(\mathrm{kg} / \mathrm{m}^{2}-\mathrm{s}\right)$ \\
\hline$h$ & Heat Transfer Coefficient, $\left(\mathrm{W} / \mathrm{m}^{2}-\mathrm{K}\right)$ \\
\hline$h_{\text {oil }}$ & Oil Heat Transfer Coefficient, $\left(\mathrm{W} / \mathrm{m}^{2}-\mathrm{K}\right)$ \\
\hline$k$ & Thermal Conductivity, (W/m-K) \\
\hline$k_{\text {fluid }}$ & Fluid Thermal Conductivity, (W/m-K) \\
\hline$k_{\text {Oil }}$ & Oil Thermal Conductivity, (W/m-K) \\
\hline$K n$ & Knudsen Number \\
\hline$k_{\text {wall }}$ & Thermal Conductivity of Wall (i.e. Aluminum), (W/m-K) \\
\hline$L$ & Individual Channel Length in One Slab, (m) \\
\hline$L^{*}$ & Channel Non-Dimensional Length \\
\hline$L_{h y}$ & Hydrodynamic Entry Length, (m) \\
\hline$L_{t h}$ & Thermal Entry Length, (m) \\
\hline$M$ & Axial Heat Conduction Parameter \\
\hline$m$ & Exponent for Friction Factor Correction with Variable Property Ratio \\
\hline$\dot{m}$ & Mass flow Rate, $(\mathrm{kg} / \mathrm{s})$ \\
\hline$\dot{m}_{\text {air }}$ & Air Mass flow Rate, $(\mathrm{kg} / \mathrm{s})$ \\
\hline$\dot{m}_{\text {oil }}$ & Oil Mass flow Rate, $(\mathrm{kg} / \mathrm{s})$ \\
\hline$\dot{m}_{o i l, M C}$ & Oil Mass flow Rate of an Individual Channel, $(\mathrm{kg} / \mathrm{s})$ \\
\hline$n$ & Exponent for Nusselt Number Correction with Variable Property Ratio \\
\hline$N u$ & Nusselt Number \\
\hline
\end{tabular}




\begin{tabular}{|c|c|}
\hline$N u_{\text {bulk }}$ & Nusselt Number at Bulk Temperature \\
\hline$N u_{c}$ & Nusselt Number Corrected for Temperature with Variable Property Ratio \\
\hline$N u_{o i l}$ & Oil Nusselt Number \\
\hline$N u_{o i l, b}$ & Oil Nusselt Number at Bulk Temperature \\
\hline$N u_{o i l, c}$ & Oil Nusselt Number Corrected for Temperature with Variable Property Ratio \\
\hline$N T U$ & Number of Transfer Unit \\
\hline$P$ & Temperature Effectiveness \\
\hline$P e$ & Péclet Number \\
\hline$P e_{o i l}$ & Oil Péclet Number \\
\hline $\operatorname{Pr}$ & Prandtl Number \\
\hline$P r_{o i l}$ & Oil Prandtl Number \\
\hline$\Delta P$ & Pressure Drop, $(\mathrm{kPa})$ \\
\hline$\dot{Q}$ & Heat Transfer Rate, (W) \\
\hline$\dot{Q}_{\text {actual }}$ & Actual Heat Transfer Rate, (W) \\
\hline$\dot{Q}_{\text {air }}$ & Air Heat Transfer Rate, (W) \\
\hline$\dot{Q}_{\text {avg }}$ & Average Heat Transfer Rate, (W) \\
\hline$\dot{Q}_{\text {maximum }}$ & Maximum Heat Transfer Rate, (W) \\
\hline$\dot{Q}_{o i l}$ & Oil Heat Transfer Rate, (W) \\
\hline$Q^{*}$ & Normalized Heat Transfer Quantity, $\left(\mathrm{kW} / \mathrm{m}^{2}{ }^{\circ} \mathrm{C}\right)$ \\
\hline$R$ & Heat Capacity Rate Ratio \\
\hline $\operatorname{Re}$ & Reynolds Number \\
\hline$R e_{o i l}$ & Oil Reynolds Number \\
\hline$R_{\text {wall }}$ & Wall Thermal Resistance, $(\mathrm{K} / \mathrm{W})$ \\
\hline
\end{tabular}




\begin{tabular}{|c|c|}
\hline$T_{\text {air,in }}$ & Air Inlet Temperature, $\left({ }^{\circ} \mathrm{C}\right)$ \\
\hline$T_{\text {air }, \text { out }}$ & Air Outlet Temperature, $\left({ }^{\circ} \mathrm{C}\right)$ \\
\hline$T_{\text {air,bulk }}$ & Air Bulk Temperature, $\left({ }^{\circ} \mathrm{C}\right)$ \\
\hline$T_{\text {bulk }}$ & Bulk Temperature, $\left({ }^{\circ} \mathrm{C}\right)$ \\
\hline$T_{o i l, i n}$ & Oil Inlet Temperature, $\left({ }^{\circ} \mathrm{C}\right)$ \\
\hline$T_{\text {oil }, \text { out }}$ & Oil Outlet Temperature, $\left({ }^{\circ} \mathrm{C}\right)$ \\
\hline$T_{\text {oil }, \text { bulk }}$ & Oil Bulk Temperature, $\left({ }^{\circ} \mathrm{C}\right)$ \\
\hline$T_{s, i}$ & Inside Wall Temperature, $\left({ }^{\circ} \mathrm{C}\right)$ \\
\hline$T_{s, o}$ & Outside Wall Temperature, $\left({ }^{\circ} \mathrm{C}\right)$ \\
\hline$T_{\text {wall }}$ & Wall Temperature, $\left({ }^{\circ} \mathrm{C}\right)$ \\
\hline$\Delta T_{\text {oil }}$ & Oil Inlet and Outlet Temperature Difference, $\left({ }^{\circ} \mathrm{C}\right)$ \\
\hline$\Delta T_{L M T D}$ & Log-Mean-Temperature Difference, $\left({ }^{\circ} \mathrm{C}\right)$ \\
\hline$U A$ & Overall Heat Transfer Conductance, (W / K) \\
\hline$V$ & Velocity, $(\mathrm{m} / \mathrm{s})$ \\
\hline$V_{\text {air }}$ & Air Velocity, (m/s) \\
\hline$V_{\text {avg }}$ & Average Oil Velocity in All Channels, $(\mathrm{m} / \mathrm{s})$ \\
\hline$V_{M C}$ & Oil Velocity in an Individual Channel, $(\mathrm{m} / \mathrm{s})$ \\
\hline$\rho$ & Density, $\left(\mathrm{kg} / \mathrm{m}^{3}\right)$ \\
\hline$v$ & Kinematic Viscosity, (cSt or $\mathrm{mm}^{2} / \mathrm{s}$ ) \\
\hline$\mu$ & Dynamic Viscosity, (cP or mPa.s) \\
\hline$\mu_{\text {bulk }}$ & Dynamic Viscosity of Oil at Bulk Temperature, (cP or mPa.s) \\
\hline$\mu_{\text {wall }}$ & Dynamic Viscosity of Oil at inside Wall Temperature, (cP or mPa.s) \\
\hline$n$ & Exponent for Viscosity Correction with Temperature \\
\hline
\end{tabular}


Heat Exchanger Effectiveness

Fluid Molecular Mean Free Path, (m)

$\begin{array}{ll}\text { ASME } & \text { American Society of Mechanical Engineers } \\ \text { ATF } & \text { Automatic Transmission Fluid } \\ \text { DFD } & \text { Computational Fluid Dynaimcs } \\ \text { DPT } & \text { Data Acquisition System } \\ \text { HB } & \text { Heat Balance } \\ \text { MF } & \text { Micro-Filter } \\ \text { MICHX } & \text { Minichannel Heat Exchanger } \\ \text { PTD } & \text { Pressure Transducer Transmitter } \\ \text { RTD } & \text { Resistance Temperature Detector } \\ \text { VI } & \text { Viscosity Index } \\ \text { VLSI } & \text { Very Large Scale Integrated }\end{array}$




\section{CHAPTER I}

\section{INTRODUCTION}

Energy is broadly identified as the ability of a physical system to do work on other physical systems. It can be presented in several forms, such as thermal, kinetic, potential, electrical, mechanical, and chemical energy. However, the only type of energy that will be covered in this thesis is thermal energy (or heat) and the study of this particular type of energy, called thermodynamics. Although the phenomenon of thermodynamics has been present since the beginning of time, it was not established as an area of interest, until the invention of the steam engine in England in 1697 [Çengel (2002) and (2007)].

The form of energy that transfers from one system to another as a result of discrepancy in temperature is known as heat. On the other hand, the topic "heat transfer" specifies the rate of heat transferred to or from a system, which results in thermal heating or cooling, due to temperature difference. Therefore, heat transfer has many relevant aspects that impact our daily lives. There are specific applications of heat transfer, including, but not limited to, the human body, household appliances, air-conditioning systems, refrigerators, and industrial equipment such as cars, radiators and evaporators [Çengel (2002) and (2007)].

A heat exchanger is a piece of equipment that transfers heat from a hot fluid to a colder fluid through single-phase convection (forced or free), two-phase convection (condensation or evaporation), and combined convection and radiation heat transfer 
[Shah and Sekulić (2003)]. In most heat exchangers, a metal wall separates the two fluids. All heat exchangers are similar in their principle of operation, but may differ in the working fluids used in the heat transfer process, the layout of the metal tubes, and the configuration of the enclosure. There are a wide variety of heat exchanger applications, such as refrigeration, air conditioning, and residential purposes.

There are two ways to categorize heat exchangers; the first is based on flow arrangement, and the second is based on construction of the equipment. Types of the former classification include parallel flow, counter-flow, and cross-flow arrangements. The latter has numerous types, such as cooling towers, process furnaces, shell-and-tube, doublepipe, plate-and-frame, and tube-fin heat exchangers.

Since the invention of heat exchangers, they have been a major piece of equipment used in factories and oil plants. Their significance has come from the primary function of swapping heat between two fluids, which has spawned room for investigation and development in this equipment. An extensive effort has been made in evolving the shape, size, and flow arrangements of heat exchangers to reach optimum results. One of the most recent improvements in heat exchangers is the alteration in its entire size, particularly the size of its channels. There are three focal purposes for using the channel [Kandlikar and King (2006)]:

(1) It lets the fluid have a direct contact with its walls.

(2) Due to the transport process that takes place inside the channel, previous fluids are moved by new fluids. 
(3) As the channel diameter decreases, the ratio of the heat transfer surface area of the heat exchanger to its volume (i.e. area density " $\beta$ ”) increases.

Investigations using small channels in compact heat exchangers have recently gained a great deal of interest. The utilization of minichannels has led the compact heat exchanger to even more advanced compactness to reach a higher heat transfer rate. Even though there has been a straightforward guide for expressing the dimensional range of the channel size, which is based on hydraulic diameter, there have been distinct views on the dimensional categorizations of channels. For example, Mehendale et al. (2000) classified the range from 1 to $100 \mu \mathrm{m}$ as minichannels, $100 \mu \mathrm{m}$ to $1 \mathrm{~mm}$ as meso-channels, 1 to 6 $\mathrm{mm}$ as compact channels, and larger than $6 \mathrm{~mm}$ as conventional channels. Another categorization (TABLE 1.1) has been made by Kandliker and Grande (2004) which will be considered in this thesis:

Table 1.1: Micro-Scale Channel Categorization

\begin{tabular}{|c|c|}
\hline Conventional channels & $D_{h}>3 \mathrm{~mm}$ \\
\hline Minichannels & $3 \mathrm{~mm} \geq D_{h}>200 \mu \mathrm{m}$ \\
\hline Microchannels & $200 \mu \mathrm{m} \geq D_{h}>10 \mu \mathrm{m}$ \\
\hline Transitional Microchannels & $10 \mu \mathrm{m} \geq D_{h}>1 \mu \mathrm{m}$ \\
\hline Transitional Nanochannels & $1 \mu \mathrm{m} \geq D_{h}>0.1 \mu \mathrm{m}$ \\
\hline Nanochannels & $0.1 \mu \mathrm{m} \geq D_{h}$ \\
\hline
\end{tabular}

The minichannel has gained interest in the last three decades because of the downsizing of the thermal devices used in various aspects of everyday life. The cooling of the Very 
Large Scale Integrated (VLSI) Circuits, biomedical applications, micro-heat-exchangers are some examples of the fundamental ideas of the minichannel heat transfer and fluid flow and why they are considered essential for proper design. Utilizing minichannels as a cooling medium is a technique of forced convection cooling, which is accomplished by forcing liquid through miniature channels.

In 1981, the micro-scale channel cooling theory was initiated by Tuckerman and Peace (1981). They managed to dissipate heat, of a flux of rate $790 \mathrm{~W} / \mathrm{cm}^{2}$, by utilizing a watercooled heat sink. Phillips (1987) widened the investigation and developed flow friction and Nusselt Number correlations by taking into consideration both laminar and turbulent regimes. It is important to mention that Tuckerman and Philips' studies were based on macroscale correlations and the effects of microscale were not considered. Later, many researchers conducted experimental and numerical investigations to broaden the understanding of the heat transfer phenomenon in microscale channels.

However, the performance of the minichannel heat exchanger (MICHX) cannot be evaluated with the other microscale heat sinks that have already been investigated in the literature. The majority of the previous studies focused on investigating minichannels in isolation, in hopes of developing a solution for cooling of electronics, where a coolant flowing through tiny channels is used to remove heat from the microelectronic components. The present study considers an entire cross-flow heat exchanger that has a different function to transfer heat from a liquid to a gas. Therefore, a direct comparison between the cross-flow minichannel and cooling the microelectronic is irrelevant. 


\section{$\underline{1.1 \text { Motivation }}$}

The utilization of micro-scale heat exchangers instead of the conventional ones is inevitable, as it has been proven by numerical studies that the smaller passages provide a great deal of heat transfer per unit volume, compared to larger passages. Furthermore, the overheads needed to build a conventional heat exchanger and the time required to perform maintenance are two vital reasons that micro scales heat exchangers will surpass the conventional types.

In a broader view, MICHXs offer several enhancements compared to the conventional ones, as indicated below:

- Improving heat transfer performance. The thickness of the thermal boundary layer is reduced due to the small cross-sectional size of the narrow channel. Having a thin thermal boundary layer enhances the heat transfer [Gui and Scaringe (1995)].

- Forcing the fluid to flow through a channel having a small hydraulic diameter results in enhancing the heat transfer coefficient.

- The cost of material used to fabricate the heat exchanger may be reduced since less material is used.

- Tighter package space. The reduction in size and weight of MICHX results in a smaller and lighter system.

The majority of the published studies and papers have used water and different types of gas as working fluids in minichannels. On the other hand, investigation on the behavior of motor oil flowing in a small diameter has not been active in the previous works. Hence, an extensive exploration is needed to become familiar with the heat transfer and fluid flow characteristics of motor oil inside minichannels. Cooling motor oil by using 
cross-flow serpentine minichannels heat exchangers is virtually non-existent in open literature.

\subsection{Objectives}

The capability of transferring heat between fluids using lightweight compact heat exchangers is essential in a number of applications, such as automotive and air conditioning applications. As a result, numerous examinations have been performed on these miniature passages using different configurations, (cross-flow and counter-flow) as well as using different working fluids.

Performing an investigation on serpentine cross-flow minichannel heat exchangers using motor oil, as a working fluid, is considered literally scarce in the open literature. Hence, a thorough analysis and derivation of correlations on the engine oil performance in such a configuration will be addressed and scrutinized in this thesis.

The objective of this work is to conduct experiments and examine the collected data from the cross-flow minichannel heat exchanger system (motor oil - air) to obtain the following:

- Study the fluid flow characteristics of motor oil inside the channels.

- Experimentally analyze the heat transfer characteristics $(h, N u)$ of motor oil in minichannel heat exchanger.

- Investigate the pressure drop $(\Delta P)$ and friction factor $(f)$. Motor oil pressure drop across the minichannel will be studied. 
- Examine the proto-type heat exchanger performance. Overall thermal conductance $(U A)$, heat exchanger effectiveness $(\varepsilon)$, and Number of transfer units $(N T U)$.

- Investigate the scaling effects (wall axial heat conduction and viscous dissipation) on heat transfer behaviors.

- Establish correlations among the heat transfer characteristics, fluid flow characteristics, and other dimensionless numbers.

- Compare the experimental results with the findings of a low viscous fluid (Automatic Fluid Transmission) analyzed in the same MICHX test specimen.

In order to have the aforementioned objectives accomplished, experimental runs will be conducted. A cross-flow multi-port serpentine minichannels heat exchanger with motor oil and air as working fluids will be utilized. Both working fluids are in single phase conditions throughout all of the experiments. In the current study, concentration will only be on motor oil side and thus equations and correlations related to the liquid-side will be presented and discussed. 


\section{CHAPTER II}

\section{REVIEW OF LITERATURE}

Heat exchangers are used to take heat from one fluid to another mainly via convection heat transfer modes. Their engineering applications and processes, as mentioned before, are indispensible to any industrial plants. As such, a great deal of research has been made to reach the optimum heat transfer rate that can result from these pieces of equipment.

One of the recent developments of these studies is to minimize the size of the heat exchanger, particularly the size of tubes or channels, to even a nanoscale. Therefore, the literature found on this development is relatively limited compared to the conventional heat exchangers. During the last thirty years, the investigation of the miniature heat exchanger has become overly popular that almost all aspects of fluid flow and heat transfer characteristics have been examined. Some criteria have been considered for the literature research area in order to perfectly evaluate and validate the outcomes of the current investigation. These criteria are:

- The flow regime inside the channel is laminar $(R e<2000)$.

- The type of the fluid is single-phase liquid flow.

- Both experimental and numerical investigations are considered.

- The size of channel, which is based on the hydraulic diameter, is $10 \mu m \geq D_{h} \geq$ $6 \mathrm{~mm}$. 
- Due to the limited studies made on the circular cross-sectional shape, studies done on rectangular and trapezoidal channel shapes are also included in the literature review.

Several experimental and numerical works in the literature have shown that the fluid flow and heat transfer characteristics of micro-scale channels depart from the well-known macro-scale correlations and equations. Choi et al. (1991) calculated the convective heat transfer coefficients for flow of nitrogen gas in circular microtubes. The hydraulic diameter of these microtubes ranges from 3 to $81 \mathrm{~mm}$. They found that the measured Nusselt number in laminar flow is a strong function of the Reynolds number. This result contrasts with the conventional prediction for fully developed laminar flow, in which the Nusselt number is constant.

Qu et al. (2000) conducted experiments to examine the convective heat transfer of water flowing through trapezoidal silicon microchannels with a hydraulic diameter ranging from 62 to $169 \mu \mathrm{m}$. The authors also performed a numerical analysis to validate the experimental results. It was found that the experimental Nusselt number values in laminar regime are lower than the predicted ones by the numerical study. They attributed this discrepancy to the effect of surface roughness (i.e. roughness viscosity) on walls of the microchannels.

$\mathrm{Wu}$ and Cheng (2003) experimentally investigated the heat transfer phenomenon of deionized water in 13 different trapezoidal silicon microchannels $\left(D_{h}=25.1-\right.$ 
$291 \mu \mathrm{m})$. It was demonstrated that the values of the Nusselt number depends greatly on different geometric parameters (height-to-top width ratio and bottom-to-top width ratio). The authors concluded that the laminar convective heat transfer showed two different characteristics at low and high Reynolds number ranges. At low $\operatorname{Re}(0<\operatorname{Re}<100)$, the $\mathrm{Nu}$ increases sharply with the increase of Re. In contrast, the $\mathrm{Nu}$ mildly increases for $\mathrm{Re}$ $>100$.

As the size of a flow channel gets smaller and smaller, wall effects on fluid flow and heat transfer become significant. It also approaches the mean free path between two molecules, which is mainly true for a gaseous flow. As a result, the traditional continuum assumption in flow analysis cannot be held valid in very small channel flows.

One way to verify the applicability of the continuum assumption is by calculating a dimensionless number, called the Knudsen number $(K n)$. It is defined as the ratio of the average distance traveled by a fluid's molecules without colliding with each other, which is known as the fluid molecular mean free path $(\lambda)$, to the characteristic length of the flow field, which is the channel hydraulic diameter $\left(D_{h}\right)$ [Kandliker (2003)].

$$
\begin{gathered}
\text { Kn }=\frac{\text { fluid molecular mean free path }}{\text { Characteristic length }}=\frac{\lambda}{D_{h}} \\
\text { where } \lambda=\frac{\mu \sqrt{\pi}}{\rho \sqrt{2 R T}} \times 10^{6}[\mu \mathrm{m}]
\end{gathered}
$$

Where $R, T, \rho$, and $\mu$ are the universal gas constant $[J / k g . K]$, temperature $[K]$, density $\left[\mathrm{kg} / \mathrm{m}^{3}\right]$, and dynamic viscosity $[\mathrm{kg} / \mathrm{m} . \mathrm{s}]$ respectively. 
For gas flows, the continuum flow assumption holds for small values of the $K n$ number $(K n<0.001)$, and the well known Navier-Stokes equations are applicable for the flow field. As the $K n$ number increases, the continuum approach fails to be valid; and fluid flow and heat transfer problems are solved by using statistical mechanics or molecular dynamics simulations.

Morini (2006) stated that the distance between the molecules in liquids is usually much smaller than that for gases, leading to even a smaller value of the $K n$ number. Hence, the assumption of continuum flow holds for liquid flow and the conventional theories are valid in describing the fluid flow and heat transfer characteristics. Herwig and Hausner (2003) reported that flows in channels having a hydraulic diameter $\left(D_{h}\right)$ of $\simeq 1 \mathrm{~mm}$ are definitely considered continuum flows described by the Navier-Stokes equations, if the fluid is Newtonian. Hetsroni and Mosyak (2005) also stated that in liquid flow and channels with hydraulic diameter between $1 \mu \mathrm{m} \leq D_{h} \leq 1 \mathrm{~mm}$, the $K n$ number is much less than unity. In addition, Qu and Mudawar (2002) confirmed that the conventional Navier-Stokes and energy equations would be sufficient for predicting the fluid flow and heat transfer characteristics at a micro-scale channel.

\section{$\underline{2.1 \text { Scaling Effects }}$}

Herwig and Hausner (2003) observed that in order to examine the forced convection of liquids in the laminar regime, a general theoretical basis for both macro- and micro-flows can be utilized. However, certain effects have to be taken into account and cannot be ignored for narrow channels. These effects are called "scaling effects with respect to a 
standard macro-analysis." Herwig (2002) defined these effects as "Scaling effects are those influences that can be neglected in the original scales but become important in different (larger or smaller) scales."

Some of these effects for single-phase flows in micro-channels, which will be greatly discussed in the following chapters, are "axial heat conduction in the channel wall" and "viscous dissipation." Unexpected experimental and numerical results, which were found in open literature, have been mostly attributed to these two scaling effects. For instance, Morini (2006) examined the role of axial heat conduction in the wall and viscous dissipation on the mean value of the Nusselt number in rectangular and circular microchannels. The strong dependency of the Nusselt number on the Reynolds number was demonstrated, even in the laminar regime. Moreover, the author found that the scaling effects play an alternate role if different working fluids and channel geometries are considered.

\subsection{Axial Heat Conduction in Channel Wall}

The effect of axial heat conduction in the wall on heat transfer in narrow channels has been one of the hottest topics in the last ten to fifteen years. The axial wall heat conduction represents one of the factors which can lead to some discrepancies in values between the minichannel heat transfer data and the well known standard correlations for conventional size channels. In forced convection, heat transfer applications involving channels of conventional size, the channel wall thickness is very small compared to the 
channel hydraulic diameter. As such, the axial heat conduction in the walls can be neglected when it is compared to the convective heat transfer in macro-scale flows.

However, in narrow channels, the area of the transverse section of the wall (or solid material) perpendicular to the flow direction is comparable to the channel cross-sectional area. In other words, the wall thicknesses of narrow channels are of the same order of the channel hydraulic diameter. Consequently, the heat transfer occurring in the solid walls by conduction cannot be disregarded as it has a profound role on the heat transfer mechanism. According to several published studies, when the effect of axial heat conduction in the wall is not taken into account in the calculation of convective heat transfer coefficients from experimental data, the corresponding Nusselt number is generally underestimated.

Besides the wall thickness, there are several proven factors which enhance the effect of axial heat conduction on the convective heat transfer in narrow channels. Two of them include: Low Reynolds number and high thermal conductivity of the wall material. In the low Reynolds number, the effect of the axial heat conduction in the wall on the average Nusselt number is crucial because the conduction occurring in the wall becomes a comparable mechanism of heat transfer with respect to the fluid convection.

As proven by Herwig and Hausner (2003) and Marazana et al. (2004), the temperature distribution along the micro-scale channel is non-linear when the wall axial heat conduction is predominant. This leads to an underestimated value of the Nusselt number 
since the fluid bulk temperature in the channel is also underestimated. Hence, if the experimental values of the Nusselt number are compared with their theoretical fully developed values, a discrepancy can be noticed. The experimental value of the Nusselt number, which is calculated from a liquid passing through a micro-scale channel at a low flow rate, can exhibit a strong dependency on the Reynolds number due to the axial heat conduction along the solid walls of the channel.

\subsection{Literature Review on Axial Heat Conduction in Channel Wall}

Axial heat conduction in micro-scale channels have been studied experimentally and numerically by several authors. Herwig and Hausner (2003) applied a numerical approach to the experimental investigation done by Tso and Mahulikar (2000). The result showed that the bulk temperature is not linearly distributed between the inlet and outlet values at a low Reynolds number. The authors attributed the low Nusselt number to the effect of axial heat conduction, not to the viscous dissipation.

Hetsroni et al. (2004) reported that the experimental Nusselt number values of water flowing through a circular pipe of a $1.07 \mathrm{~mm}$ hydraulic diameter were significantly lower than the theoretical predicted values. The flow was fully developed laminar and the range of Reynolds number was $10<\operatorname{Re}<450$. They suggested that the effect of thermal conduction along the solid wall leads to a decrease in the Nusselt numbers, if a linear change of the fluid temperature in the flow direction is assumed. Unlike Tso and Mahulikar (1998 and 2000), their results did not show substantial effect of the Brinkman number on behavior of the Nusselt number in the range of $10<\operatorname{Re}<450$. 
Maranzana et al. (2004) performed a numerical analysis on water flowing between two heated microscale parallel plates to examine the axial conduction in the wall. The authors reported that disregarding the effect of axial conduction in the wall can lead to an underestimation of the experimental value of the heat transfer coefficient, especially for small Reynolds numbers. A new non-dimensional number M quantifying the relative part of axial heat conduction in the walls has been generated. The physical importance of $\mathrm{M}$ will be discussed in Chapter III.

Li et al. (2004) conducted a numerical simulation to analyze forced convection heat transfer occurring in rectangular microchannel. The results showed that the bulk liquid temperature varies in a quasi-linear form along the flow direction only for high flow rates, but not for low flow rates. They came to a conclusion that axial heat conduction in the wall has an impact on heat transfer at low liquid flow rates.

Li et al. (2007) examined numerically the axial heat conduction in the wall of circular microtubes having a range of hydraulic diameters from $50-1570 \mu \mathrm{m}$. The results reveal that the large ratio of the wall thickness over tube diameter in the low Reynolds number region causes significant axial heat conduction in the tube wall. This leads to a non-linear distribution of water temperature along the flow direction. The authors also reported that the effect of axial heat conduction is slowly diminished with the increase of Reynolds number and the decrease of the tube wall thickness. 
Gan et al. (2008) carried out an experimental investigation to evaluate the effect of axial heat conduction on the heat transfer characteristics of methanol passing through triangular silicon microchannels. The authors concluded that the axial heat conduction in the wall greatly affects the convective heat transfer in channels having small hydraulic diameter. It was also observed that as the Reynolds number decreases, the axial conduction in the channel walls becomes more prominent.

Nonino et al. (2009) numerically analyzed the effect of axial heat conduction in the walls of circular cross-section microchannels on the convective heat transfer. The authors reported that larger reductions in local Nusselt numbers are found for larger values of the ratio of wall thermal conductivity over fluid thermal conductivity $\left(k_{\text {wall }} / k_{\text {fluid }}\right)$.

Cole and Çetin (2011) numerically analyzed the axial heat conduction in the fluid and in the channel wall in a parallel-plate microchannel for a fully developed laminar flow. It was found that the effect of axial heat conduction in the fluid becomes more pronounced if the Péclet number is small $(\mathrm{Pe} \ll<100)$. The authors also concluded that when the thermal conductivity of wall material is high, relative to the thermal conductivity of the working fluid, the effect of the axial conduction in the channel wall cannot be ignored.

There have been several contradictory results from the above reviews. One of which is the investigation made by Tiselj et al. (2004). The authors performed experimental and numerical investigation to evaluate heat transfer characteristics of water flowing through heated triangular silicon microchannels. CFD analysis was performed to explain the axial 
heat conduction phenomenon and an acceptable agreement between the experimental and numerical results was achieved. Consequently, the authors confirmed the validity of using the conventional theory to describe the liquid heat transfer in microchannels.

The other study was performed by Gamrat et al. (2005). In this analysis, the authors presented both two and three- dimensional numerical analysis of convective heat transfer in rectangular microchannels, taking into account the effect of axial heat conduction in the wall. The range of the Reynolds number of water in the study was between 200 and 3000. As a result of their work, the strong reduction in the Nusselt number observed in previous experiments cannot be explained by conduction effects due to the complex geometry. However, the authors suggested that the effects of conduction would be much stronger for flows at very low Reynolds numbers.

\subsection{Axial Heat Conduction in Fluid}

There is another kind of axial heat conduction which occurs in the fluid itself. From heat transport perception, the characteristic time for convection and conduction becomes comparable at the micro-scale level; and the convection term no longer dominates the conduction term in the longitudinal direction. This only happens if the Péclet number (Pe) of the fluid is small. If this is the case, the axial heat conduction in the fluid cannot be ignored.

From Pe definition, the effect of the fluid axial heat conduction becomes more pronounced as Pe decreases. The effect of the heat conduction in the fluid on the heat 
transfer has been studied by Jeong (2006), Cetin et al. (2008 \& 2009), and Cole and Çetin (2011) for different boundary conditions. This type of heat conduction is not considered in the current study, as the calculated Pe number of the motor oil is large. As such, it is out of the scope of this research.

\section{$\underline{2.5 \text { Viscous Dissipation }}$}

Viscous dissipation effect was demonstrated to be a typical "scaling effect" for narrow channel flows. It is the heating of the fluid due to the work done against the viscous forces. When a fluid passes through a channel having a small hydraulic diameter, the internal heat generation, due to the viscous forces, can produce a temperature increase. The temperature variation, due to the viscous dissipation, affects the values of the fluid thermo-physical properties, especially viscosity, between the inlet and outlet of the channel. The effect of viscous dissipation on heat transfer is considered significant for:

1. Flows with high velocities.

2. Flows of highly viscous fluids at moderate velocities.

3. Flows in micro-scale channels with a moderate Pr number and moderate velocities but having small fluid-to-wall temperature difference.

\subsection{Literature Review on Viscous Dissipation}

The viscous dissipation is quantified by a dimensionless number called the Brinkman number $(\mathrm{Br})$, which is defined as the ratio of the heat generated by the viscous action of the dissipation to the conduction. The effect of viscous heating in narrow channels on fluid flow and heat transfer characteristics have been studied intensively. Tso and 
Mahulikar (1998) were able to quantify the presence of the viscous dissipation via the Brinkman number $(\mathrm{Br})$. The authors used experimental results from previous investigations done on microchannels in a laminar regime. They found that when the water is cooled through the microchannel under a constant velocity, $\mathrm{Nu}$ decreases with decreasing $\mathrm{Re}$, due to the increase in $\mathrm{Br}$, which represents the viscous heating.

Moreover, Tso and Mahulikar (2000) experimentally analyzed the role of the Brinkman number in circular microchannels $\left(D_{h}=0.73 \mathrm{~mm}\right)$ in explaining the significance of the radial and axial variations occurring in water fluid temperature. For the radial case, the variation is captured by the change in wall-fluid temperature $(\Delta \mathrm{T})$. On the other hand, the axial variation is captured by variations in the bulk viscosity $(\mu)$. When $\mathrm{Br}$ is small, the authors identified the effect of its variations in microchannels, as being the result of changes in liquid properties. This is the secondary effect of Br. The authors stated that the secondary effect might be utilized to explain the reduction in $\mathrm{Nu}$ when $\mathrm{Re}$ increases in laminar regime, if constant heat flux is applied. When $\mathrm{Br}$ is of the order of unity or higher, Br directly influences liquid temperature, due to the effect of viscous dissipation. This is the primary effect of $\mathrm{Br}$.

Tunc and Bayazitoglu (2001) mathematically analyzed the effect of viscous dissipation on heat transfer in microtubes. The investigation included uniform temperature and uniform heat flux boundary conditions, where the gas was heated and cooled. In both cases, it was found that the viscous dissipation actually boosts the heat transfer in laminar fully developed flow. 
Xu et al. (2002) numerically studied the viscous dissipation impacts for water flows in a circular micro-channel. They stated that for a micro-scale channel, viscous heating cannot be overlooked, due to the high velocity gradient occurring in the channel. They found that the importance of the viscous dissipation can be examined based on the temperature rise from the inlet and the outlet of the channel. Moreover, a criterion to verify the presence of the viscous dissipation inside the channel was proposed.

Koo and Kleinstreuer (2004) applied the computer simulation to study the viscous dissipation effects in rectangular microchannels for three distinct liquids: namely water, methanol, and iso-propanol. They demonstrated that the key factors by which the viscous heating is determined are: channel size, the Reynolds number and the Brinkman number (or the Eckert number and the Prandtl number). Moreover, they found the impact of viscous dissipation might be essential for fluids with low specific heat capacities and high viscosities, even in relatively low Reynolds number flows.

Morini (2005) observed that even for a very low Reynolds number, the effects of viscous dissipation can be significant, if the hydraulic diameter is small. He also found that crosssectional geometry plays a major role in viscous heating. Arici et al. (2009) numerically studied the effect of viscous dissipation on laminar forced convection. The authors concluded that viscous dissipation does affect both the wall and bulk fluid temperature profiles. They also noticed that as the $\mathrm{Br}$ number increases, the viscous dissipation becomes more significant. 
JiangFeng et al. (2011) analytically studied the influence of viscous heating on parallel and counter conventional heat exchangers. The authors concluded that for liquid having a small dynamic viscosity, such as water, the effect of viscous heating can be ignored. On the other hand, the influence of viscous heating cannot be ignored for liquid with a large dynamic viscosity, such as olive oil.

\subsection{Effects of Thermo-Physical Properties}

There are a plethora of papers that have been devoted to analyzing the effects of the thermo-physical property variations with fluid temperature. The main outcome of these studies shows that it is essential to take into account the variation of the fluid thermal conductivity and viscosity in the investigation of conventional [Xie and Hartnett (1992), and Shin and Cho (1993)] and narrow channel flows [Park et al. (2001) and Li et al. (2004)], especially at low Reynolds numbers. On the other hand, other properties, such as fluid density and specific heat, can be considered independent on temperature.

\subsection{Working Fluid}

\subsubsection{Definition}

Motor Oil is made from a heavier, thicker petroleum hydrocarbon base stock that is derived from crude oil after undertaking several processes. This base oil is blended with additives to either enhance certain physical properties of the base oil or to introduce properties that do not naturally exist in the base oil. These additives can perform their 
tasks in one of three ways [Heisler (1999) and SAE Fuels and Lubricants Technical Committee (2006)]:

1. Protection of the engine surfaces from oil sludge build-up, which includes antiwear agents, corrosion inhibitors, detergents, and friction modifiers.

2. Modification of oil properties, such as pour point, antifoam agents, and viscosity index (VI) improvers.

3. Protection of base oil, which includes antioxidation and metal deactivators.

Motor oil is a lubricant used in various internal combustion engines. These include engines of road vehicles (motorcycles, cars, buses and commercial vehicles), and nonroad vehicles (boats, snowmobiles, lawn mowers, large agricultural machinery, construction equipment, locomotives, and aircraft).

\subsubsection{Functions}

Before considering the properties of motor oil, a clear knowledge of the functions of the lubricant is required. The motor oil has to perform four vital functions [Heisler (1999)]:

1. Lubricating the rubbing, moving and rotating parts of the engine. The contact between moving metallic surfaces deteriorates the parts, which leads to degradation of the engine. Therefore, the motor creates a separating film or layer between these rubbing surfaces, in order to reduce the occurrence of the contact and friction.

2. Dissipating both the heat generated due to the combustion cycle, and any heat caused by bearings, crankshafts, and camshafts. 
3. Inhibiting corrosion of the internal parts of the engine by diminishing the exposure to oxygen and protecting the components from oxidation.

4. Maintaining the cleanliness of the engine. When metal engine parts are rubbing together, they inevitably produce microscopic particles and start accumulating. Therefore, the motor oil removes these tiny particles from the engine.

\subsubsection{Thermo-Physical Properties}

As mentioned earlier, the motor oil used in combustion engines in the recent past has natural properties (viscosity, density, thermal conductivity, and specific heat) as well as concocted ones, which are added to improve the overall performance of the oil and make them suitable for intended applications. For most liquids, the density, thermal conductivity, and specific heat are nearly independent of temperature. Viscosity, however, markedly decreases with increasing temperature [SAE Fuels and Lubricants Technical Committee (2006)].

\subsubsection{Viscosity}

Viscosity is a physical property of a fluid, liquid or gas, which displays the fluid's resistance to flow at specific temperatures and pressures. Also, the viscosity of a fluid can be considered as its "thickness." A high viscous fluid is "thick" and a low viscous fluid is "thin." The thicker a fluid is, the slower it will flow. Viscosity plays a major role in analyzing the convective heat transfer phenomenon in the current investigation, as the 
magnitude of several dimensionless numbers $\left(R e_{\text {oil }}, P r_{\text {oil }}, B r_{\text {oil }}, \ldots .\right.$. etc $)$ are governed by its value.

Viscosity is considered an indispensable property of motor oil as it maintains the ability of the oil to lubricate and protect the moving parts of an internal combustion engine. Under all conditions, it must be high enough to retain a lubricating film, but low enough to give oil the ability to flow around the engine parts. If the oil is too viscous (too thick), the pump will encounter difficulties in circulating the motor oil. Also, the oil that is too thick cannot infiltrate into the tiny space between the moving parts. As a consequence, failure from premature deterioration will take place. On the other hand, if the oil is not viscous enough (too thin), the pump will not be able to maintain the required pressure to circulate the oil. As a result, the metal parts will come into contact with each other and eventually wear out because of a lack of proper lubrication. Therefore, it is vital to have an appropriate balance of the viscosity of the motor oil.

A viscosity index is a measure of how much oil's viscosity changes as temperature changes. A high viscosity index indicates there should be slight change in viscosity with a reasonable temperature rise. In other words, the less change motor oil has from high to low temperatures, gives it a high viscosity index. It is desirable to have a high viscosity index because it provides a wider range of operating temperatures in which the working oil will grant satisfactory lubrication. 
There are two types of viscosity; dynamic and kinematic.

Dynamic or simple viscosity $(\mu)$

It describes the movement of the different layers of a fluid when subjected to a horizontal force. The unit of this kind is centipoise (cP or mPa.s) and it is equivalent to $\left(\mathrm{N} \cdot \mathrm{s} / \mathrm{m}^{2}\right)$ or $\mathrm{kg} /(\mathrm{m} \cdot \mathrm{s}) \cdot(1 \mathrm{mPa} \cdot \mathrm{s}=1 \mathrm{cP})$

The formula is as follows [SAE Fuels and Lubricants Technical Committee (2006)]:

$$
\text { Dynamic Viscosity }=\frac{\frac{\text { Force }}{\text { Sheared Area }}}{\frac{\text { Velocity }}{\text { Film Thickness }}}=\frac{\text { Shear Stress }}{\text { Shear Rate }}
$$

Oils that exhibit a constant viscosity at all shear rates in this equation are known as "Newtonian" Oils. On the other hand, oils that display a viscosity, which varies with changing shear rates in this equation, are known as "non-Newtonian" oils.

Dynamic viscosity of the motor oil decreases rapidly as the temperature increases. A sample of the investigated motor oil was sent to a commercial laboratory (Can-Am Instruments Ltd., Located in Oakville, ON) to determine the viscosity. A high-end rheometer is employed to perform the test at seven different temperatures $(0,10,20,40$, 60,80 and $\left.100{ }^{\circ} \mathrm{C}\right)$. From the lab results, the dynamic viscosity value was found to be constant at all shear rates for their respective test temperatures. Hence, the motor oil used in the current study can be considered as a Newtonian fluid. The relationship between the viscosity and temperature can be seen below in Figure 2.1. 


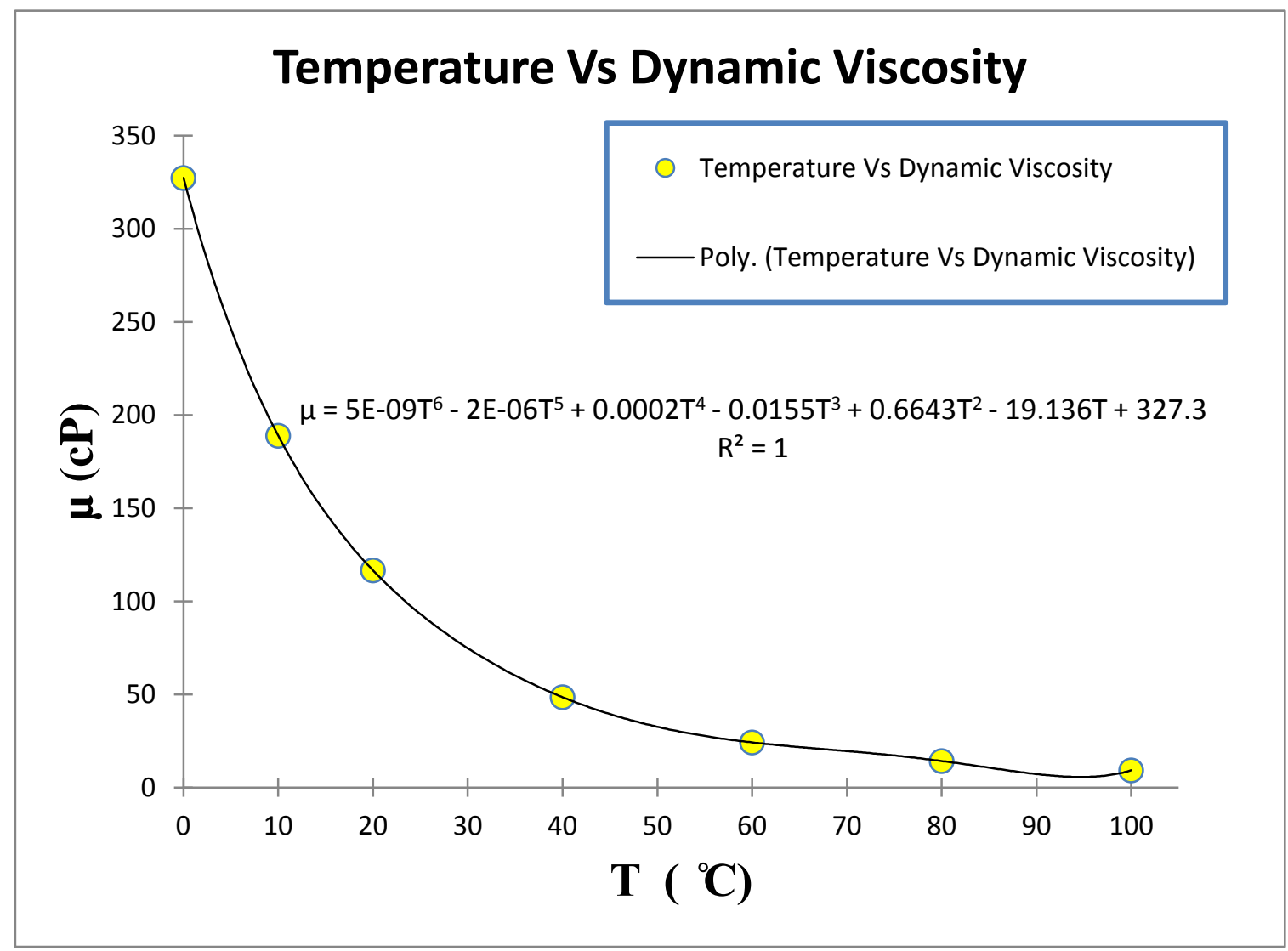

Figure 2.1: Oil Dynamic Viscosity Variation with Temperature

As can be seen from the figure, there is a sharp decrease in the viscosity at temperature below $35^{\circ} \mathrm{C}$. On the contrary, above $40{ }^{\circ} \mathrm{C}$ the change in viscosity is not as much. The best fit curve is a $6^{\text {th }}$ order polynomial between the temperature and dynamic viscosity and it is as follows:

$$
\mu=5 E^{-09} T^{6}-2 E^{-06} T^{5}+0.0002 T^{4}-0.0155 T^{3}+0.6643 T^{2}-18.136 T+327.3
$$

Figure 2.2 portrays the effect of temperature variation on three different automotive fluids' viscosities. The fluids are Motor Oil, Automatic Transmission Fluid (ATF), and Ethylene Glycol. This figure shows how highly viscous the motor oil is compared with the ATF and Ethylene Glycol. At low temperature, the difference in viscosity values for 
the three fluids is distinctive. However, the viscosity values of the fluids become very close as the temperature increases.

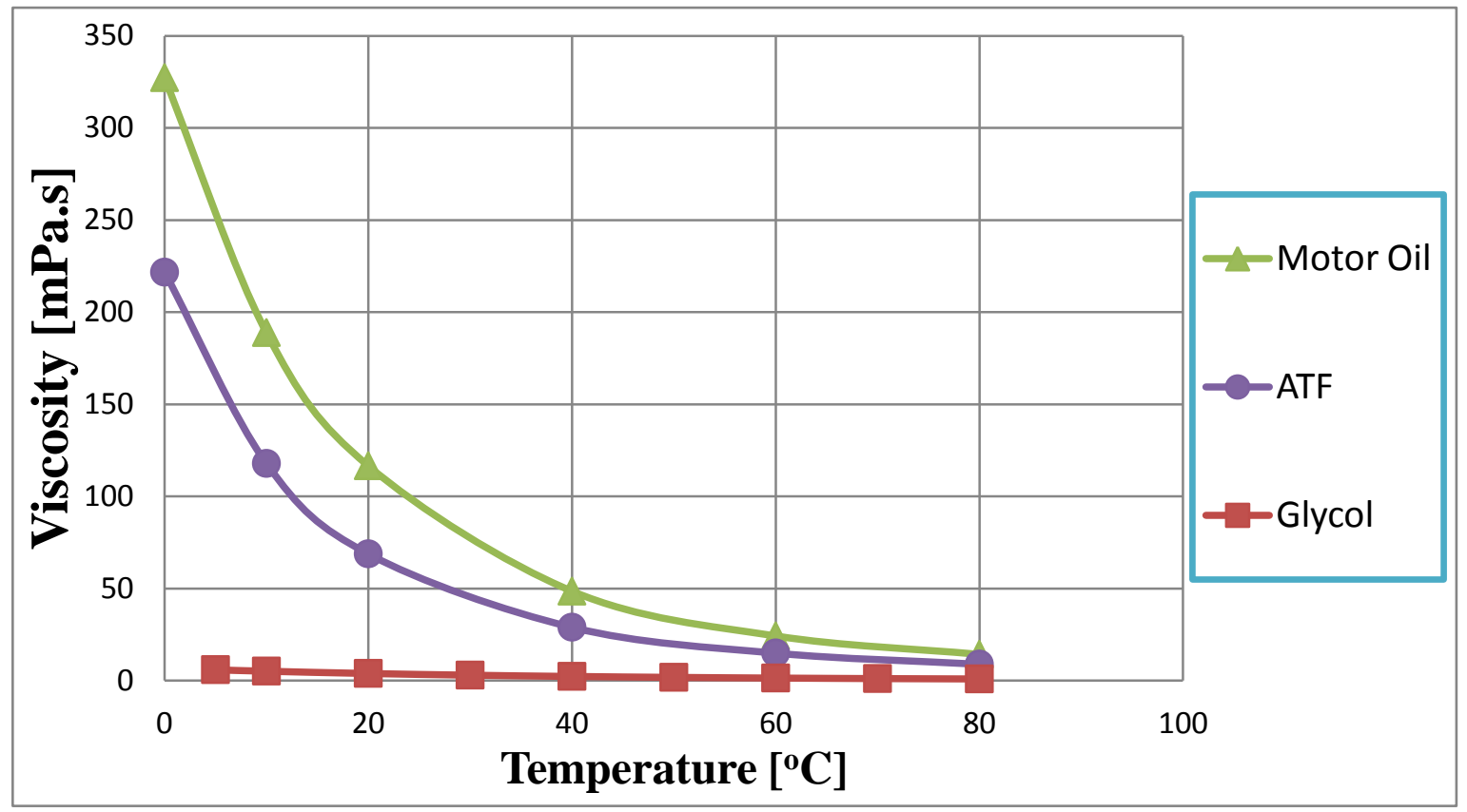

Figure 2.2: Viscosity Comparison

\section{$\underline{\text { Kinematic viscosity }(v)}$}

Kinematic viscosity describes the ease with which a fluid moves under the force of gravity. The unit of kinematic viscosity is centistokes (cSt or $\left.\mathrm{mm}^{2} / \mathrm{s}\right) .\left(1 \mathrm{~mm}^{2} / \mathrm{S}=1 \mathrm{cSt}\right)$ The formula is as follows:

$$
v=\frac{\mu}{\rho}
$$

Here,

v: Kinematic Viscosity $\left(\mathrm{m}^{2} / \mathrm{s}\right)$

$\mu:$ Dynamic Viscosity (kg/ (m.s))

$\rho:$ Density $\left(\mathrm{kg} / \mathrm{m}^{3}\right)$ 


\subsubsection{Density}

The motor oil's density has an inverse linear correlation with temperature, as shown in Figure 2.3. The densities at three different temperatures $\left(15,20\right.$, and $\left.40^{\circ} \mathrm{C}\right)$ were determined by the same commercial laboratory (Can-Am Instruments Ltd). The other points were interpolated and extrapolated. The following figure displays the density with respect to temperature. From the figure below, the density of oil does not significantly vary between $0-100{ }^{\circ} \mathrm{C}$, the range is only $60 \mathrm{~kg} / \mathrm{m}^{3}$.

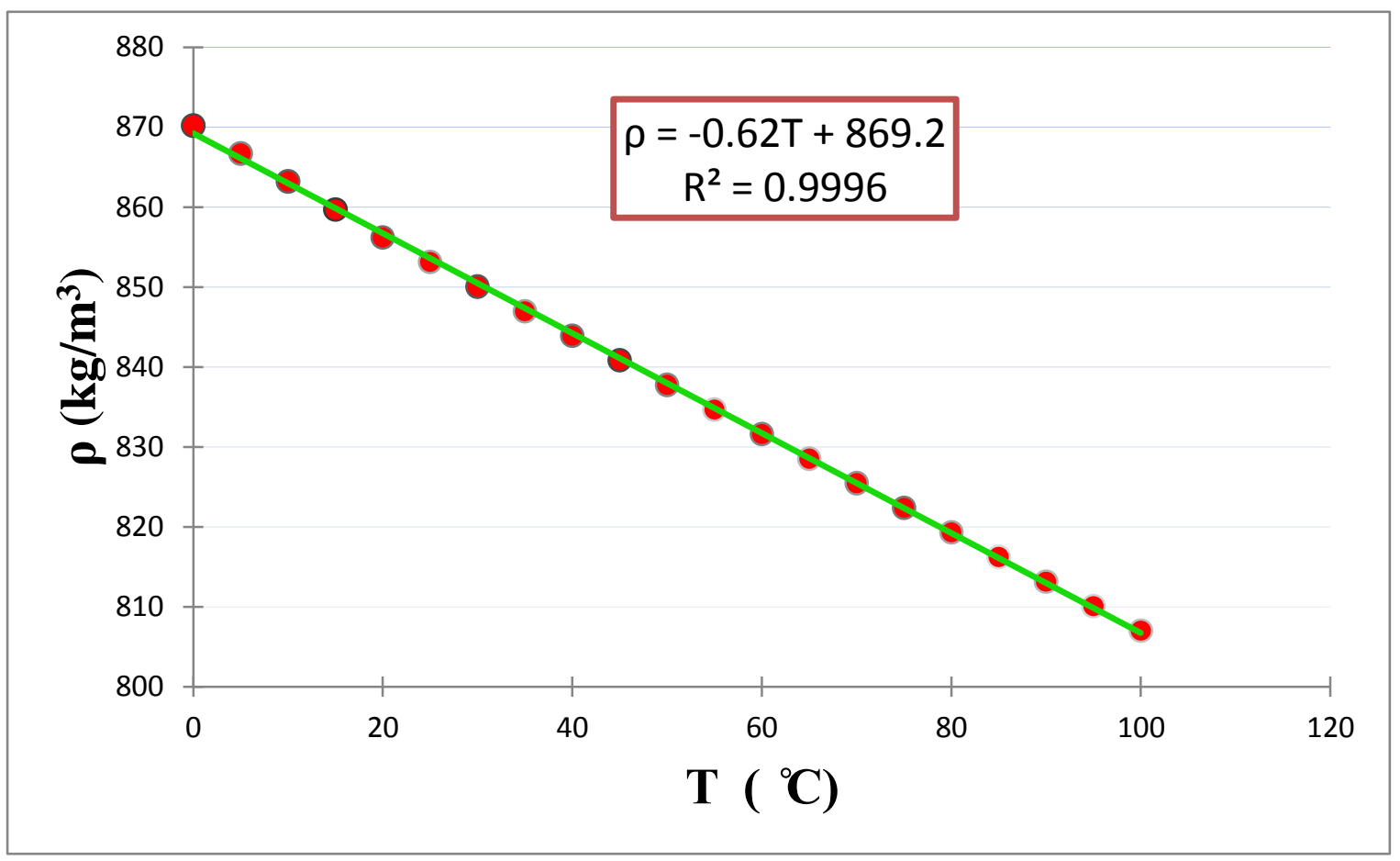

Figure 2.3: Oil Density Variation with Temperature 


\subsubsection{Thermal Conductivity}

Similar to oil density, the thermal conductivity conversely and slowly varies with temperature. The thermal conductivity of motor oil was provided by the manufacturer. In Figure 2.4 , with the change in temperature from $0-100{ }^{\circ} \mathrm{C}$, the conductivity varies only $0.0075 \mathrm{~W} / \mathrm{m}-\mathrm{K}$. For the current study, the oil temperature difference between the inlet and outlet is $35 \geq \Delta \mathrm{T} \geq 55^{\circ} \mathrm{C}$; the values of oil thermal conductivity extracted from the below figure are very close. Thus, the conductivity has no major effect on the convective heat transfer characterization.

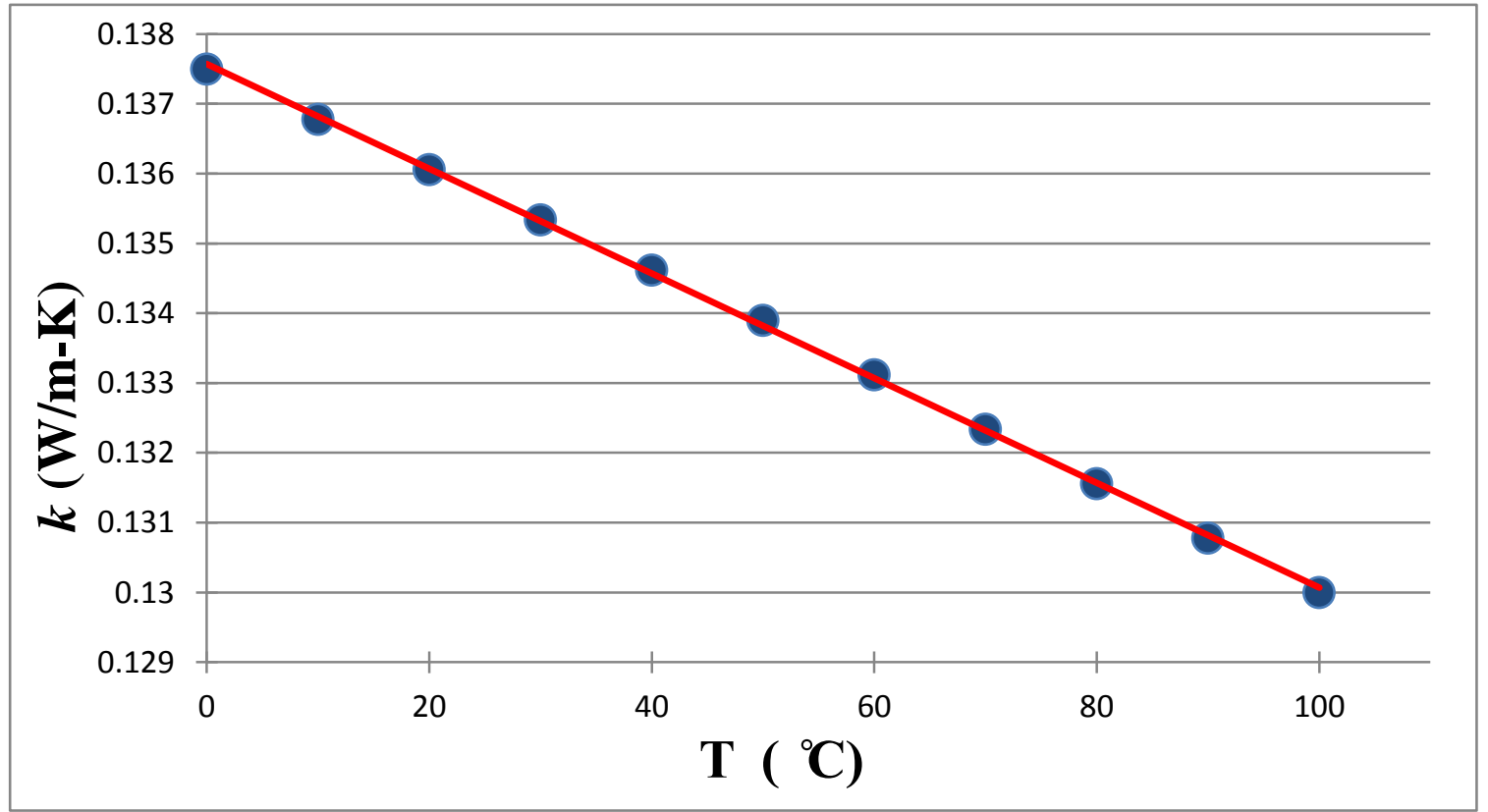

Figure 2.4: Oil Thermal Conductivity Variation with Temperature

\subsubsection{Specific Heat Capacity}

The motor oil specific heat increases as the temperature increases. The correlation is linear as shown in Figure 2.5. Similar to the thermal conductivity, the specific heat of oil was obtained directly from the manufacturer. Within the $100{ }^{\circ} \mathrm{C}$ temperature difference, the specific heat capacity varies only $0.4 \mathrm{~kJ} / \mathrm{kg}-\mathrm{K}$. 


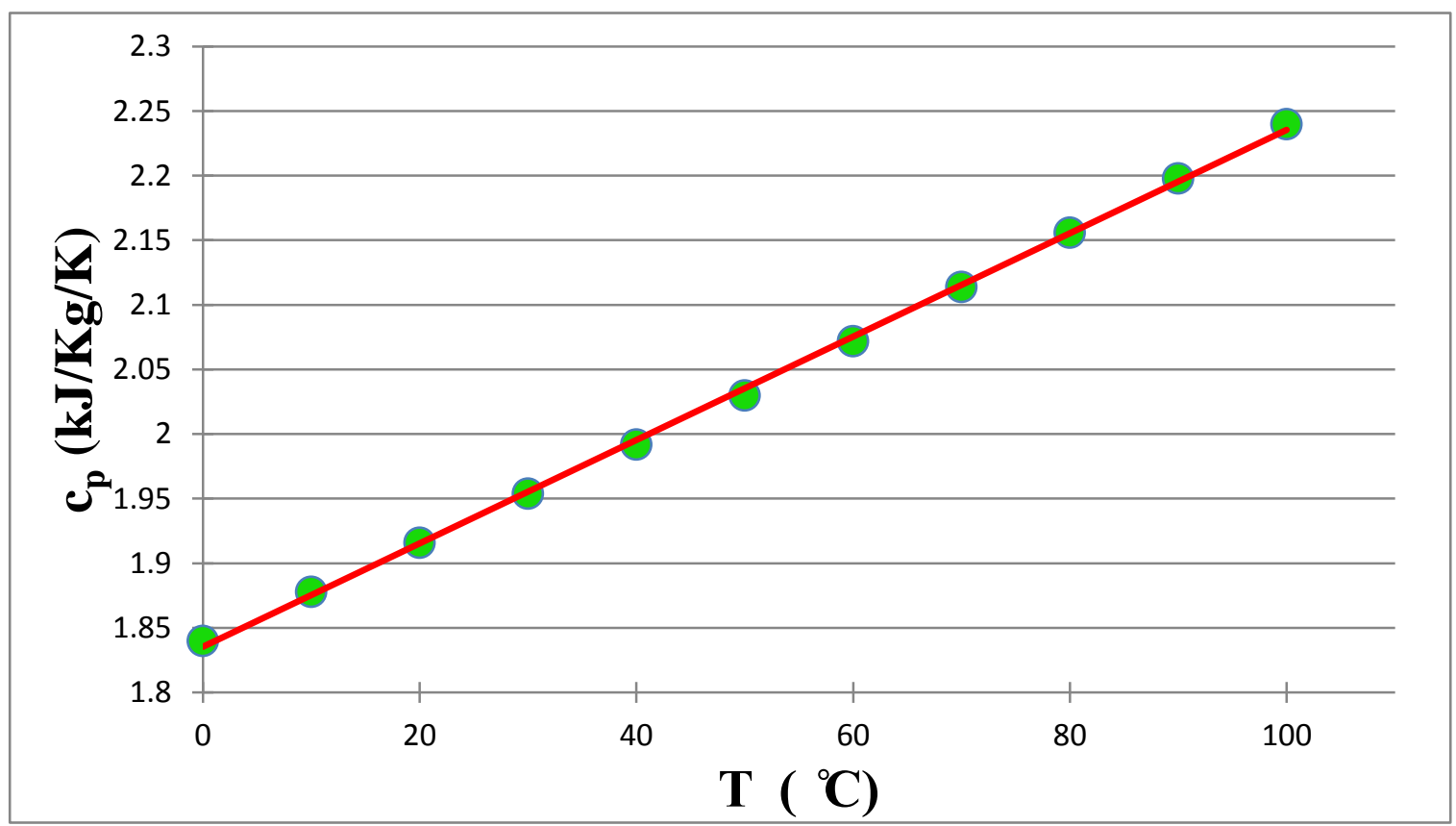

Figure 2.5: Oil Specific Heat Variation with Temperature

\section{$\underline{\text { 2.8.4 Oil coolers }}$}

The engine oil is circulated in the engine while it is running, and along with the engine, the oil also becomes hot on running. As Figure 2.1 shows, the oil loses its viscosity (becomes thinner) as the temperature increases. Thus, the lubricating effect of oil reduces, which increases friction between the engine parts.

As a result, the circulating oil passes through the oil cooler (heat exchanger) to dissipate heat to a cooler medium, such as an air stream or the coolant from the engine's cooling system. This helps to ensure that the oil maintains at an optimum temperature. There are two basic types of oil coolers [Heisler (1999)]:

\subsubsection{Liquid to air (tube-and-fin heat exchanger)}

This type of heat exchanger acts like that of the engine cooling system radiator. It lets the hot oil pass through finned tubes which are exposed to the surrounding air stream. This 
air stream is caused by the moving vehicle or the engine's cooling system fan. Heat is extracted through the metal walls of each tube to the external fins and then it is absorbed by the surrounding atmosphere.

\subsubsection{Liquid to liquid (shell-and-tube heat exchanger)}

Two fluids of different starting temperatures flow through this oil cooler. One fluid; the cooler coolant, flows through the tubes (tube side). On the other hand, the other fluid; the hot oil, flows outside the tubes (shell side). The heat is therefore transferred by conduction through the metal wall of each tube and then by convection through cycling of the ethylene glycol coolant.

\subsection{Scope of Current Investigation}

After reviewing a large number of published articles and papers, as well as several books, cooling a highly viscous fluid, motor oil, via a minichannel heat exchanger is virtually not-existent. The predominant studies were on heating standalone narrow channel and analyzing the heating effect on the fluid flowing through the channel. In addition, the majority of the working fluids that have been analyzed so far contain very low dynamic viscosity. Thus, it can be claimed that this investigation is considered as unique, since it examines the applicability of a minichannel heat exchanger for cooling motor oil.

In current investigations, experimental endeavours have been performed using a closed loop thermal wind tunnel to verify the aptness of cooling the motor oil through a crossflow minichannel heat exchanger. The proto-type heat exchanger utilized in the current 
examination is a finned multi-port serpentine circular minichannel slab heat exchanger. It consists of 3 circuits; each circuit has five slabs, which are connected to each other by four serpentines. There are 68 channels of $1 \mathrm{~mm}$ circular diameter drilled through each slab. The minichannel heat exchanger comprises of wavy fins arranged parallel to the flow of air. The inlet temperature of the motor oil was kept constant at $75^{\circ} \mathrm{C}$. On the other hand, the air inlet temperatures were varied within the range of $20^{\circ} \mathrm{C}$ and $40^{\circ} \mathrm{C}$ for five steps.

The flow of the oil falls in the laminar regime, due to the high viscosity, which consequently resulted in low Reynolds numbers. The Reynolds numbers were found to be from 0.85 to 3.5. Correlations were developed between the liquid side Nusselt number and liquid Re, and Pr. The effect of Re on the heat transfer coefficient, NTU, and effectiveness were carefully investigated. The outcome of the investigation showed a good level of agreement with the findings of the research works in open literature. 


\section{CHAPTER III}

\section{THEORETICAL BACKGROUND AND ANALYSIS}

In the current investigation, a prototype cross-flow minichannel heat exchanger is utilized to cool motor oil by passing air through fins. The investigation is solely on the behavior of motor oil (liquid side) inside the channels, since the air side of this test specimen has already been heavily analyzed by Siddiqui (2011) and Dasgupta (2011) while heating and cooling the air by ethylene-glycol and distilled water, respectively. Some milestones or important points and assumptions need to be considered for proper usage of equations:

1) The motor oil is Newtonian fluid as affirmed by the results obtained from the Can-Am laboratory, discussed in Chapter II.

2) The wetted perimeter of the inlet and outlet manifolds of the test specimen is 10 times larger than the diameter of the individual channel. As such, the distribution of the oil flow is taken as uniform.

3) The system is assumed to be insulated; hence there is no heat transfer to/from the surroundings.

4) The minichannels walls are smooth. In the current study, the minichannels are made with laser beam or multi-port extruded (MPE) tubing, which is considered having smoother channel surface (or wall) when it is compared with channels made by chemical etching. The minichannels diameter used in present study makes a relative roughness $\left(\varepsilon / D_{h}\right)$ of 0.0005 (i.e. the surface roughness height of the channels is $0.05 \%$ of channel diameter). Kandlikar et al. (2003) examined the 
role of channel roughness on heat transfer and pressure drop for different diameters. They concluded that the circular channel of $1.067 \mathrm{~mm}$ diameter having $\varepsilon / D_{h}=0.003$ can be dealt with as smooth channel. Consequently, the minichannels $\left(D_{h}=1 \mathrm{~mm}\right.$ and $\left.\varepsilon / D_{h}=0.0005\right)$ in this investigation are taken as smooth and the influence of $\varepsilon / D_{h}$ on heat transfer and pressure drop can be disregarded.

The representations of the two phenomena, fluid flow and heat transfer, of MICHX are in many ways similar to that of the conventional heat exchangers. Traditionally, these two phenomena are quantified by several parameters and dimensionless numbers which demonstrate the significance of certain concepts occurring on the fluids or channel walls.

\subsection{Reference (Bulk) and Wall Temperatures}

The dependency of heat transfer from one fluid to another is largely on the thermophysical properties of the fluids involved; especially density, specific heat, thermal conductivity, and dynamic viscosity. The effects of these properties on motor oil with respect to temperature were dealt with in the working fluid part. The aforementioned thermo-physical properties were determined at the bulk temperature of motor oil. Several authors have taken the bulk temperature for estimating the thermo-physical properties of the tested fluids [Xie and Hartnett (1992), Qu et al. (2000), Park et al. (2001), Xu et al (2002), Wu and Cheng (2003), Tiselj et al. (2004), Hetsroni et al. (2004), Gamrat et al. (2005), Gan et al. (2008)]. Air thermo-physical properties were also measured at the bulk temperature. 
The bulk temperature was calculated as the arithmetic average of the motor oil inlet and outlet temperatures which were determined by the RTDs:

$$
T_{\text {oil }, \text { bulk }}=\frac{T_{\text {oil }, \text { in }}+T_{\text {oil,out }}}{2}
$$

The air inlet and outlet temperatures were measured by thermocouples, it will be discussed in Chapter IV. Hence, the air bulk temperature, if needed, is evaluated by the following equation:

$$
T_{\text {air,bulk }}=\frac{T_{\text {air, }, \text { in }}+T_{\text {air }, \text { out }}}{2}
$$

Another temperature that needs to be considered and calculated is the wall temperature $\left(T_{\text {wall }}\right) . T_{\text {wall }}$ is involved in calculating several parameters and dimensionless numbers, such as the heat transfer coefficient $(h)$, the Eckert number $(E c)$, and the Brinkman number $(B r) . T_{\text {wall }}$ is actually the inner wall surface temperature $\left(T_{s i}\right)$, and it is computed as:

$$
T_{\text {wall }}=T_{s, i}=T_{s, o}+\left(\dot{Q}_{\text {avg }} * R_{\text {wall }}\right)
$$

Where $T_{s, o}$ is the outer wall surface and is taken from the reading of the thermocouples installed on the test specimen's outer surface. $R_{\text {wall }}$ is the wall thermal resistance and It can be calculated as:

$$
R_{\text {wall }}=\frac{\ln \left(\frac{D_{o}}{D_{i}}\right)}{2 \pi k_{\text {wall }}^{L}}
$$




\subsection{Dimensionless Groups}

Fluid flow and heat transfer characteristics, as mentioned earlier, are presented in terms of dimensionless numbers, such as the Reynolds number, the friction factor, the Nusselt number, and the Prandtl number. These and other important dimensionless parameters used in internal flow forced convection are listed with their definitions, physical meanings, and formulae. It is known that the hydraulic diameter $\left(D_{h}\right)$ is used as a characteristic length in the following dimensionless numbers.

\subsubsection{Reynolds Number $(R e)$}

Fluid flows in a heat exchanger are classified as Laminar, Transitional, or Turbulent flows. Laminar flow heat transfer relies utterly on fluid thermal conductivity to transfer heat from within a stream to a heat exchanger wall. Turbulent flow; on the other hand, generates better heat transfer because it intermingles the fluid particles and thus creates a disordered motion within the flow. The Reynolds number is often interpreted as a ratio of inertial force to viscous force. For internal flow, an exchanger's fluid flow in a circular geometry channel can be determined as follows:

$$
R e=\frac{\text { Inertial force }}{\text { Viscous force }}=\frac{\rho V D_{h}}{\mu}
$$

The units cancel each other, making the Reynolds number a dimensionless parameter. If viscous force dominates, the result would be a small value of $\mathrm{Re}$ and thus smooth flow, which is called Laminar flow. However, if the inertial force completely and considerably prevails over viscous force, the Re value would be high and thus disordered motion is created. Therefore, in this case, it would be known as Turbulent flow. 


\subsubsection{Prandtl Number $(P r)$}

The Prandtl number is a non-dimensional number. It is defined as the ratio of momentum diffusivity to thermal diffusivity of the fluid. It can be expressed as:

$$
\operatorname{Pr}=\frac{\text { Molecular diffusivity of Momentum }}{\text { Molecular diffusivity of heat }}=\frac{\mu c_{p}}{k}
$$

From the above equation, it can be noted that the Prandtl number is considered as a fluid property as it is calculated by the thermo-physical properties of the fluid itself. Compared to other non-dimensional numbers, the Prandtl number does not contain a length scale in its definition and is reliant only on the fluid and fluid state. In heat transfer phenomenon, it represents the relative thickness of the momentum (velocity) and the thermal boundary layers.

- If $\operatorname{Pr} \gg>1 \longrightarrow$ heat diffuses very slowly from the fluid (such as oil, $\operatorname{Pr}=$ 50 to 2000), consequently the thermal boundary layer is thinner relative to the velocity boundary, and the thermal entrance length is longer compared with the hydrodynamic length.

- If $\operatorname{Pr}<<1 \longrightarrow$ heat diffuses very quickly from the fluid (such as air, $\operatorname{Pr}=$ 0.2 to 1 ), consequently the thermal boundary layer is thicker relative to the velocity boundary, and the thermal entrance length is shorter compared with the hydrodynamic length.

For motor oil in the current study, the Prandtl numbers range from 387 to 528, which are calculated at oil bulk temperatures. Since $\operatorname{Pr} \gg>1$, this indicates that the thermal 
boundary layer is much thinner compared to the velocity boundary layer. As such, heat transfers very slowly from the oil.

\subsubsection{Péclet Number $(\mathrm{Pe})$}

The Péclet number represents the ratio of the thermal energy convected to the fluid to the thermal energy axially conducted within the fluid [Shah and London (1987)]. It also can be the outcome of the product of the Reynolds and Prandtl numbers. It is expressed by the following equation:

$$
P e=\frac{\text { Thermal energy convected to the fluid (rate of advection) }}{\text { Thermal energy axially conducted within the fluid (rate of diffusion) }}=\frac{\rho V D C_{p}}{k}=R e \cdot P r
$$

As seen in the above equation, the viscosity parameter is not included. The Péclet number is often used to investigate the heat transfer mechanism without taking into account the viscous effect. The inverse of $\mathrm{Pe}$ is a representation of the significance of axial heat conduction in the fluid.

\section{$\underline{3.2 .4 \text { Eckert Number }(E c)}$}

The Eckert number $(\mathrm{Ec})$ is another dimensionless number, which represents a correlation between the kinetic energy and the enthalpy of a fluid flowing inside a tube or channel. It is often used to characterize and quantify the viscous dissipation. It is defined as follows:

$$
E c=\frac{\text { Flow kinetic Energy }}{\text { Boundary layer enthalpy difference }}=\frac{V^{2}}{c p\left(T_{b u l k}-T_{\text {wall }}\right)}
$$




\section{$\underline{\text { 3.2.5 Brinkman Number }(\mathrm{Br})}$}

The Brinkman Number $(\mathrm{Br})$ is a dimensionless number and is a measure of the effect of viscous dissipation relative to the heat transferred by conduction. It is essential when a viscous fluid is investigated as it shows the presence of the viscous dissipation. It is given by the following equation:

$$
B r=\frac{\text { Viscous dissipation }}{\text { Heat conduction }}=\frac{\mu V^{2}}{k\left(T_{\text {bulk }}-T_{\text {wall }}\right)}
$$

Where $\mu$ and $k$ are the oil dynamic viscosity and thermal conductivity and both are evaluated at the bulk temperature. It presents the importance of the heat added to the fluid due to viscous forces. $\mathrm{Br}$ also can also be computed from the dimensionless general energy equation (as the multiplication of $\mathrm{Pr}$ and Ec) as follows:

$$
B r=\operatorname{Pr} . E C
$$

\section{$\underline{\text { 3.2.6 Nusselt Number }(\mathrm{Nu})}$}

The Nusselt Number is the kernel of heat transfer phenomenon which is usually known as the ratio of convection heat transfer to conduction heat transfer. The Nusselt number is dependent on the flow passage geometry and the thermal boundary condition, especially in a laminar regime. It is defined as the ratio of the convective conductance to pure molecular thermal conductance:

$$
N u=\frac{\text { convective conductance }}{\text { pure molecular thermal conductance }}=\frac{h}{k / D_{h}}=\frac{h D_{h}}{k}
$$

For forced convection, the Nusselt number is a function of the Reynolds number (flow type) and the Prandtl number (thermal boundary layer thickness or physical properties); 
or $\mathrm{Nu}=f(\mathrm{Re}, \mathrm{Pr})$. Hence, the Nusselt numbers are normally described by empirical correlations and the most common is expressed by Yataghene et al. (2009):

$$
N u=C \cdot R e^{m} \cdot P^{n}
$$

The determination of the values of the constant $\mathrm{C}$ and the exponents $\mathrm{m}$ and $\mathrm{n}$ are performed experimentally.

One of the rudimentary assumptions considered in the hypothetical correlations for $\mathrm{Nu}$ is that the fluid properties remain unchanged during the flow passage. However, fluid temperatures do alter significantly in practical situations, especially for high Prandtl number fluids. As such, oil viscosity alters considerably for motor oil. On the other hand, the variations in the thermal conductivity, specific heat, and density with temperature for oil; on the other hand, are insignificant [Xie and Hartnett (1992), Shin and Cho (1993), Shah and Sekulić (2003) ].

In the current study, heat is transferred from oil to the channel wall. This will create a temperature gradient in the radial direction at a channel cross section. Motor oil will be cooler near the channel wall and hotter near the channel centerline. Since the oil viscosity increases with decreasing temperature, the oil near the channel wall will have high viscosity (Figure 3.1). Consequently, oil velocity near the channel wall will be slower than the oil near the channel centerline. Therefore, this results in lower heat transfer coefficients $h$ (lower $\mathrm{Nu}$ ) and lower heat transfer rates. 


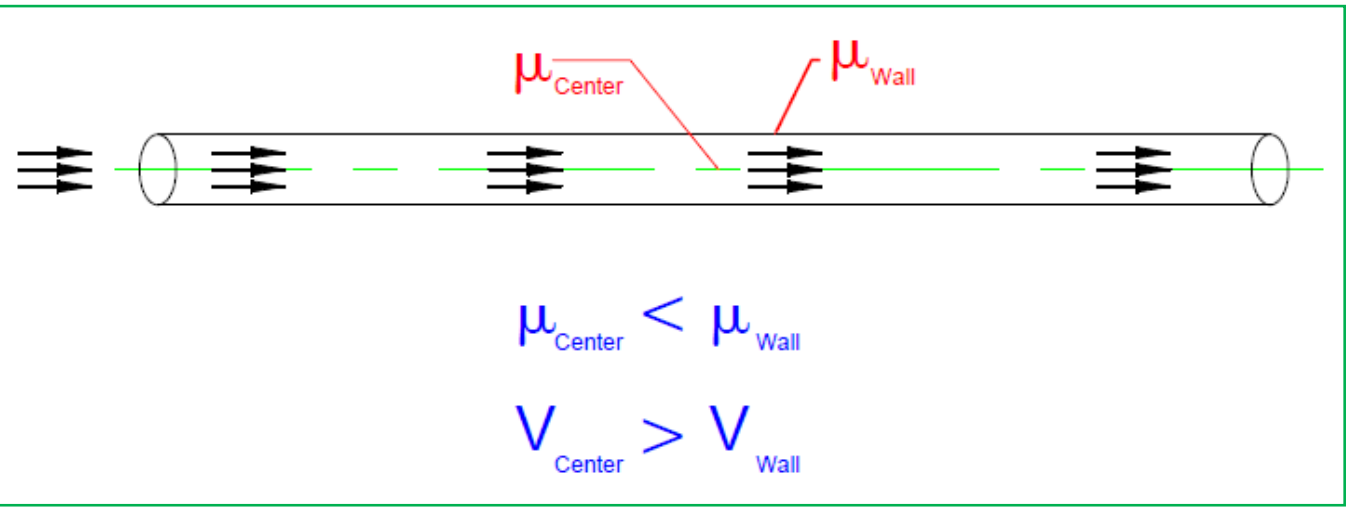

Figure 3.1: Oil Viscosity inside a Flow Passage

For taking into account the influence of temperature-dependent oil property (i.e. viscosity), the following correlation for the Nusselt Number $(\mathrm{Nu})$ is suggested [Phillips (1987), Xie and Hartnett (1992), Shin and Cho (1993), Shah and Sekulić (2003) ]:

$$
\frac{N u_{c}}{N u_{b u l k}}=\left(\frac{\mu_{\text {bulk }}}{\mu_{\text {wall }}}\right)^{n}, \quad N u_{c}=N u_{b u l k}\left(\frac{\mu_{\text {bulk }}}{\mu_{\text {wall }}}\right)^{n}
$$

Here, $N u_{c}$ is the corrected Nusselt number, and $N u_{b u l k}$ is calculated at bulk temperature. $\mu_{\text {bulk }}$ and $\mu_{w a l l}$ are the viscosities at bulk and wall temperatures, correspondingly. The value of the exponent $\mathrm{n}$ for fully developed laminar liquid flow in a circular duct is found numerically to be 0.14 [Phillips (1987), Shin and Cho (1993), Shah and Sekulić (2003)].

\section{$\underline{3.2 .7 \text { Axial Heat Conduction Number }(M)}$}

To evaluate and verify the presence of the axial heat conduction effect in the channel wall, the so-called axial heat conduction number $(M)$ was introduced by Maranzana et al. (2004) and used by Gamrat et al. (2005), Li et al. (2007), Gan et al. (2008), and Nonino et al. (2009). 


$$
\begin{gathered}
M=\frac{\text { axial heat conduction in the tube wall }}{\text { convective heat transfer of the flowing fluid inside tube }} \\
M=\frac{\dot{Q}_{\text {cond }}}{\dot{Q}_{\text {conv }}}=\frac{k_{\text {wall }} A_{\text {wall }} \frac{\Delta T_{\text {wall }}}{L}}{(\dot{m} C p)_{\text {oil }} \Delta T_{\text {oil }}}
\end{gathered}
$$

The above dimensionless number allows comparing "axial heat transfer by conduction in the wall" and "convective heat transfer of the flowing fluid inside tube". Here $\dot{Q}_{c o n d}$, which is only a nominal value of the axial heat conduction in the wall, is calculated assuming the heat transfer is one-dimensional (in the $\mathrm{x}$-direction) through the same fluid temperature difference [Maranzana et al. (2004) and Gan et al. (2008)]. Since it was experimentally difficult to measure exactly the temperature difference in the channel wall, $\Delta T_{\text {wall }}$ is taken to be equal to the $\Delta T_{\text {oil }}$. Li et al. (2007) were able to numerically determine the exact values of the temperature difference of the fluid and wall. The above equation can be simplified as follows (Appendix D):

$$
M=\left(\frac{k_{w a l l}}{k_{o i l}}\right) \cdot\left(\frac{\left(D_{o}^{2}-D_{i}^{2}\right)}{D_{i} L}\right) \cdot \frac{1}{R e P r}
$$

\section{$\underline{3.3 \text { Fluid Flow Characteristics }}$}

The fundamental correlations and equations in analyzing the fluid flow characteristics of the working fluid, motor oil, are listed below.

\subsubsection{Entrance Lengths}

When a fluid enters a tube at a uniform velocity, the fluid particles in contact with the tube wall come to a complete stop because of wall friction and also make the neighboring fluid particles slow down. Consequently, fluid particles velocity at the midsection increase and thus a velocity boundary layer starts developing along the tube axial direction. The thickness of this layer increases in the flow direction until it reaches the 
centerline of the tube. The region from the tube inlet to the location where the boundary layer merges at the tube centre is called hydrodynamic entrance region (flow is called hydrodynamically developing flow) and its length is called hydrodynamic entry length $\left(L_{h y}\right)$. The region beyond the entrance length in which the velocity profile is fully developed and remains unchanged is called hydrodynamically fully developed region [Çengel (2007)].

Similarly, a fluid at a uniform temperature enters a tube whose surface temperature is maintained. This instigates convection heat transfer between the fluid particles in contact with the tube surface, as well as the surface itself. As such, a thermal boundary layer starts developing along the tube. The thickness of this layer increases in the flow direction until it reaches the tube centerline. The region from the tube inlet to the location where the boundary layer merges at the tube centre is called thermal entrance region (flow is called thermally developing flow) and its length is called thermal entry length $\left(L_{t h}\right)$. The region beyond the entrance length in which the dimensionless temperature profile is fully developed and remains unchanged is called thermally fully developed region [Çengel (2007)].

The region in which the flow is both hydrodynamically and thermally developed is called fully developed flow. In laminar flow, the hydrodynamically and thermally entry lengths are computed by the following:

$$
\begin{gathered}
L_{h y}=0.05 \operatorname{Re} . D_{h} \\
L_{t h}=0.05 \operatorname{Re} . \operatorname{Pr} . D_{h}=\operatorname{Pr} . L_{h y}
\end{gathered}
$$




\subsubsection{Motor Oil Flow Rate and Reynolds Number}

The total mass flow rate of motor oil $\left(\dot{m}_{\text {oil }}\right)$ through the minichannel heat exchanger is determined by taking the weight of oil in the bucket and dividing it by the time needed to fill the bucket. This can be expressed as follows:

$$
\dot{m}_{o i l}=\frac{\Delta m}{\Delta t}
$$

However, the calculated flow rate is for the full heat exchanger (204 channels); thus the mass flow rate of an individual channel can be evaluated by the following:

$$
\dot{m}_{o i l, M C}=\frac{\dot{m}_{o i l}}{204}
$$

From the mass conservation principle, oil velocity can be evaluated as follows:

$$
\begin{gathered}
\dot{m}_{o i l}=\rho V_{a v g} A_{c s} \\
V_{a v g}=\frac{\dot{m}_{o i l}}{\rho A_{c s}}
\end{gathered}
$$

Therefore,

$$
V_{M C}=\frac{\dot{m}_{o i l, M C}}{\rho A_{C S, M C}}=\frac{4 \dot{m}_{o i l, M C}}{\rho \pi D_{h}^{2}}=\left[\frac{\dot{m}_{o i l}}{204}\right] \frac{4}{\pi \rho D_{h}^{2}}=\frac{\dot{m}_{o i l}}{51 \rho \pi D_{h}^{2}}
$$

The oil mass velocity $\left(G_{\text {oil }}\right)$ into the minichannel heat exchanger core is calculated based on the total cross-sectional area of the channels:

$$
G_{o i l}=\frac{\dot{m}_{o i l}}{A_{c s}}
$$

The motor oil Reynolds number value for one individual channel is then calculated as:

$$
R e_{o i l}=\frac{\rho V_{M C} D_{h}}{\mu}=\left(\frac{\rho D_{h}}{\mu}\right)\left(\frac{\dot{m}_{o i l}}{51 \pi \rho D_{h}^{2}}\right)=\left(\frac{\dot{m}_{o i l}}{51 \pi \mu D_{h}}\right)
$$




\subsubsection{Pressure Drop}

The evaluation of the pressure drop $(\Delta \mathrm{P})$ in a heat exchanger device is necessary for several reasons. The fluid pressure drop impacts the exchanger heat transfer, operation, size, mechanical characteristics, and economic considerations [Shah and Sekulić (2003)]. In current investigation, the total pressure drop of the test specimen combines the pressure drop occurred in the minichannel itself (straight and serpentine parts) and the pressure drop associates with fluid distribution devices (inlet/outlet headers and inlet/outlet headers). The pressure drop that takes place due to fluid distribution devices was extensively elaborated and discussed by Khan (2011). Hence, only the channel hydraulic pressure drop will be considered in this research.

\section{I) Pressure Drop in a Straight Tube}

The calculations for the laminar hydrodynamic and thermal lengths indicate that the flow is fully developed (it will be explained in section 5.1) inside the minichannel. Hence, for a fully developed laminar flow in a straight tube, the pressure drop can be computed using the following equation [Kandlikar et al. (2003), Fox et al. (2004), Cui Silber-Li (2004), Çengel (2007)]:

$$
\begin{gathered}
\Delta P=\frac{128 \mu L \dot{V}}{\pi D^{4}} \\
\Delta P=\frac{128 \mu L\left(A V_{M C}\right)}{\pi D^{4}} \\
\Delta P=\frac{128 \mu L V_{M C}}{\pi D^{4}}\left(\frac{\pi D^{2}}{4}\right) \\
\Delta P=32 \frac{L}{D} \frac{\mu V_{M C}}{D}
\end{gathered}
$$




\section{II) Pressure Drop in a Curved Tube}

When a certain fluid flow goes through a curved tube, the flow is subjected to two types of pressure drop: the radial and axial pressure drops. The radial pressure drop occurs due to the added loss which results from the secondary flow. To calculate the radial pressure drop, the following equation is used [Vashisth et al. (2008)]:

$$
\Delta P_{\text {radial }}=2 \rho V^{2}\left(\frac{D}{D_{c}}\right)
$$

\subsubsection{Friction Factor}

Friction factor $(f)$ is a dimensionless parameter. It can be used to estimate the major head losses, which is the pressure drop. In case of steady fully developed laminar flow, the equation with which the friction factor can be determined is as follows [Jiang, X.N. et al. (1995), Park et al. (2001), Wu and Cheng (2003), Iyengar and Garimella (2006), Çengel (2007)]:

$$
f=\Delta P \frac{D}{L} \frac{2}{\rho V^{2}}
$$

From the above equation, the friction factor is highly dependent on the flow path geometry. For a circular cross-sectional geometry and fully developed laminar flow, friction factor is inversely proportional to the Reynolds number and it can be shown as [Jiang, X.N. et al. (1995), Fox et al. (2004) and Çengel (2007)]:

$$
f=\frac{64}{R e}
$$

Moreover, friction factor can be dependent on fluid thermo-physical properties, especially viscosity. As explained in section 3.2.6, the oil dynamic viscosity at the wall is higher than the viscosity at the center due to the variation in temperature. As a result, friction factor and pressure drop would be higher at the channel wall. This fluid property 
variation can be compensated by the following equation [Phillips (1987), Xie and Hartnett (1992), Shin and Cho (1993), Shah and Sekulić (2003)]:

$$
\frac{f_{c}}{f_{\text {bulk }}}=\left(\frac{\mu_{\text {bulk }}}{\mu_{\text {wall }}}\right)^{m}
$$

For a fully developed laminar flow in a circular tube and for a cooling mode, the value of the exponent $m$ is found to be - 0.54 [Phillips (1987), Shah and Sekulić (2003)].

\subsection{Heat Transfer Characteristics}

The basic equations in computing the forced convection heat transfer mechanism of both fluids (motor oil and air) are summarized here.

\subsubsection{Heat Transfer Rate $(\dot{Q})$}

The amount of heat dissipated by a hot fluid and absorbed by a cold fluid in a heat exchanger is crucial for the heat transfer study. The steady state heat transfer between the hot fluid (motor oil) and the cold fluid (air) using the examined minichannel heat exchanger was basically due to the forced convection mechanism. The two heat duties can be computed from the following two equations:

$$
\begin{gathered}
\dot{Q}_{\text {oil }}=(\dot{m} c p)_{\text {oil }}\left(T_{\text {oil }, \text { in }}-T_{\text {oil }, \text { out }}\right) \\
\dot{Q}_{\text {air }}=(\dot{m} c p)_{\text {air }}\left(T_{\text {air }, \text { out }}-T_{\text {air }, \text { in }}\right)
\end{gathered}
$$

\subsubsection{Heat Balance (HB)}

The heat rejected by the motor oil should perfectly be equivalent to the heat taken by the air $\left(\dot{Q}_{o i l}=\dot{Q}_{\text {air }}\right)$ in theory. In practice, though, this is not a viable solution due to a 
number of factors such as heat infiltration to the ambient and experimental errors of some instruments used in the system.

One of the methods to verify the reliability of the test specimen and its measurement instruments is the approach of heat balance (HB). This approach was recommended by the ASME PTC 30-1991 for an air cooled heat exchanger. The method to calculate the heat balance is to take the difference of the heat transfer rate between the two fluids and divide it by the arithmetic mean of the heat transfer rate of two fluids. The advisable Heat Balance (HB) limit is $\pm 15 \%$. The formula is as following:

$$
H B=\frac{\dot{Q}_{\text {oil }}-\dot{Q}_{\text {air }}}{\dot{Q}_{\text {avg }}} * 100
$$

Where $\dot{Q}_{a v g}$ is the arithmetic mean of the heat transfer rate of oil and air, as shown below in the equation:

$$
\dot{Q}_{\text {avg }}=\frac{\dot{Q}_{o i l}+\dot{Q}_{a i r}}{2}
$$

\section{$\underline{\text { 3.4.3 Heat Transfer Coefficient }(h)}$}

The heat transfer coefficient $(h)$ is a quantitative representation of convection heat flux per unit temperature difference between a fluid and a surface (wall) or vice versa.

$$
h_{\text {oil }}=\frac{\dot{Q}_{\text {oil }}}{A_{s, \text { oil side }}\left(T_{\text {oil }, \text { bulk }}-T_{\text {wall }}\right)}=\frac{N u_{\text {bulk }} k_{\text {oil }}}{D_{h}}
$$

The complexity of the heat transfer phenomenon for a heat transfer surface is fully shown in the definition of $h$, letting it be reliant on several variables and operating conditions. These variables/conditions are, but not limited to, phase condition, flow regime, flow 
passage geometry, fluid physical properties, convection type, viscous dissipation, heat transfer rate, and flow and thermal boundary conditions. Hence, in general, the notion of $h$ to signify the convection phenomenon is valid, but only in a restricted number of applications and might not provide a straightforward solution to a vast range of convective heat transfer problems [Shah and Sekulić (2003)].

\section{$\underline{3.5 \text { Heat Transfer Performance }}$}

A set of experiments is conducted to analyze the thermal performance of MICHX, whose configuration is cross-flow serpentine multi-pass. There are several approaches to analyze the heat exchanger performance, such as Overall Conductance $(U A)$, Heat Exchanger Effectiveness $(\varepsilon)$, and Number of Transfer Unit $(N T U)$.

\subsubsection{Overall Heat Transfer Conductance $(U A)$}

One method to examine the performance is by computing the overall Heat Transfer conductance $(U A)$, which is actually equal to the inverse of the overall thermal resistance. The overall conductance shows the reliability of a heat exchanger on transferring heat. As per Newton's law of cooling, for a cross-flow heat exchanger the following equation can be used:

$$
U A=\frac{\dot{Q}_{\text {avg }}}{F \Delta T_{L M T D}}
$$

$\dot{Q}_{a v g}$ is the average heat duty between oil and air and can be computed by equation 3. 33 . $\Delta \mathrm{T}_{\mathrm{LMTD}}$ is the log-mean temperature difference and it is defined as the average effective temperature difference between the two fluid streams over the length of the heat exchanger. For a two-fluid heat exchanger with $\mathrm{C}^{*} \approx 0\left(\mathrm{C}^{*}\right.$ will be defined in section 
3.5.3), the log-mean temperature difference $\left(\Delta T_{L M T D}\right)$ on the hot- and cold-fluid sides is calculated as following [Shah and Sekulić (2003)]:

$$
\Delta T_{L M T D}=\frac{\Delta T_{1}-\Delta T_{2}}{\ln \frac{\Delta T_{1}}{\Delta T_{2}}} \quad\left\{\begin{array}{c}
\Delta T_{1}=T_{\text {oillin }}-T_{\text {air, bulk }} \\
\Delta T_{2}=T_{\text {oil,out }}-T_{\text {air, bulk }}
\end{array}\right\}
$$

The correction factor $(F)$ depends on the geometry of the heat exchanger and the inlet and outlet temperatures of the hot and cold fluids. It is defined as the ratio of the effective mean temperature difference to the log-mean temperature difference [Shah and Sekulić (2003)]:

$$
\begin{gathered}
F=\frac{\Delta T_{\text {mean }}}{\Delta T_{L M T D}} \\
\text { Where } \quad \Delta T_{\text {mean }}=\frac{\Delta T_{1}+\Delta T_{2}}{2}
\end{gathered}
$$

$F$ can also be calculated from specific charts for a cross-flow heat exchanger if the values of temperature effectiveness " $P$ " and heat capacity rate ratio " $R$ " are provided [Shah and Sekulić (2003), Çengel (2007)]:

$$
\begin{gathered}
P=\frac{T_{\text {oil,out }}-T_{\text {oil }, \text { in }}}{T_{\text {air }, \text { in }}-T_{\text {oil }, \text { in }}} \\
R=\frac{(\dot{m} c p)_{o i l}}{(\dot{m} c p)_{a i r}}=\frac{C_{o i l}}{C_{\text {air }}}
\end{gathered}
$$

\subsubsection{Number of Transfer Unit (NTU)}

One more way in which the heat exchanger performance can be analyzed is by the number of transfer units (NTU). It is a design parameter and it is the ratio of the overall conductance $(U A)$ to the minimum heat capacity rate $\left(C_{\min }\right)$, [Shah and Sekulić (2003), Çengel (2007)]:

$$
N T U=\frac{U A}{\left(\dot{m} C_{p}\right)_{\min }}=\frac{U A}{C_{\min }}
$$


It designates the non-dimensional expression of the "heat transfer size or thermal size" of a heat exchanger. As shown from the above equation, NTU can be large if the product of overall heat transfer coefficient $(U)$ and heat transfer surface area $(A)$ is large. Hence, a large value of NTU does not denote the physical size of a heat exchanger. However, when the value of $\frac{U}{C_{\min }}$ does not vary as much, a higher value of NTU then refers to a large physical size.

\section{$\underline{\text { 3.5.3 Heat Exchanger Effectiveness }(\varepsilon)}$}

Another approach of verifying the performance of heat exchanger is by calculating the effectiveness $(\varepsilon)$. Heat exchanger effectiveness is the measure of the ratio of the actual heat transfer to the maximum heat that could be transferred by a heat exchanger of infinite size. It is defined for a given heat exchanger regardless of its flow arrangement. The effectiveness can be calculated from the following equation [Shah and Sekulić (2003), Çengel (2007)]:

$$
\varepsilon=\frac{\dot{Q}_{\text {actual }}}{\dot{Q}_{\text {maximum }}}
$$

Or

$$
\varepsilon=\frac{(\dot{m} c p)_{o i l}\left(T_{o i l, i n}-T_{o i l, o u t}\right)}{(\dot{m} c p)_{\min }\left(T_{o i l, i n}-T_{a i r, i n}\right)}=\frac{(\dot{m} c p)_{a i r}\left(T_{a i r, o u t}-T_{a i r, i n}\right)}{(\dot{m} c p)_{\min }\left(T_{o i l, i n}-T_{a i r, i n}\right)}
$$

In heat exchanger analysis, it is also suitable to obtain another dimensionless parameter called heat capacity rate ratio $\left(\mathrm{C}^{*}\right)$. It is a ratio of the smaller to larger heat capacity rate for the two fluid streams; and it is as follows [Shah and Sekulić (2003), Çengel (2007)]:

$$
C^{*}=\frac{(\dot{m} C p)_{\min }}{(\dot{m} C p)_{\max }}=\frac{C_{\min }}{C_{\max }}
$$


$\mathrm{C}^{*}$ is considered an operating parameter of the heat exchanger since it relies on fluid mass flow rates and fluid temperatures. The fluid that has $\mathrm{C}_{\max }$ is subjected to a lower temperature difference than the temperature difference for the $\mathrm{C}_{\min }$ fluid.

Heat exchanger effectiveness $(\varepsilon)$ is a function of number of transfer units $(N T U)$, heat capacity rate ratio $\left(C^{*}\right)$, and flow arrangement [Çengel (2007)]:

$$
\varepsilon=\text { function }\left(N T U, C^{*}, \text { flow arrangement }\right)
$$

For any given value of NTU, the $\varepsilon$ is maximum when $C^{*}=0$ and minimum when $C^{*}=1$ regardless of the heat exchanger flow arrangement. In the current investigation, the flow arrangement is a cross-flow and $\mathrm{C}^{*}$ is almost equal to 0 . Hence, for a given NTU value, the $\varepsilon$ is maximum. Thus, the following equation can be applied [Shah and Sekulić (2003), Çengel (2007)]:

$$
\varepsilon=1-e^{-N T U}
$$




\section{CHAPTER IV}

\section{EXPERIMENTAL SET-UP AND PROCEDURE}

The experimental runs pertaining to this investigation were undertaken at the University of Windsor's Thermal Research Facility, room B05, of Essex Hall. This facility is fully equipped with accurate measurement devices and system controllers. An appropriate picture of the research facility is shown in Figure 4.1. Several apparatus are integrated together to perform and record the experiments. In order to depict a practical application, a gear pump and a blower were used in the current investigation. This incorporated and complex layout, which was designed and built by Dr. Mesbah Khan [Khan and Fartaj (2011) and Khan (2011)], offers some flexibility such as adapting with different working fluids and acquiring heating or cooling modes.

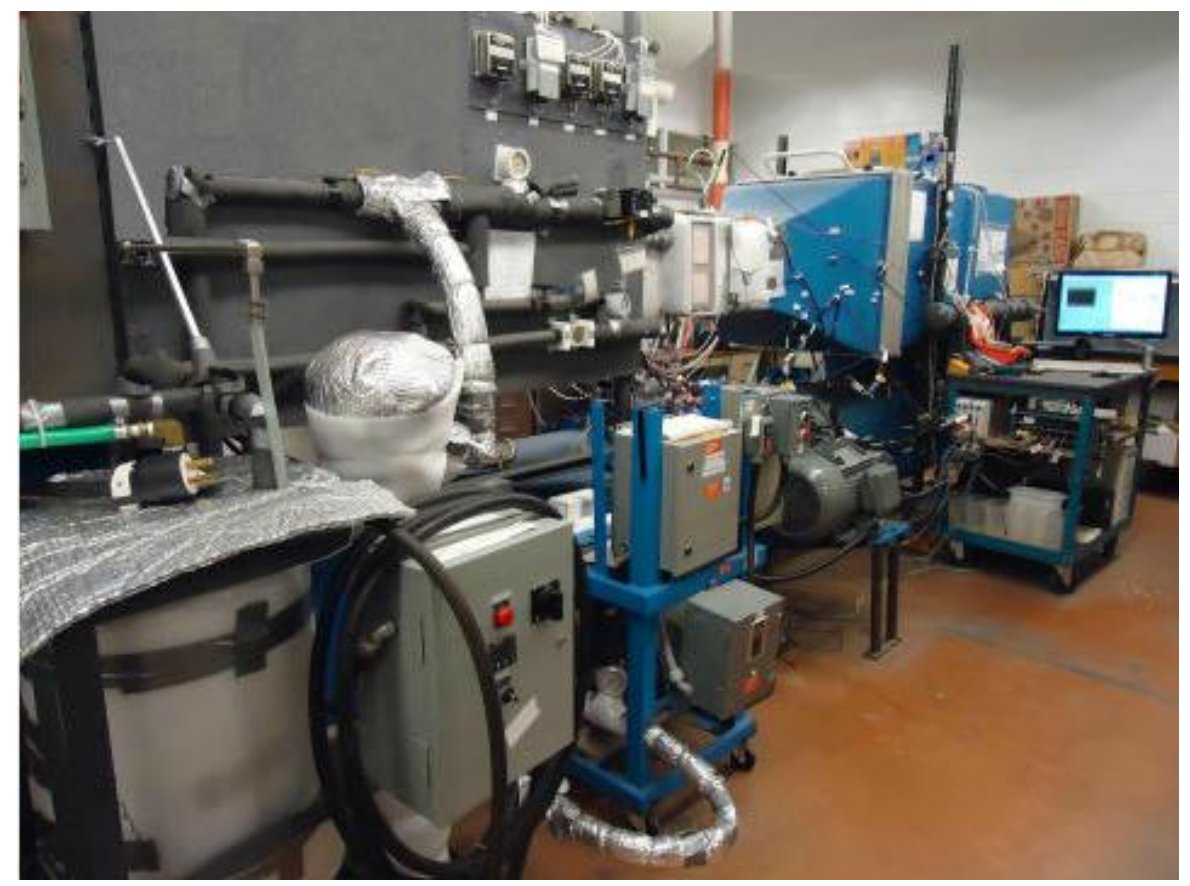

Figure 4.1: Research Facility 
A schematic diagram of the experimental set-up used to investigate fluid flow and heat transfer characteristics of motor oil in a cross-flow minichannels heat exchanger is shown in Figure 4.2. As seen in the diagram, the set-up can be divided into closed oil loop (tested fluid), closed air loop (cooling fluid), and test specimen (minichannels heat exchanger). The components, functions, and specifications of each part will be expounded separately.

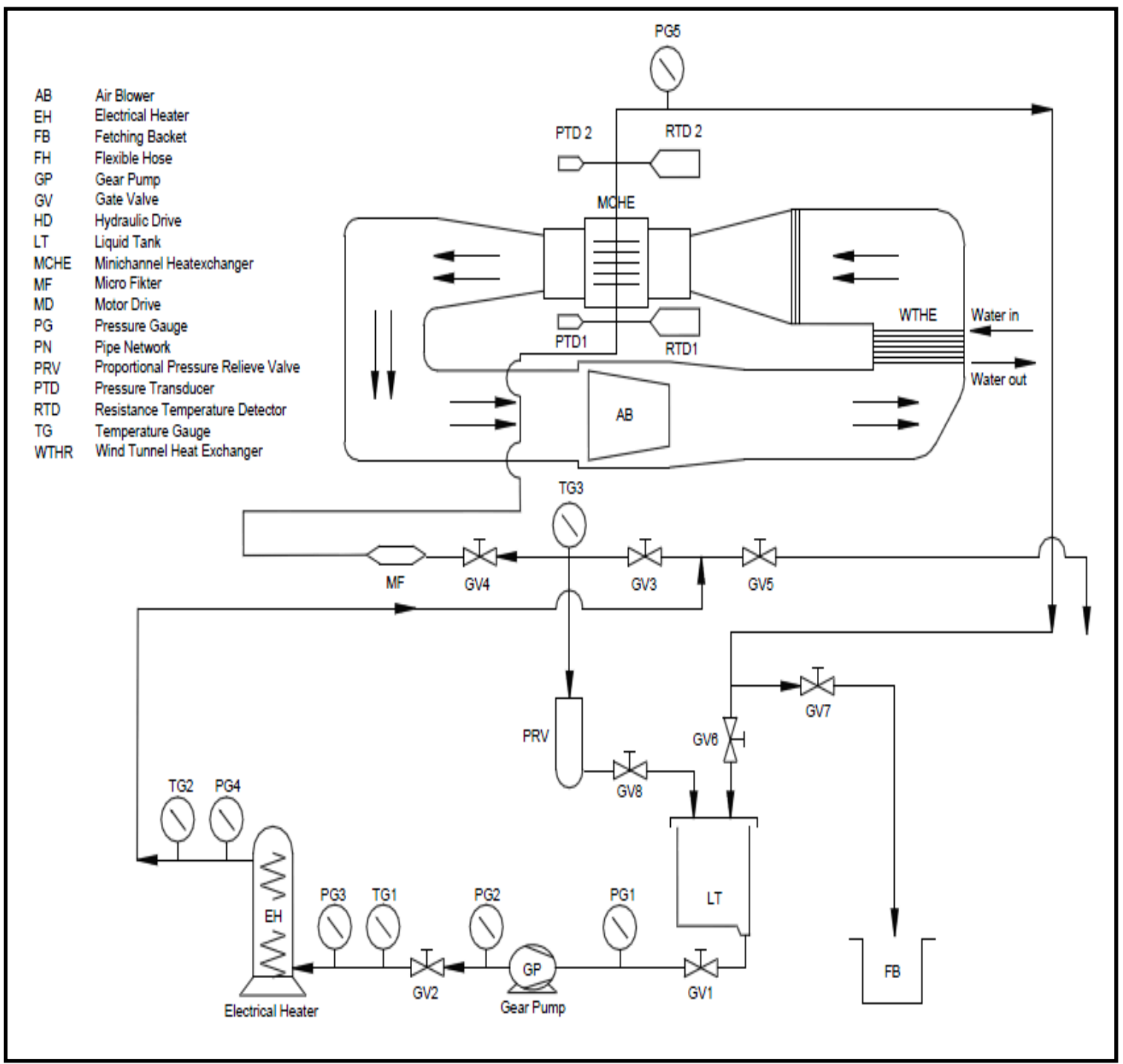

Figure 4.2: Schematic Diagram of the Experimental Set-Up 


\section{$\underline{4.1 \text { Oil Loop (Tested Fluid) }}$}

Motor oil loop is considered as the main loop since the working fluid, motor oil, is circulating through. The thermo-physical properties and the function of the motor oil was discussed in Chapter II. The circulation of the motor oil is taken from a tank and driven by a gear pump. The oil then passes through an electric pre-heater to maintain the inlet temperature to the Minichannel Heat Exchanger (MICHX). A micro-filter was placed between the outlet of the heater and the inlet of the minichannel to avoid any particles or bubbles from flowing through and blocking the minichannels. After that, the oil goes through channels inside the heat exchanger test specimen and finally it is sent back to the tank. Two resistance temperature detectors (RTD 1 \& RTD 2) and two pressure transducers (PTD 1 \& PTD 2) were fixed at the inlet and exit of the MICHX to measure the temperatures and the pressures, correspondingly.

Generally, this loop can be said to consist of major and minor components. Major components are the oil tank, gear pump, and electric heater. Minor components are flow management accessories, flow monitoring devices, and flow measurement instruments.

\subsubsection{Major Components}

\subsubsection{Oil Tank}

The tank is made of Ultra High Molecular Weight Polyethylene (UHMWPE). This type of material is highly resistant to corrosion, self-lubricating and has extremely low moisture absorption. It is also odourless, tasteless, and of a non-toxic material. The following table presents the tank's dimensions: 
Table 4.1: Tank Dimensions

\begin{tabular}{|c|c|}
\hline Height & $23.5 \mathrm{in} / 60 \mathrm{~cm}$ \\
\hline Diameter & 17 in $/ 43 \mathrm{~cm}$ \\
\hline Wall Thickness & $0.16 \mathrm{in} / 0.4 \mathrm{~cm}$ \\
\hline Cover's Thickness & $0.24 \mathrm{in} / 0.6 \mathrm{~cm}$ \\
\hline Height above ground & $17.3 \mathrm{in} / 44 \mathrm{~cm}$ \\
\hline Volume & 23 gallons $/ 0.087 \mathrm{~m}^{3}$ \\
\hline
\end{tabular}

\subsubsection{Gear Pump}

The oil is circulated through the system by utilizing a positive displacement gear pump shown in Figure 4.3. Unlike other types of pumps, the gear pump can provide a constant flow rate of liquid without taking into account the pressure drop that usually occurs across the minichannels [Khan and Fartaj (2011), Steinke ${ }^{1}$ et al. (2006), and Steinke ${ }^{2}$ et al. (2006)].

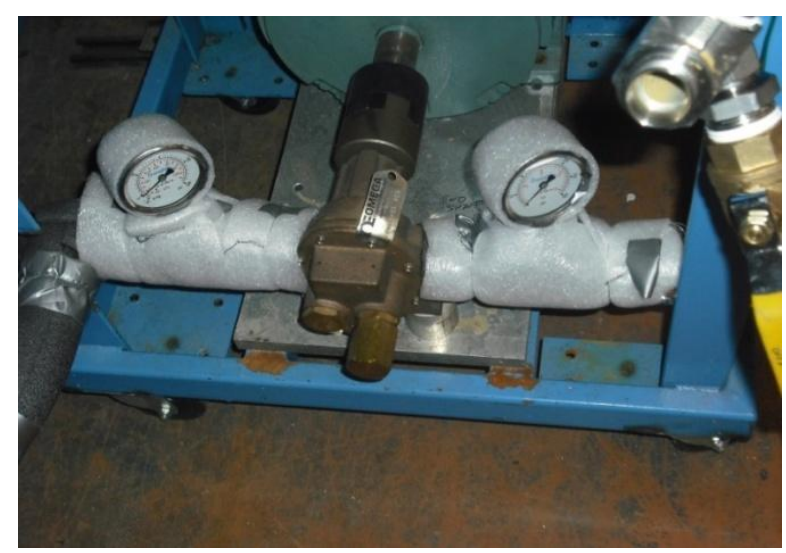

Figure 4.3: Gear Pump 
The pump is driven by an external variable-speed motor which is managed by a frequency controller. Thus, the oil flow rate can be conveniently adjusted as desired by only varying the frequency of the motor. As been recommended by the pump's manufacturer, a pressure relief valve is installed after the pump's discharge line to protect the pump against excessive back pressure. The specifications of this pump are shown in TABLE 4.2.

Table 4.2: Gear Pump Specifications

\begin{tabular}{|c|c|}
\hline Make & OMEGA \\
\hline Model (Part) Number & FPUGR205 - RCB \\
\hline Temperature Range & -54 to $121^{\circ} \mathrm{C}$ \\
\hline Maximum Capacity & $17.4 \mathrm{GPM}$ \\
\hline Maximum Pressure & $(150 \mathrm{psi} / 1034 \mathrm{kPa})$ for Oil \\
& $(100 \mathrm{psi} / 690 \mathrm{kPa})$ for Water \\
\hline Maximum Viscosity & $100,000 \mathrm{SSU}(21,630 \mathrm{cSt})$ \\
\hline Maximum Motor Speed & $1725 \mathrm{rpm}$ \\
\hline Horse Power & $7.5 \mathrm{hp} / 5.6 \mathrm{~kW}$ \\
\hline
\end{tabular}

\section{$\underline{\text { 4.1.1.3 Electric Heater }}$}

In this investigation, the motor oil is heated up by an inline electric heater which is capable of providing up to $6 \mathrm{KW}$. The components of the heater are presented in Figure 4.4 [Siddiqui (2011)]. There are 6 heating elements fitted inside the steel casing which are in a direct contact with the motor oil, in order to increase its temperature. 


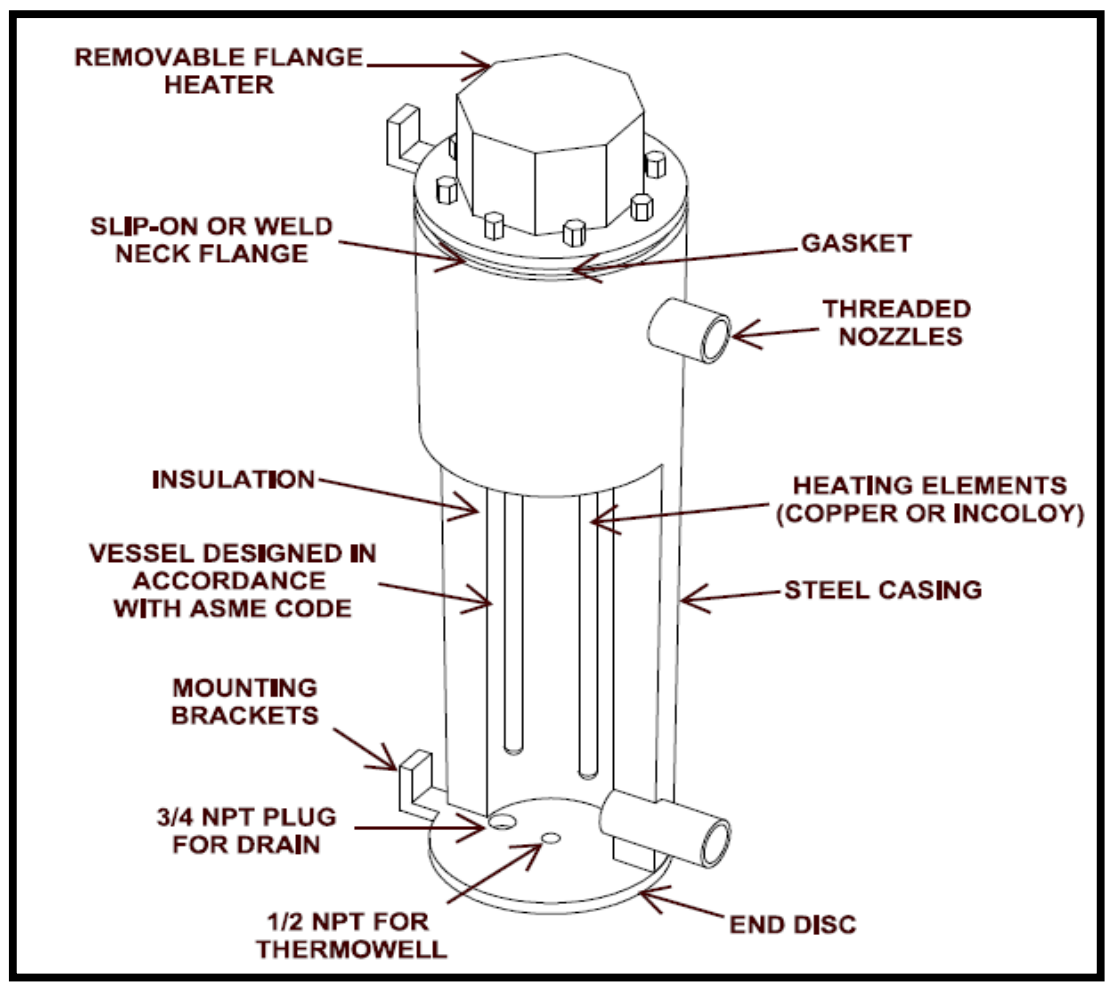

Figure 4.4: Electric Heater

A programmed control panel is connected to the electric heater to adjust the required heating temperature. The controller type is a proportional integral derivative (PID) control which is able to automatically maintain the inserted temperature value with more accuracy than the on/off control. The temperature inside the electric heater is measured by a thermocouple. The specifications of the heater are shown in TABLE 4.3.

Table 4.3: Electrical Heater Specifications

\begin{tabular}{|c|c|}
\hline Make & Wattco \\
\hline Model (Part) Number & MFLI606X2818 \\
\hline Maximum Temperature & $150{ }^{\circ} \mathrm{C}$ \\
\hline Maximum Pressure & $980 \mathrm{psi} / 6.8 \mathrm{MPa}$ \\
\hline
\end{tabular}




\subsubsection{Minor Components}

\subsubsection{Flow Management Accessories}

Valves: Ball valve types are distributed to control and direct the motor oil to the minichannel heat exchanger. Each valve can withstand pressure up to 3000 psi.

Filter: A 440 micro-filter (MF) is mounted before the inlet of MICHX to prevent the unwanted particles from entering the MICHX. The maximum pressure that the filter can bear is around $580 \mathrm{psi}$.

\subsubsection{Flow Monitoring Devices}

As shown in Figure 4.2, temperature and pressure gauges are located throughout the motor oil path to observe the values of the oil's temperatures and pressures before and after certain components, such as the gear pump, electric heater, and MICHX. These gauges are employed for monitoring purposes only.

\subsubsection{Flow Measurement Instruments}

Two sets of Resistance Temperature Detector (RTD) and Pressure Transducer Transmitter (PTD) are fixed. One set (RTD 1 and PTD 1) is located just before the inlet header of MICHX and the other set (RTD 2 and PTD 2) is installed before the outlet header of MICHX.

I) Resistance Temperature Detector (RTD)

The RTD is basically a type of sensor used to determine temperature by relating the RTD element's resistance with temperature. The working principle of the RTD is based on the 
Wheatstone bridge circuit. As mentioned earlier, the motor oil inlet and outlet temperatures are measured by the RTDs. The inlet and the outlet ultra precise immersion RTD sensors have similar specifications, shown in TABLE 4.4. Both are equipped with a mounting thread for an easy installation and removal from the pipe networking. A picture of an uninstalled RTD is shown in Figure 4.5.

Table 4.4: RTD Specifications

\begin{tabular}{|c|c|}
\hline Make & Omega \\
\hline Temperature Range & -25 to $80^{\circ} \mathrm{C}$ \\
\hline The probe Diameter & $6 \mathrm{~mm}(1 / 4 \mathrm{in})$ \\
\hline The probe Length & $51 \mathrm{~mm}(2 \mathrm{in})$ \\
\hline
\end{tabular}

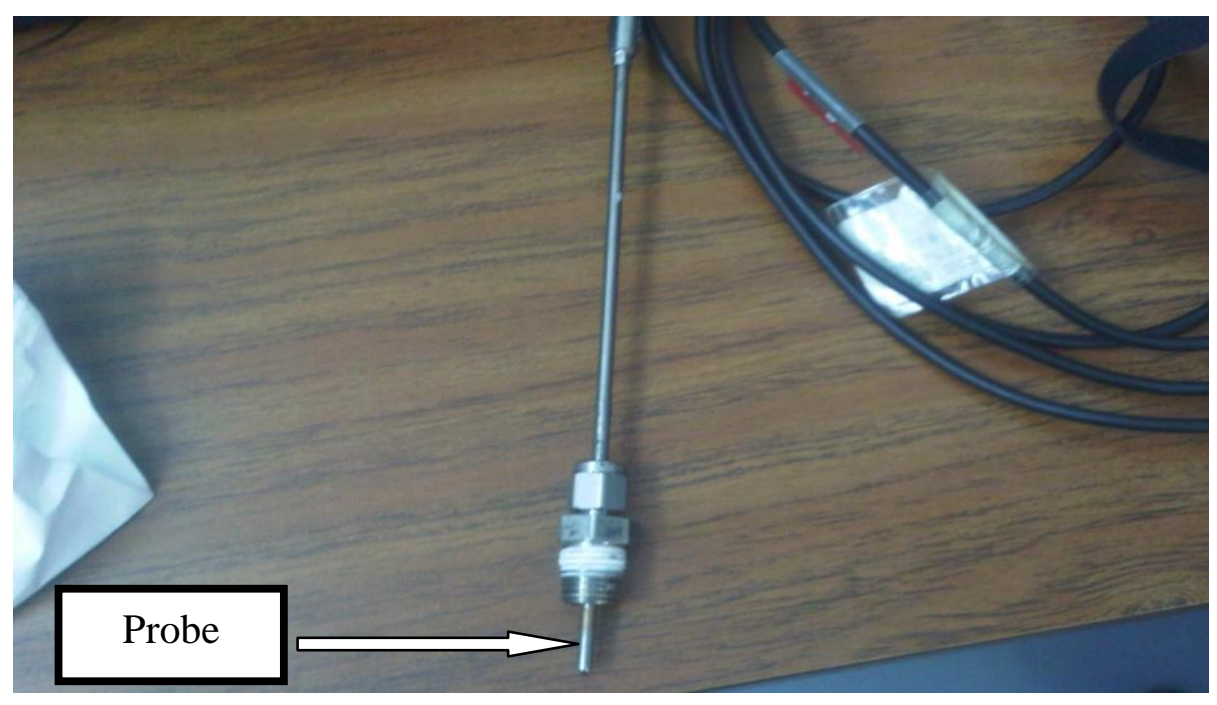

Figure 4.5: Resistance Temperature Detector (RTD)

II) Pressure Transducer Transmitter (PTD)

PTD is an instrument that converts an amount of pressure to electrical signal. This conversion is accomplished by measuring the change in resistance of a strain gauge 
connected to a diaphragm, which is being distorted by applied pressure. The Wheatstone bridge arrangement is often applied. The pressure drop across the minichannel heat exchanger test specimen is determined by using pressure transducers installed immediately before the inlet header and after the outlet header. The inlet and the outlet PTDs have almost identical specifications except for the pressure range, shown in TABLE 4.5. A lower pressure range $(0-50$ Psi) of PTD is installed at the outlet due to the anticipated drop of pressure occurring inside the MICHX. The PTDs, shown in Figure 4.6, are furnished with a connector to mount it on the pipe networking.

Table 4.5: PTD Specifications

\begin{tabular}{|c|c|}
\hline Make & Omega \\
\hline Model \# & Inlet: PX309-500G5V \\
& Outlet: PX309-050G5V \\
\hline Pressure Range & Inlet: $0-500$ Psi / 3448 kPa \\
& Outlet: $0-50$ Psi / 344 kPa \\
\hline Output Voltage & $0-5 \mathrm{~V}$ \\
\hline
\end{tabular}

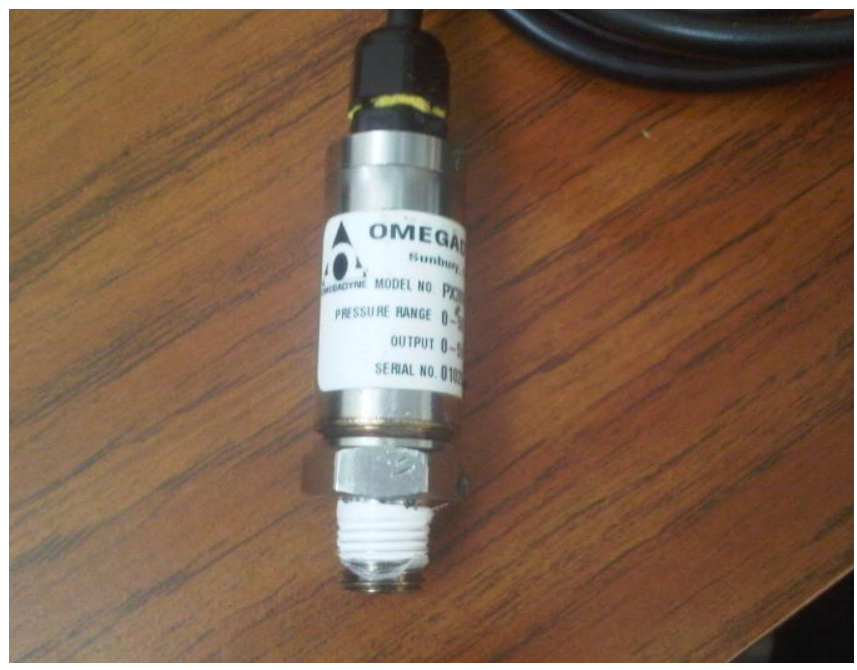

Figure 4.6: Pressure Transducer Transmitter (PTD) 


\section{$\underline{4.2 \text { Air Loop (Cooling Fluid) }}$}

Air (cooling fluid) is the fluid used to absorb the heat from the motor oil in this research. Air circulation occurs through a closed thermal wind tunnel, in which the air is driven by a blower. A built-in (tube-fin) heat exchanger inside the wind tunnel is installed before the heat exchanger test specimen to adjust and retain the required air inlet temperature. In the built-in exchanger, city water supply is passed through the tubes to exchange heat with air which goes through fins. To measure the temperature rise of air in the test section, two thermal grids with nine (at inlet) and 25 (at outlet) type-T thermocouples were mounted. Differential pressure transducers (DPT) were utilized to determine air pressure drop across the MICHX.

Air loop comprises a thermal wind tunnel, test chamber, and air flow measurement instruments (thermocouples and differential pressure transducers). In the following subsections, each part will be discussed separately.

\subsubsection{Thermal Wind Tunnel}

An integrated, well-insulated, vertical wind tunnel functions as the air passage in the current study. This wind tunnel is made of fiber glass material with high insulating feature. The bottom part of the wind tunnel contains the blower which circulates the air in the direction shown in Figure 4.7. The blower is driven by a motor with a power of $20 \mathrm{HP}$ and a rotational speed of $1750 \mathrm{rpm}$. The maximum air velocity can be produced is $18 \mathrm{~m} / \mathrm{s}$ with the existence of the test specimen. 


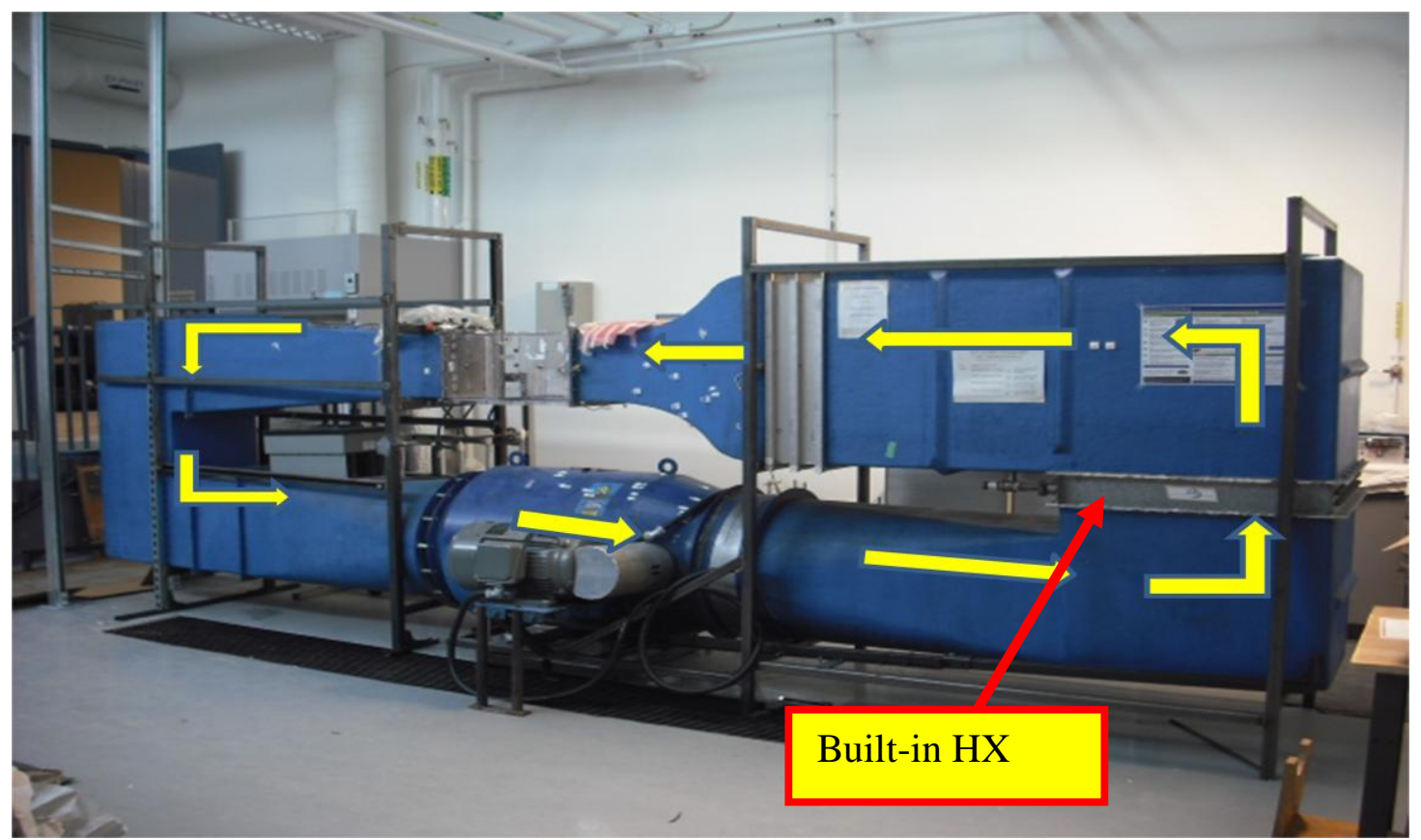

Figure 4.7: Thermal Wind Tunnel

The top part, on the other hand, includes the test chamber. As mentioned earlier, a builtin heat exchanger (tube-fin type) is fitted at the air upstream side to maintain the air inlet temperature by exchanging heat with city water supply. A hot and cold water mixing chamber is used to adjust the water temperature before entering the heat exchanger. The dimensions of the wind tunnel are shown in TABLE 4.6.

Table 4.6: Wind Tunnel Dimensions

\begin{tabular}{|c|c|}
\hline Length & 214 in $/ 544 \mathrm{~cm}$ \\
\hline Width & 29 in $/ 75 \mathrm{~cm}$ \\
\hline Height & 64 in $/ 164 \mathrm{~cm}$ \\
\hline Wall thickness & $0.4 \mathrm{in} / 1 \mathrm{~cm}$ \\
\hline
\end{tabular}




\subsubsection{Test Chamber}

The test chamber contains the prototype minichannel heat exchanger. The picture of the test chamber before and after installing the test specimen are shown in Figures 4.8 and 4.9, respectively. The dimensions of the test chamber are presented in Figures 4.10. Small voids are drilled to make it possible to measure the air pressure drop and air velocity by using the specific instruments. After fitting the heat exchanger, the top and the sides' lids are properly mounted. Additional insulating materials are enfolded to make the test chamber thermally insulated.

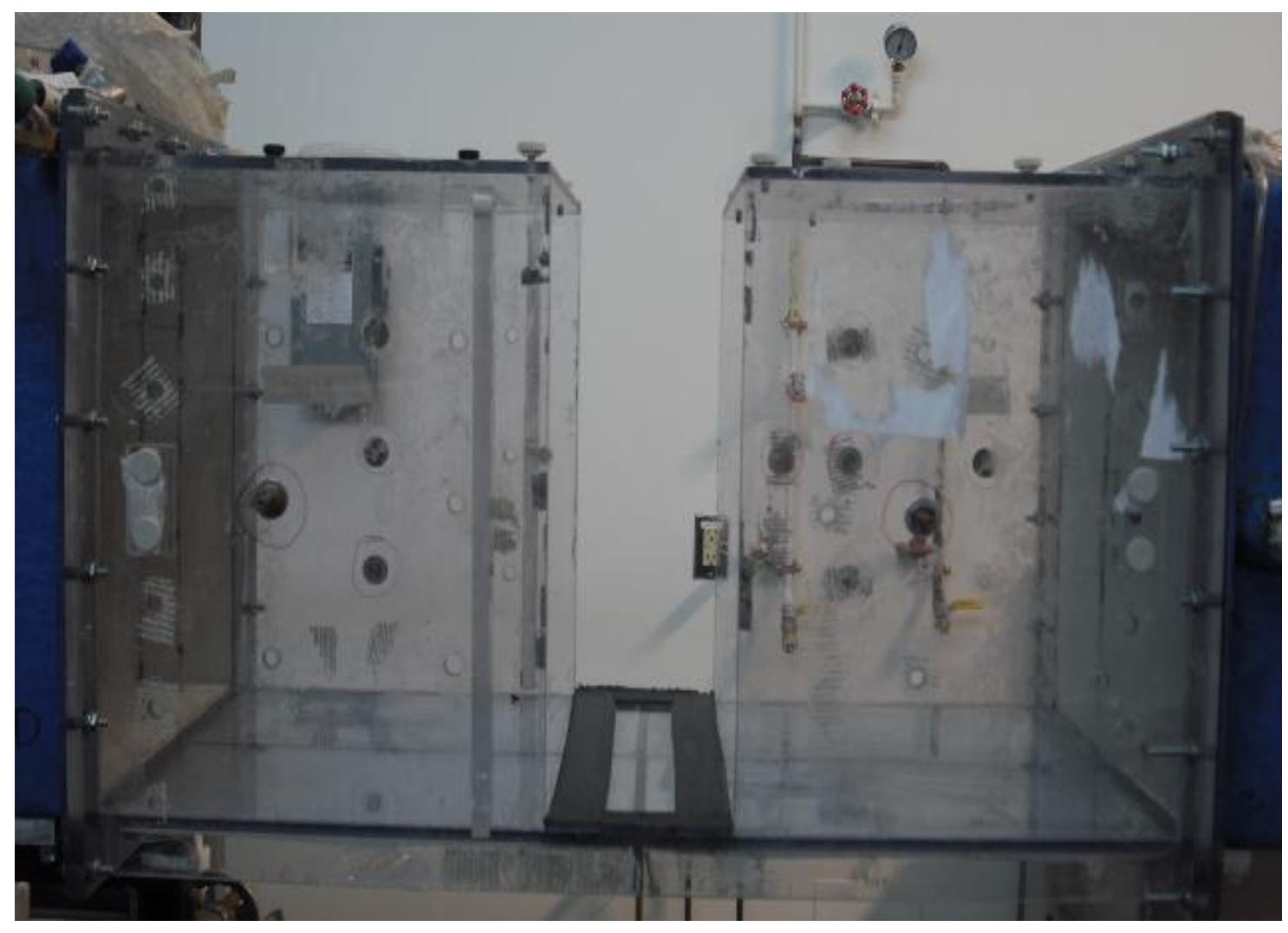

Figure 4.8: Test Chamber without Test Specimen 


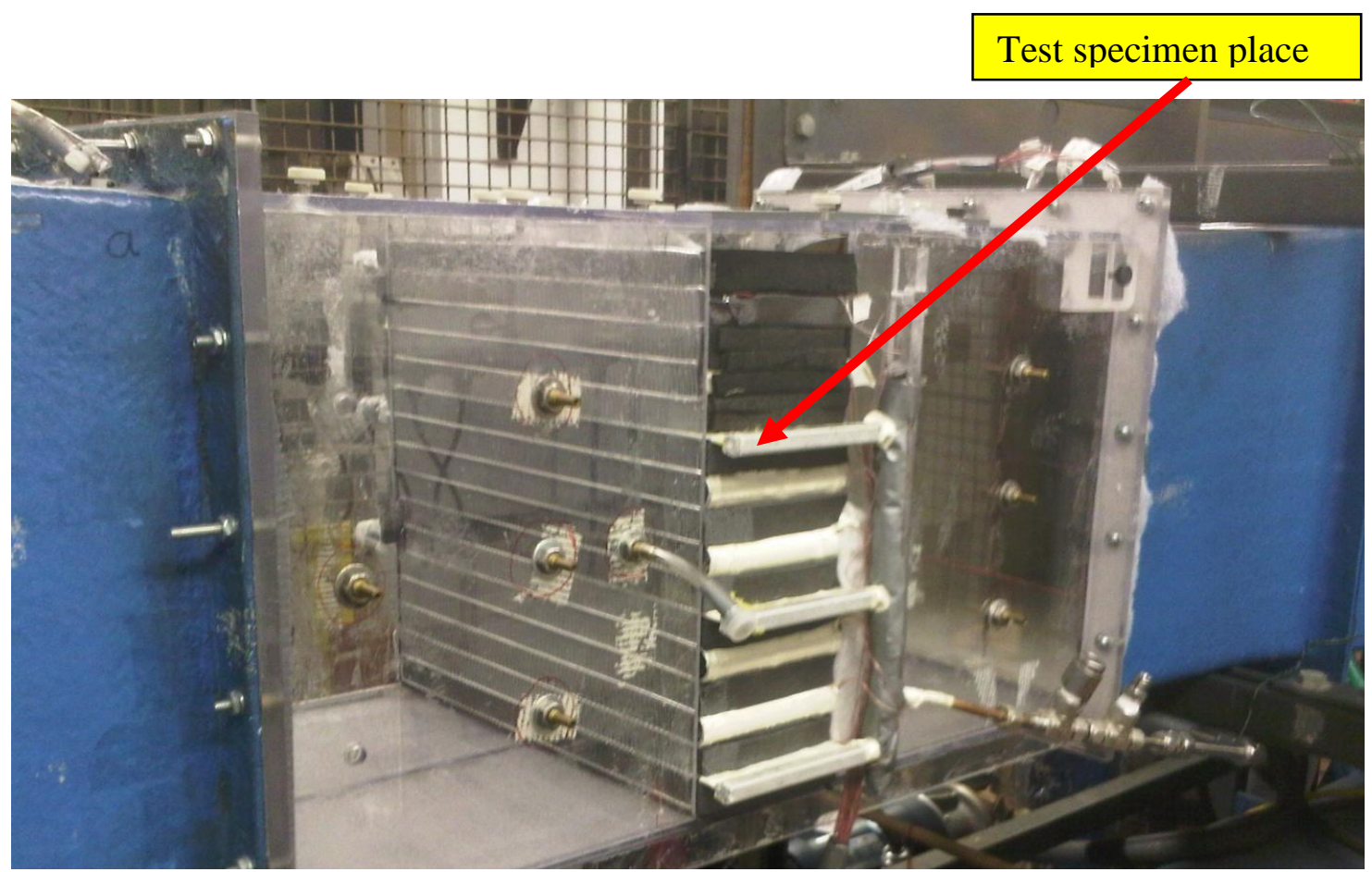

Figure 4.9: Test Chamber with Test Specimen

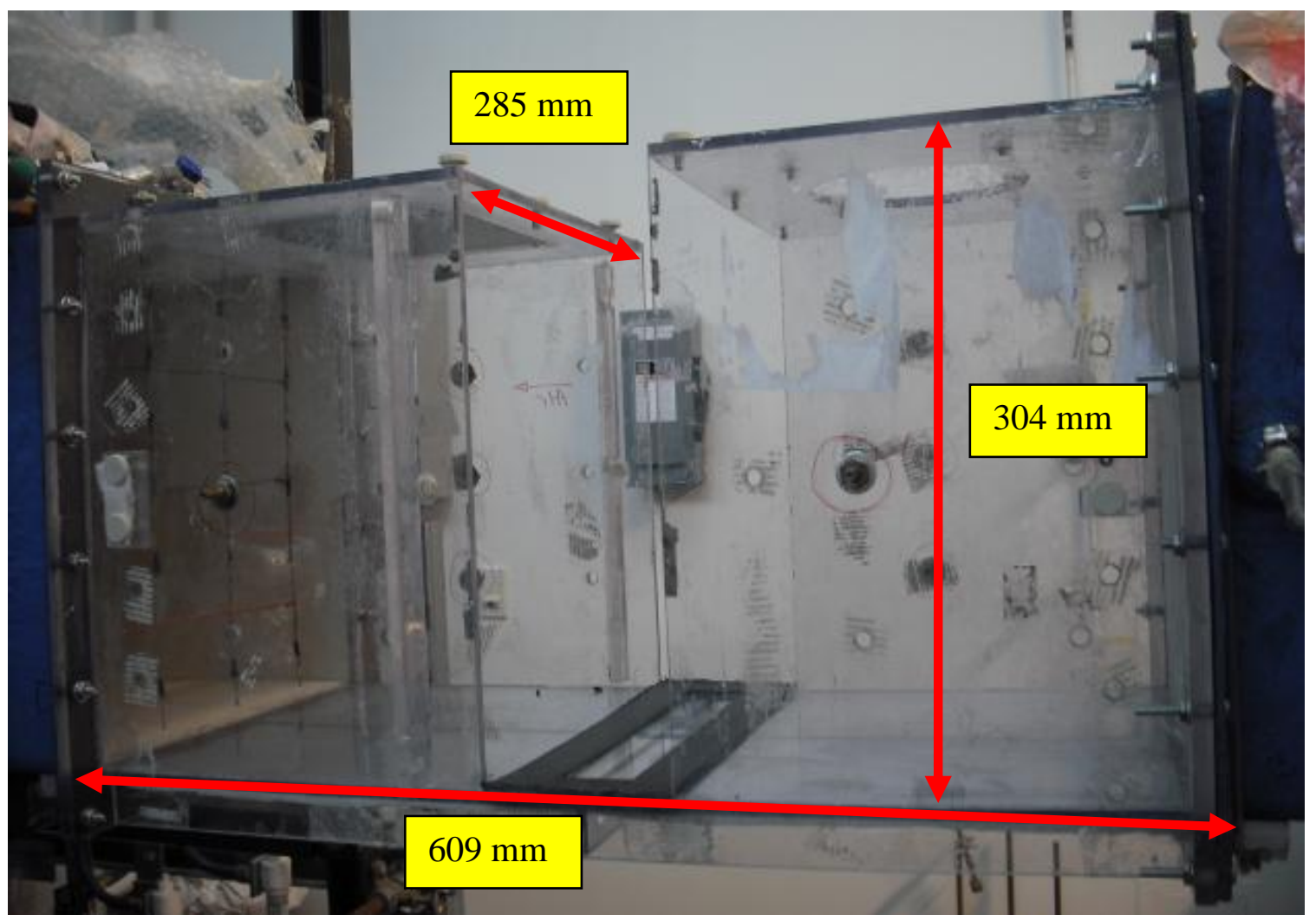

Figure 4.10: Test Chamber Dimensions 


\subsubsection{Thermocouples}

Inlet and outlet air temperatures, as well as the surface temperature of the MICHX, were determined by T-type thermocouples. The upstream air temperature was evaluated by mounting a grid of 9 equally spaced thermocouples, $4 \mathrm{~mm}$ distance from the test chamber inlet. To take into account the variation in the downstream air temperature that occurred due to the existence of MICHX, a grid of 25 equally spaced thermocouples was installed. The inlet and outlet grids were fitted in the wind tunnel rather than the test chamber to ease the removal process if a new test specimen needed to be investigated in the future. The inlet and outlet grids are shown in Figures 4.11.

For considering the representative air inlet and outlet temperatures in data reduction and heat transfer calculating, the arithmetic average values of the 9 and 25 thermocouples are obtained as following:

$$
\begin{aligned}
T_{\text {air }, \text { in }} & =\left[\frac{\left(T_{1}+\ldots \ldots \ldots+T_{9}\right.}{9}\right] \\
T_{\text {air }, \text { out }} & =\left[\frac{\left(T_{1}+\ldots \ldots \ldots+T_{25}\right.}{25}\right]
\end{aligned}
$$



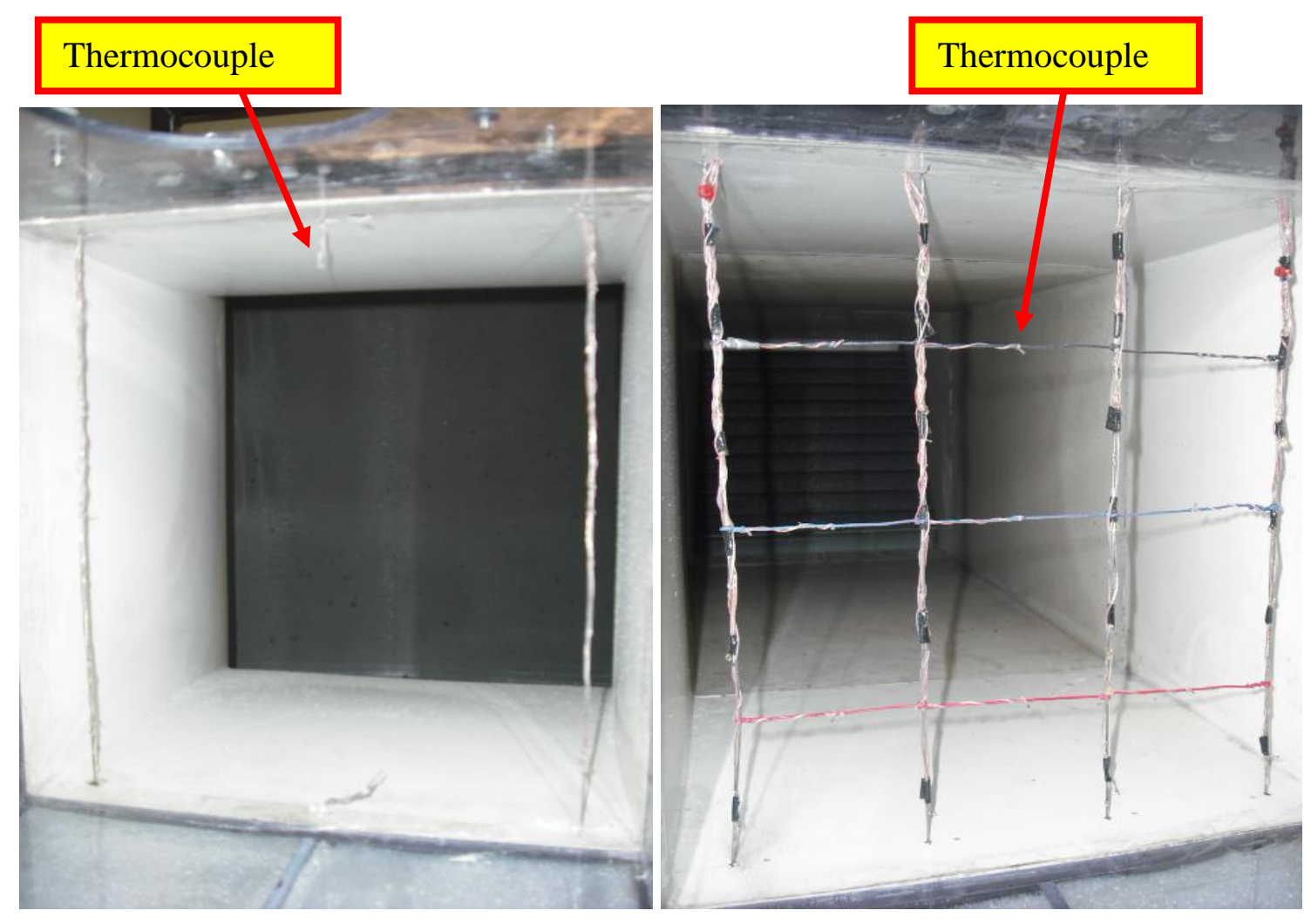

Inlet Grid (9 Thermocouples)

Outlet Grid (25 Thermocouples)

Figure 4.11: Thermocouples Grids

Concerning the outside wall temperature, 46 T-type thermocouples were strategically attached to the bends or serpentines, manifolds, headers, and inlet and outlet pipes of the MICHX. All thermocouples were calibrated to read a maximum temperature of $50{ }^{\circ} \mathrm{C}$. The considered surface temperature is computed as follows:

$$
T_{S, O}=\left[\frac{\left(T_{1}+\ldots \ldots .+T_{46}\right.}{46}\right]
$$




\subsubsection{Differential Pressure Transducers (DPTs)}

Differential pressure transducers (DPTs) are utilized to account for the air pressure drop. Holes are drilled at the upstream and downstream air-side test chamber to determine the air pressure drop occurred across the test specimen. Small tubes are used to connect the holes to DPTs. Three DPTs are employed to measure the air pressure drop at different locations, namely at the top, middle, and bottom of the air stream direction. DPTs' specifications are shown in TABLE 4.7.

\section{Table 4.7: DPT Specifications}

\begin{tabular}{|c|c|}
\hline Make & Omega \\
\hline \multirow{2}{*}{ Model \# } & Top: PX653 - 05D5V \\
& Middle: PX277 - 05D5V \\
& Bottom: PX653-03D5V \\
\hline Pressure Range & Top: $0-0.18$ Psi / 1.25 kPa \\
& Middle: $0-0.18$ Psi / $1.25 \mathrm{kPa}$ \\
& Bottom: $0-0.11$ Psi / $0.748 \mathrm{kPa}$ \\
\hline
\end{tabular}

\section{$\underline{4.3 \text { Test Specimen }}$}

The prototype MICHX is a cross-flow serpentine compact heat exchanger shown in Figure 4.12. It consists of 3 circuits. Each circuit has five slabs (total of 15 slabs) which are connected to each other by four serpentines (total of 12 serpentines) shown in Figure 4.13 [Siddiqui (2011)]. There are 68 channels, with a $1 \mathrm{~mm}$ circular diameter, that are drilled through each slab. The motor oil goes through these channels, whereas the air flows over rectangular fins to cool the oil, shown in Figure 4.14. 

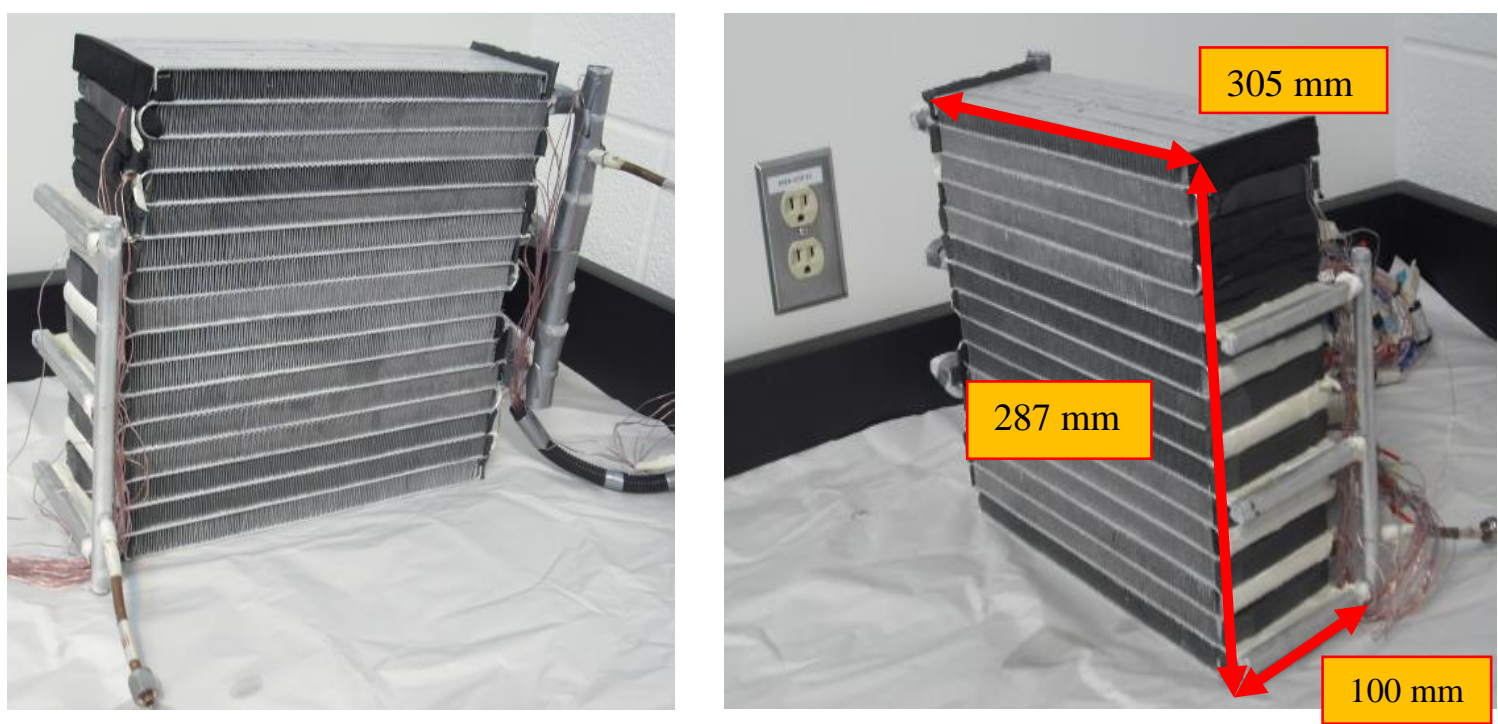

Figure 4.12: Prototype MICHX Test Specimen

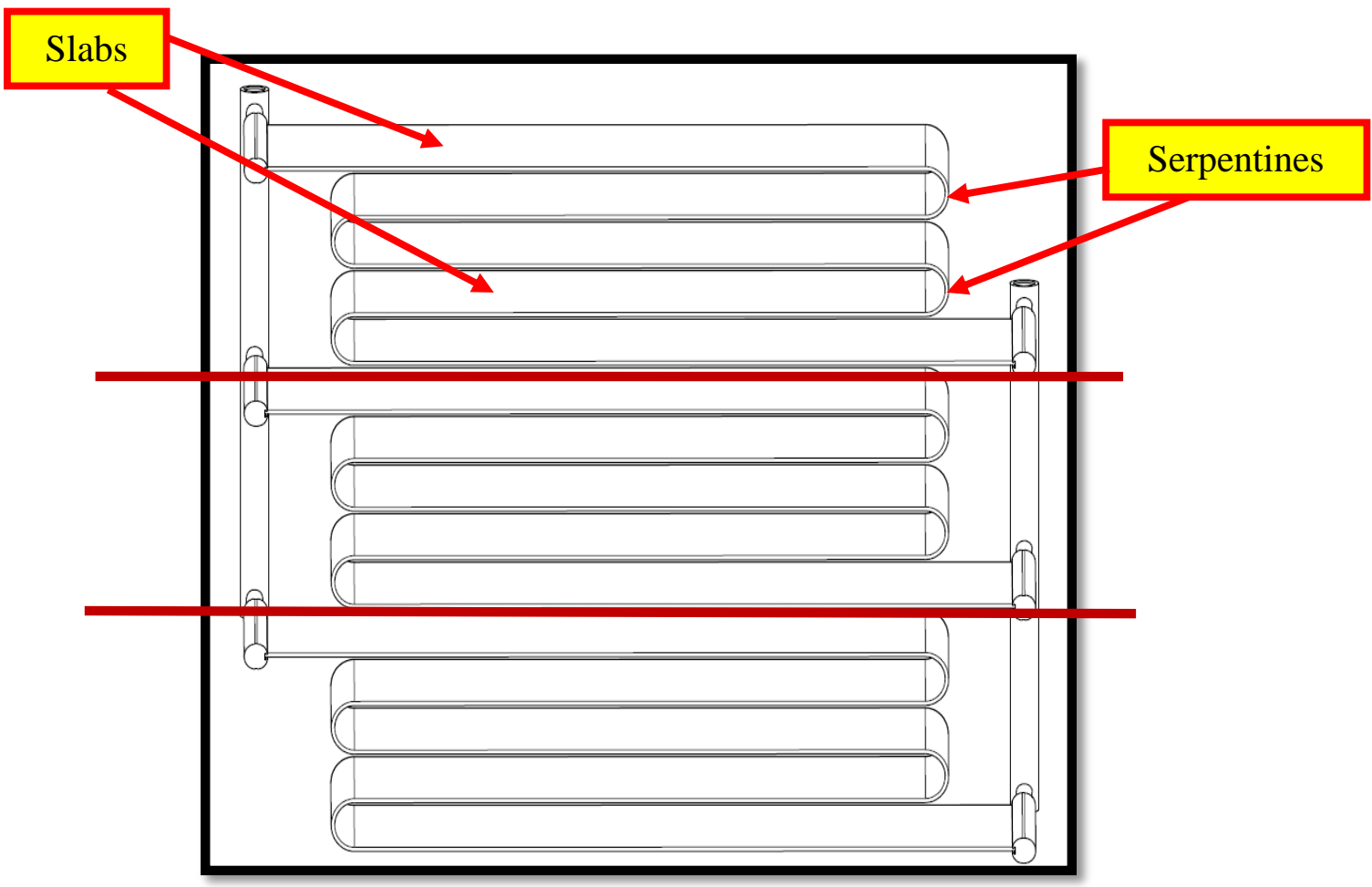

Figure 4.13: MICHX Three Loops 
A total of 14 horizontal aluminum sheets are fitted tightly between the 15 slabs in order to transfer the largest amount of heat possible from the slab to the fins. Each aluminum sheet has a number of 144 fins. MICHX is made of aluminum. This material is selected due to the practical popularity in using it for manufacturing heat exchangers, especially in automotive and thermal applications. Not only is aluminum considered lighter and cheaper, but it is also a corrosion-resistant material. The thermo-physical properties of this type of aluminum are close to aluminum A3003. The maximum pressure that the MICHX can withstand is up to $2200 \mathrm{psi}(15 \mathrm{MPa})$ and its capacity is $6 \mathrm{~kW}$.

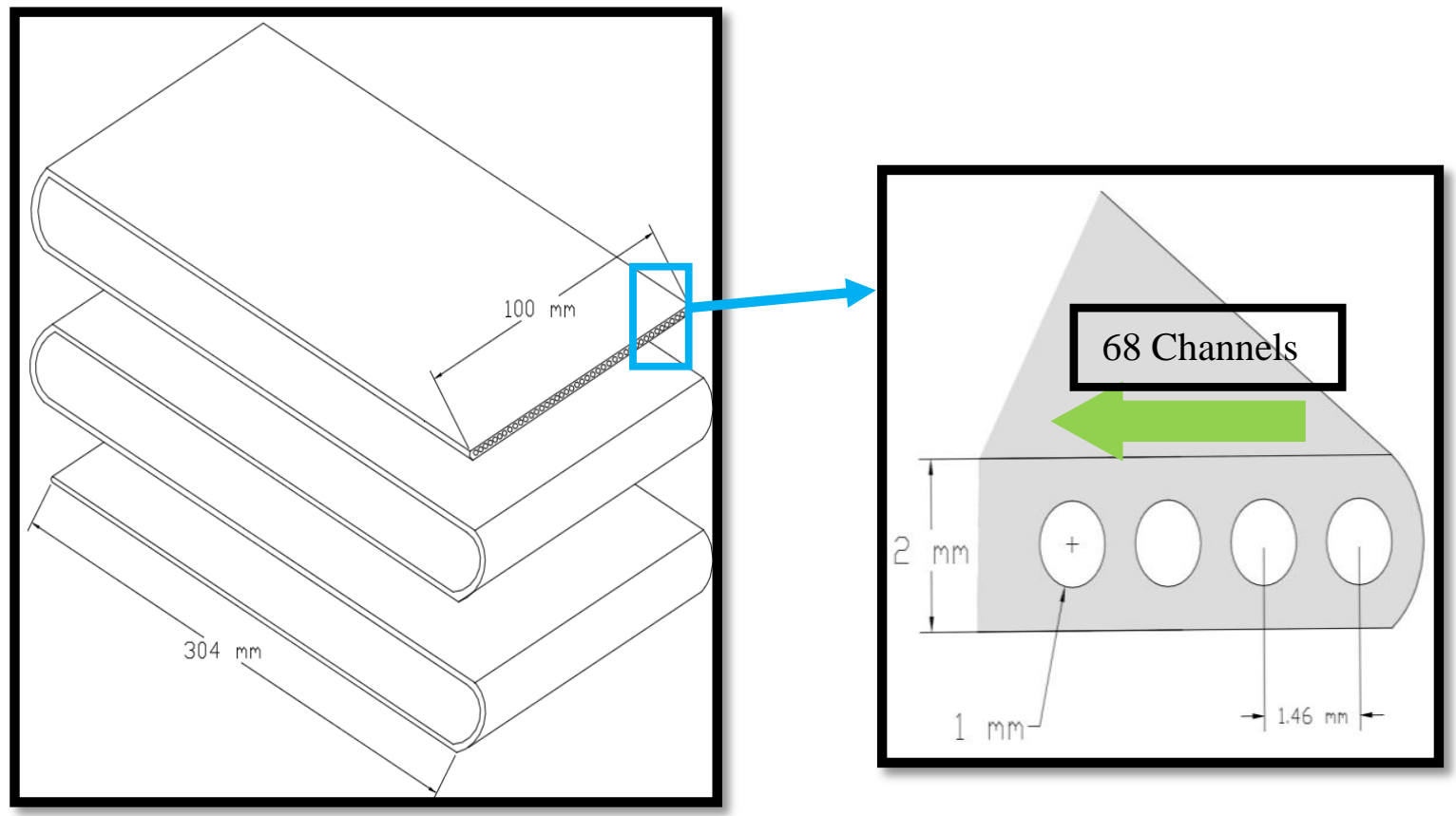

Figure 4.14: Channel Arrangement 
Oil Pathway before and after the core (slab) :

The oil pathway consists of inlet and exit pipes, inlet and exit vertical headers, and three inlet and three outlet manifolds, shown in Figure 4.15. The hot motor oil enters the inlet vertical header coming from the inlet pipe. Then, the header distributes the oil to the three inlet manifolds attached to the inlet slabs. After the oil is flown through the slab, the opposite scenario occurs. The cooled motor oil enters the three exit manifolds and it is then accumulated in the exit vertical header which is connected to the exit pipe.

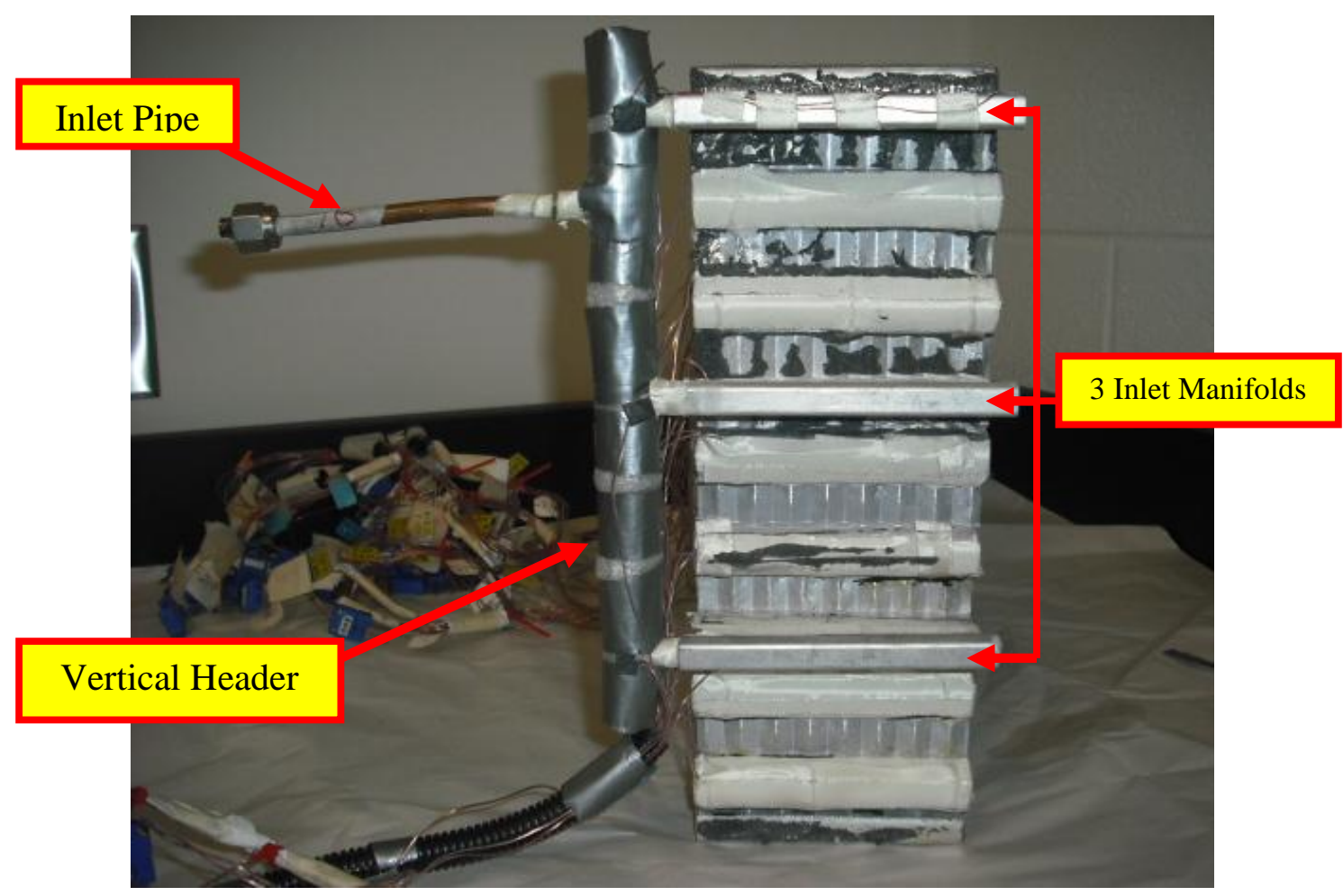

Figure 4.15: MICHX Header and Manifolds 


\subsection{Data Acquisition System}

The study of fluid flow and heat transfer includes several operating parameters that need to be dealt with. Hence, A 16-bit NI Data Acquisition (DAQ) system was incorporated to monitor and record all the experimental data, and measurements, except for oil flow rates. The temperature and pressure values of both fluids are displayed on a personal computer screen, in which LabVIEW (Laboratory Virtual Instrumentation Engineering Workbench) version 8 is installed. RTDs and thermocouples were calibrated and adjusted in such a way that they are recorded directly in ${ }^{\circ} \mathrm{C}$ without the need for any further conversion. However, pressure transducers (PTD \& DPT) are displayed in voltage, which in turn need to be converted into psi or $\mathrm{kPa}$.

\section{$\underline{4.5}$ Operating Conditions}

This study is conducted to verify the applicability of the prototype heat exchanger test specimen to cool motor oil. Thus, taking into account all feasible operating conditions, that are relevant to a practical situation of oil cooler (air cooled), is the target of this experimental investigation. There are four major input parameters by which the fluid flow and heat transfer characteristics are managed. The parameters are oil inlet temperature $\left(T_{\text {oil,in }}\right)$, oil mass flow rate $\left(\dot{m}_{\text {oil }}\right)$, air velocity $\left(V_{\text {air }}\right)$, and air inlet temperature $\left(T_{\text {air }, \text { in }}\right)$.

Motor oil acquires the longest function life and proper lubricating state when its temperature is below $78{ }^{\circ} \mathrm{C}$. As such, the oil inlet temperature is remained constant at 75 ${ }^{\circ} \mathrm{C}$. With regards to oil mass flow rate, motor oil is a highly viscous fluid; and by letting it 
go through a narrow channel at high mass flow rate can lead to a high pressure. Therefore, the flow rate is maintained within a small range due to the limitations of the system pressure.

It is well known that around only $60 \%$ of the total airflow strikes the car's parts located under bonnet (i.e. the hood). If the vehicle is assumed to be driven at the highway (which is around $100 \mathrm{~km} / \mathrm{h}=28 \mathrm{~m} / \mathrm{s}$ ), the air velocity that faces the parts would be equivalent to about $18 \mathrm{~m} / \mathrm{s}$. Whereas, if the vehicle speed $40 \mathrm{~km} / \mathrm{h}(=11 \mathrm{~m} / \mathrm{s})$ which is the case at the city, the air velocity would be around $6 \mathrm{~m} / \mathrm{s}$. Setting up 18 and $6 \mathrm{~m} / \mathrm{s}$ to be the maximum and minimum air velocities that confront the heat exchanger prototype.

The air inlet temperatures are managed by exchanging heat with city water supply via built-in heat exchanger. The lowest and the highest air temperatures can be reached during the experiment period were $20{ }^{\circ} \mathrm{C}$ and $40{ }^{\circ} \mathrm{C}$. In order to obtain additional output information, which results in deeper and better assessment of the heat exchanger, another three air inlet temperatures 25,30 , and $35{ }^{\circ} \mathrm{C}$ are taken into account.

A wide range of test conditions were recorded (total of 80 runs) to attain adequate data for analyzing the performance of the MICHX. Both of the fluid's velocities were varied corresponding to each other at different temperatures, in order to gather several fluid flow and heat transfer data sets to obtain full exposure on the capability of the test specimen thermal performance. The operating conditions are tabulated in TABLE 4.8. 
Table 4.8: Operating Conditions

\begin{tabular}{|c|c|c|c|c|}
\hline$T_{\text {oil,in }}$ & $T_{\text {air,in }}$ & $\dot{m}_{o i l}$ & $V_{\text {air }}$ & \# of Steps \\
\hline $75^{\circ} \mathrm{C}$ & $20^{\circ} \mathrm{C}$ & $\begin{array}{l}0.29 \mathrm{~kg} / \mathrm{min} \\
0.41 \mathrm{~kg} / \mathrm{min} \\
0.63 \mathrm{~kg} / \mathrm{min} \\
0.83 \mathrm{~kg} / \mathrm{min}\end{array}$ & $\begin{array}{l}6 \mathrm{~m} / \mathrm{s} \\
10 \mathrm{~m} / \mathrm{s} \\
14 \mathrm{~m} / \mathrm{s} \\
18 \mathrm{~m} / \mathrm{s}\end{array}$ & 16 \\
\hline $75^{\circ} \mathrm{C}$ & $25^{\circ} \mathrm{C}$ & $\begin{array}{l}0.29 \mathrm{~kg} / \mathrm{min} \\
0.41 \mathrm{~kg} / \mathrm{min} \\
0.63 \mathrm{~kg} / \mathrm{min} \\
0.83 \mathrm{~kg} / \mathrm{min}\end{array}$ & $\begin{array}{l}6 \mathrm{~m} / \mathrm{s} \\
10 \mathrm{~m} / \mathrm{s} \\
14 \mathrm{~m} / \mathrm{s} \\
18 \mathrm{~m} / \mathrm{s}\end{array}$ & 16 \\
\hline $75^{\circ} \mathrm{C}$ & $30^{\circ} \mathrm{C}$ & $\begin{array}{l}0.29 \mathrm{~kg} / \mathrm{min} \\
0.41 \mathrm{~kg} / \mathrm{min} \\
0.63 \mathrm{~kg} / \mathrm{min} \\
0.83 \mathrm{~kg} / \mathrm{min}\end{array}$ & $\begin{array}{l}6 \mathrm{~m} / \mathrm{s} \\
10 \mathrm{~m} / \mathrm{s} \\
14 \mathrm{~m} / \mathrm{s} \\
18 \mathrm{~m} / \mathrm{s}\end{array}$ & 16 \\
\hline $75^{\circ} \mathrm{C}$ & $35^{\circ} \mathrm{C}$ & $\begin{array}{l}0.29 \mathrm{~kg} / \mathrm{min} \\
0.41 \mathrm{~kg} / \mathrm{min} \\
0.63 \mathrm{~kg} / \mathrm{min} \\
0.83 \mathrm{~kg} / \mathrm{min}\end{array}$ & $\begin{array}{l}6 \mathrm{~m} / \mathrm{s} \\
10 \mathrm{~m} / \mathrm{s} \\
14 \mathrm{~m} / \mathrm{s} \\
18 \mathrm{~m} / \mathrm{s}\end{array}$ & 16 \\
\hline $75^{\circ} \mathrm{C}$ & $40^{\circ} \mathrm{C}$ & $\begin{array}{l}0.29 \mathrm{~kg} / \mathrm{min} \\
0.41 \mathrm{~kg} / \mathrm{min} \\
0.63 \mathrm{~kg} / \mathrm{min} \\
0.83 \mathrm{~kg} / \mathrm{min}\end{array}$ & $\begin{array}{l}6 \mathrm{~m} / \mathrm{s} \\
10 \mathrm{~m} / \mathrm{s} \\
14 \mathrm{~m} / \mathrm{s} \\
18 \mathrm{~m} / \mathrm{s}\end{array}$ & 16 \\
\hline
\end{tabular}




\subsection{Data Collection Methodology}

For any successful experimental investigation, the readings of the parameters obtained from the system instrument devices need to be precise to some extent. In order to ensure that the collected data in current study accurate and realistic, some actions were implemented:

- The pipes that carry the motor oil from the tank to the test specimen and vise versa were dried by blowing air with high pressure.

- All fittings (inlet and outlet of tank, gear pump, heater, and test specimen) and the measuring devices were tightened.

- The data acquisition system was turned on to check all readings related to the thermocouples, RTD, pressure transducers.

After drying the pipes, the motor oil was poured into the liquid tank. Then, main switches for the liquid pre-heater, gear pump, and air blower were turned on. City water valves were opened. The gear pump starter's button was turned on to begin the oil loop. The motor oil is drawn from the tank with four different flow rates, which were controlled by the motor frequency. The oil then enters a circulation heater where the oil temperature is raised up to $75 \pm 1{ }^{\circ} \mathrm{C}$. The oil inlet temperature to the test specimen), which is set and maintained by using the PID controller, will be kept constant for all runs.

Afterwards, the oil goes through the channels of the test specimen and travels back to the starting point which is the tank. Motor oil inlet and outlet temperatures are measured by placing RTDs at the inlet and the outlet pipes. These RTDs are connected to the DAQ and their temperature readings are recorded. 
An open loop configuration is arranged, where the oil flown out of the MICHX is collected by a bucket in a measured time period. The recorded time was determined by a stop watch. Flow rates are determined by weighing the collected oil by a precision scale capable of measuring the weight of $0.01 \mathrm{~g}$.

The air is thrust inside the closed loop wind tunnel by a blower with four different velocities. The built-in heat exchanger, located before the air upstream from the test chamber, is used to adjust and retain the air inlet temperature to the test chamber. In this investigation, five distinct air inlet temperatures were recorded for each air velocity. As stated before, two planes of 9 and 25 thermocouples for measuring air inlet and outlet temperatures are mounted in the wind tunnel. The values of the 9 thermocouples on the upstream plane are recorded by DAQ and then averaged to get the representative air inlet temperature $\left(T_{\text {air,in }}\right)$. A similar approach is applied on the downstream plane $\left(T_{\text {air,out }}\right)$. The MICHX slab surface temperature is determined by 46 thermocouples placed and scattered on bends, manifolds, headers, and inlet and outlet pipes. Again, all readings are averaged and taken to be the outer surface temperature of the MICHX.

Concerning the pressure drop of both fluids, pressure transducers are utilized. All pressure drop readings are recorded by DAQ, which in turns displays the values in voltage. The conversion from voltage to psi is provided by the DAQ manufacturer. Prior to recording each of the 80 runs, the system is allowed to reach a steady state condition. A steady state is reached (30 to 45 minutes) when the fluctuations of the oil and air inlet temperatures become stable (within $\pm 1^{\circ} \mathrm{C}$ ). As soon as the system reaches the state of 
stability, readings of certain parameters, shown in TABLE 4.8, are taken by the data acquisition system. The readings are saved in an Excel sheet.

As seen from TABLE 4.9, five different air inlet temperatures between the range of $20{ }^{\circ} \mathrm{C}$ to $40{ }^{\circ} \mathrm{C}$ are considered in this study. For each of these inlet temperatures, four air velocity steps between $6 \mathrm{~m} / \mathrm{s}$ to $18 \mathrm{~m} / \mathrm{s}$ are examined against a constant oil inlet temperature and four dissimilar oil flow rates. The oil Reynolds number that resulted from these flow rates is $0.85<\mathrm{Re}_{\text {oil }}<3.5$. The Reynolds number is based on the MICHX diameter which is equal to $1 \mathrm{~mm}$. The details of the calibration curves as well as for the instruments' calibration are given in Khan (2011).

Table 4.9: Parameters Shown in DAQ

\begin{tabular}{|c|c|c|}
\hline Parameter & Entry & Unit \\
\hline Inlet Thermocouples $\left(T_{\text {air }, \text { in }}\right)$ & 9 & ${ }^{\circ} \mathrm{C}$ \\
\hline Outlet Thermocouples ( $\left.T_{\text {air,out }}\right)$ & 25 & ${ }^{\circ} \mathrm{C}$ \\
\hline Surface Thermocouples $\left(T_{s, \text { out }}\right)$ & 46 & ${ }^{\circ} \mathrm{C}$ \\
\hline $\operatorname{RTD}\left(T_{\text {oil }, i n}\right)$ & 1 & ${ }^{\circ} \mathrm{C}$ \\
\hline $\operatorname{RTD}\left(T_{\text {oil }, \text { out }}\right)$ & 1 & ${ }^{\circ} \mathrm{C}$ \\
\hline $\operatorname{PTD}\left(P_{\text {oil }, \text { in }}\right)$ & 1 & Volt \\
\hline $\operatorname{PTD}\left(P_{\text {oil }, \text { out }}\right)$ & 1 & Volt \\
\hline $\operatorname{DPT}\left(\Delta P_{\text {air }, \text { top }}\right)$ & 1 & Volt \\
\hline $\operatorname{DPT}\left(\Delta P_{\text {air }, \text { middle }}\right)$ & 1 & Volt \\
\hline $\operatorname{DPT}\left(\Delta P_{\text {air }, \text { bottom }}\right)$ & 1 & Volt \\
\hline
\end{tabular}




\section{CHAPTER V}

\section{RESULTS AND DISCUSSIONS}

The main aim of the current study is to experimentally investigate how a highly viscous fluid would behave and perform inside the minichannels when it is cooled. To effectively achieve this aim, heat transfer and fluid flow characteristics of the motor oil are attained and as such correlations among the key parameters (heat transfer coefficient, Nusselt number, Reynolds number, Prandtl number and Peclet number) were generated. The performance of the prototype heat exchanger was also examine by obtaining the effectiveness $(\varepsilon)$ and the number of transfer units (NTU). Moreover, two important scaling effects, axial heat conduction and viscous dissipation were studied in order to justify the reduction occurred in the Nusselt number value. It is worth noting that the investigation of the current study will solely be focusing on the motor oil side.

For practical purposes, the motor oil temperature was fixed at $75 \pm 1{ }^{\circ} \mathrm{C}$, this is the highest temperature that the system can reach, where the air was subjected to a wide range of inlet temperatures $\left(20,25,30,35\right.$, and $\left.40^{\circ} \mathrm{C}\right)$. The details of the other operating conditions are presented in Table -8 . The range of motor oil Reynolds number was found to be 0.85 $\leq R e_{\text {oil }} \leq 3.5$, and the Prandtl number $387 \leq P r_{\text {oil }} \leq 528$.

\subsection{Entrance Effect}

To verify whether the oil flow inside the minichannel is developing or fully developed, the hydrodynamic and the thermal entrance lengths were calculated for all 80 operating 
conditions using equations (3.16 and 3.17). The hydrodynamic entrance length was computed to be within the range of $0.04-0.18 \mathrm{~mm}$ (occupying only $0.013-0.06 \%$ of an individual channel length), and the thermal entrance length was within the range of 22$68.5 \mathrm{~mm}$ (occupying 7-22 \% of an individual channel length). The computed entrance lengths revealed that the flow is hydrodynamically and thermally fully developed almost along all the channel length.

As the ratios of the length to hydraulic diameter of the minichannels are large and Reynolds number is low, the entrance effect can be ignored and fully developed (hydrodynamically and thermally) laminar flow in the minichannels is assumed, Qu (2000). The investigation of the entrance effect on the convective heat transfer and pressure drop analysis inside the minichannel has been made by several authors. Morini (2006) proposed the following inequality in order to test the impact of the entrance effect on heat transfer mechanism and pressure drop calculation.

$$
\frac{R e_{\text {oil }} P r_{o i l} D_{h}}{L}>10
$$

If the above inequality is satisfied, then the entrance effects in the tested minichannel become negligible. In other words, if the fraction is less than 10 , the effect of the entrance on the heat transfer is insignificance. The calculated fraction's largest value among the 80 operating conditions is 4.5 . Hence, it can be claimed that the entrance effect in the current study can be disregarded. 


\subsection{Heat Transfer Characteristics:}

In this subheading, the convective heat transfer characteristics of motor oil is presented and discussed. General correlations among the parameters are generated.

\subsubsection{System Heat Balance (HB)}

As stated by the ASME PTC, if the heat balance (HB) that is acquired from equation 3.32 is within $\pm 15 \%$, then the heat rates of both fluids can be employed to represent the experimental heat transfer data. The heat balance results of this investigation are plotted against Reynolds number of the motor oil, which is deduced from equation 3.23. As shown in Figure 5.1, the results are varied from -8.6 to $+8.8 \%$, which fits in the acceptable limit advocated by the ASME PTC. Therefore, it can be concluded that the conducted test facility is reliable and can be examined by analyzing and studying the heat transfer phenomenon.

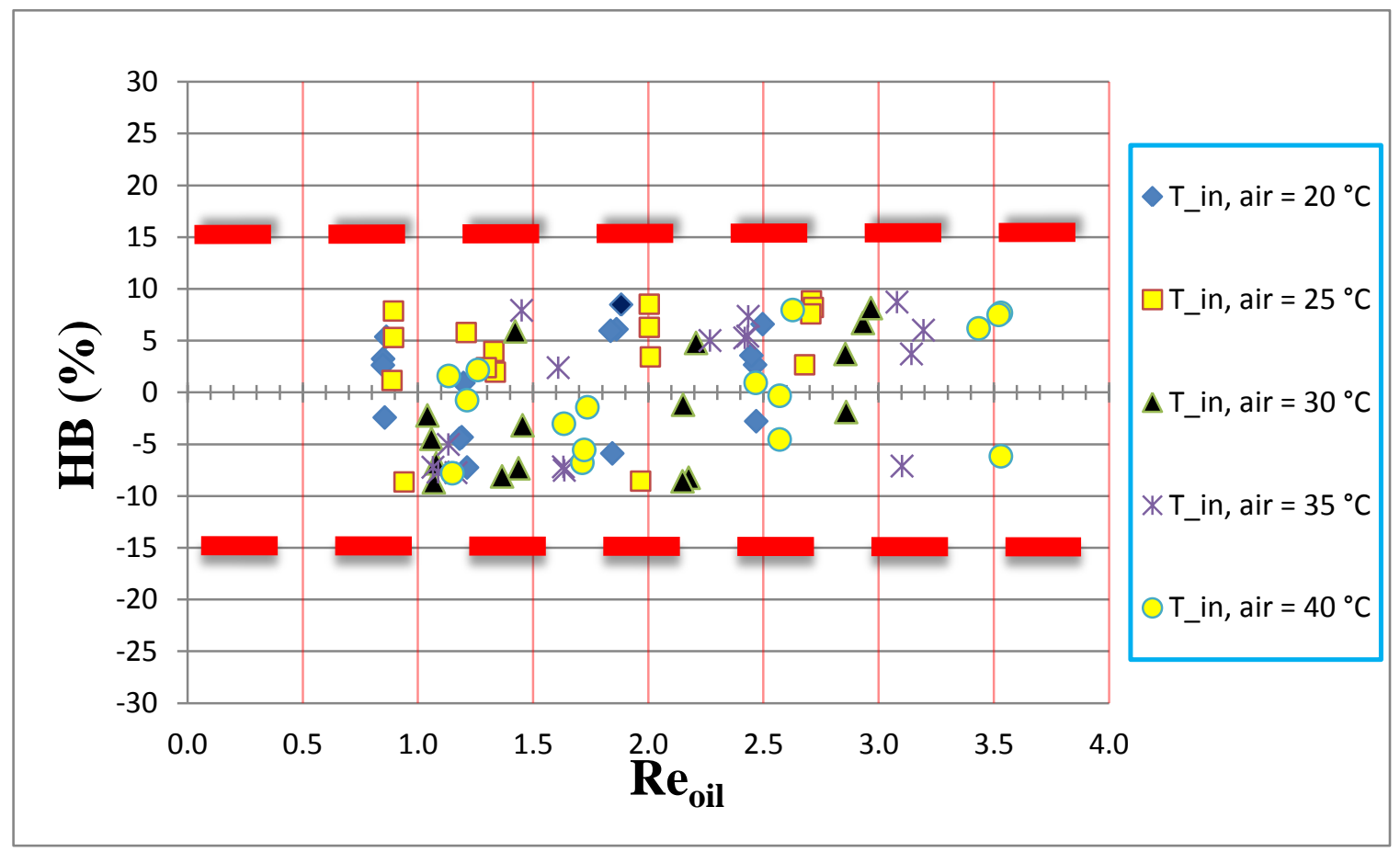

Figure 5.1: Heat Balance Vs Oil Reynolds Number 


\subsubsection{Oil Temperature Difference $\left(\Delta \boldsymbol{T}_{\boldsymbol{o i l}}\right)$}

The motor oil temperature difference (inlet to outlet) is plotted against oil Reynolds number $\left(R e_{\mathrm{oil}}\right)$ in Figure 5.2. The figure below shows the effect of air inlet temperature on oil temperature difference. For a given air inlet temperature, $\Delta T_{\text {oil }}$ decrease as oil Reynolds number increases. By taking into account only one air inlet temperature value, the exit temperature of motor oil is governed by the heat transfer mechanism. The figure includes all 80 operating conditions data. The oil obviously stays longer inside the minichannel at low $R e_{\text {oil }}$, so the oil loses more of its temperature and the outlet temperature becomes lower. Therefore, the inlet-outlet temperature difference is higher at lower $R e_{\text {oil }}$ and lower at higher $R e_{\mathrm{oil}}$, as shown in the figure. Moreover, the plot reveals that the Reynolds number of air does not affect the heat transfer mechanism.

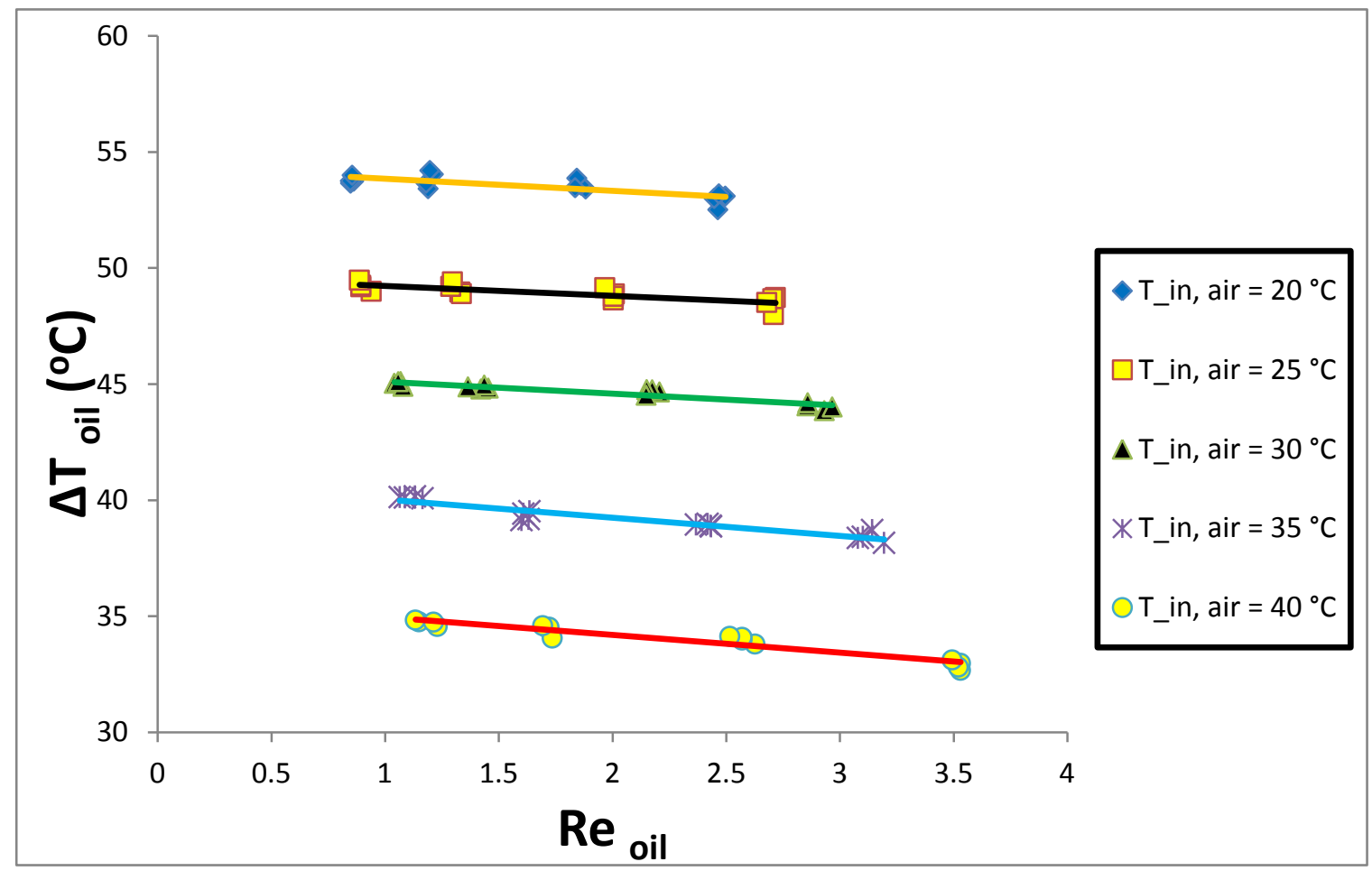

Figure 5.2: Oil Temperature Difference Vs Oil Reynolds Number 


\subsubsection{Oil Heat Transfer Rate $\left(\dot{\boldsymbol{Q}}_{\text {oil }}\right)$}

The heat transfer rate $\left(\dot{Q}_{o i l}\right)$ was calculated using equation 3.30. The Heat transfer rate of motor oil $\left(\dot{Q}_{o i l}\right)$ is seen to increase as Reynolds number $\left(R e_{\text {oil }}\right)$ increases for each air inlet temperature as shown in Figure 5.3. The correlation is a power law curve-fit with a positive exponent with an average $\mathrm{R}$-squared value of 0.998 . For a given $R e_{\text {oil }}$, the heat transfer rate is always lower at higher air inlet temperature. This is due to large oil temperature difference $\left(\Delta T_{\text {oil }}\right)$ when the air inlet temperature is reduced. Moreover, the slope of the line tends to be sharper as the air inlet temperature decreases. That implies that a higher heat performance occurs when the difference of both fluids inlet temperatures is high.

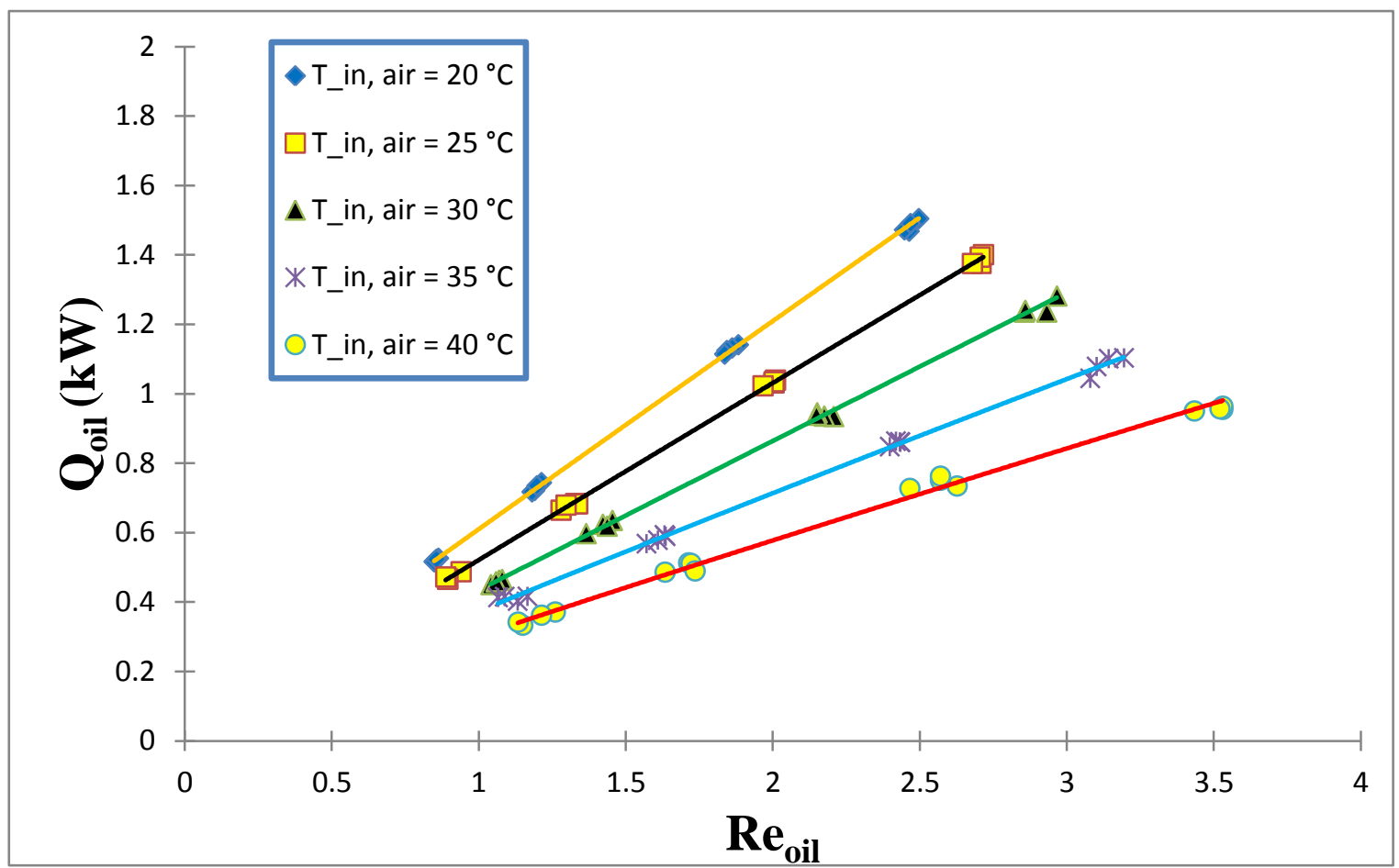

Figure 5.3: Oil Heat Transfer Rate Vs Oil Reynolds Number 


\subsubsection{Normalized Heat Transfer $\left(\boldsymbol{Q}^{*}\right)$}

MICHX performance data or heat transfer rate needs to be normalized so that different oil coolers might be compared on an equal basis. The normalized heat transfer quantity $\left(Q^{*}\right)$ can be computed from the following equation:

$$
Q^{*}=\frac{\dot{Q}_{\text {oil }}}{A_{\text {frontal }}\left(T_{\text {oil }, \text { in }}-T_{\text {air }, \text { in }}\right)}
$$

The normalized heat transfer is plotted against oil Reynolds number, as shown in Figure 5.4. All the 80 operating conditions are included in the figure below. Compared to Figure 5.3, the data almost collapses into one trend line with some uncertainties. The figure illustrates with the increase of $R e_{o i l}$, the normalized heat transfer increases. The correlation is found to be in power-law mode and it is developed as:

$$
Q^{*}=0.33 \operatorname{Re}_{\text {oil }}^{0.94}
$$

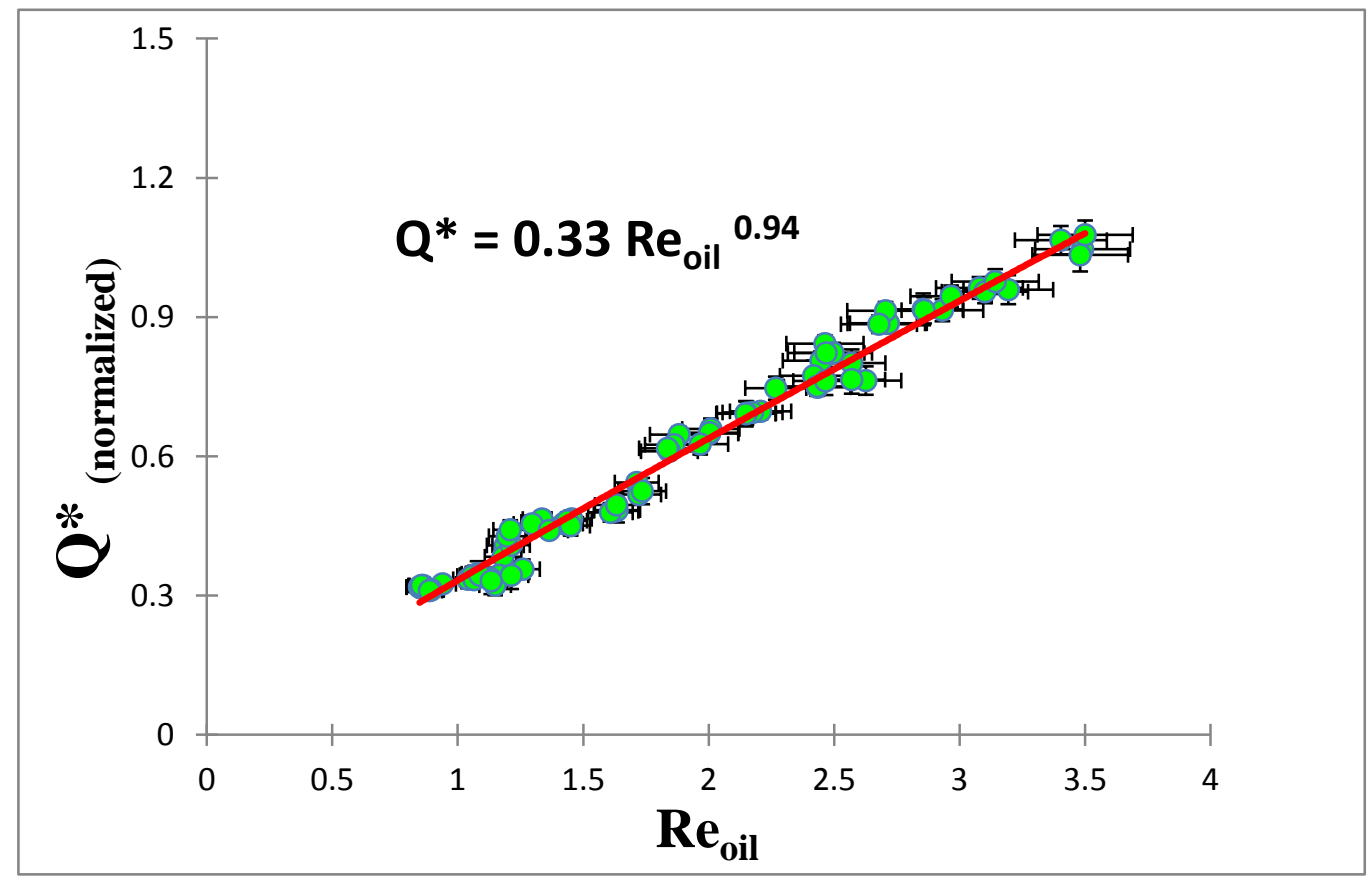

Figure 5.4: Normalized Heat Transfer Quantity Vs Oil Reynolds Number 


\subsubsection{Non-Dimensional Temperatures and $\left(\Delta \boldsymbol{T}_{\boldsymbol{L M T D}}\right)$}

The non-dimensional temperature is the ratio of the oil inlet-outlet temperatures to the oil inlet temperature as presented below:

$$
\text { Non - Dimensional Temperature }=\frac{\left(T_{\text {in }}-T_{\text {out }}\right)_{\text {oil }}}{T_{\text {oil, in }}}=\frac{\Delta T_{\text {oil }}}{T_{\text {oil, in }}}
$$

The 80 values of the non-dimensional temperature are plotted against their respective oil Reynolds number $\left(R e_{\text {oil }}\right)$ in Figure 5.5. It can be noticed that the dimensionless temperature value slightly increases with decreasing $R e_{\text {oil }}$ in polynomial relationship. The value of non-dimensionless temperature is larger at a lower air inlet temperature for a particular $R e_{\text {oil }}$ due to the higher oil temperature difference.

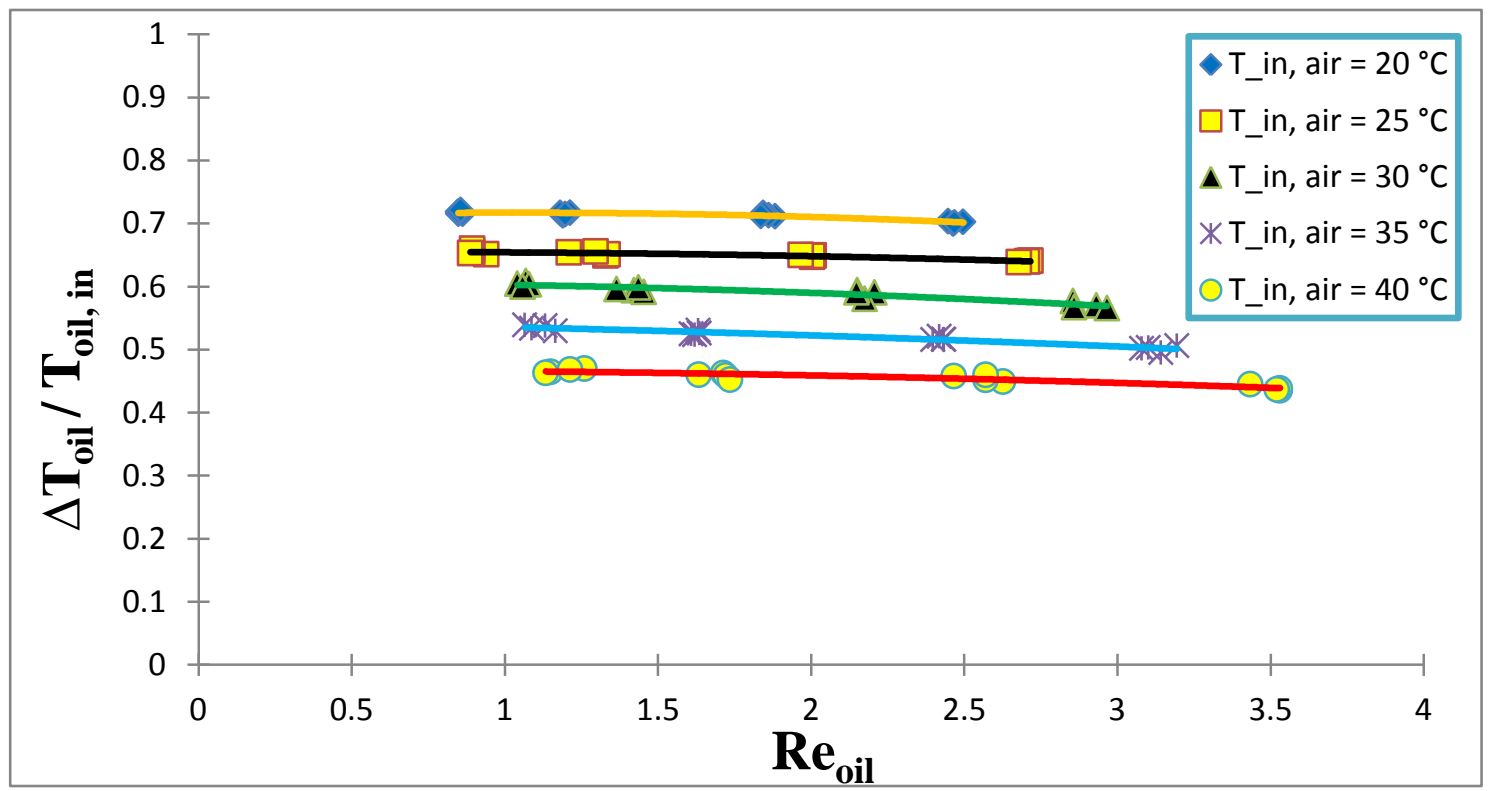

Figure 5.5: Non-Dimensional Temperature Vs Oil Reynolds Number

One of the two methods in evaluating performance of a heat exchanger is the log mean temperature difference $\left(\Delta T_{L M T D}\right)$. This method is utilized to determine the size of a heat exchanger when both fluids inlet-outlet temperatures are known, which is true in current research. All four temperatures are measured by specific instrumentations, as mentioned 
in Chapter IV. In Figure 5.6, the $\Delta T_{L M T D}$ increases with increasing in oil Reynolds number for all five different air inlet temperatures. This increase in $\Delta T_{L M T D}$ is expected due to the fact that the heat transfer rate increases as the oil flow rate (i.e. $R e_{\text {oil }}$ ) increases. Moreover, the plot shows that for a given value of $R e_{\text {oil }}$, a higher $\Delta T_{L M T D}$ value can be obtained at a lower air inlet temperature and vise versa. The dependency of $\Delta T_{L M T D}$ on $R e_{\text {oil }}$ in current investigation can be best described by the power law fit curve.

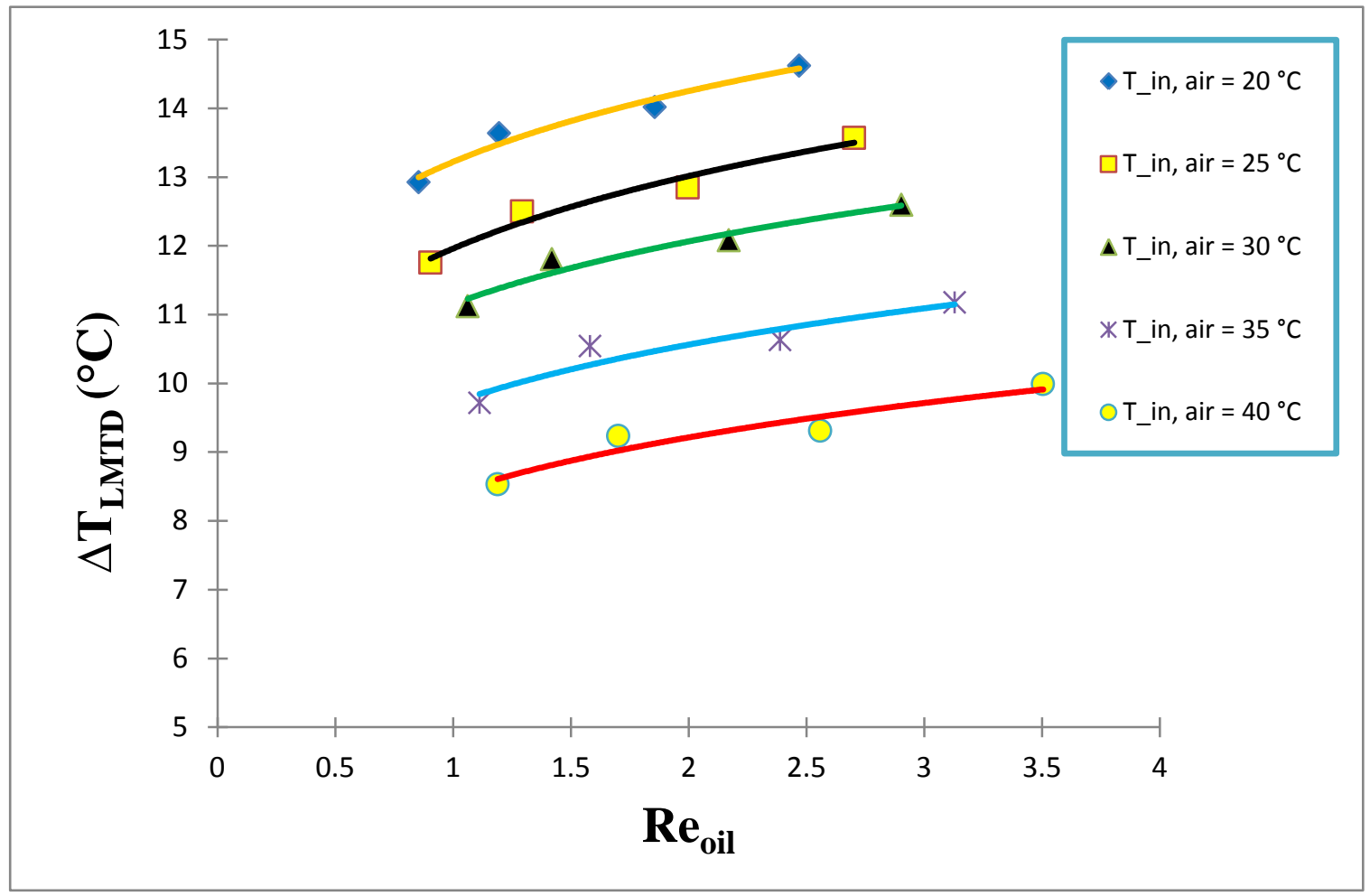

Figure 5.6: Log Mean Temperature Difference Vs Oil Reynolds Number 


\subsubsection{Oil Heat Transfer Coefficient $\left(\boldsymbol{h}_{\text {oil }}\right)$}

The variation of the experimental values of heat transfer coefficient with the oil Reynolds numbers is shown in Figure 5.7. One obvious observation is that the heat transfer coefficient increases with increasing $R e_{\text {oil }}$ for a particular air inlet temperature. Moreover, it is evident from the figure that the heat transfer mechanism is greatly affected by oil flow rates. On the other hand, air inlet temperature and the air velocity have a nominal influence on the convective phenomenon.

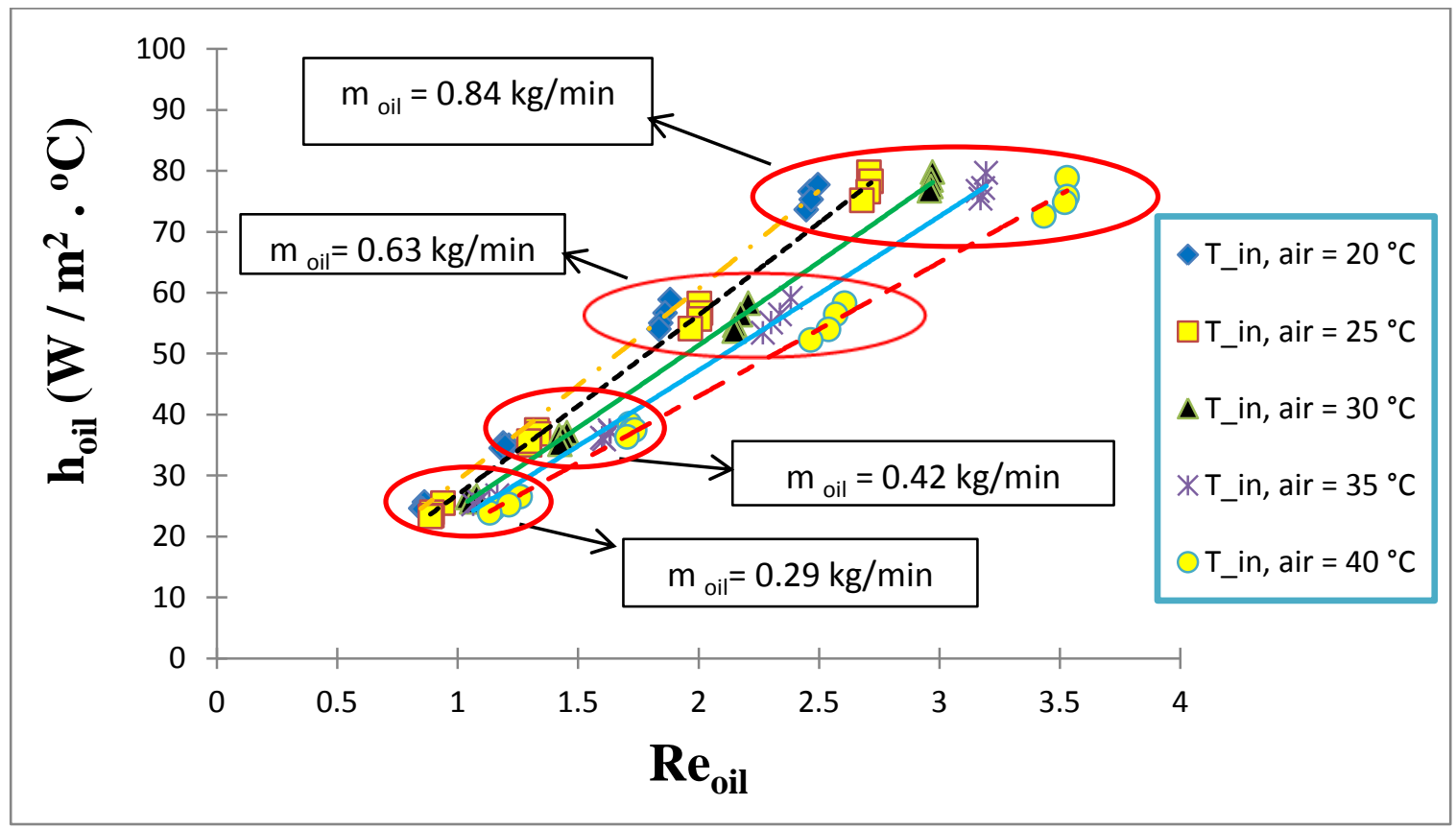

Figure 5.7: Oil Heat Transfer Coefficient Vs Oil Reynolds Number

The values of Reynolds number were different even for a given oil flow rate. This shows the strong effect of temperature variation on oil viscosity. In order to negate the viscosity effect, and thus make the data collapsed, Péclet number is plotted against the heat transfer coefficient values, as shown in Figure 5.8. The correlation between the $h_{\mathrm{oil}}$ and $P e_{\text {oil }}$ is found to be in power-law mode, as shown below:

$$
h_{\text {oil }}=0.04 P e_{\text {oil }}^{1.052}
$$




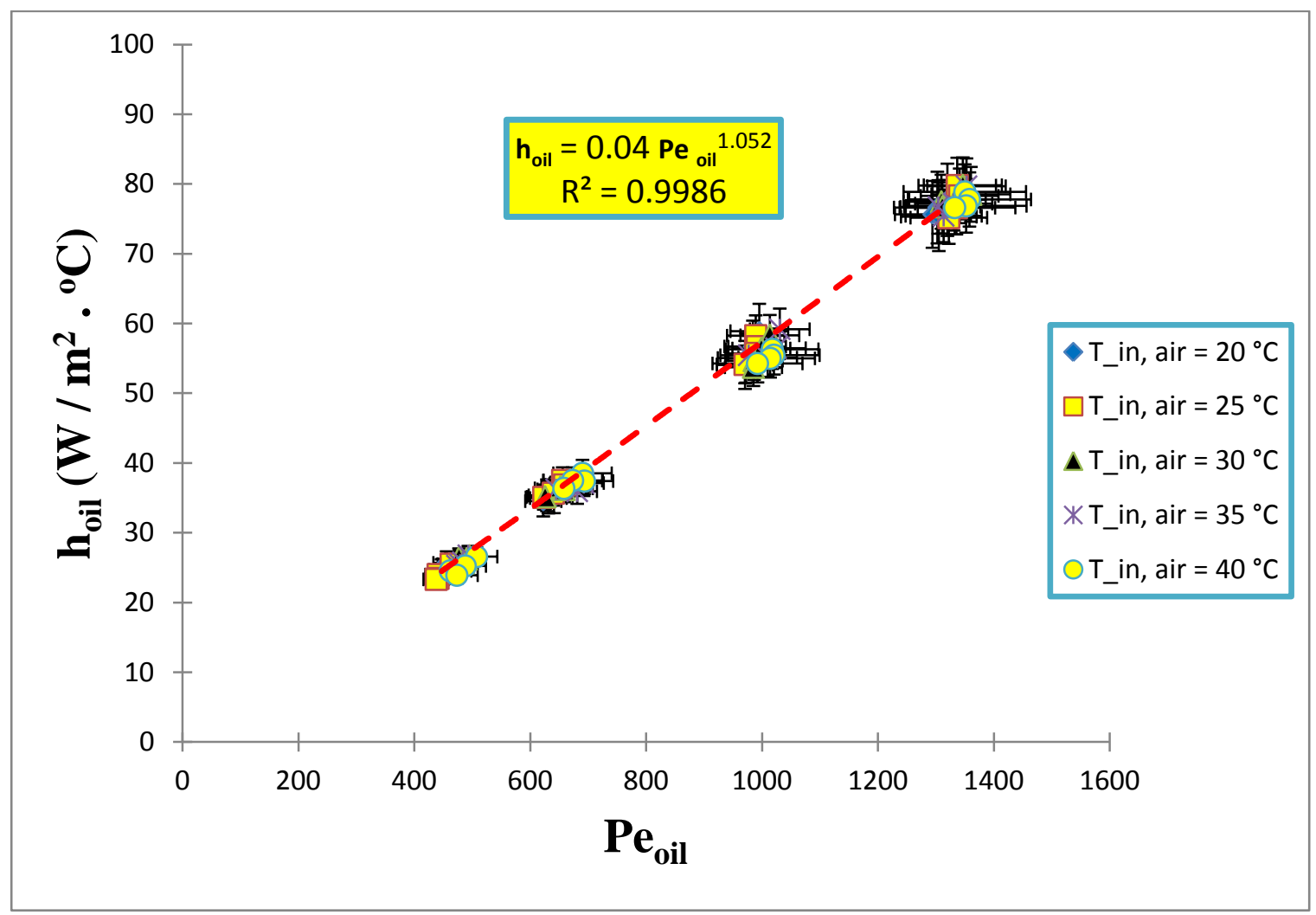

Figure 5.8: Oil Heat Transfer Coefficient Vs Oil Péclet Number

\subsubsection{Oil Nusselt Number $\left(\boldsymbol{N} \boldsymbol{u}_{\text {oil }}\right)$ and Channel Non-dimensional Length $\left(\boldsymbol{L}^{*}\right)$}

In general, the characteristics and heat transfer performance can be assessed by the average Nusselt number. Figure 5.9 shows the variation of the average Nusselt number with the channel non-dimensional length. The dimensionless length can be computed from the following equation:

$$
L^{*}=\frac{L}{D_{h} R e_{o i l} P r_{o i l}}
$$

The solid trend line represents the average Nusselt number without taking into account the viscosity ratio. On the other hand, the dashed trend line denotes the values of the corrected Nusselt number with the viscosity ratio. More explanation about the effect of 
viscosity ratio on Nusselt number values will be mentioned in the coming subheading. $L^{*}$ decreases as the product of Re and Pr numbers (i.e. Pe number) increases. As shown in the figure below, the data points are best fitted with a power-law mode for the values of both Nusselt numbers. The correlations can be stated as:

$$
\begin{aligned}
& N u_{o i l, b}=0.0 .716 L^{*-1.06} \\
& N u_{o i l, c}=0.0 .656 L^{*-1.06}
\end{aligned}
$$

To some extent, it can be said that the convective heat transfer would become less significant as the oil flows through the entire channel. Figure 5.9 is plotted for a given channel length, individual channel length in one loop ( $\mathrm{L}=1.658 \mathrm{~m})$. Equations 6.6 and 6.7 are valid for $D_{h}=1 \mathrm{~mm}$ and $438 \leq P e_{o i l} \leq 1370$. Gui and Scaringe (1995) studied the cooling performance of water through microchannels $\left(D_{h}=388 \times 10^{-3} \mathrm{~mm}\right.$ and $\mathrm{L}=$ $0.046 \mathrm{~m})$ and found the same $N u_{\text {avg }}-L^{*}$ correlation in their results.

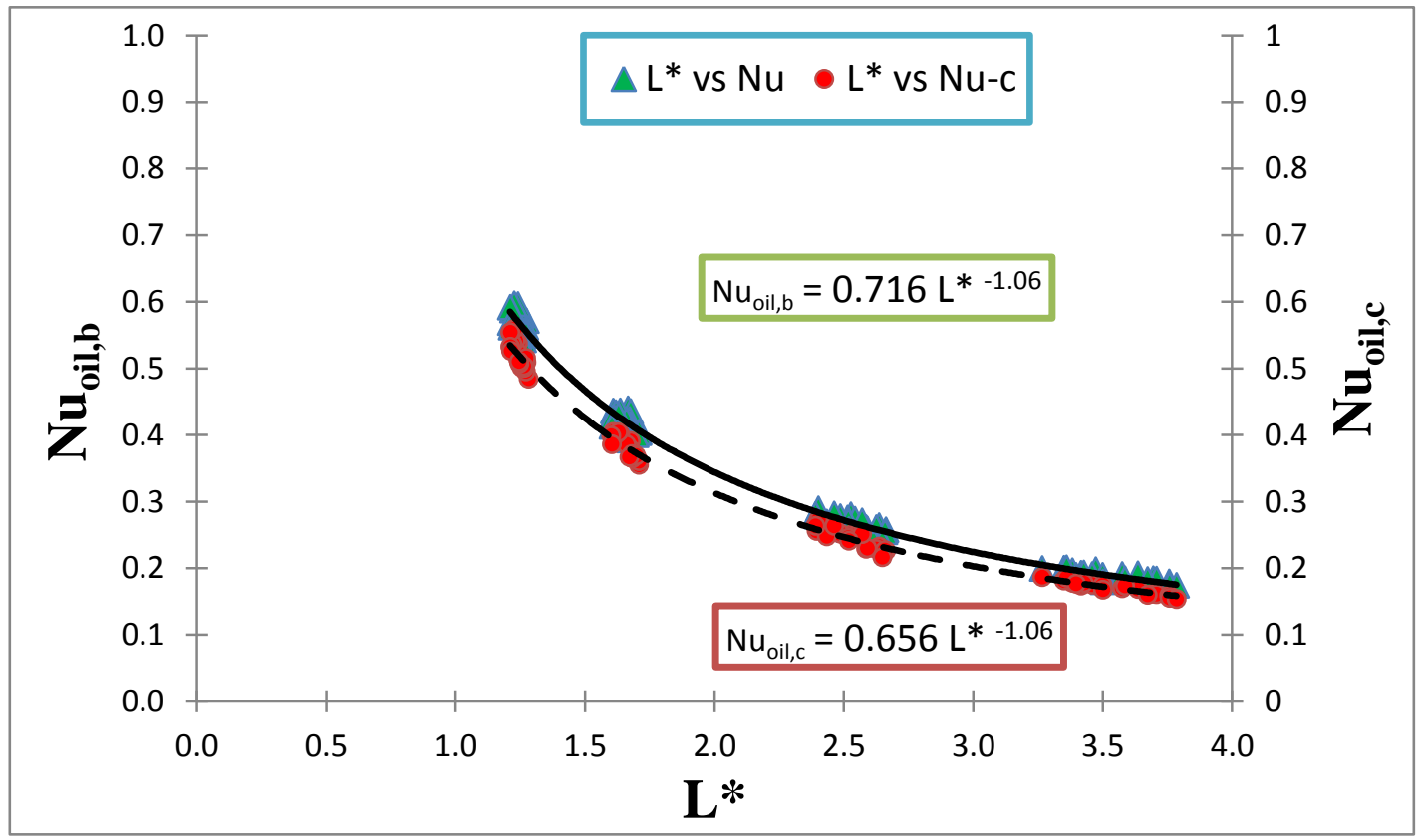

Figure 5.9: Oil Nusselt Number Vs Channel Non-dimensional Length 


\subsubsection{Oil Nusselt Number $\left(\boldsymbol{N} \boldsymbol{u}_{\text {oil }}\right)$ and Flow Mode}

In forced convection analysis, the primarily interest is to determine a correlation between the heat transfer rate (representing in Nusselt number), and the fluid flow (representing in Reynolds number). The average Nusselt number was calculated from equation 3.11. Oil viscosity is highly dependent on temperature, and thus it cannot be considered constant along the radial direction inside the minichannel, as explained in section 3.2.6. Therefore, Nusselt number needs to be corrected to take into account this radial variation in oil layers by using the viscosity ratio, equation 3.13.

The average motor oil Nusselt numbers $\left(N u_{o i l, b}\right)$ are plotted against their respective Reynolds number values as shown in Figure 5.10. The plot illustrates that $N u_{o i l, b}$ increases with the increase of $R e_{o i l}$. This dependency of $\mathrm{Nu}$ on $\mathrm{Re}$ has been reported in the literature before. Wu and Cheng (2003) experimentally investigated the heat transfer mechanism of deionized water in trapezoidal microchannels. They reported that Nusselt number sharply increases with increasing in Reynolds number $(0<\operatorname{Re}<100)$. Hetsroni et al. (2004) performed a study for water and water-surfactant solution flowing through a pipe of $1.07 \mathrm{~mm}$ diameter in low range of Reynolds numbers. It was found that the average Nusselt number increases as Reynolds number increases.

Two trend lines are shown in the figure below. The solid line represents the Nusselt number values before considering the variable property ratio. After correcting the Nusselt number with the viscosity ratio, the values (dashed line) were found to be slightly lower than the original ones as shown in Figure 5.10. This reduction in Nusselt number 
occurred due to the high viscosity of the oil layers near the wall which in turn causes a lower heat transfer rate.

The influence of variable properties on the heat transfer varies in magnitude for different flow channel geometries. For circular channel flow, Deissler (1951) and Shannon and Depew (1962) analytically investigated the effect of variable viscosity on fully developed flow. They stated that the value of the exponent " $n$ " in equation 3.13 is equal to 0.14 . Sieder and Tate (1936) experimentally studied the fully developed flow region with heating and cooling modes and they reported an " $n$ " value of 0.14 .

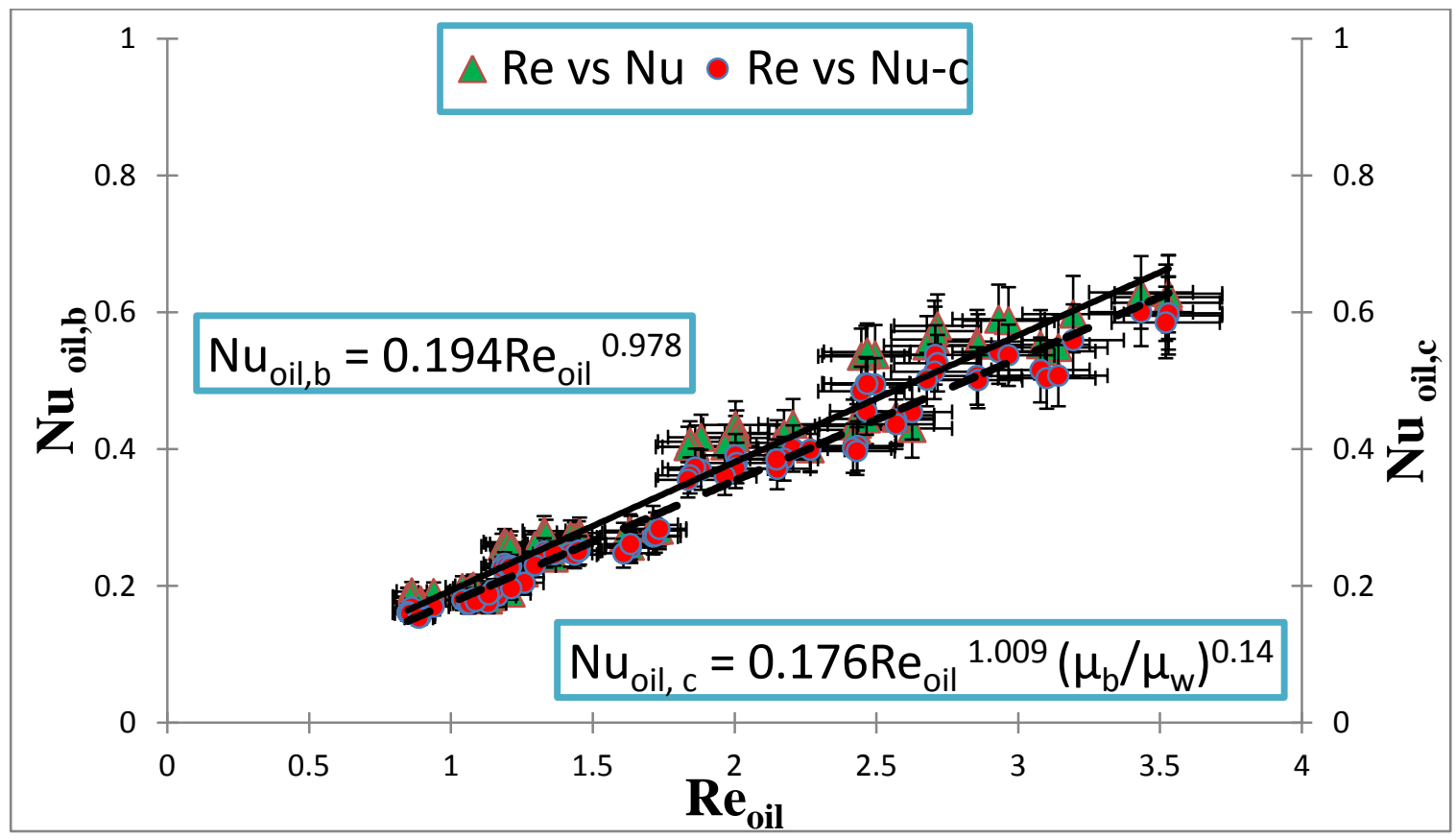

Figure 5.10: Oil Nusselt Number Vs Oil Reynolds Number

The slope of the 80 experimental data points was best fitted in a power regression type. For the constant property case, a $N u_{o i l}-R e_{o i l}$ correlation capable of foreseeing the $N u_{o i l, b}$ value within $\pm 11 \%$ is generated from the current study:

$$
N u_{o i l, b}=0.194 R e_{\text {oil }}^{0.978}
$$


After correcting the Nusselt number values with variable property ratio, the maximum influence of variable viscosity ratio on Nusselt number values is generally less than $10 \%$ for the current investigation. The new values were plotted against the same values of Reynolds number and the correlation was found to be as follows:

$$
N u_{o i l, c}=0.176 R e_{\text {oil }}^{1.009}\left(\frac{\mu_{\text {bulk }}}{\mu_{\text {wall }}}\right)^{0.14}
$$

However, for the internal forced convection pipe flow, the average Nusselt number of a viscous fluid is not only a function of Reynolds number, but it is also a strong function of Prandtl number. Moreover, since the oil bulk temperature $\left(T_{\text {oil,bulk }}\right)$ varied between 47.8 and $58.7{ }^{\circ} \mathrm{C}$ during the experimental runs, the Prandtl number also significantly altered from 387.6 to 528.9. As such, the experimental data for heat transfer is regularly represented with reasonable accuracy by a power-law relation of the following form:

$$
N u=C R e^{m} \operatorname{Pr}^{n}
$$

The values of the constant $\mathrm{C}$ and the exponents $\mathrm{m}$ and $\mathrm{n}$ are determined by experimental analysis and curve fitting. Based on the nature of the temperature profile in the thermal boundary layer determined by the $\operatorname{Pr}$, the exponent $n$ is usually taken as $1 / 3$.

The oil $\mathrm{Nu}$ as a function of both $\mathrm{Re}$ and $\mathrm{Pr}$ of oil is plotted in Figure 5.11. The variation followed a power-law relationship. As mentioned earlier, Prandtl number is a fluid property and it decreases as the bulk temperature increases. This inverse relationship is due to the high dynamic viscosity of oil, since the specific heat and thermal conductivity do not vary significantly with the change in oil bulk temperature. The estimated uncertainty for oil Nusselt number varies from 7.14 to $10.3 \%$ in all the operating 
conditions. The correlation generated between $\mathrm{Re}, \mathrm{Pr}$, and $\mathrm{Nu}$ in the current investigation is as follows:

$$
N u_{o i l, b}=0.03 \operatorname{Re}_{\text {oil }}^{1.001} \operatorname{Pr}_{\text {oil }}^{1 / 3}
$$

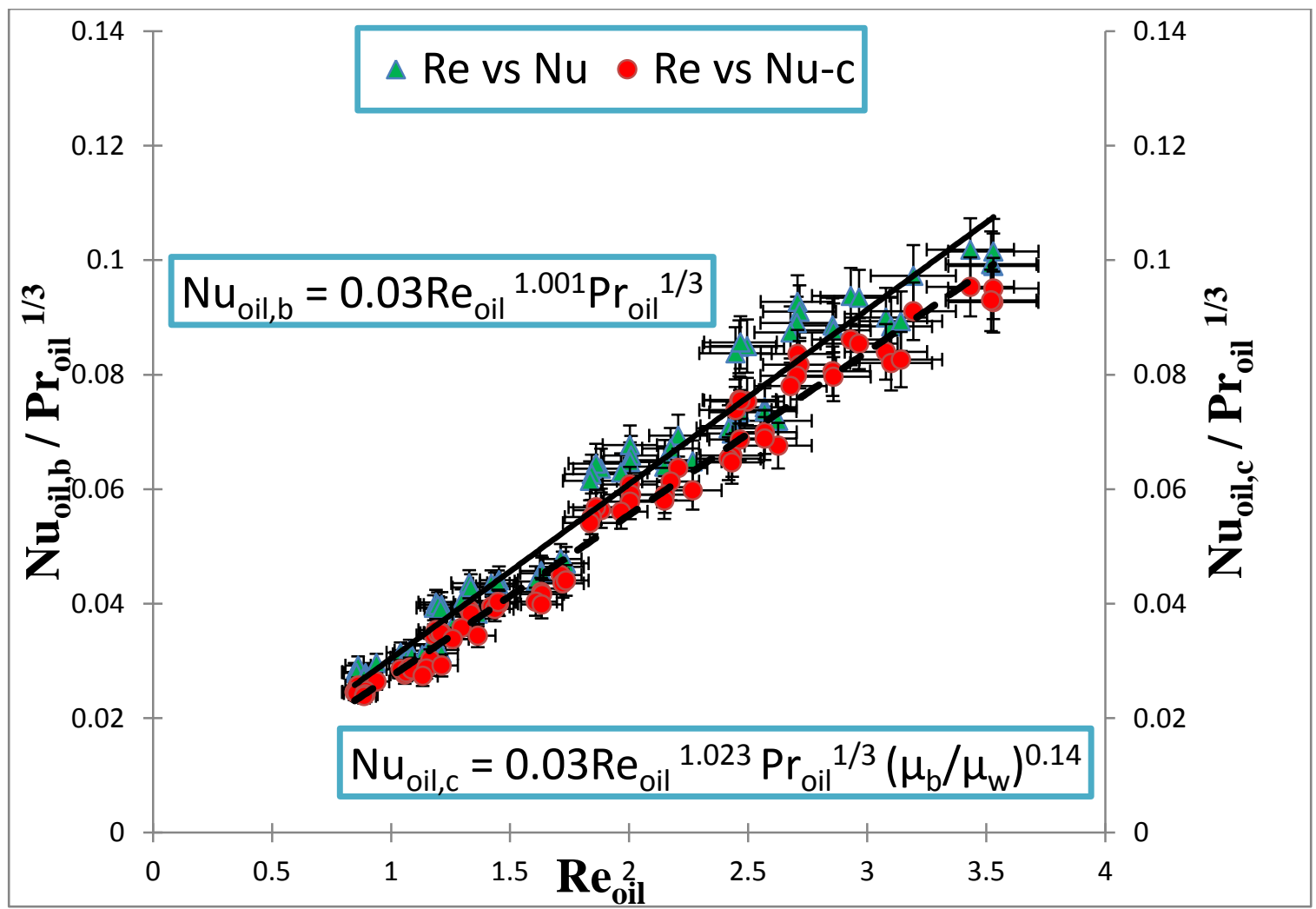

Figure 5.11: Effect of Oil Reynolds and Prandtl Numbers on Oil Nusselt Number

The corrected Nusselt number values (dashed lines) with the viscosity ratio are also correlated with Reynolds and Prandtl numbers as shown in Figure 5.11. As can be discerned from the figure, new values of the corrected $\mathrm{Nu}$ are lower than the values of the constant property $\mathrm{Nu}$. This is due to the high difference between the wall and bulk temperatures. Thus, the new correlation developed in the current study is found to be as follows:

$$
\begin{gathered}
N u_{\text {oil }, c}=0.03 \operatorname{Re}_{\text {oil }}^{1.023} \operatorname{Pr}_{\text {oil }}^{1 / 3}\left(\frac{\mu_{\text {bulk }}}{\mu_{\text {wall }}}\right)^{0.14} \\
\text { for } 387.6 \leq \operatorname{Pr} \leq 528.9 \text { and } 0.85 \leq R e \leq 3.53
\end{gathered}
$$


Quaiyum (2012) conducted a study on Automatic Transmission Fluid (ATF) for characterizing the fluid flow and heat transfer through the same minichannel heat exchanger test specimen. The corrected $\mathrm{Nu}$ of motor oil and ATF as a function of both Re and Pr are plotted in Figure 5.12. Log-log plot is used in order to cover both oil and ATF Reynolds number ranges. The variation of both trend lines followed a power law correlation.

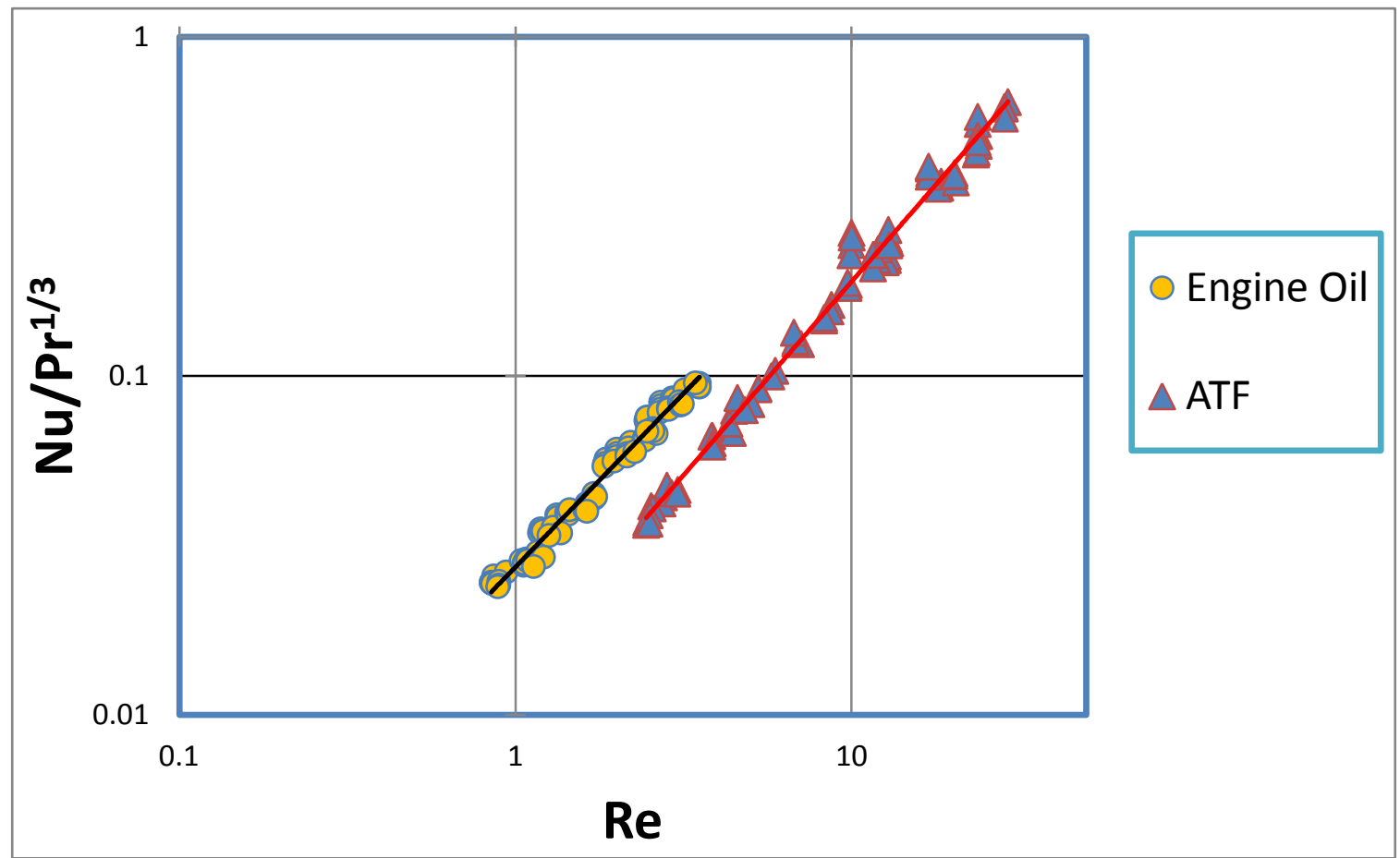

Figure 5.12: Comparison of $\mathrm{Nu}=\mathrm{f}(\mathrm{Re}, \mathrm{Pr})$ of Motor oil and ATF

\section{$\underline{5.3 \text { Wall Axial Heat Conduction }}$}

The effect of axial heat conduction in the wall on the heat transfer in narrow channels has been recently investigated by several authors. As mentioned in Chapter II, the convective heat transfer mechanism is usually underestimated if the wall axial thermal conduction in 
narrow channels is neglected, especially at low flow rates. In the current investigation, the dissipated heat from the motor oil actually has another avenue other than the cold fluid (i.e. air) which is the channel wall. The heat travels inside the wall axially along the flow direction. This amount of heat carried away by the wall is bounded by the wall thickness and the wall thermal conductivity.

In order to verify the presence of the axial heat conduction occurred in the channel wall, axial conduction number (M) was introduced by Maranzana et al. (2004). M is defined as the ratio of axial heat conduction in the tube wall to the convective heat transfer of the flowing fluid in the tube (equation 3.14). Maranzana et al. (2004) performed numerical investigations on the effect of the axial heat conduction in the wall. They found that the fluid bulk temperature variation becomes non-linear at lower flow rate $(\operatorname{Re}<20)$. This likely implies that considerable amount of heat is distributed axially along the channel wall, rather than absorbed by the coolant. This started occurring when the axial conduction parameter $(\mathrm{M})$ is greater than 0.01 .

Later, several authors have assumed that $\mathrm{M}>0.01$ to be the milestone value for considering the wall axial heat conduction effect. In the present study, $\mathrm{M}$ is calculated from equation 3.15 and its values vary from $0.0104 \leq M \leq 0.0324$. Thus, the effect of wall axial heat conduction may play a role on the heat transfer mechanism.

Figure 5.13 shows a plot of the values of average Nusselt number $(\mathrm{Nu})$ as a function of the axial conduction parameter $(\mathrm{M})$. As the value of $\mathrm{M}$ increases, the larger the reduction 
in Nusselt number is. From this relationship, it can be discerned that the heat conduction in the solid wall does affect the convective heat transfer mechanism. The data sets fit quite well with the power law curve fit with a negative exponent and a very high $\mathrm{R}^{2}$ value in the following form:

$$
N u_{o i l, c}=0.0043 M^{-1.057}
$$

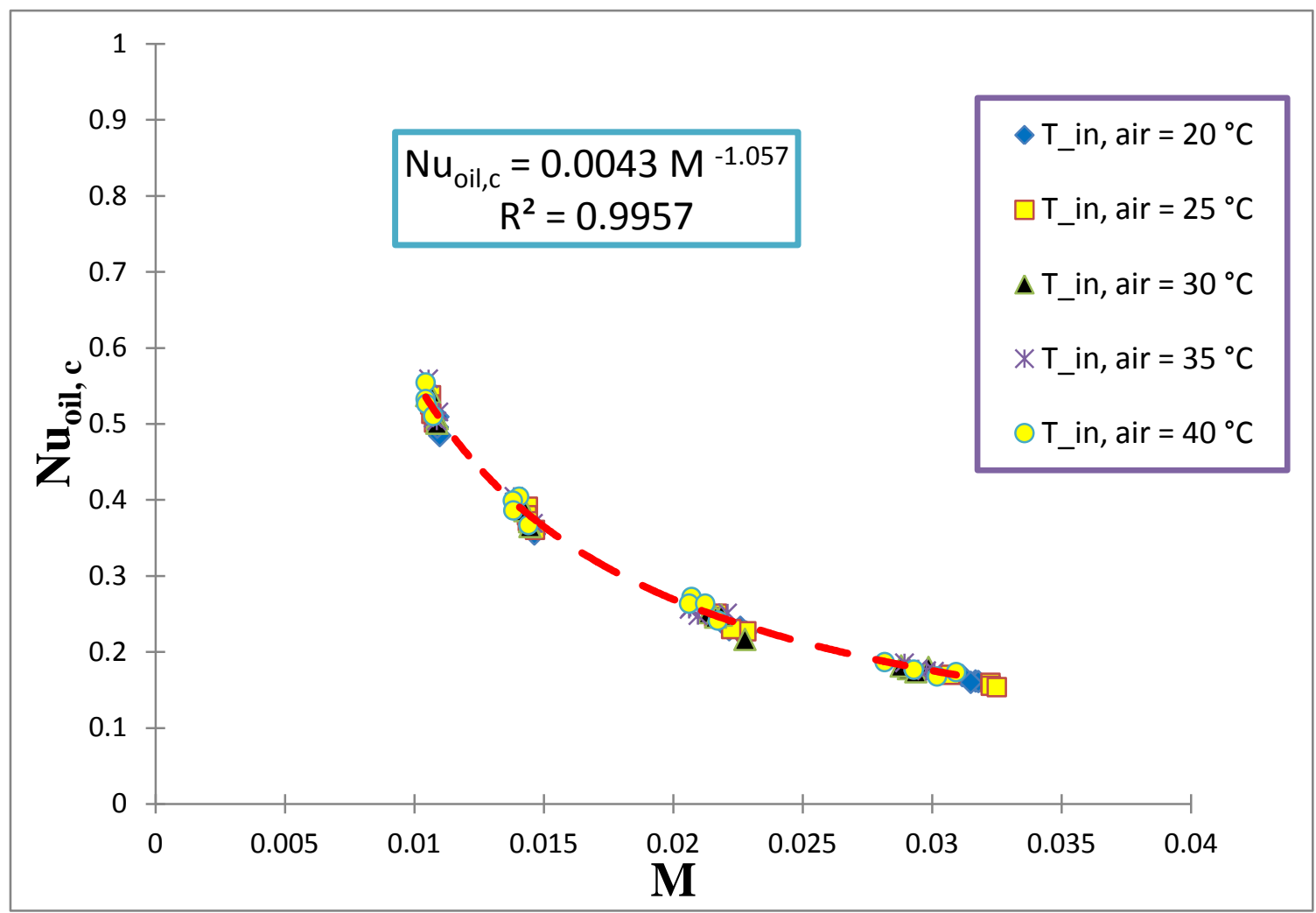

Figure 5.13: Oil Nusselt Number Vs Axial Heat Conduction Parameter

From equation 3.15, it can be observed that the wall axial heat conduction has an inverse relationship with the fluid flow. When Reynolds number values are plotted against with their respective values of heat conduction parameter, the intersection points give a peculiar trend line due to the high viscosity of motor oil. As mentioned earlier in section 5.2.6, the Péclet number is utilized here in order to take out the viscosity role and to relate 
the axial heat conduction with the fluid rate of advection. Thus, Péclet number is drawn against the heat conduction parameter in Figure 5.14. The data sets perfectly match with the power law mode with a negative exponent in the following form:

$$
M=\frac{14.21}{P e_{\text {oil }}}
$$

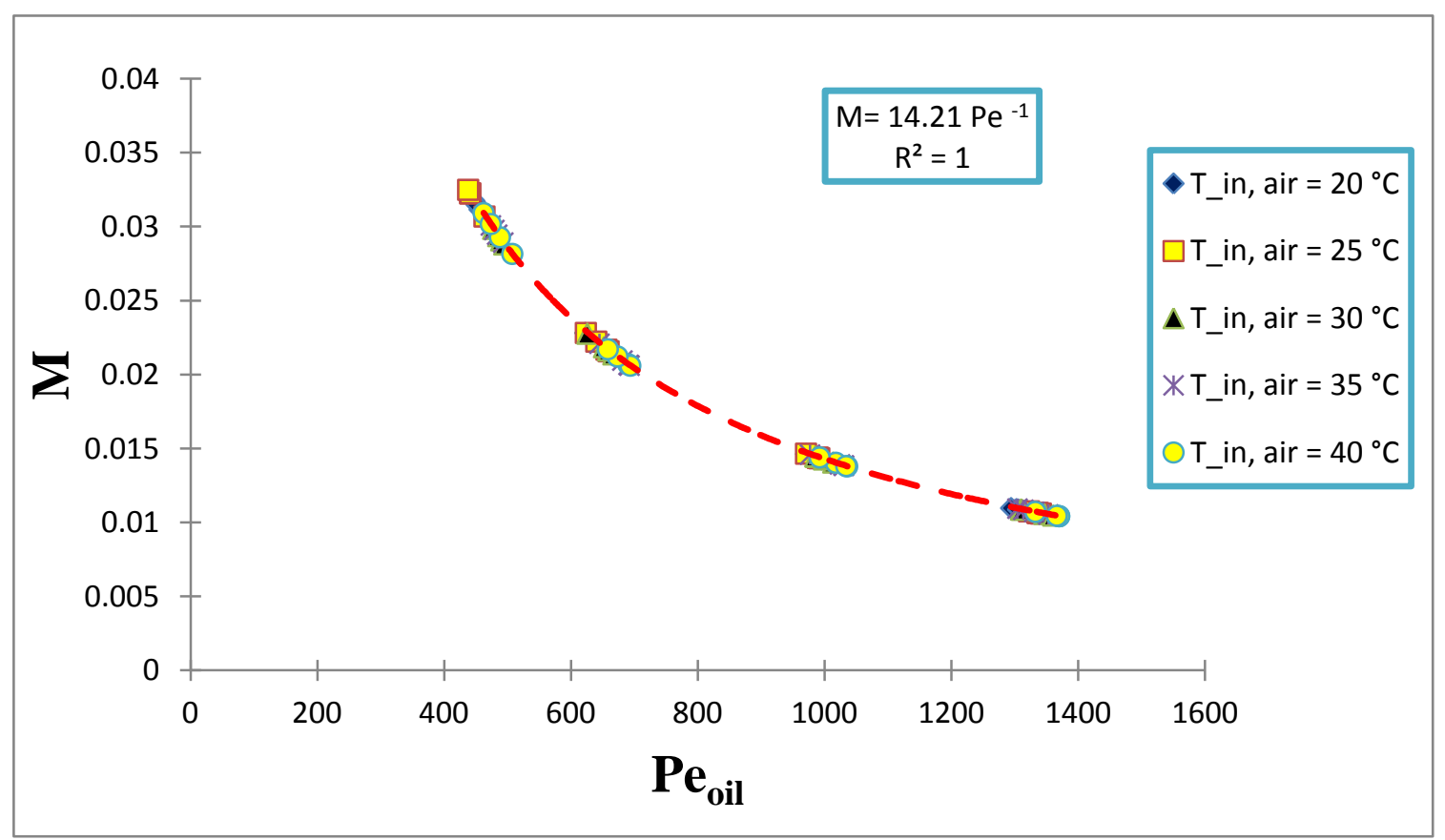

Figure 5.14: Axial Heat Conduction Parameter Vs Oil Péclet Number

From the above graph, it can be deduced that the wall axial conduction effects is gradually strengthened as the fluid flow rate decreases. Moreover, the air velocity and inlet temperature do not have a considerable effect on the axial heat conduction in the channel wall. 


\section{$\underline{5.4 \text { Viscous Dissipation }}$}

Viscous dissipation is observed in certain viscous flow problems, especially those pertaining to lubrication. As been concluded by Koo and Kleinstreuer (2004), the viscous heating effects may be of an interest for fluids with high viscosities and relatively low specific heat capacities, even in low Reynolds number flows. In current investigation, a highly viscous fluid, motor oil, is cooled while flowing through multi-port minichannels. One way to characterize the effect of viscous dissipation is by analyzing the change in liquid kinetic energy due to the velocity, which can be presented when calculating Eckert number $(\mathrm{Ec})$.

The computed Ec, using equation 3.8, is plotted against Péclet number (Pe) of oil and the relation is shown in Figure 5.15. Ec number varies positively in power mode with increase in oil velocity. Even though the values of Ec number seem to be very small $\left(2.8 \mathrm{E}^{-08} \leq \mathrm{Ec} \leq 4.4 \mathrm{E}^{-07}\right)$, they need to be taken into account as viscous dissipation effects can be neglected in the limit of Ec $\rightarrow 0$ [Tso and Mahulikar (2000)]. The increase in Ec would indicate that the viscous dissipation occurs at higher fluid velocities. Thus, however smaller the value of Ec is, viscous dissipation cannot be ignored for a highly viscous fluid, such as motor oil. 


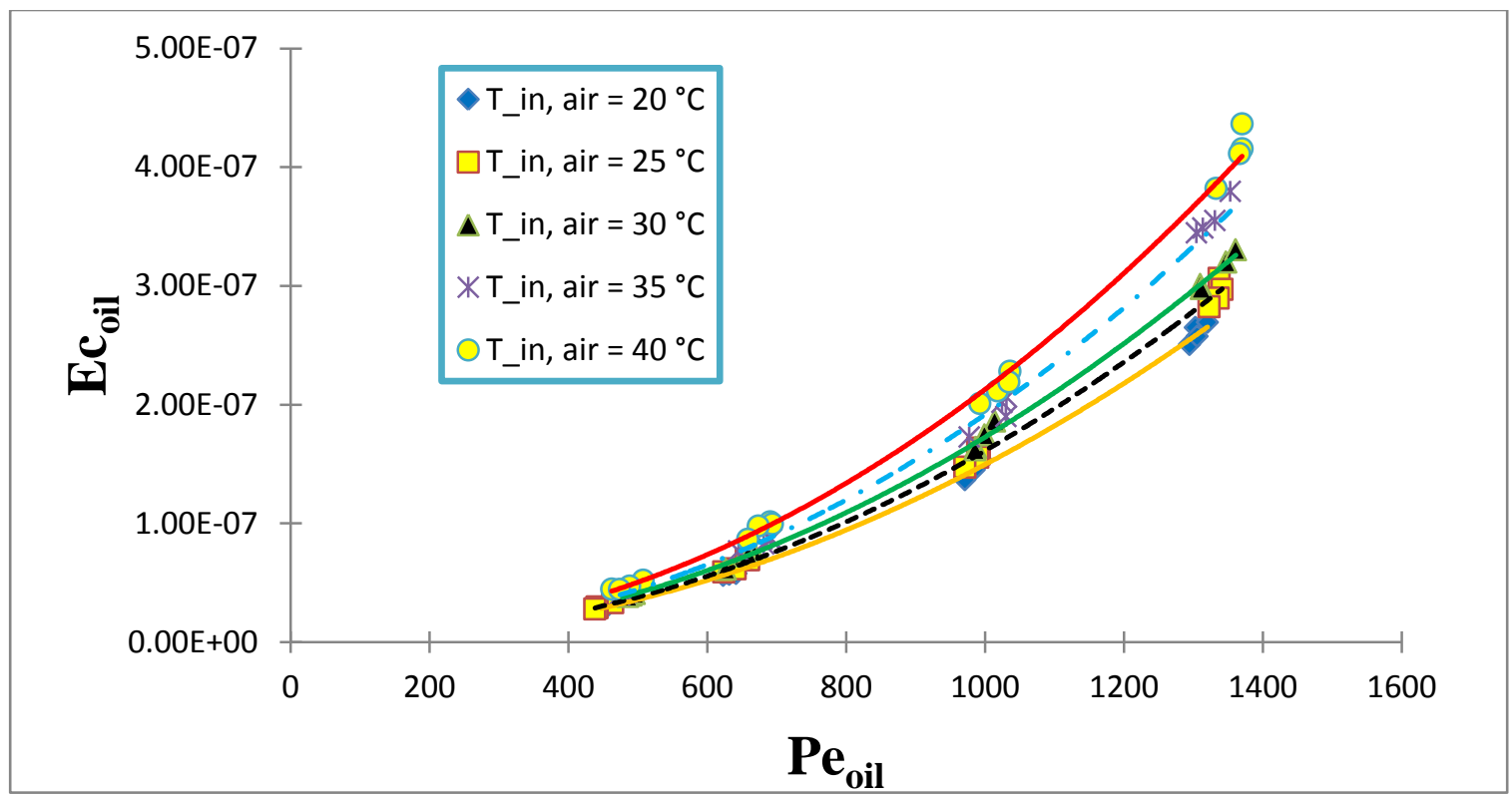

Figure 5.15: Oil Eckert Number Vs Oil Péclet Number

At a higher air inlet temperature, the oil has a higher bulk temperature than that at a lower air inlet temperature; thus it provides higher kinetic energy due to the low oil viscosity, which allows the oil to move faster inside the channel.

The effect of Ec on the heat transfer phenomenon is also examined. Figure 5.16 shows that oil Nusselt number increases in power-law mode with the increase in Ec number for a given air inlet temperature. From the figure below, the air inlet temperature conditions have no substantial impact on the convective heat transfer as Nusselt number values increase only from 0.5 to 0.6 when increasing the air inlet temperature from $20{ }^{\circ} \mathrm{C}$ to 40 ${ }^{\circ} \mathrm{C}$ for a given oil velocity. On the other hand, Figure 5.17 exhibits the all 80 operating conditions in one trend line. The correlation extracted from the plot is as follows:

$$
N u_{o i l, c}=114.9 E c_{o i l}^{0.514}
$$




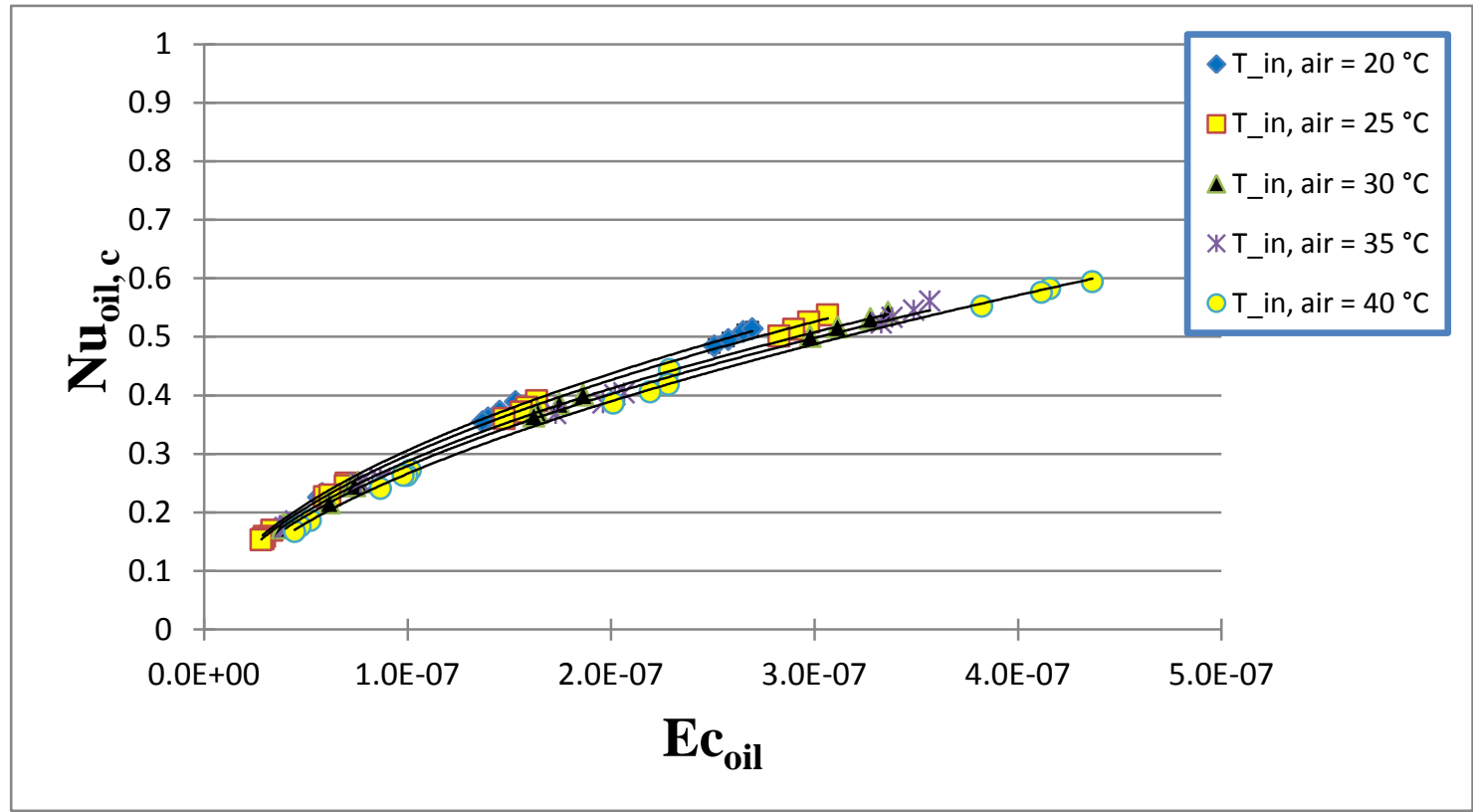

Figure 5.16: Oil Nusselt Number Vs Oil Eckert Number

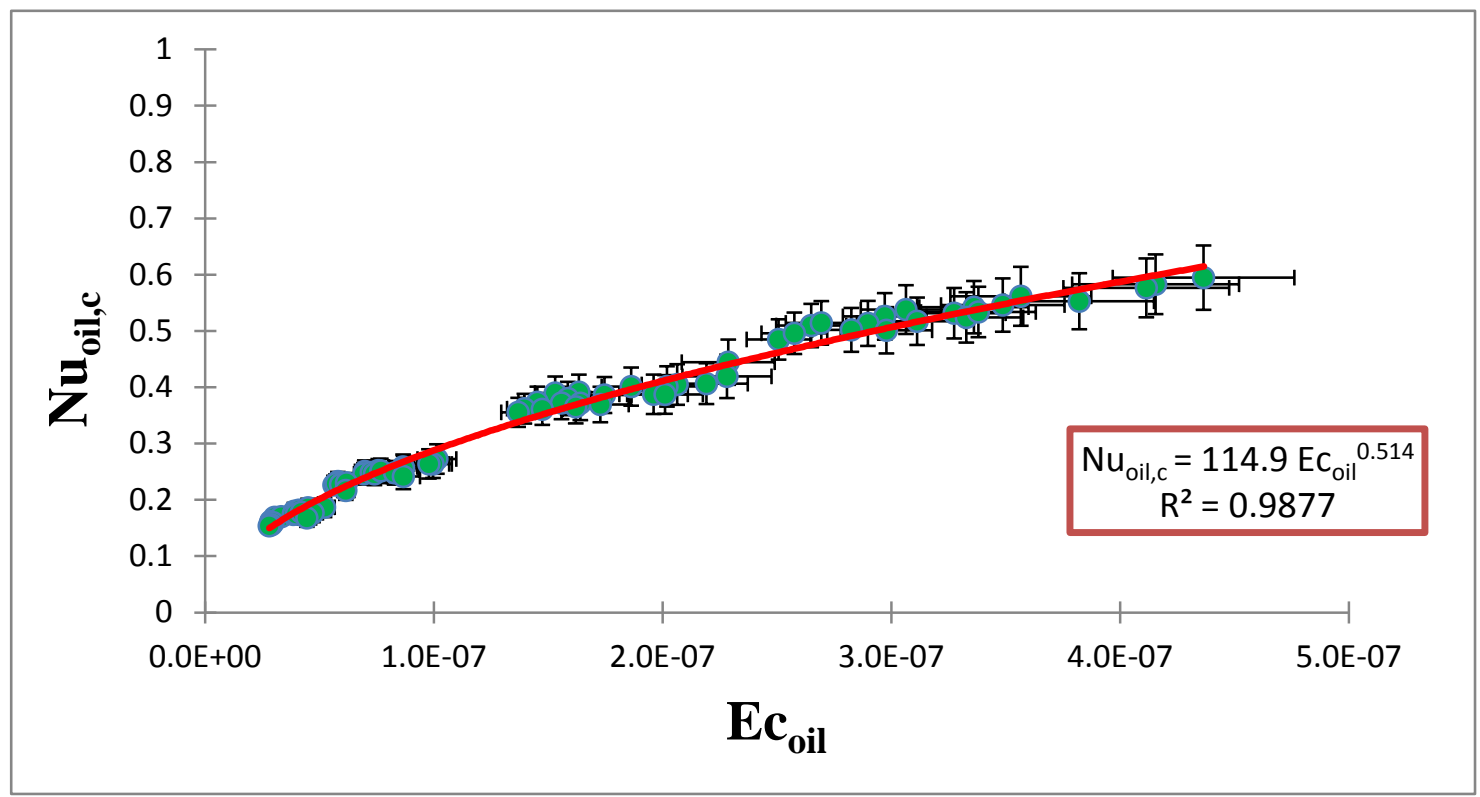

Figure 5.17: Oil Nusselt Number Vs Oil Eckert Number

Another approach by which the presence of viscous dissipation phenomenon can be sensed is the approach of Brinkman number. $\mathrm{Br}$ is used to couple between viscous dissipation (signified by " $\mu X V^{2}$ ") and conduction heat transfer (signified by " $k X \Delta T$ ") 
across the flow [Tso and Mahulikar (2000)]. Viscous dissipation is simply defined as the amount of heat added to the fluid due to its high viscosity. This added heat may lead to a significant variation in velocity and temperature fields. Brinkman number can be calculated from equation 3.9 or 3.10. Figure 5.18 shows that the Brinkman number, i.e. viscous dissipation, increases when Reynolds number increases for a given air inlet temperature. Again, the huge effect of oil temperature variation on dynamic viscosity can easily be denoted as the values of Reynolds number are plummeted due to higher viscosity at lower oil bulk temperature.

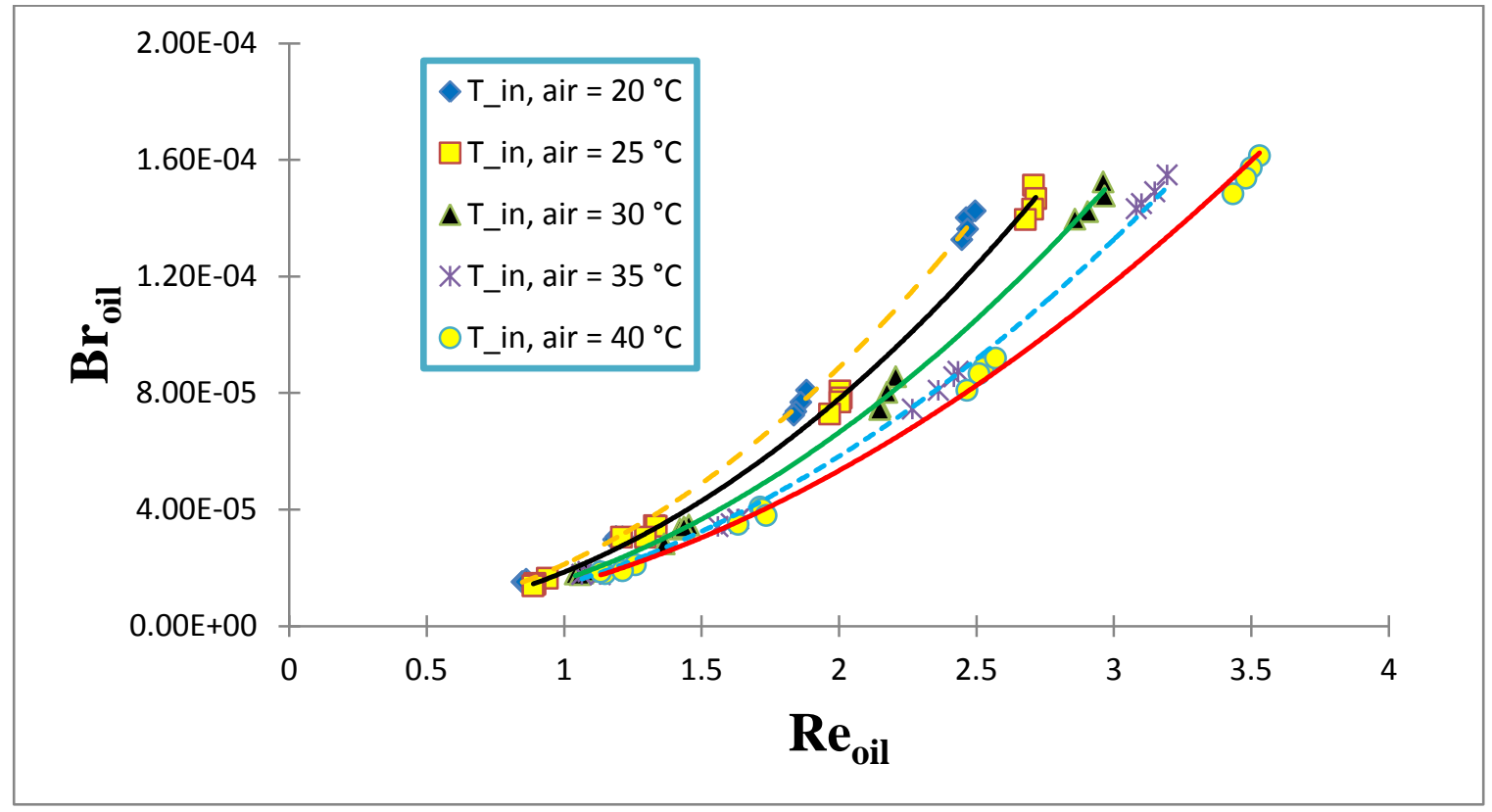

Figure 5.18: Oil Brinkman Number Vs Oil Reynolds Number

Figure 5.19 displays the relationship between Péclet and Brinkman numbers. The 80 experimental data is collapsed into four clusters. The only difference in the operating conditions of the two fluids in each cluster is the oil flow rate. This can be discerned from Péclet number's definition in section 3.2 .3 as oil velocity is the only parameter which can be altered considerably due to the change in temperature. From this figure, it is also 
proven that air inlet temperature and air velocity do not play a role in viscous heating. The correlation adopted between Péclet and Brinkman numbers in current investigation is as follows:

$$
B r_{\text {oil }}=5 E-11 P e_{\text {oil }}^{2.07}
$$

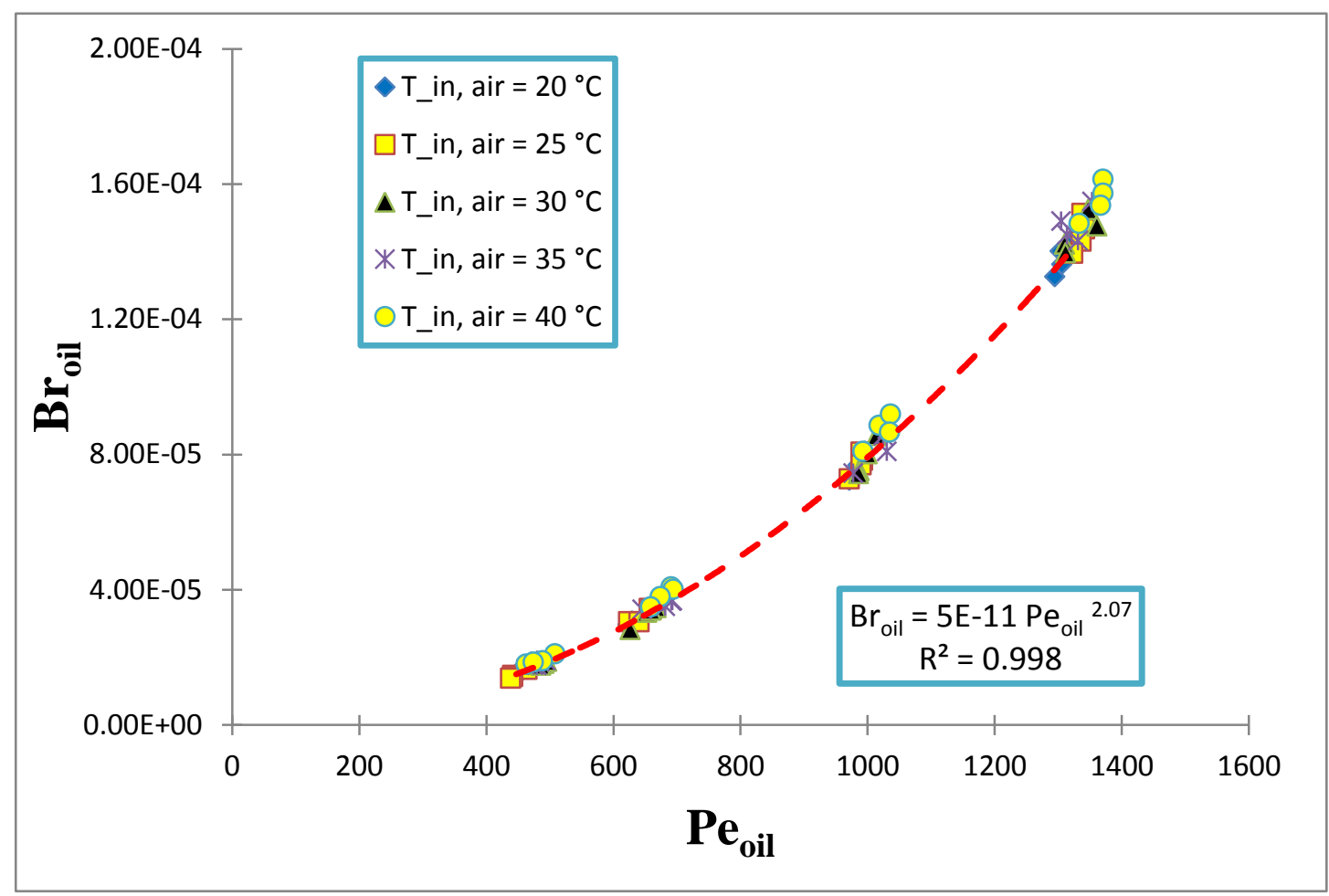

Figure 5.19: Oil Brinkman Number Vs Oil Péclet Number

In present study, the values of Brinkman number resulted from flowing motor oil through a minichannel are within $1.4 \mathrm{E}-05 \leq \mathrm{Br} \leq 1.7 \mathrm{E}-04$. Tso and Mahulikar (2000) performed an experimental study on water flowing through a circular microchannel with Reynolds number of $12.8-47.4$, and the values of Brinkman number were below 1.7E-07. They concluded that having low values in $\mathrm{Br}(\mathrm{Br}<1)$ in a narrow channel affects the liquid thermo-physical properties, which in turn impacts the single-phase connective heat 
transfer. It is highly expected that if the oil's flow rate is higher, the value of Br would considerably increase, thus more viscous dissipation would occur.

Since the fluid-wall temperature difference determines heat transfer coefficient, variations in $\mathrm{Br}$ affect directly the heat transfer mechanism. Figure 5.20 presents the effect of viscous heating on the convective heat transfer. The Nusselt number increases as Brinkman increases in power-law mode. Since the viscosity near the surface is higher than that in the middle of the tube, viscous dissipation influences the surface temperature more pronounced than the fluid bulk temperature. Therefore, the difference between the bulk and surface temperatures decreases, and this leads to a higher Nusselt number, which is evident in the figure below. The correlation obtained between Brinkman and Nusselt numbers is as follows:

$$
N u_{o i l, c}=49.5 B r_{o i l}^{0.52}
$$

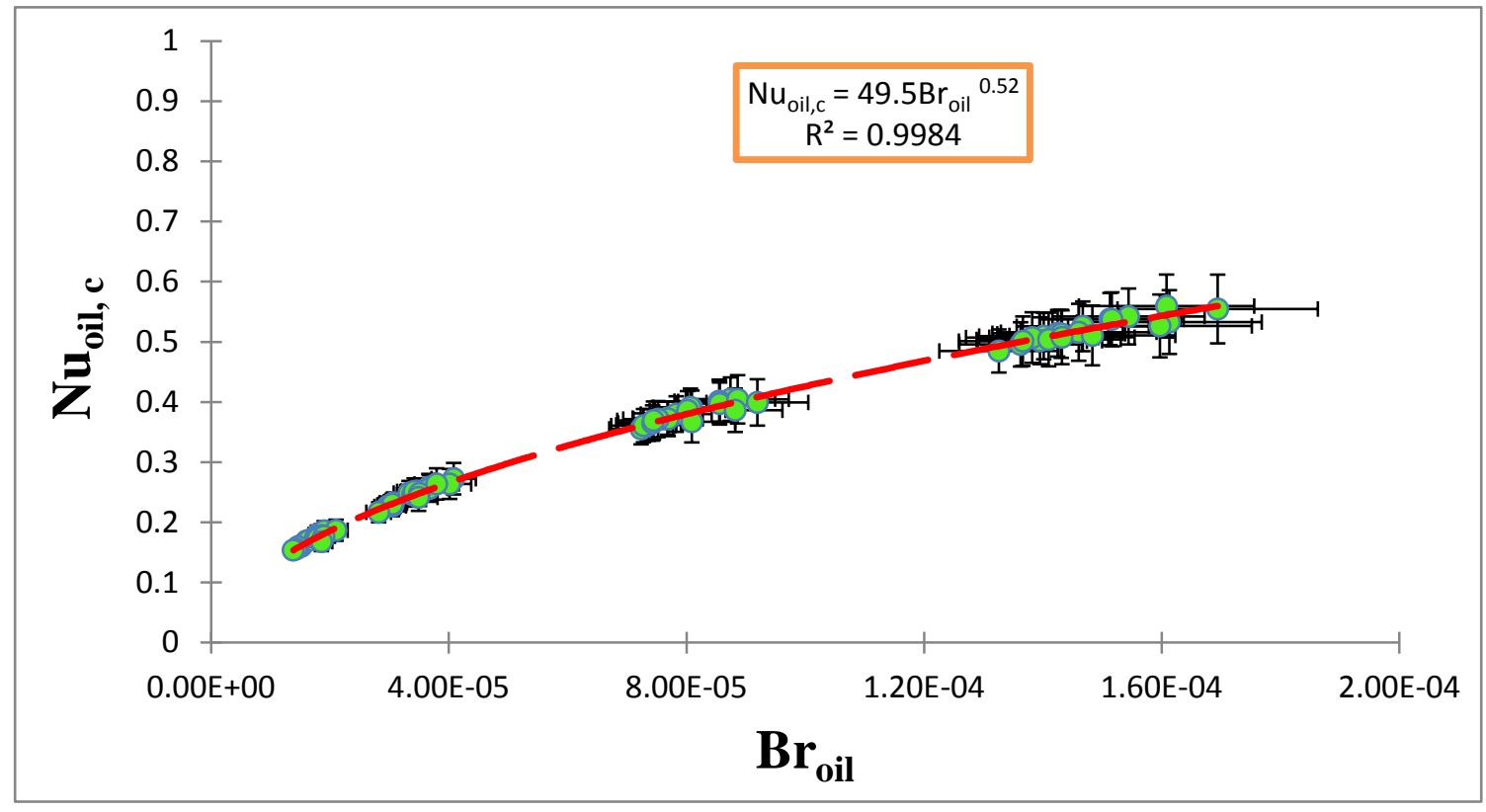

Figure 5.20: Oil Nusselt Number Vs Oil Brinkman Number 


\section{$\underline{5.5 \text { Pressure Drop and Friction Factor }}$}

In the design of narrow channel heat exchanger, it is crucial to predict the overall pressure drop between the inlet and outlet of the test specimen. In the current investigation, it is speculated to have a high pressure drop in the core (i.e. minichannel), since a highly viscous working fluid, motor oil, is forced to go through a narrow channel of $1 \mathrm{~mm}$ in hydraulic diameter. As explained at the beginning of this chapter, the entrance effect can be ignored when examining the pressure drop and friction factor.

\subsubsection{Pressure Drop}

As mentioned in section 3.3.3, the pressure drop in the minichannel constructed into two parts, namely straight and serpentine. The straight path pressure drop is calculated from equation 3.25 , whereas equation 3.26 is utilized to take into account the radial pressure drop at the serpentine portion. The calculated pressure drop in the radial direction is found to be very small compared to the axial direction (only $0.001 \%$ ).

Figure 5.21 presents the effect of oil Reynolds number on the pressure drop for the five air inlet temperatures. The channel pressure drop increases with the increase of oil Reynolds number. The graph includes the whole 80 experimental data. For a given $\mathrm{Re}_{\text {oil }}$, the pressure drop is seen to be higher at a lower air inlet temperature. This is because of the higher oil viscosity, which is determined based on the oil bulk temperature. 


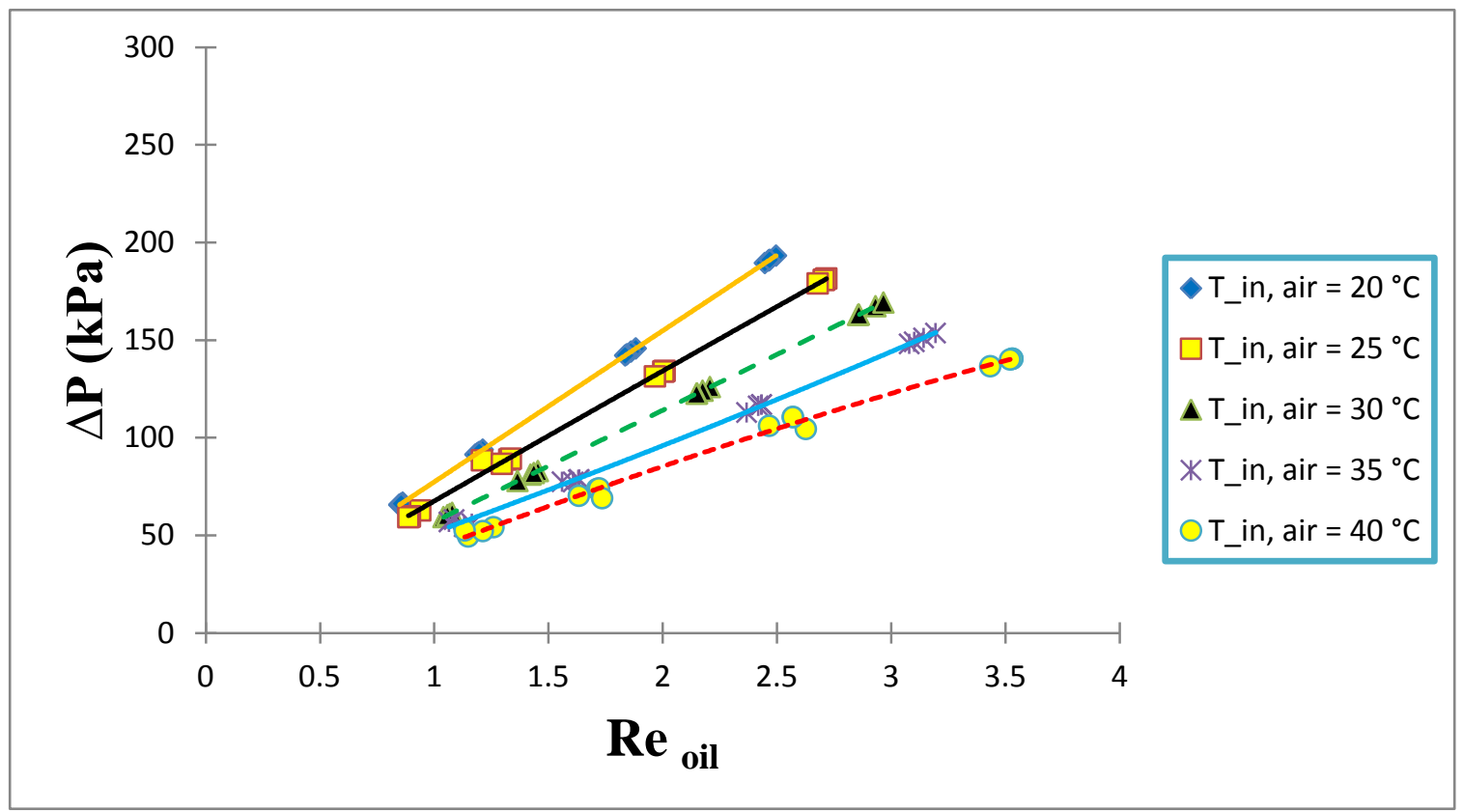

Figure 5.21: Pressure Drop Vs Oil Reynolds Number

\subsubsection{Friction Factor $(f)$}

As shown from equation 3.27, the relation between the friction factor and pressure drop is linear. The friction factor at the radial direction is neglected; since the calculated radial pressure drop was very small. So, equation 3.27 is utilized to determine the friction factor of the heat exchanger core. As illustrated in section 3.3.4, due to the high dependency of friction factor on the oil thermo-physical property, especially viscosity, friction factor needs to be amended by using equation 3.29.

Figure 5.22 correlates both friction factors with oil Reynolds number. In the current study, all 80 values of friction factor for constant property are compatible with the conventional correlation for a fully developed laminar flow in a circular cross-sectional path, eqution 3.28. The correlation is generated to be as follows: 


$$
f_{\text {bulk }}=\frac{64}{R e_{o i l}}
$$

When the friction factor is corrected with a viscosity ratio, the values diverge from the conventional correlation. The new empirical correlation is also in a power-law curve fit and it is given as:

$$
f_{c}=97.43 R e_{\text {oil }}^{-1.087}\left(\frac{\mu_{\text {bulk }}}{\mu_{\text {wall }}}\right)^{-0.54}
$$

From the figure below, it can be recognized that the deviation of the amended friction factor from the conventional correlation is higher at a lower Reynolds number. At a higher Reynolds; however, the data seems to be gradually going to collapse and follow the conventional relation. This departure occurs due to the higher oil viscosity at a lower Reynolds number. This can be easily recognized from equation 3.28, which shows that the friction factor is inversely proportional to Reynolds number.

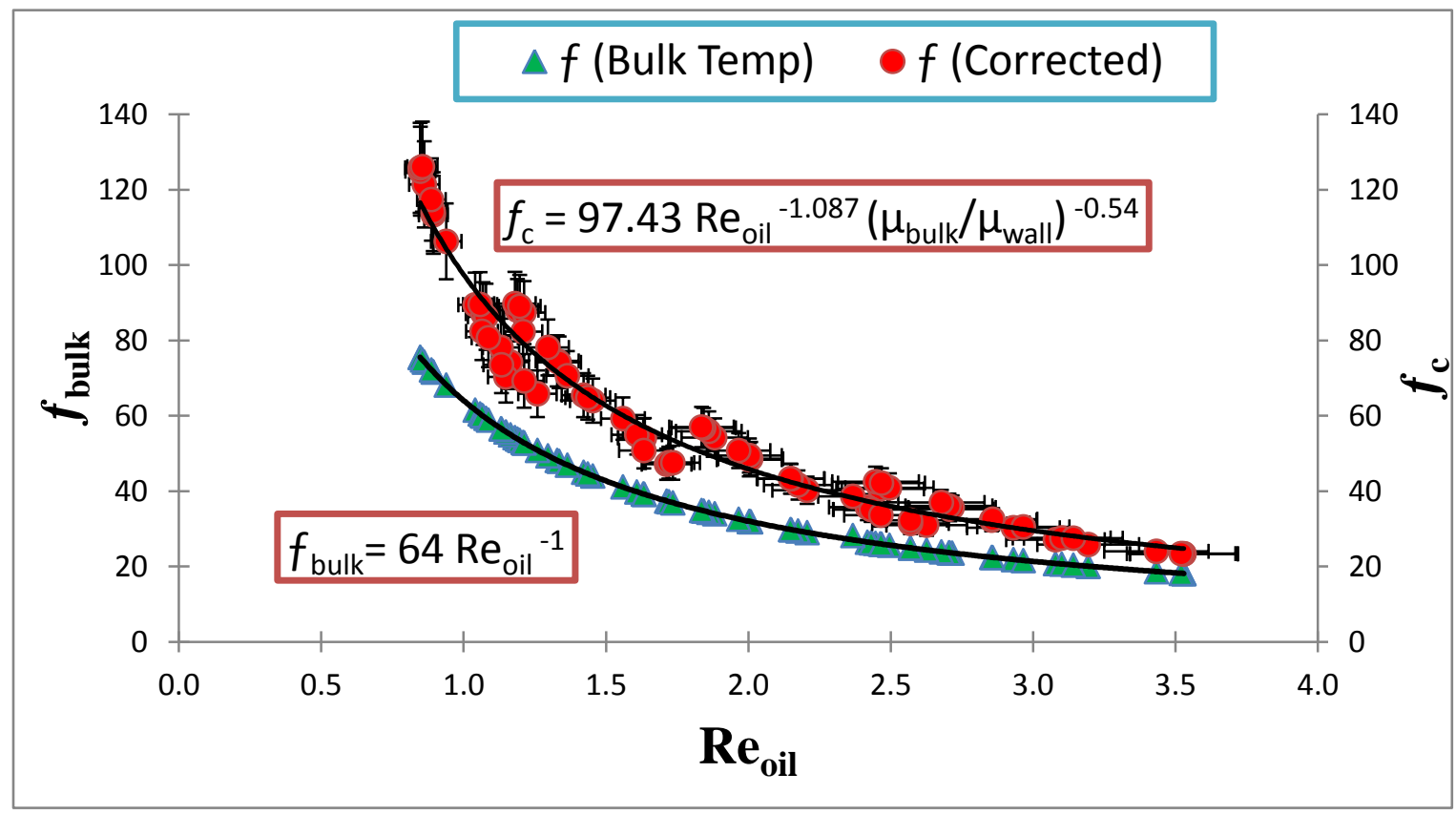

Figure 5.22: Friction Factor Vs Oil Reynolds Number 


\subsection{Heat Exchanger Performance}

In this section, several performance parameters $(U A, N T U, \varepsilon)$ pertaining to the current prototype heat exchanger will be examined.

\section{$\underline{\text { 5.6.1 Overall Heat Exchanger Conductance (UA) }}$}

The Overall Heat Exchanger Conductance $(U A)$ value is the inverse of the total thermal resistance $\left(R_{\text {total }}\right)$ and is the measure of how well heat is dissipated via a heat exchanger. The $U A$ values based on experimentally measured parameters are computed using equation 3.35. The effect of motor oil Reynolds Number $\left(\mathrm{Re}_{\mathrm{oil}}\right)$ on $U A$ value is presented in Figure 5.23. The $U A$ values increase as $\mathrm{Re}_{\mathrm{oil}}$ increases regardless of the air operating conditions. The relationship between $U A-\mathrm{Re}_{\text {oil }}$ in the current study is best represented by polynomial curve fit for all air inlet temperatures. It is important to mention that the difference among each data point taking at a constant air inlet temperature is the oil flow rate; noting that each data point represents the averaged value of the four air velocities for that specific air inlet temperature.

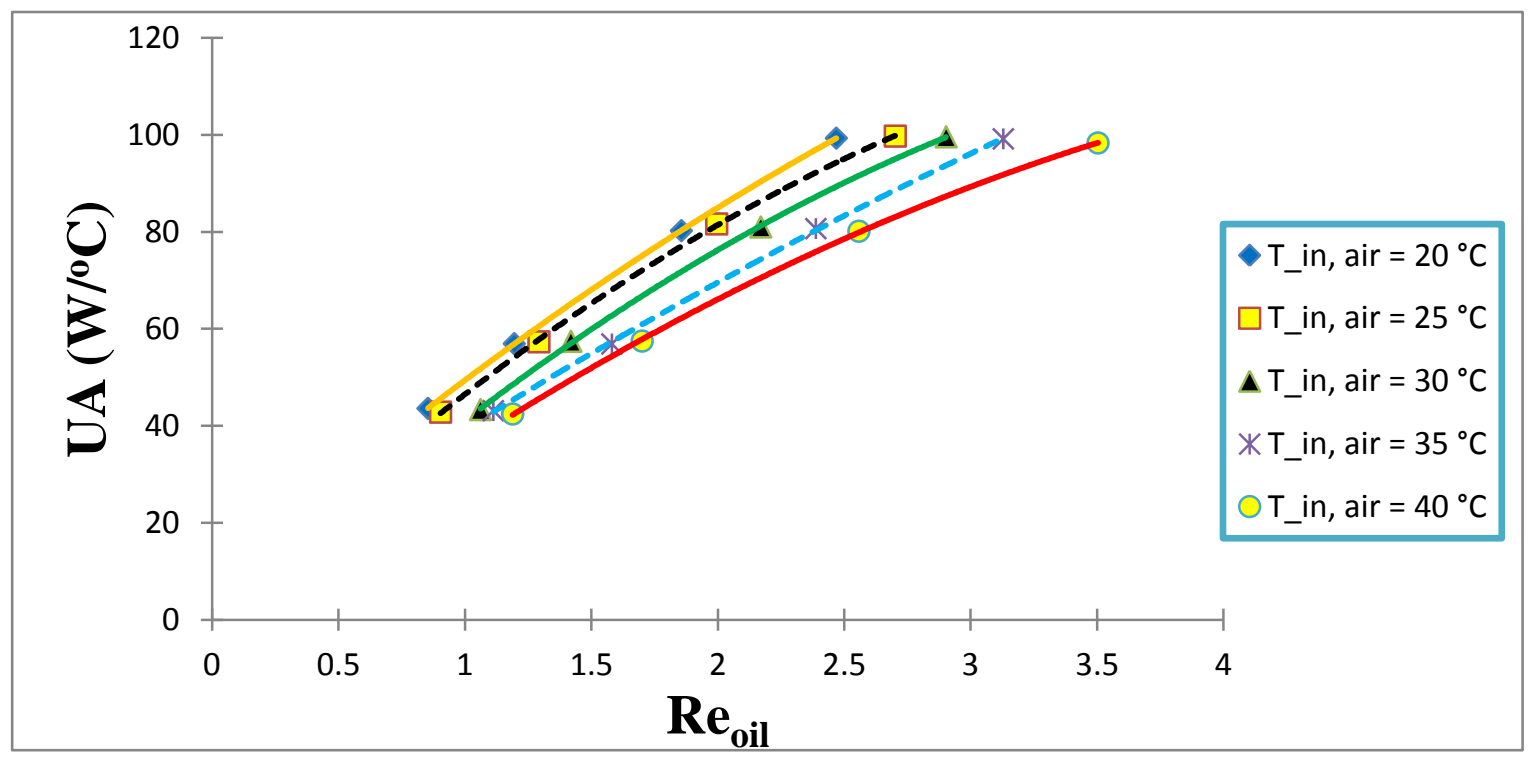

Figure 5.23: Overall Thermal Conductance Vs Oil Reynolds Number 
Abdul (2012) conducted a study on cooling ATF (Transmission Oil) using the same heat exchanger prototype for his M. A. Sc program, and he found similar slope trends when $U A$ values plotted against $\operatorname{Re}_{\mathrm{ATF}}$. In the current investigation, the overall conductance $(U A)$ value ranges $42<U A<99.7$. As the value of $U A$ gets higher, the total thermal resistance gets lower and thus heat transfer occurs faster.

\subsubsection{Number of Transfer Unit (NTU)}

From equation 3.40, it can be noted that Number of transfer units (NTU) is proportional to the heat transfer surface area of the heat exchanger $\left(A_{s}\right)$. Therefore, for a given values of $U$ and $C_{\min }$, the value of $N T U$ is a measure of the heat transfer surface area. Figure 5.24 shows the obtained values of $N T U$ for all operating conditions data points slowly decreases with increasing $R e_{\text {oil }}$ in a power-law correlation as:

$$
N T U=4.29 \operatorname{Re}_{\text {oil }}{ }^{-0.186}
$$

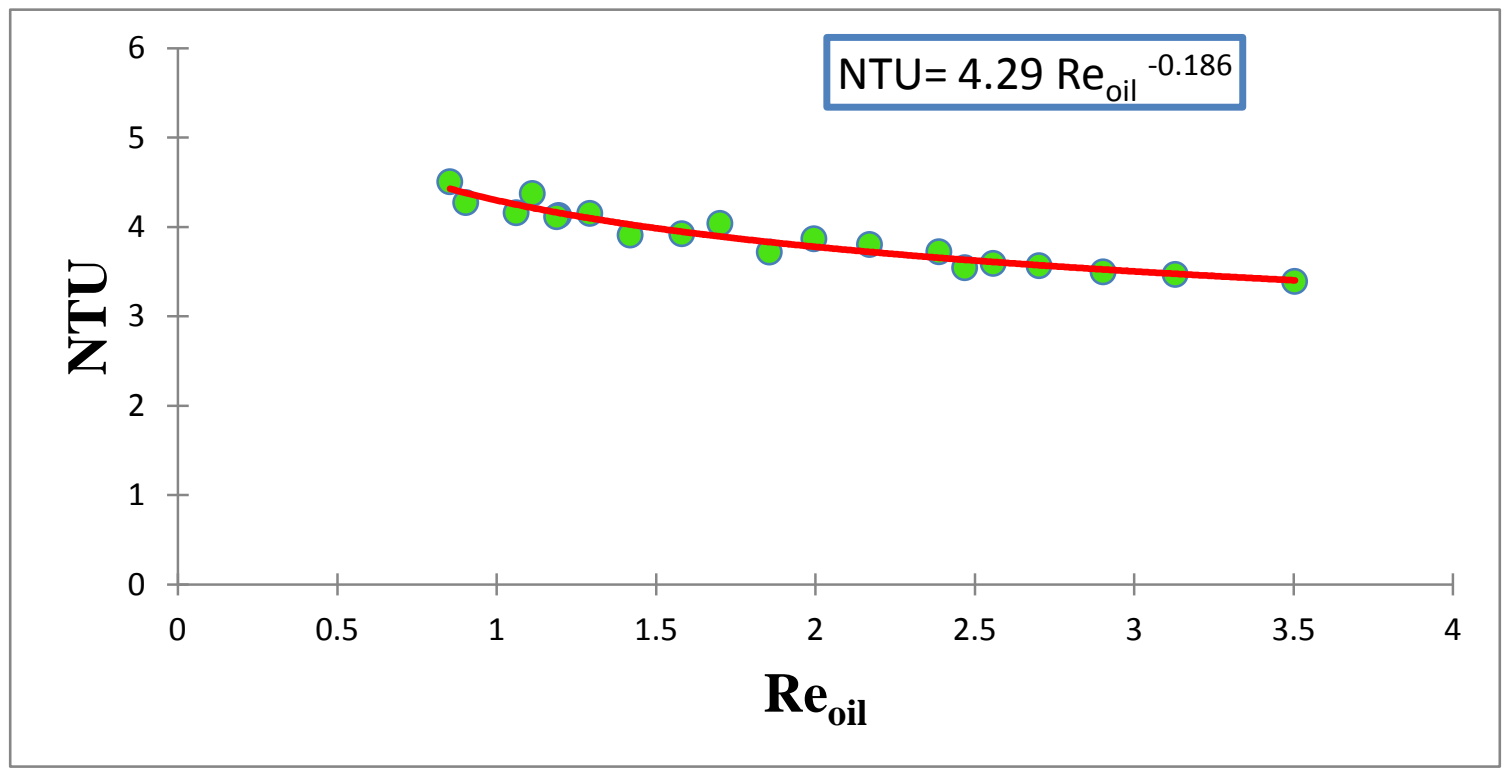

Figure 5.24: NTU Vs Oil Reynolds Number 
As stated and documented by several investigations, for a given $N T U$ value, the effectiveness of heat exchanger gets the highest value when $C^{*}=0$ and lowest when $C^{*}$ $=1$ [Çengel (2007)]. In the present study, $C^{*}$ ranges from $0.006-0.062$, which is virtually zero. Thus, the current heat exchanger for cooling motor at the stated operating condition is supposed to give the highest possible effectiveness. The $\varepsilon-N T U$ relation is drawn in Figure 5.25 and the best curve fit is found to be power-law curve.

As can be seen from the figure below, the effectiveness increases at a snail's pace compared to the increment occurred in NTU value for a particular air inlet temperature. This indicates that there is no need to enlarge the heat exchanger surface area (i.e. size) in order to get a higher effectiveness as NTU values in the current study (NTU > 3) are not desirable from an economic point of view [Çengel (2007)].

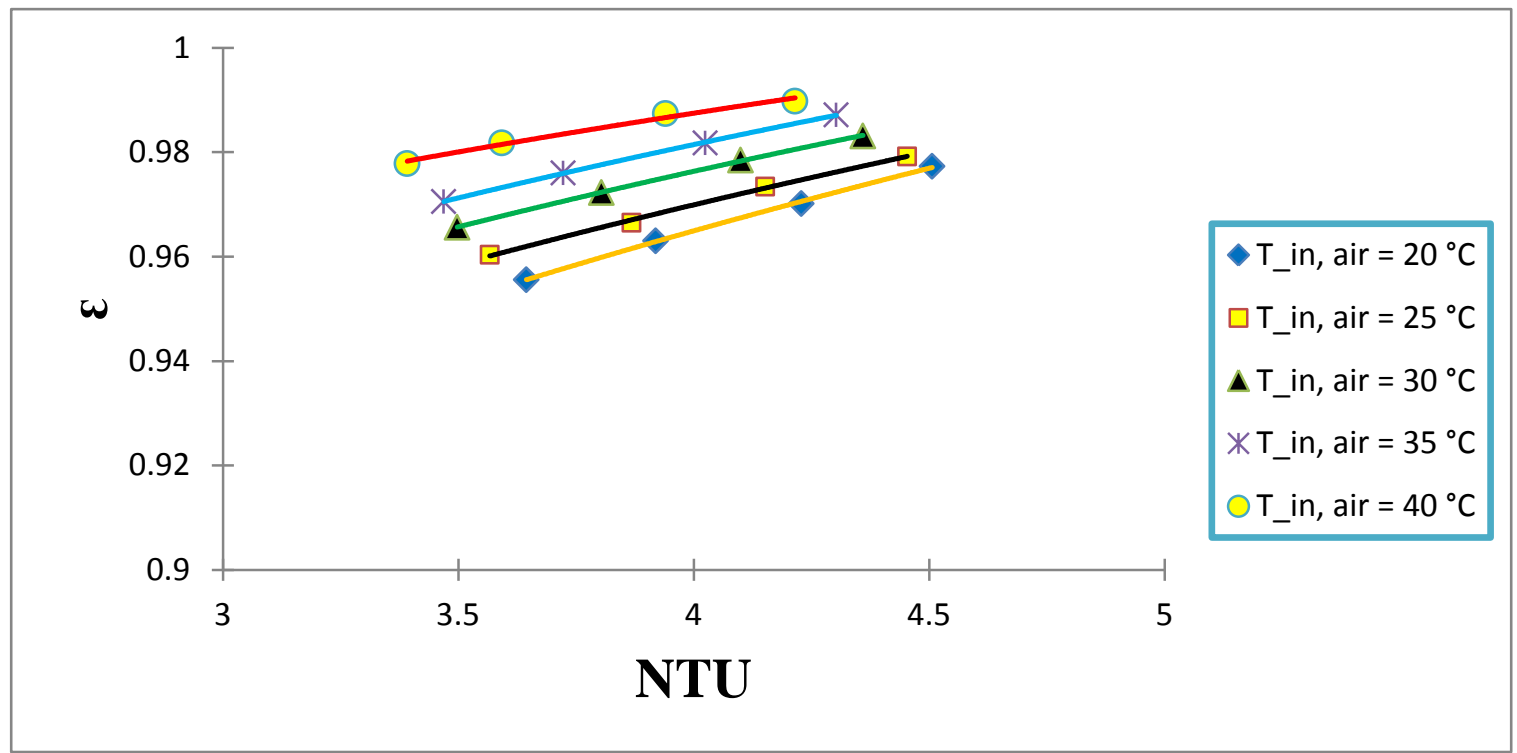

Figure 5.25: Effectiveness Vs NTU 


\subsubsection{Heat Exchanger Effectiveness $(\varepsilon)$}

The effectiveness of the prototype heat exchanger is determined using equation 3.41. Figure 5.26 presents the effect of oil Reynolds number $\left(\mathrm{Re}_{\mathrm{oil}}\right)$ on the effectiveness. As can be noticed, the $\varepsilon$ decreases with the increase of $\mathrm{Re}_{\mathrm{oil}}$ for the all five air inlet temperatures conditions. For a given $\mathrm{Re}_{\mathrm{oil}}$, the effectiveness is seen to be greater with an increase in air inlet temperature. This can be illustrated from equation 3.42, if air inlet temperature $\left(T_{\text {air }, \text { in }}\right)$ is high, that will lead to a lower $\dot{Q}_{\text {maximum }}$ which is inversely proportional to the effectiveness. The correlations between $\mathrm{Re}_{\mathrm{oil}}$ and $\varepsilon$ in the present study are found to be in power-law curve fit with negative exponents.

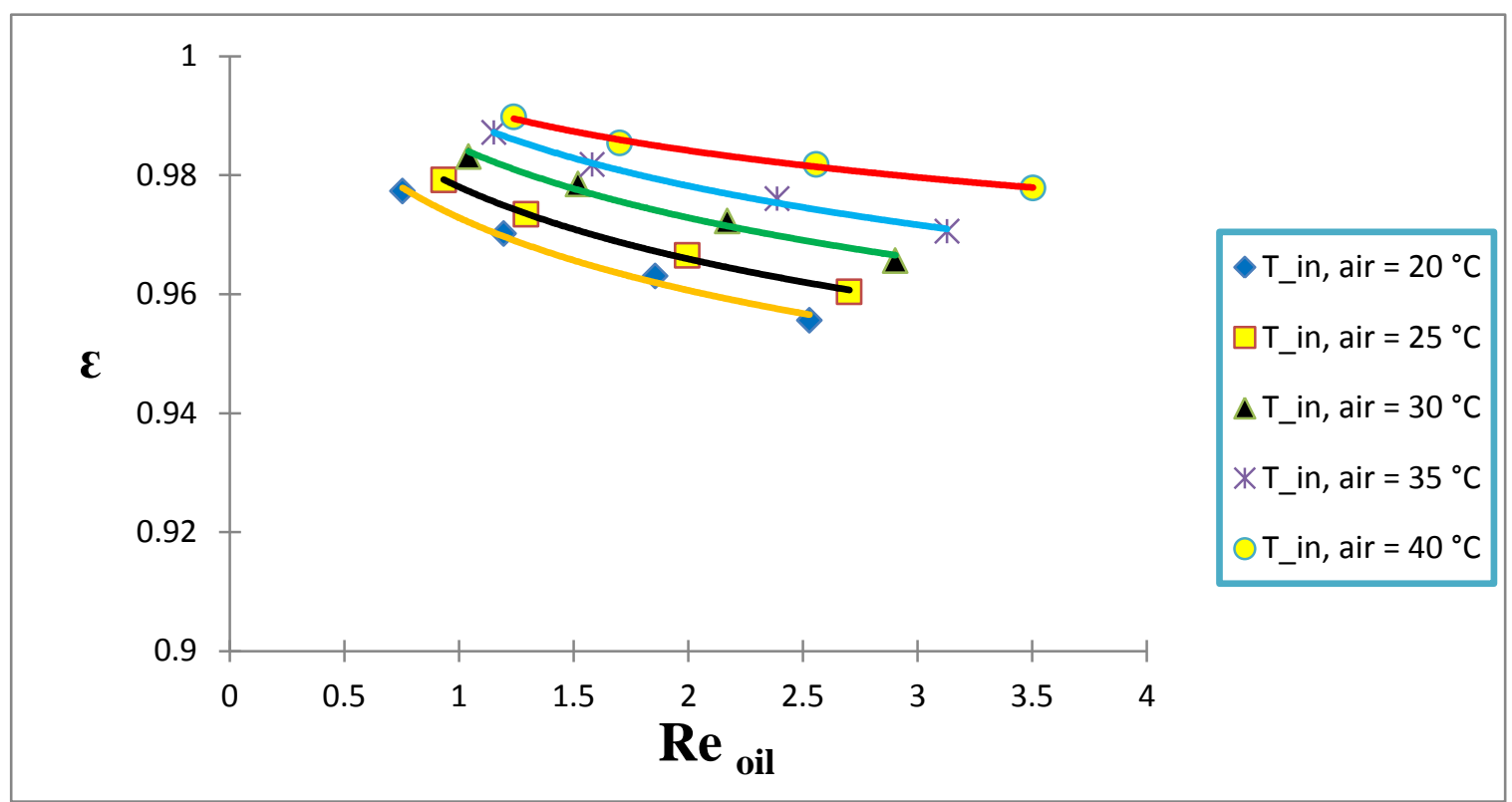

Figure 5.26: Effectiveness Vs Oil Reynolds Number 


\section{CHAPTER VI}

\section{CONCLUSIONS AND RECOMMENDATIONS}

\subsection{Summary and Conclusion}

The main purpose of the present study is to verify the applicability of cooling motor oil via the prototype minichannel heat exchanger. Thus, an experimental study is performed to investigate motor oil fluid flow and heat transfer characteristics inside the minichannels. The oil is forced to flow through an air-cooled type heat exchanger in a cross-flow arrangement, while air passes by through wavy fins. The prototype heat exchanger test specimen is mounted inside a test chamber, which is fitted to a close loop wind tunnel. The investigation of the air side of the prototype heat exchanger test specimen is out of the scope of the current study.

Focal parameters to assess the fluid flow behaviors such as Reynolds number $(R e)$, pressure drop $(\Delta \mathrm{P})$, and friction factor $(f)$ are closely examined. In order to evaluate the heat transfer characteristics, heat transfer rates $(\dot{Q})$, heat transfer coefficient $(h)$, Nusselt number $(\mathrm{Nu})$, and axial heat conduction parameter $(M)$ are carefully scrutinized. In addition, some parameters like overall conductance $(U A)$, number of transfer units $(N T U)$, and effectiveness $(\varepsilon)$ are determined to analyze the thermal performance of the prototype heat exchanger test specimen when it is utilized to extract the heat from a highly viscous working fluid, such as motor oil. Empirical correlations are developed and generated among the above parameters. 
To successfully achieve the aforementioned objectives, eighty (80) distinct experimental operating conditions are conducted. The motor oil inlet temperature remained constant at $75^{\circ} \mathrm{C}$ during all experimental runs; whereas the air side inlet temperature was set at 20 , $25,30,35$, and $40{ }^{\circ} \mathrm{C}$. Pertaining to the mass flow rate of the two fluids, oil mass flow rates are adjusted to four values, yielding Reynolds number of $0.85<\operatorname{Re}_{\mathrm{oil}}<3.5$. For every oil flow rate, air velocities are changed four times $6,10,14,18 \mathrm{~m} / \mathrm{s}$.

The characteristics of fluid flow and heat transfer behaviors of the test working fluid (i.e. motor oil) as well as the evaluation of thermal performance of the heat exchanger test specimen are often presented in dimensionless forms and correlations. The outcomes and observations of the current investigation are listed as follows:

1) The range of the air velocity was too narrow to have a major impact in the heat transfer mechanism.

2) Changing the air inlet temperature affects several oil side heat transfer parameters as well as a number of fluid flow characteristics.

3) The calculated heat balance (HB) values of all operating conditions are within \pm 8.8\%. As recommended by the ASME PTC, the acceptable limit of the heat balance of any system has to be with \pm 15 .

4) Oil heat transfer rate $\left(\dot{Q}_{o i l}\right)$ and log mean temperature difference $\left(\Delta T_{L M T D}\right)$ are highly dependent on oil Reynolds number $\left(R e_{o i l}\right)$. Both $\left(\dot{Q}_{\text {oil }}\right)$ and $\left(\Delta T_{L M T D}\right)$ 
increase with an increase of Reynolds number of oil in power-law correlations. However, their values decrease as $T_{a i r, i n}$ increases for a particular $R e_{o i l}$.

5) Oil convective heat transfer coefficient $\left(h_{\text {oil }}\right)$ is found to be best represented with Péclet number $\left(P e_{o i l}\right)$. The reason for selecting Pe instead of Reynolds number is due to the viscosity contribution is not being included in the value of Pe. For the same oil mass flow rate, all the 20 different operating conditions are collapsed in one point. The correlation between $h_{\text {oil }}$ and $P e_{o i l}$ is linear with power-law mode.

$$
h_{\text {oil }}=0.04 P e_{o i l}^{1.052}
$$

6) The core correlation between the fluid flow and heat transfer is characterized in Nusselt, Reynolds, and Prandtl numbers. The correlation is as follows:

$$
N u_{o i l, b}=0.03 \operatorname{Re}_{\text {oil }}^{1.001} \operatorname{Pr}_{\text {oil }}^{1 / 3}
$$

The Nusselt number is corrected with the variable property ratio and the correlation is as follows:

$$
N u_{o i l, c}=0.03 \operatorname{Re}_{o i l}^{1.023} \operatorname{Pr}_{\text {oil }}^{1 / 3}\left(\frac{\mu_{\text {bulk }}}{\mu_{\text {wall }}}\right)^{0.14}
$$

7) The effect of the axial heat conduction in the channel wall on the convective heat transfer can clearly be observed when the oil Nusselt number $\left(N u_{o i l, c}\right)$ is plotted against the axial heat conduction parameter (M). The correlation is best fitted with a power law curve with negative exponent:

$$
N u_{o i l, c}=0.0043 M^{-1.057}
$$

The relationship between the wall axial heat conduction, the fluid flow, and the fluid thermo-physical properties is shown when the heat conduction parameter is 
drawn against the Péclet number. All the 80 data sets perfectly conform to the power law curve with a negative exponent:

$$
M=\frac{14.21}{P e_{\text {oil }}}
$$

8) Viscous dissipation phenomenon is investigated in this work. The presence of this phenomenon can be verified by calculating the Brinkman number. Even though the calculated values of Brinkman number are small, it shows that the viscous dissipation affects the convective heat transfer even for a low oil flow rate. The generated empirical correlation in the current study is as follows:

$$
N u_{o i l, c}=49.5 \mathrm{Br}_{o i l}^{0.52}
$$

9) As expected, the pressure drop inside the minichannel is relatively high compared to the conventional size channel. The oil pressure drop increases as $R e_{\text {oil }}$ increases in power-law trend. Moreover, the air inlet temperature seems to engage in determining the amount of pressure drop from the inlet and outlet of the channel. As demonstrated before, a higher air inlet temperature results in a lower pressure drop occurs in the channel. This is due to the viscosity of oil, which is lower at higher oil bulk temperature.

10) The relationship between the friction factor and Reynolds number matches the conventional formula when the friction factor is computed based on the constant properties.

$$
f_{\text {bulk }}=\frac{64}{R e_{\text {oil }}}
$$


While when the variable property ratio is imposed, the values of the friction factor diverge from the traditional formula, and the new correlation found is:

$$
f_{\mathrm{c}}=97.43 \operatorname{Re}_{\text {oil }}^{-1.087}\left(\mu_{\text {bulk }} / \mu_{\text {wall }}\right)^{-0.54}
$$

11) The thermal performance of the prototype heat exchanger test specimen is analyzed by the following parameters:

a) Overall conductance (UA):

The UA-value as a function of oil Reynolds number is observed to be higher at higher $R e_{\text {oil }}$ in polynomial correlation as expected.

b) Number of transfer units (NTU):

With $\mathrm{C}^{*} \approx 0$ calculated in current investigation, the values of NTU range from 3.33 to 4.5 . Hence, the prototype heat exchanger may be considered large. The NTU values are found to decrease with the increase in $\mathrm{Re}_{\text {oil }}$. The relation is as follows:

$$
N T U=4.29 \operatorname{Re}_{o i l}{ }^{-0.186}
$$

c) Heat exchanger effectiveness $(\varepsilon)$ :

The correlation between the effectiveness and $R e_{o i l}$ is seen to be highly dependent on the air inlet temperature. For a given $R e_{o i l}$, the effectiveness decreases while decreasing the inlet temperature of air.

This investigation presents a number of empirical relationships that correlate fluid flow and heat transfer characteristics of motor oil when it is cooled via minichannel heat exchanger. These correlations let also examine the thermal performance of the prototype heat exchanger test specimen. Due to the insufficient information in the literature concerning the behavior of the motor oil inside the minichannels, the present study 
cannot be exactly compared to other works. As such, the aforementioned correlations and findings might be of an interest for the upcoming researchers.

\section{$\underline{6.2 \text { Recommendations }}$}

A wide range of experimental operating conditions were conducted to obtain and highlight the different scenarios of the test specimen performance. Still, a broader variety in working fluids mass flow rates and inlet temperatures would have been better to attain and spot the optimum thermal performance of the tested minichannel heat exchanger. There were various limitations in the current study which limited the accuracy in calculating several heat transfer phenomena and fluid flow parameters. Therefore, a number of suggestions are listed below in order to accomplish more useful and precise findings.

- Substituting the current liquid side gear pump with a higher differential pressure to have high mass flow rate inside the minichannels, especially if the working fluid is a highly viscous. By doing so, the comparison with a practical situation can be feasible to some extent.

- Utilizing a higher capacity heater in order to achieve high liquid inlet temperature.

This would allow to simulate more realistic conditions in order to acquire a superior heat transfer rate.

- Replacing the existing blower motor with a more powerful one to obtain a greater range of air velocity inside the windtunnel. 
Study of Motor Oil Cooling at Low Reynolds Number in Multi-Port Narrow Channels

- With having a higher mass flow rate inside the channel, a constant heat flux boundary conditions proper permits to measure, not to quantify, the amount of heat added to the fluid due to viscous dissipation. 


\section{APPENDICES}

\section{APPENDIX (A) DIMENSIONAL ANALYSIS}

Dimensional analysis is an analytical method which employs the study of the dimensions for solving numerous engineering problems. It can help to comprehend, to a certain extent, that physical problems of very different sizes and dimensions have a common background and that it is only our human way to think our macro world sets the standards from which problems in other dimensions deviate [Herwig (2002)]. It is of use in displaying experimental results in a brief and short form.

One of the usages of dimensional analysis for a physical phenomenon is to develop correlations and equations expressed in terms of dimensionless parameters. As such, dimensional analysis is proposed to verify the applicability of the dimensionless numbers used in the current investigation. From the several methods of dimensional analysis, the Buckingham's $\pi$-method/theorem is performed below.

For a fully developed forced convection laminar flow in conventionally-sized channels, heat transfer coefficient $(h)$ depends on thermal conductivity $(k)$ and hydraulic diameter $\left(D_{h}\right)$ [Tso and Mahulikar (1998)]. For narrow channels, several investigations have revealed that h depends also on Reynolds number, and thus on density $(\rho)$, velocity $\left(V_{\text {avg }}\right)$, and viscosity $(\mu)$. Moreover, $h$ relies on fluid properties, local wall and fluid temperatures. Hence, the general relationship that includes all pertinent parameters can be written as: 


$$
\begin{gathered}
h=f\left(k, \rho, V_{a v g}, D_{h}, \mu, c p, \Delta T\right) \\
f\left(h, k, \rho, V_{a v g}, D_{h}, \mu, c p, \Delta T\right)=0
\end{gathered}
$$

So, the number of the dimensional parameters is 8 (i.e. $n=8$ ). The primary dimensions of these parameters are $\mathrm{M}$ for mass, $\mathrm{L}$ for length, $\mathrm{t}$ for time, and $\mathrm{T}$ for temperature (i.e. $\mathrm{r}=$ 4). The dimensions of the 8 parameters in terms of primary dimensions are as follows:

$$
\begin{array}{llr}
h=\frac{M}{T \cdot t^{3}} & , & k=\frac{M \cdot L}{T \cdot t^{3}} \\
\rho=\frac{M}{L^{3}} & V_{\text {avg }}=\frac{L}{t} \\
D_{h}=L & \quad \mu=\frac{M}{L \cdot t} \\
c_{p}=\frac{L^{2}}{T \cdot t^{2}} \quad, & \Delta T=T
\end{array}
$$

Since there are eight parameters and four primary dimensions, the Buckingham $\prod$ theorem expects having four independent dimensionless groups, $\prod_{1}, \prod_{2}, \prod_{3}, \prod_{4}$ Fox et al. (2004). Hence, equation (ii) can be written as

$$
f\left(\prod_{1}, \Pi_{2}, \Pi_{3}, \Pi_{4}\right)=0
$$

Since the repeating parameters (A) must contain jointly all of the primary dimensions involved in the phenomenon and (B) should not include the dependent parameter (i.e. $h$ ), $\rho, V_{a v g}, D_{h}$, and $\Delta T$ have been selected to be the repeating parameters. By setting up the dimensional equations, the following can be obtained:

$$
\begin{aligned}
& \prod_{l}=\rho^{a} V_{\text {avg }}^{b} D_{h}^{c} \Delta T^{d}(h) \\
& \prod_{2}=\rho^{a} V_{\text {avg }}^{b} D_{h}^{c} \Delta T^{d}(k) \\
& \prod_{3}=\rho^{a} V_{\text {avg }}^{b} D_{h}^{c} \Delta T^{d}(\mu) \\
& \prod_{4}=\rho^{a} V_{\text {avg }}^{b} D_{h}^{c} \Delta T^{d}\left(c_{p}\right)
\end{aligned}
$$


Considering each $\prod$-term at a time:

$$
\begin{gathered}
\prod_{\boldsymbol{l}}=\boldsymbol{\rho}^{\boldsymbol{a}} \boldsymbol{V}_{\boldsymbol{a} \boldsymbol{v} \boldsymbol{g}}^{\boldsymbol{b}} \boldsymbol{D}_{\boldsymbol{h}}^{\boldsymbol{c}} \Delta \boldsymbol{T}^{\boldsymbol{d}}(\boldsymbol{h}) \\
\left(\frac{M}{L^{3}}\right)^{a}\left(\frac{L}{t}\right)^{b}(L)^{c}(T)^{d}\left(\frac{M}{T \cdot t^{3}}\right)=M^{0} L^{0} t^{0} T^{0}
\end{gathered}
$$

Equating the exponents of M, L, t, and T:
M: $\quad a+1=0$

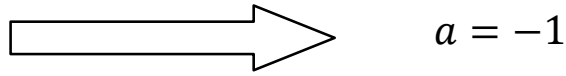
$\mathrm{L}: \quad-3 a+b+c=0$

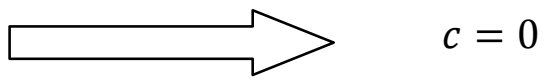
$\mathrm{t}: \quad-b-3=0$
$b=-3$
$\mathrm{T}: \quad d-1=0$

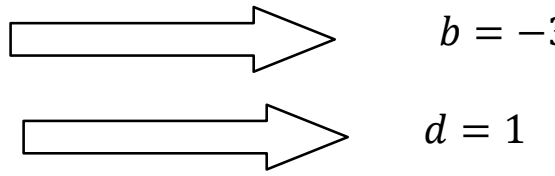

Therefore, substituting the values in (A), the following is obtained:

$$
\begin{gathered}
\prod_{1}=\rho^{-1} V_{\text {avg }}^{-3} D_{h}^{0} \Delta T^{1}(h) \\
\prod_{l}=\frac{h \Delta T}{\rho V_{\text {avg }}^{3}} \\
\prod_{2}=\boldsymbol{\rho}^{\boldsymbol{a}} \boldsymbol{V}_{\boldsymbol{a} \boldsymbol{b} \boldsymbol{g}}^{\boldsymbol{b}} \boldsymbol{D}_{\boldsymbol{h}}^{\boldsymbol{c}} \Delta \boldsymbol{T}^{\boldsymbol{d}}(\boldsymbol{k}) \\
\left(\frac{M}{L^{3}}\right)^{a}\left(\frac{L}{t}\right)^{b}(L)^{c}(T)^{d}\left(\frac{M \cdot L}{T \cdot t^{3}}\right)=M^{0} L^{0} t^{0} T^{0}
\end{gathered}
$$

Equating the exponents of $\mathrm{M}, \mathrm{L}, \mathrm{t}$, and $\mathrm{T}$ :
M: $\quad a+1=0$
$\mathrm{L}: \quad-3 a+b+c+1=0$
$\mathrm{t}: \quad-b-3=0$
$\mathrm{T}: \quad d-1=0$
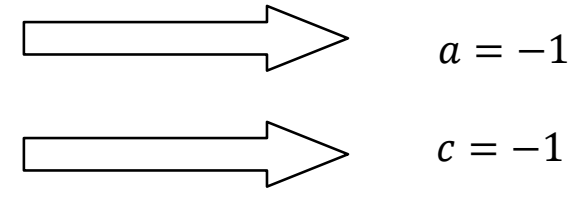

$c=-1$

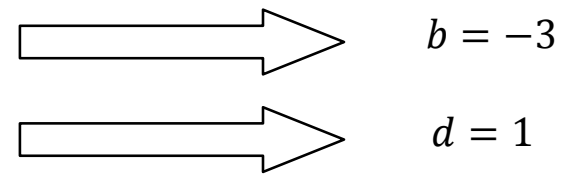

Therefore, substituting the values in (B), the following is obtained 


$$
\begin{gathered}
\prod_{2}=\rho^{-1} V_{\text {avg }}^{-3} D_{h}^{-1} \Delta T^{1}(k) \\
\prod_{2}=\frac{k \Delta T}{\rho V_{\text {avg }}^{3} D_{h}} \\
\prod_{3}=\boldsymbol{\rho}^{\boldsymbol{a}} \boldsymbol{V}_{\boldsymbol{a} \boldsymbol{g} \boldsymbol{g}}^{\boldsymbol{b}} \boldsymbol{D}_{\boldsymbol{h}}^{\boldsymbol{c}} \Delta \boldsymbol{T}^{\boldsymbol{d}}(\boldsymbol{\mu}) \\
\left(\frac{M}{L^{3}}\right)^{a}\left(\frac{L}{t}\right)^{b}(L)^{c}(T)^{d}\left(\frac{M}{L \cdot t}\right)=M^{0} L^{0} t^{0} T^{0}
\end{gathered}
$$

Equating the exponents of $\mathrm{M}, \mathrm{L}, \mathrm{t}$, and $\mathrm{T}$ :

$$
\begin{array}{ll}
\mathrm{M}: & a+1=0 \\
\mathrm{~L}: & -3 a+b+c-1=0 \\
\mathrm{t}: & -b-1=0 \\
\mathrm{~T}: & d=0
\end{array}
$$$$
\longrightarrow a=-1
$$$$
\longrightarrow c=-1
$$

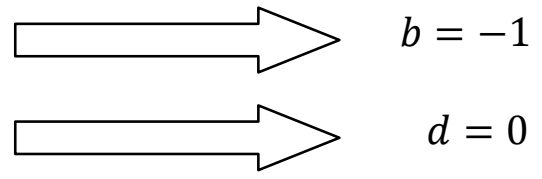

Therefore, substituting the values in $(\mathrm{C})$, the following is obtained

$$
\begin{gathered}
\prod_{3}=\rho^{-1} V_{\text {avg }}^{-1} D_{h}^{-1} \Delta T^{0}(\mu) \\
\prod_{3}=\frac{\mu}{\rho V_{\text {avg }} D_{h}} \\
\prod_{4}=\boldsymbol{\rho}^{\boldsymbol{a}} \boldsymbol{V}_{\boldsymbol{a v} \boldsymbol{g}}^{\boldsymbol{b}} \boldsymbol{D}_{\boldsymbol{h}}^{\boldsymbol{c}} \Delta \boldsymbol{T}^{\boldsymbol{d}}\left(\boldsymbol{c}_{\boldsymbol{p}}\right) \\
\left(\frac{M}{L^{3}}\right)^{a}\left(\frac{L}{t}\right)^{b}(L)^{c}(T)^{d}\left(\frac{L^{2}}{T \cdot t^{2}}\right)=M^{0} L^{0} t^{0} T^{0}
\end{gathered}
$$

Equating the exponents of $\mathrm{M}, \mathrm{L}, \mathrm{t}$, and $\mathrm{T}$ :
M: $\quad a=0$
$a=0$
$\mathrm{L}: \quad-3 a+b+c+2=0$
$c=0$
$\mathrm{t}: \quad-b-2=0$
$b=-2$ 
$\mathrm{T}: \quad d-1=0$

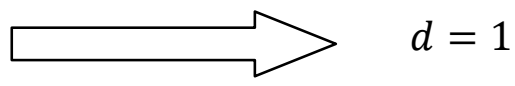

Therefore, substituting the values in (D), the following is obtained

$$
\begin{gathered}
\prod_{4}=\rho^{0} V_{\text {avg }}^{-2} D_{h}^{0} \Delta T^{1}\left(c_{p}\right) \\
\prod_{4}=\frac{c_{p} \cdot \Delta T}{V_{\text {avg }}^{2}}
\end{gathered}
$$

The four dimensionless groups are:

$$
\begin{gathered}
\prod_{l}=\frac{h \Delta T}{\rho V_{\text {avg }}^{3}} \\
\prod_{2}=\frac{k \Delta T}{\rho V_{\text {avg }}^{3} D_{h}} \\
\prod_{3}=\frac{\mu}{\rho V_{\text {avg }} D_{h}} \\
\prod_{4}=\frac{c_{p} \cdot \Delta T}{V_{\text {avg }}^{2}}
\end{gathered}
$$

As can be discerned, the inverse of $\prod_{3}$ and $\prod_{4}$ are Reynolds and Eckert numbers, respectively. That is:

$$
\begin{aligned}
& \prod_{3}=\frac{\mu}{\rho V_{\text {avg }} D_{h}} \quad R e=\frac{\rho V_{\text {avg }} D_{h}}{\mu} \\
& \prod_{4}=\frac{c_{p} \cdot \Delta T}{V_{\text {avg }}^{2}}
\end{aligned}
$$

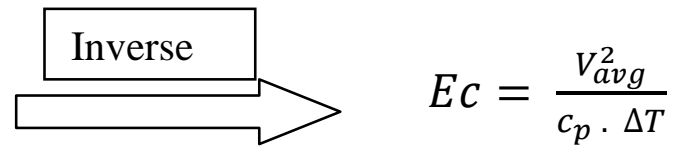

Moreover, dividing $\prod_{1}$ over $\prod_{2}$ yields the dimensionless heat transfer coefficient, which is Nusselt number. 


$$
\prod_{l} / \prod_{2}=N u=\frac{\frac{h \Delta T}{\rho V_{a v g}^{3}}}{\frac{k \Delta T}{\rho V_{a v g}^{3} D_{h}}}=\frac{h \Delta T}{\rho V_{a v g}^{3}} \cdot \frac{\rho V_{a v g}^{3} D_{h}}{k \Delta T}=\frac{h D_{h}}{k}
$$

Finally, $\prod_{2}, \prod_{3}$, and $\prod_{4}$ obtained from the above dimensional analysis can be re-grouped to form Prandtl number as following:

$$
\left(\prod_{3} . \prod_{4}\right) / \prod_{2}=\operatorname{Pr}=\frac{\frac{\mu}{\rho V_{\text {avg }} D_{h}} \cdot \frac{c_{p} \cdot \Delta T}{V_{\text {avg }}^{2}}}{\frac{k \Delta T}{\rho V_{\text {avg }}^{3} D_{h}}}=\frac{\mu}{\rho V_{\text {avg }} D_{h}} \cdot \frac{c_{p} \cdot \Delta T}{V_{\text {avg }}^{z}} \cdot \frac{\rho V_{\text {avg }}^{3} D_{h}}{k \Delta T}=\frac{\mu c_{p}}{k}
$$




\section{APPENDIX (B) UNCERTAINTY ANALYSIS}

In the present investigation, a significant number of data was gathered and computed. A several devices and instruments were utilized to determine the working fluids operating conditions. In addition, a plethora of formulae and equations were employed to characterize the oil fluid flow and heat transfer behaviors inside the minichannels. During performing an experimental study, there are possibilities in getting errors, either due to a human or an instrument. These errors, consequently, impact the credibility and reliability of the study. The execution of the uncertainty analysis allows estimating the deviation from the actual and supposed values. Previous uncertainty analyses performed on narrow channels have revealed that lower Reynolds Number tends to exhibit large uncertainties due to the errors associated with flow rate measurements. Smaller diameter channels have also been found to have higher overall uncertainty values due to the relative difficulty in measuring [Kandlikar and King (2006)].

In general, the types of parameters need to be considered in any uncertainty analysis can be safely divided into: independent and dependent parameters. Independent parameters are the measured values from specific instruments (RTD, PTD, thermocouples....etc) or from tools to determine the basic geometrical dimensions (length, width...etc). On the other hand, the dependent parameters are calculated based on the uncertainty values of the independent parameters (mass flow rate, Reynolds number, heat transfer...etc). The values of the independent parameters in the current study are recorded by the data 
acquisition system (DAQ). Whereas, the dependent ones are found and based on their respective formulae, which literally consist of the independent parameters.

\section{B.1 Uncertainty Analysis of Independent Parameters}

The errors of independent parameters are usually provided by the manufacturers. The errors are classified to be either bias or precision. The bias error includes the linearity, hysteresis, and accuracy. This type of error can be computed by utilizing the Root Sum Square (RSS) method as follows:

$$
B= \pm \sqrt{{B_{1}{ }^{2}+B_{2}{ }^{2}+\cdots+B_{n}{ }^{2}}^{2}}
$$

The precision error, which basically account for the repeatability, is computed as follows:

$$
P= \pm \sqrt{P_{1}^{2}+P_{2}^{2}+\cdots+P_{n}^{2}}
$$

The combined error generated from the independent parameters is calculated from the following equation:

$$
U= \pm \sqrt{B^{2}+P^{2}}
$$

\section{B.1.1 Uncertainties of Oil Inlet and Outlet Temperatures}

To determine the values of the inlet and outlet oil temperatures, RTDs are utilized in current study. The evaluation of their uncertainties has to include the errors given by the manufacturer (Omega). From the data obtained and the readings of the RTDs, their uncertainties can be computed as follows [Siddiqui (2011)]:

$$
U_{T, o i l}= \pm \sqrt{\begin{array}{c}
{\left[\frac{6.033 \times 10^{-6} V}{3.908 \times 10^{-5}-1.16038 \times 10^{-8}|T|}\right]^{2}+\left[\frac{1}{10}(0.3+0.005|T|)\right]^{2}} \\
+\left[1.96 \frac{S_{R T D, T}}{\sqrt{N}}\right]^{2}
\end{array}}
$$




\section{B.1.2 Uncertainties of Some Key Geometrical Parameters}

The uncertainties in the geometrical parameters of the current heat exchanger test specimen uncertainties have already been computed by Siddiqui (2011).

Table B.1: Uncertainties Values for Geometrical Parameters

\begin{tabular}{|c|c|c|}
\hline Description & Mean Value & Uncertainty (\%) \\
\hline Minichannel Hydraulic Diameter, $\left(D_{h}\right)$ & $0.001 \mathrm{~m}$ & \pm 3.48 \\
\hline Total Inner Heat Transfer Surface Area of all \\
minichannels, $\left(A_{s, \text { oil side }}\right)$ & $0.975 \mathrm{~m}$ & \pm 3.49 \\
\hline $\begin{array}{c}\text { Combined Cross-Sectional area of all } \\
\text { minichannels }\left(A_{c s, \text { oil }}\right)\end{array}$ & $1.60 \times 10^{-4} \mathrm{~m}^{2}$ & \pm 6.96 \\
\hline Frontal Area of the Minichannel Heat & $0.08748 \mathrm{~m}^{2}$ & \pm 0.29 \\
\hline Exchanger $\left(A_{\text {frontal }}\right)$ & & \pm 0.15 \\
\hline Individual Channel Length in One Slab $(L)$ & $0.304 \mathrm{~m}$ & \\
\hline
\end{tabular}

\section{B.2 Uncertainty Analysis of Dependent Parameters}

The uncertainty of the dependent parameters is calculated by evaluating the uncertainty of each related dependent parameter. Then, the RSS method is applied:

$$
U_{Y}=\sqrt{\left(\frac{\partial Y}{\partial X_{1}} U_{X_{1}}\right)^{2}+\left(\frac{\partial Y}{\partial X_{2}} U_{X_{2}}\right)^{2}+\left(\frac{\partial Y}{\partial X_{3}} U_{X_{3}}\right)^{2}+\cdots+\left(\frac{\partial Y}{\partial X_{n}} U_{X_{n}}\right)^{2}}
$$

\section{B.2.1 Uncertainty Analysis of Thermo-Physical Properties}

Dynamic viscosity, specific heat, density, and thermal conductivity of motor oil are heavily utilized in current study. These properties are evaluated at the oil bulk 
temperature. Their uncertainties are usually calculated based on their values at the maximum and minimum bulk temperatures, as follow:

$$
U_{\text {fluid property }}= \pm\left[\frac{\text { fluid property } \text { at }_{\text {in }}-\text { fluid property }_{\text {at }} T_{\text {out }}}{T_{\text {in }}-T_{\text {out }}}\right]
$$

\section{B.2.2 Uncertainties of Oil Bulk Temperatures}

The bulk temperature of oil can be calculated from:

$$
T_{\text {oil }, \text { bulk }}=\frac{T_{\text {oil,in }}+T_{\text {oil }, \text { out }}}{2}
$$

And its uncertainty is as follows:

$$
\begin{aligned}
& T_{\text {oil,bulk }}= \pm \sqrt{\left(\frac{\partial T_{\text {oil }, \text { bulk }}}{\partial T_{\text {oil }, \text { in }}} U_{T_{\text {oil }, \text { in }}}\right)^{2}+\left(\frac{\partial T_{\text {oil }, \text { bulk }}}{\partial T_{\text {oil }, \text { out }}} U_{T_{\text {oil }, \text { out }}}\right)^{2}} \\
& \frac{\partial T_{o i l, b u l k}}{\partial T_{o i l, i n}}=\frac{1}{2}
\end{aligned}
$$

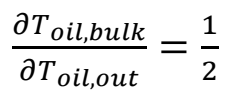

\section{B.2.3 Uncertainty of Oil Mass Flow Rate}

Oil mass flow rate can be found as follows:

$$
\begin{gathered}
\dot{m}_{o i l}=\dot{\forall}_{o i l} \rho_{o i l} \\
\frac{\partial \dot{m}_{o i l}}{\partial \rho_{\text {oil }}}=\dot{\forall}_{o i l} \\
\frac{\partial \dot{m}_{\text {oil }}}{\partial \dot{\forall}_{\text {oil }}}=\rho_{\text {oil }}
\end{gathered}
$$

The overall uncertainty of the oil mass flow rate is:

$$
U_{\dot{m}_{o i l}}= \pm \sqrt{\left[\frac{\partial \dot{m}_{o i l}}{\partial \rho_{o i l}} U_{\rho_{o i l}}\right]^{2}+\left[\frac{\partial \dot{m}_{o i l}}{\partial \dot{\forall}_{o i l}} U_{\dot{\forall}_{o i l}}\right]^{2}}
$$




\section{B.2.4 Uncertainty of Oil Mass Flux}

Mass flux can be calculated from the following:

$$
\begin{gathered}
G_{o i l}=\frac{\dot{m}_{o i l}}{A_{c s, o i l}} \\
\frac{\partial G_{o i l}}{\partial \dot{m}_{o i l}}=\frac{1}{A_{c s, o i l}} \\
\frac{\partial G_{o i l}}{\partial A_{c s, o i l}}=-\frac{\dot{m}_{o i l}}{A_{c s, o i l}^{2}}
\end{gathered}
$$

The total uncertainty associated with the oil mass velocity is calculated as,

$$
U_{G_{o i l}}= \pm \sqrt{\left[\frac{\partial G_{o i l}}{\partial \dot{m}_{o i l}} U_{\dot{m}_{o i l}}\right]^{2}+\left[\frac{\partial G_{o i l}}{\partial A_{c s, o i l}} U_{A_{c s, o i l}}\right]^{2}}
$$

\section{B.2.5 Uncertainty of Oil Velocity}

Oil velocity inside the minichannel can be calculated from the following:

$$
\begin{gathered}
V=\frac{\dot{m}_{o i l}}{51 \rho \pi D_{h}^{2}} \\
\frac{\partial V}{\partial \dot{m}_{o i l}}=\frac{1}{51 \rho \pi D_{h}^{2}} \\
\frac{\partial V}{\partial \rho}=-\frac{\dot{m}_{o i l}}{51 \rho^{2} \pi D_{h}^{2}} \\
\frac{\partial V}{\partial D_{h}}=-2\left[\frac{\dot{m}_{o i l}}{51 \rho \pi D_{h}^{3}}\right]
\end{gathered}
$$

The total uncertainty associated with the oil mass velocity is calculated as,

$$
U_{\mathrm{V}}= \pm \sqrt{\left[\frac{\partial \mathrm{V}}{\partial \dot{m}_{o i l}} U_{\dot{m}_{o i l}}\right]^{2}+\left[\frac{\partial \mathrm{V}}{\partial \rho} U_{\rho}\right]^{2}+\left[\frac{\partial \mathrm{V}}{\partial D_{h}} U_{D_{h}}\right]^{2}}
$$




\section{B.2.6 Uncertainty of Oil Reynolds Number}

Reynolds number of motor oil for the current study can be computed from the following:

$$
\begin{gathered}
R e_{o i l}=\frac{\dot{m}_{g}}{51 \pi \mu_{o i l} D_{h}} \\
\frac{\partial R e_{o i l}}{\partial \dot{m}_{o i l}}=\frac{1}{51 \pi \mu_{o i l} D_{h}} \\
\frac{\partial R e_{o i l}}{\partial \mu_{o i l}}=-\frac{\dot{m}_{o i l}}{51 \pi \mu_{o i l}^{2} D_{h}} \\
\frac{\partial R e_{o i l}}{\partial D_{h}}=-\frac{\dot{m}_{o i l}}{51 \pi \mu_{o i l} D^{2} h}
\end{gathered}
$$

The total uncertainty associated with the oil Reynolds number is calculated as,

$$
U_{R e_{o i l}}= \pm \sqrt{\left[\frac{\partial R e_{o i l}}{\partial \dot{m}_{o i l}} U_{\dot{m}_{o i l}}\right]^{2}+\left[\frac{\partial R e_{o i l}}{\partial \mu_{o i l}} U_{\mu_{o i l}}\right]^{2}+\left[\frac{\partial R e_{o i l}}{\partial D_{h}} U_{D_{h}}\right]^{2}}
$$

\section{B.2.7 Uncertainty of Oil Prandtl Number}

Prandtl number can be calculated from the following:

$$
\begin{gathered}
P r_{o i l}=\frac{\mu_{o i l} C p_{o i l}}{k_{o i l}} \\
\frac{\partial P r_{o i l}}{\partial \mu_{o i l}}=\frac{C p_{o i l}}{k_{o i l}} \\
\frac{\partial P r_{o i l}}{\partial C p_{o i l}}=\frac{\mu_{o i l}}{k_{o i l}} \\
\frac{\partial P r_{o i l}}{\partial k_{o i l}}=-\frac{\mu_{o i l} C p_{o i l}}{\left(k_{o i l}\right)^{2}}
\end{gathered}
$$

The total uncertainty associated with the oil Prandtl number is calculated as,

$$
U_{P r_{o i l}}= \pm \sqrt{\left[\frac{\partial P r_{o i l}}{\partial \mu_{o i l}} U_{\mu_{o i l}}\right]^{2}+\left[\frac{\partial P r_{o i l}}{\partial C p_{o i l}} U_{C p_{o i l}}\right]^{2}+\left[\frac{\partial P r_{o i l}}{\partial k_{o i l}} U_{k_{o i l}}\right]^{2}}
$$




\section{B.2.8 Uncertainty of Oil Péclet Number}

Péclet number can be calculated from the following:

$$
\begin{gathered}
P e_{o i l}=R e_{o i l} \cdot P r_{o i l} \\
\frac{\partial P e_{o i l}}{\partial R e_{o i l}}=P r_{o i l} \\
\frac{\partial P e_{o i l}}{\partial P r_{o i l}}=R e_{o i l}
\end{gathered}
$$

The total uncertainty associated with the oil Péclet number is calculated as,

$$
U_{P e_{o i l}}= \pm \sqrt{\left[\frac{\partial P e_{o i l}}{\partial R e_{o i l}} U_{R e_{o i l}}\right]^{2}+\left[\frac{\partial P e_{o i l}}{\partial P r_{o i l}} U_{P r_{o i l}}\right]^{2}}
$$

\section{B.2.9 Uncertainty of Oil Eckert Number}

$$
\begin{gathered}
E c=\frac{V^{2}}{c p\left(T_{\text {oil }, \text { bulk }}-T_{s, i}\right)} \\
\frac{\partial E c}{\partial V}=\frac{2 V}{c p\left(T_{\text {oil }, \text { bulk }}-T_{S, i}\right)} \\
\frac{\partial E c}{\partial c p}=-\frac{V^{2}}{c p^{2}\left(T_{o i l, b u l k}-T_{s, i}\right)} \\
\frac{\partial E c}{\partial T_{o i l, b u l k}}=-\frac{V^{2} c p}{\left[c p\left(T_{o i l, b u l k}-T_{S, i}\right)\right]^{2}} \\
\frac{\partial E c}{\partial T_{s, i}}=\frac{V^{2} c p}{\left[c p\left(T_{o i l, b u l k}-T_{s, i}\right)\right]^{2}}
\end{gathered}
$$

The total uncertainty associated with the oil Eckert number is calculated as,

$$
U_{E c}= \pm \sqrt{\left[\frac{\partial E c}{\partial V} U_{V}\right]^{2}+\left[\frac{\partial E c}{\partial c p} U_{c p}\right]^{2}+\left[\frac{\partial E c}{\partial T_{\text {oil }, \text { bulk }}} U_{T_{\text {oil }, \text { bulk }}}\right]^{2}+\left[\frac{\partial E c}{\partial T_{s, i}} U_{T_{s, i}}\right]^{2}}
$$

\section{B.2.10 Uncertainty of Oil Brinkman Number}

$$
\begin{aligned}
& B r=\frac{\mu V^{2}}{k\left(T_{\text {oil }, \text { bulk }}-T_{s, i}\right)} \\
& \frac{\partial B r}{\partial \mu}=\frac{V^{2}}{k\left(T_{\text {oil,bulk }}-T_{S, i}\right)}
\end{aligned}
$$




$$
\begin{gathered}
\frac{\partial B r}{\partial V}=\frac{2 \mu V}{k\left(T_{o i l, b u l k}-T_{s, i}\right)} \\
\frac{\partial B r}{\partial k}=-\frac{\mu V^{2}}{k^{2}\left(T_{o i l, b u l k}-T_{s, i}\right)} \\
\frac{\partial B r}{\partial T_{o i l, b u l k}}=-\frac{\mu V^{2} k}{\left[k\left(T_{o i l, b u l k}-T_{S, i}\right)\right]^{2}} \\
\frac{\partial B r}{\partial T_{s, i}}=\frac{\mu V^{2} k}{\left[k\left(T_{o i l, b u l k}-T_{s, i}\right)\right]^{2}}
\end{gathered}
$$

The total uncertainty associated with the oil Brinkman number is calculated as,

$$
U_{B r}= \pm \sqrt{\left[\frac{\partial B r}{\partial \mu} U_{\mu}\right]^{2}+\left[\frac{\partial B r}{\partial V} U_{V}\right]^{2}+\left[\frac{\partial B r}{\partial k} U_{k}\right]^{2}+\left[\frac{\partial B r}{\partial T_{\text {oil }, \text { bulk }}} U_{T_{\text {oil }, \text { bulk }}}\right]^{2}+\left[\frac{\partial B r}{\partial T_{s, i}} U_{T_{s, i}}\right]^{2}}
$$

\section{B.2.11 Uncertainty of Oil Heat Transfer Rate}

The oil heat transfer rate depends on the liquid mass flow rate, temperature difference, and the specific heat:

$$
\begin{gathered}
\dot{Q}_{o i l}=\dot{m}_{o i l} c p_{o i l}\left(T_{o i l, i n}-T_{o i l, o u t}\right) \\
\frac{\partial \dot{Q}_{o i l}}{\partial \dot{m}_{o i l}}=c p_{o i l} \Delta T_{o i l} \\
\frac{\partial \dot{Q}_{o i l}}{\partial c p_{o i l}}=\dot{m}_{o i l} \Delta T_{o i l} \\
\frac{\partial \dot{Q}_{o i l}}{\partial \Delta T_{o i l}}=c p_{o i l} \dot{m}_{o i l}
\end{gathered}
$$

The total uncertainty associated with the oil heat transfer rate is calculated as,

$$
U_{\dot{Q}_{o i l}}= \pm \sqrt{\left[\frac{\partial \dot{Q}_{o i l}}{\partial \dot{m}_{o i l}} U_{\dot{m}_{o i l}}\right]^{2}+\left[\frac{\partial \dot{Q}_{o i l}}{\partial c p_{o i l}} U_{c p_{o i l}}\right]^{2}+\left[\frac{\partial \dot{Q}_{o i l}}{\partial \Delta T_{o i l}} U_{\Delta T_{o i l}}\right]^{2}}
$$

\section{B.2.12 Uncertainty of Oil Heat Transfer Coefficient}

$$
\begin{aligned}
h_{\text {oil }} & =\frac{\dot{Q}_{\text {oil }}}{A_{s, \text { oil side }}\left(T_{\text {oil }, \text { bulk }}-T_{S, i}\right)} \\
\frac{\partial h_{\text {oil }}}{\partial \dot{Q}_{\text {oil }}} & =\frac{1}{A_{S, \text { oil side }}\left(T_{\text {oil }, \text { bulk }}-T_{S, i}\right)}
\end{aligned}
$$




$$
\begin{gathered}
\frac{\partial h_{\text {oil }}}{\partial A_{s, \text { oil side }}}=-\frac{\dot{Q}_{\text {oil }}}{A_{s, \text { oil side }}^{2}\left(T_{\text {oil }, \text { bulk }}-T_{S, i}\right)} \\
\frac{\partial h_{\text {oil }}}{\partial T_{\text {oil }, \text { bulk }}}=-\frac{\dot{Q}_{\text {oil }} \cdot A_{S, \text { oil side }}}{\left[A_{S, \text { oil side }}\left(T_{\text {oil }, \text { bulk }}-T_{S, i}\right)\right]^{2}} \\
\frac{\partial h_{\text {oil }}}{\partial T_{S, i}}=\frac{\dot{Q}_{\text {oil }} \cdot A_{S, \text { oil side }}}{\left[A_{S, \text { oil side }}\left(T_{\text {oil }, \text { bulk }}-T_{S, i}\right)\right]^{2}}
\end{gathered}
$$

The total uncertainty associated with the oil heat transfer coefficient is calculated as,

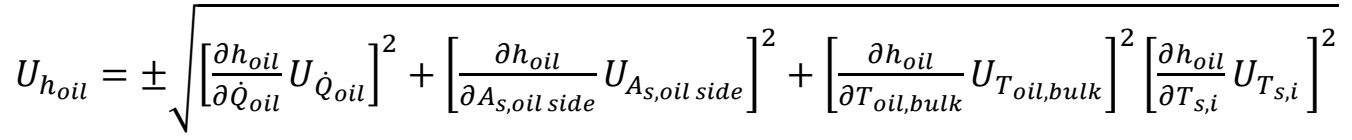

\section{B.2.13 Uncertainty of Oil Nusselt Number}

The average oil Nusselt number can be found from the following relationship:

$$
\begin{gathered}
N u_{o i l, b}=\frac{h_{o i l} D_{h}}{k_{o i l}} \\
\frac{\partial N u_{o i l, b}}{\partial h_{o i l}}=\frac{D_{h}}{k_{o i l}} \\
\frac{\partial N u_{o i l, b}}{\partial D_{h}}=\frac{h_{o i l}}{k_{o i l}} \\
\frac{\partial N u_{o i l, b}}{\partial k_{o i l}}=-\frac{h_{o i l} D_{h}}{\left(k_{o i l}\right)^{2}}
\end{gathered}
$$

The total uncertainty associated with the oil Nusselt number is calculated as,

$$
U_{N u_{o i l, b}}= \pm \sqrt{\left[\frac{\partial N u_{o i l, b}}{\partial h_{o i l}} U_{h_{o i l}}\right]^{2}+\left[\frac{\partial N u_{o i l, b}}{\partial D_{h}} U_{D_{h}}\right]^{2}+\left[\frac{\partial N u_{o i l, b}}{\partial k_{o i l}} U_{k_{o i l}}\right]^{2}}
$$

\section{B.2.14 Uncertainty of Corrected Oil Nusselt Number}

The corrected oil Nusselt number can be found from the following relationship:

$$
\begin{gathered}
N u_{o i l, c}=N u_{o i l, b}\left(\frac{\mu_{\text {bulk }}}{\mu_{\text {wall }}}\right)^{0.14} \\
\frac{\partial N u_{o i l, c}}{\partial N u_{o i l, b}}=\left(\frac{\mu_{\text {bulk }}}{\mu_{\text {wall }}}\right)^{0.14} \\
\frac{\partial N u_{o i l, c}}{\partial \mu_{\text {bulk }}}=N u_{o i l, b}\left(\frac{1}{\mu_{\text {wall }}{ }^{0.14}}\right)\left(0.14 \mu_{\text {bulk }}{ }^{-0.86}\right)
\end{gathered}
$$




$$
\frac{\partial N u_{o i l, c}}{\partial \mu_{\text {wall }}}=N u_{o i l, b}\left(\mu_{\text {bulk }}\right)^{0.14}\left(-0.14 \mu_{\text {wall }}{ }^{-1.14}\right)
$$

The total uncertainty associated with the corrected oil Nusselt number is calculated as,

$$
U_{N u_{o i l, c}}= \pm \sqrt{\left[\frac{\partial N u_{o i l, c}}{\partial N u_{o i l, b}} U_{N u_{o i l, b}}\right]^{2}+\left[\frac{\partial N u_{o i l, c}}{\partial \mu_{b u l k}} U_{\mu_{b u l k}}\right]^{2}+\left[\frac{\partial N u_{o i l, c}}{\partial \mu_{w a l l}} U_{\mu_{\text {wall }}}\right]^{2}}
$$

\section{B.2.15 Uncertainty of Corrected Oil Nusselt Number Empirical Formula}

$$
\begin{aligned}
& N u_{o i l, c}=C \operatorname{Re}_{o i l} \operatorname{Pr}_{o i l}^{1 / 3}\left(\frac{\mu_{\text {bulk }}}{\mu_{\text {wall }}}\right)^{0.14} \\
& \frac{N u_{o i l, c}}{P r_{o i l}^{1 / 3}}=C R e_{o i l}\left(\frac{\mu_{b u l k}}{\mu_{\text {wall }}}\right)^{0.14} \\
& \frac{\partial\left(\frac{N u_{\text {oil c }}}{\operatorname{Pr}_{\text {oil }}^{1 / 3}}\right)}{\partial \operatorname{Re}_{\text {oil }}}=C\left(\frac{\mu_{\text {bulk }}}{\mu_{\text {wall }}}\right)^{0.14} \\
& \frac{\partial\left(\frac{N u_{\text {oil }, c}}{\operatorname{Pr}_{\text {oil }}^{1 / 3}}\right)}{\partial \mu_{\text {bulk }}}=C R e_{\text {oil }}\left(\frac{1}{\mu_{\text {wall }}{ }^{0.14}}\right)\left(0.14 \mu_{\text {bulk }}{ }^{-0.86}\right) \\
& \frac{\partial\left(\frac{N u_{\text {oil }, c}}{\operatorname{Pr}_{\text {oil }}^{1 / 3}}\right)}{\partial \mu_{\text {wall }}}=C R e_{\text {oil }}\left(\mu_{\text {bulk }}\right)^{0.14}\left(-0.14 \mu_{\text {wall }^{-1.14}}\right)
\end{aligned}
$$

The total uncertainty associated with the corrected oil Nusselt number is calculated as,

$$
U_{\partial\left(\frac{N u_{o i l, c}}{\operatorname{Pr}_{\text {oil }}^{1 / 3}}\right)}= \pm \sqrt{\left[\frac{\partial\left(\frac{N u_{o i l, c}}{P r_{\text {oil }}^{1 / 3}}\right)}{\partial R e_{\text {oil }}} U_{R e_{\text {oil }}}\right]^{2}+\left[\frac{\partial\left(\frac{N u_{\text {oil }, c}}{P r_{\text {oil }}^{1 / 3}}\right)}{\partial \mu_{\text {bulk }}} U_{\mu_{\text {bulk }}}\right]^{2}+\left[\frac{\partial\left(\frac{N u_{\text {oil }, c}}{P r_{\text {oil }}^{1 / 3}}\right)}{\partial \mu_{\text {wall }}} U_{\mu_{\text {wall }}}\right]^{2}}
$$

\section{B.2.16 Uncertainty of Pressure Drop}

$$
\begin{gathered}
\Delta P=32 \frac{L}{D^{2}} \mu V \\
\frac{\partial \Delta P}{\partial L}=32 \frac{\mu V}{D^{2}} \\
\frac{\partial \Delta P}{\partial D}=(-2) 32 \frac{L}{D^{3}} \mu V \\
\frac{\partial \Delta P}{\partial \mu}=32 \frac{L V}{D^{2}}
\end{gathered}
$$




$$
\frac{\partial \Delta P}{\partial V}=32 \frac{L \mu}{D^{2}}
$$

The total uncertainty associated with the pressure drop is calculated as,

$$
U_{\Delta P}= \pm \sqrt{\left[\frac{\partial \Delta P}{\partial L} U_{L}\right]^{2}+\left[\frac{\partial \Delta P}{\partial D} U_{D}\right]^{2}+\left[\frac{\partial \Delta P}{\partial \mu} U_{\mu}\right]^{2}\left[\frac{\partial \Delta P}{\partial V} U_{V}\right]^{2}}
$$

\section{B.2.17 Uncertainty of Friction Factor}

$$
\begin{gathered}
f=\Delta P \frac{D}{L} \frac{2}{\rho V^{2}} \\
\frac{\partial f}{\partial \Delta P}=\frac{D}{L} \frac{2}{\rho V^{2}} \\
\frac{\partial f}{\partial D}=\Delta P \frac{1}{L} \frac{2}{\rho V^{2}} \\
\frac{\partial f}{\partial L}=-\Delta P \frac{D}{L^{2}} \frac{2}{\rho V^{2}} \\
\frac{\partial f}{\partial \rho}=-\Delta P \frac{D}{L} \frac{2}{\rho^{2} V^{2}} \\
\frac{\partial f}{\partial V}=(-2) \Delta P \frac{D}{L} \frac{2}{\rho V^{3}}
\end{gathered}
$$

The total uncertainty associated with the friction factor is calculated as,

$$
U_{f}= \pm \sqrt{\left[\frac{\partial f}{\partial \Delta P} U_{\Delta P}\right]^{2}+\left[\frac{\partial f}{\partial D} U_{D}\right]^{2}+\left[\frac{\partial f}{\partial L} U_{L}\right]^{2}+\left[\frac{\partial f}{\partial \rho} U_{\rho}\right]^{2}+\left[\frac{\partial f}{\partial V} U_{V}\right]^{2}}
$$

\section{B.2.18 Uncertainty of Corrected Friction Factor}

The corrected friction factor can be found from the following relationship:

$$
\begin{gathered}
f_{c}=f_{\text {bulk }}\left(\frac{\mu_{\text {bulk }}}{\mu_{\text {wall }}}\right)^{-0.54} \\
\frac{\partial f_{c}}{\partial f_{\text {bulk }}}=\left(\frac{\mu_{\text {bulk }}}{\mu_{\text {wall }}}\right)^{-0.54} \\
\frac{\partial f_{c}}{\partial \mu_{\text {bulk }}}=f_{\text {bulk }}\left(\frac{1}{\mu_{\text {wall }}-0.54}\right)\left(-0.54 \mu_{\text {bulk }}{ }^{-1.54}\right) \\
\frac{\partial f_{c}}{\partial \mu_{\text {wall }}}=f_{\text {bulk }}\left(\mu_{\text {bulk }}\right)^{-0.54}\left(0.54 \mu_{\text {wall }^{-0.46}}{ }^{-0.46}\right.
\end{gathered}
$$


The total uncertainty associated with the corrected friction factor is calculated as,

$$
U_{f_{c}}= \pm \sqrt{\left[\frac{\partial f_{c}}{\partial f_{\text {bulk }}} U_{f_{\text {bulk }}}\right]^{2}+\left[\frac{\partial f_{c}}{\partial \mu_{\text {bulk }}} U_{\mu_{\text {bulk }}}\right]^{2}+\left[\frac{\partial f_{c}}{\partial \mu_{\text {wall }}} U_{\mu_{\text {wall }}}\right]^{2}}
$$

\section{B.2.19 Uncertainty of Normalized Heat Transfer}

$$
\begin{aligned}
& Q^{*}=\frac{\dot{Q}_{\text {oil }}}{A_{\text {frontal }}\left(T_{\text {oil }, \text { in }}-T_{\text {air }, \text { in }}\right)} \\
& \frac{\partial Q^{*}}{\partial \dot{Q}_{\text {oil }}}=\frac{1}{A_{\text {frontal }}\left(T_{o i l, i n}-T_{\text {air }, \text { in }}\right)} \\
& \frac{\partial Q^{*}}{\partial A_{\text {frontal }}}=-\frac{\dot{Q}_{\text {oil }}}{A_{\text {frontal }}^{2}\left(T_{\text {oil }, \text { in }}-T_{\text {air }, \text { in }}\right)} \\
& \frac{\partial Q^{*}}{\partial T_{\text {oil }, \text { in }}}=-\frac{\dot{Q}_{\text {oil }} \cdot A_{\text {frontal }}}{\left[A_{\text {frontal }}\left(T_{\text {oil }, \text { in }}-T_{\text {air }, \text { in }}\right)\right]^{2}} \\
& \frac{\partial Q^{*}}{\partial T_{\text {air }, \text { in }}}=\frac{\dot{Q}_{\text {oil }} \cdot A_{\text {frontal }}}{\left[A_{\text {frontal }}\left(T_{\text {oil }, \text { in }}-T_{\text {air }, \text { in }}\right)\right]^{2}}
\end{aligned}
$$

The total uncertainty associated with the normalized heat transfer is calculated as,

$$
U_{Q^{*}}= \pm \sqrt{\left[\frac{\partial Q^{*}}{\partial \dot{Q}_{o i l}} U_{\dot{Q}_{\text {oil }}}\right]^{2}+\left[\frac{\partial Q^{*}}{\partial A_{\text {frontal }}} U_{A_{\text {frontal }}}\right]^{2}+\left[\frac{\partial Q^{*}}{\partial T_{\text {oil }, \text { in }}} U_{T_{\text {oil }, i n}}\right]^{2}\left[\frac{\partial Q^{*}}{\partial T_{\text {air }, \text { in }}} U_{T_{\text {air }, \text { in }}}\right]^{2}}
$$


Table B.2: Uncertainties Values for Certain Parameters

\begin{tabular}{|c|c|c|c|c|c|c|c|c|}
\hline & $T_{\text {oil,in }}\left({ }^{\circ} \boldsymbol{C}\right)$ & $\boldsymbol{T}_{\text {air,in }}\left({ }^{\circ} \mathrm{C}\right)$ & $\dot{m}_{\text {oil }}\left(\frac{k g}{\min }\right)$ & $V_{\text {air }}\left(\frac{m}{s}\right)$ & $\boldsymbol{U}_{\boldsymbol{R} e_{o i l}}(\%)$ & $\boldsymbol{U}_{\boldsymbol{P r} r_{\text {oil }}}(\%)$ & $\boldsymbol{U}_{P e_{\text {oil }}}(\%)$ & $\boldsymbol{U}_{B r_{o i l}}(\%)$ \\
\hline 1 & 75 & 20 & 0.83 & 6 & 6.25 & 5.17 & 8.11 & 7.75 \\
\hline 2 & 75 & 20 & 0.83 & 10 & 6.21 & 5.12 & 8.04 & 7.71 \\
\hline 3 & 75 & 20 & $\mathbf{0 . 8 3}$ & 14 & 6.21 & 5.13 & 8.05 & 7.56 \\
\hline 4 & 75 & 20 & 0.83 & 18 & 6.19 & 5.11 & 8.02 & 7.56 \\
\hline 5 & 75 & 20 & 0.63 & 6 & 6.19 & 5.09 & 8.01 & 7.69 \\
\hline 6 & 75 & 20 & 0.63 & 10 & 6.19 & 5.07 & 8.00 & 7.62 \\
\hline 7 & 75 & 20 & 0.63 & 14 & 6.14 & 5.04 & 7.94 & 7.40 \\
\hline 8 & 75 & 20 & 0.63 & 18 & 6.17 & 5.08 & 8.00 & 7.42 \\
\hline 9 & 75 & 20 & 0.41 & 6 & 6.19 & 5.09 & 8.01 & 7.49 \\
\hline 10 & 75 & 20 & 0.41 & 10 & 6.17 & 5.06 & 7.98 & 7.40 \\
\hline 11 & 75 & 20 & 0.41 & 14 & 6.14 & 5.03 & 7.93 & 7.29 \\
\hline 12 & 75 & 20 & 0.41 & 18 & 6.12 & 5.01 & 7.91 & 7.32 \\
\hline 13 & 75 & 20 & 0.29 & 6 & 6.17 & 5.06 & 7.98 & 7.49 \\
\hline 14 & 75 & 20 & 0.29 & 10 & 6.19 & 5.06 & 7.99 & 7.43 \\
\hline 15 & 75 & 20 & 0.29 & 14 & 6.20 & 5.05 & 8.00 & 7.49 \\
\hline 16 & 75 & 20 & 0.29 & 18 & 6.17 & 5.03 & 7.96 & 7.40 \\
\hline 17 & 75 & 25 & 0.83 & 6 & 5.70 & 4.49 & 7.26 & 7.85 \\
\hline 18 & 75 & 25 & 0.83 & 10 & 5.63 & 4.42 & 7.16 & 7.58 \\
\hline 19 & 75 & 25 & 0.83 & 14 & 5.64 & 4.43 & 7.18 & 7.52 \\
\hline 20 & 75 & 25 & 0.83 & 18 & 5.66 & 4.44 & 7.19 & 7.50 \\
\hline 21 & 75 & 25 & 0.63 & 6 & 5.69 & 4.43 & 7.22 & 7.78 \\
\hline 22 & 75 & 25 & 0.63 & 10 & 5.68 & 4.41 & 7.19 & 7.62 \\
\hline 23 & 75 & 25 & 0.63 & 14 & 5.69 & 4.42 & 7.20 & 7.56 \\
\hline
\end{tabular}


Study of Motor Oil Cooling at Low Reynolds Number in Multi-Port Narrow Channels

\begin{tabular}{|c|c|c|c|c|c|c|c|c|}
\hline 24 & 75 & 25 & 0.63 & 18 & 5.66 & 4.39 & 7.16 & 7.47 \\
\hline 25 & 75 & 25 & 0.41 & 6 & 5.68 & 4.44 & 7.21 & 7.60 \\
\hline 26 & 75 & 25 & $\begin{array}{c}0.41 \\
\end{array}$ & 10 & 5.74 & 4.46 & 7.27 & 7.65 \\
\hline 27 & 75 & 25 & 0.41 & 14 & 5.56 & 4.15 & 6.94 & 7.45 \\
\hline 28 & 75 & 25 & 0.41 & 18 & 5.68 & 4.36 & 7.16 & 7.42 \\
\hline 29 & 75 & 25 & 0.29 & 6 & 5.70 & 4.40 & 7.20 & 7.51 \\
\hline 30 & 75 & 25 & 0.29 & 10 & 5.65 & 4.38 & 7.15 & 7.32 \\
\hline 31 & 75 & 25 & 0.29 & 14 & 5.66 & 4.38 & 7.16 & 7.27 \\
\hline 32 & 75 & 25 & 0.29 & 18 & 5.65 & 4.29 & 7.09 & 7.32 \\
\hline 33 & 75 & 30 & $\begin{array}{c}0.83 \\
\end{array}$ & 6 & 5.55 & 4.28 & 7.01 & 8.29 \\
\hline 34 & 75 & 30 & $\mathbf{0 . 8 3}$ & 10 & 5.46 & 4.17 & 6.87 & 7.98 \\
\hline 35 & 75 & 30 & 0.83 & 14 & 5.52 & 4.17 & 6.91 & 8.06 \\
\hline 36 & 75 & 30 & \begin{tabular}{c|}
0.83 \\
\end{tabular} & 18 & 5.47 & 4.15 & 6.87 & 7.88 \\
\hline 37 & 75 & 30 & 0.63 & 6 & 5.53 & 4.26 & 6.98 & 8.13 \\
\hline 38 & 75 & 30 & 0.63 & 10 & 5.49 & 4.20 & 6.91 & 7.95 \\
\hline 39 & 75 & 30 & 0.63 & 14 & 5.46 & 4.10 & 6.83 & 7.80 \\
\hline 40 & 75 & 30 & 0.63 & 18 & 5.50 & 4.13 & 6.88 & 7.81 \\
\hline 41 & 75 & 30 & $\mathbf{0 . 4 1}$ & 6 & 5.41 & 4.11 & 6.79 & 7.71 \\
\hline 42 & 75 & 30 & 0.41 & 10 & 5.50 & 4.13 & 6.88 & 7.90 \\
\hline 43 & 75 & 30 & 0.41 & 14 & 5.48 & 4.19 & 6.90 & 7.77 \\
\hline 44 & 75 & 30 & 0.41 & 18 & 5.45 & 4.12 & 6.83 & 7.37 \\
\hline 45 & 75 & 30 & 0.29 & 6 & 5.67 & 4.17 & 7.04 & 8.34 \\
\hline 46 & 75 & 30 & 0.29 & 10 & 5.66 & 4.16 & 7.03 & 8.15 \\
\hline 47 & 75 & 30 & 0.29 & 14 & 5.88 & 4.18 & 7.22 & 8.79 \\
\hline 48 & 75 & 30 & 0.29 & 18 & 5.66 & 4.16 & 7.03 & 8.12 \\
\hline
\end{tabular}




\begin{tabular}{|c|c|c|c|c|c|c|c|c|}
\hline 49 & 75 & 35 & 0.83 & 6 & 5.60 & 4.29 & 7.05 & 9.18 \\
\hline 50 & 75 & 35 & 0.83 & 10 & 5.62 & 4.37 & 7.12 & 8.96 \\
\hline 51 & 75 & 35 & $\mathbf{0 . 8 3}$ & 14 & 5.54 & 4.26 & 6.99 & 8.61 \\
\hline 52 & 75 & 35 & $\mathbf{0 . 8 3}$ & 18 & 5.52 & 4.23 & 6.96 & 8.54 \\
\hline 53 & 75 & 35 & 0.63 & 6 & 5.48 & 4.20 & 6.90 & 8.60 \\
\hline 54 & 75 & 35 & 0.63 & 10 & 5.56 & 4.15 & 6.94 & 8.81 \\
\hline 55 & 75 & 35 & 0.63 & 14 & 5.49 & 4.19 & 6.90 & 8.50 \\
\hline 56 & 75 & 35 & 0.63 & 18 & 5.36 & 3.97 & 6.67 & 8.19 \\
\hline 57 & 75 & 35 & 0.41 & 6 & 5.30 & 3.78 & 6.51 & 8.37 \\
\hline 58 & 75 & 35 & 0.41 & 10 & 5.42 & 4.08 & 6.78 & 8.20 \\
\hline 59 & 75 & 35 & 0.41 & 14 & 5.60 & 4.11 & 6.95 & 8.61 \\
\hline 60 & 75 & 35 & 0.41 & 18 & 5.51 & 4.13 & 6.89 & 8.28 \\
\hline 61 & 75 & 35 & 0.29 & 6 & 5.56 & 4.15 & 6.94 & 8.56 \\
\hline 62 & 75 & 35 & 0.29 & 10 & 5.62 & 4.17 & 7.00 & 8.59 \\
\hline 63 & 75 & 35 & \begin{tabular}{c|}
0.29 \\
\end{tabular} & 14 & 5.23 & 3.82 & 6.48 & 7.91 \\
\hline 64 & 75 & 35 & 0.29 & 18 & 5.41 & 3.87 & 6.66 & 8.37 \\
\hline 65 & 75 & 40 & 0.83 & 6 & 5.36 & 4.05 & 6.71 & 9.95 \\
\hline 66 & 75 & 40 & 0.83 & 10 & 5.37 & 4.01 & 6.71 & 9.65 \\
\hline 67 & 75 & 40 & 0.83 & 14 & 5.42 & 4.03 & 6.75 & 9.68 \\
\hline 68 & 75 & 40 & 0.83 & 18 & 5.33 & 3.96 & 6.64 & 9.41 \\
\hline 69 & 75 & 40 & 0.63 & 6 & 5.37 & 3.91 & 6.64 & 9.70 \\
\hline 70 & 75 & 40 & 0.63 & 10 & 5.23 & 3.74 & 6.43 & 9.32 \\
\hline 71 & 75 & 40 & 0.63 & 14 & 5.19 & 3.68 & 6.36 & 9.02 \\
\hline 72 & 75 & 40 & 0.63 & 18 & 5.22 & 3.70 & 6.40 & 9.02 \\
\hline 73 & 75 & 40 & 0.41 & 6 & 5.10 & 3.65 & 6.28 & 9.13 \\
\hline 74 & 75 & 40 & 0.41 & 10 & 5.16 & 3.68 & 6.34 & 9.04 \\
\hline
\end{tabular}


Study of Motor Oil Cooling at Low Reynolds Number in Multi-Port Narrow Channels

\begin{tabular}{|c|c|c|c|c|c|c|c|c|}
\hline 75 & $\mathbf{7 5}$ & $\mathbf{4 0}$ & $\mathbf{0 . 4 1}$ & $\mathbf{1 4}$ & 5.48 & 3.88 & 6.71 & 9.85 \\
\hline 76 & $\mathbf{7 5}$ & $\mathbf{4 0}$ & $\mathbf{0 . 4 1}$ & $\mathbf{1 8}$ & 5.31 & 3.67 & 6.46 & 9.16 \\
\hline 77 & $\mathbf{7 5}$ & $\mathbf{4 0}$ & $\mathbf{0 . 2 9}$ & $\mathbf{6}$ & 5.48 & 3.77 & 6.65 & 9.71 \\
\hline 78 & $\mathbf{7 5}$ & $\mathbf{4 0}$ & $\mathbf{0 . 2 9}$ & $\mathbf{1 0}$ & 5.35 & 3.71 & 6.51 & 9.29 \\
\hline 79 & $\mathbf{7 5}$ & $\mathbf{4 0}$ & $\mathbf{0 . 2 9}$ & $\mathbf{1 4}$ & 5.63 & 3.66 & 6.71 & 9.83 \\
\hline 80 & $\mathbf{7 5}$ & $\mathbf{4 0}$ & $\mathbf{0 . 2 9}$ & $\mathbf{1 8}$ & 5.59 & 3.62 & 6.66 & 9.81 \\
\hline
\end{tabular}

TABLE 12: Uncertainties Values for Certain Parameters (Continue)

\begin{tabular}{|c|c|c|c|c|c|c|c|c|}
\hline & $\boldsymbol{T}_{\text {oil,in }}\left({ }^{\circ} \mathbf{C}\right)$ & $\boldsymbol{T}_{\text {air,in }}\left({ }^{\circ} \mathbf{C}\right)$ & $\dot{\boldsymbol{m}}_{\text {oil }}\left(\frac{\mathbf{k g}}{\mathbf{m i n}}\right)$ & $\boldsymbol{V}_{\text {air }}\left(\frac{\mathbf{m}}{\mathbf{S}}\right)$ & $\boldsymbol{U}_{\dot{Q}_{\text {oil }}}(\%)$ & $\boldsymbol{U}_{\boldsymbol{h}_{\text {oil }}}(\%)$ & $\boldsymbol{U}_{\boldsymbol{N} u_{\text {oil }, b}}(\%)$ & $\boldsymbol{U}_{\boldsymbol{N} u_{\text {oil, }}}(\%)$ \\
\hline 1 & $\mathbf{7 5}$ & $\mathbf{2 0}$ & $\mathbf{0 . 8 3}$ & $\mathbf{6}$ & 0.50 & 6.70 & 7.55 & 8.48 \\
\hline 2 & $\mathbf{7 5}$ & $\mathbf{2 0}$ & $\mathbf{0 . 8 3}$ & $\mathbf{1 0}$ & 0.61 & 6.66 & 7.52 & 8.48 \\
\hline 3 & $\mathbf{7 5}$ & $\mathbf{2 0}$ & $\mathbf{0 . 8 3}$ & $\mathbf{1 4}$ & 0.55 & 6.51 & 7.38 & 8.37 \\
\hline 4 & $\mathbf{7 5}$ & $\mathbf{2 0}$ & $\mathbf{0 . 8 3}$ & $\mathbf{1 8}$ & 0.43 & 6.55 & 7.41 & 8.41 \\
\hline 5 & $\mathbf{7 5}$ & $\mathbf{2 0}$ & $\mathbf{0 . 6 3}$ & $\mathbf{6}$ & 0.63 & 6.66 & 7.52 & 8.48 \\
\hline 6 & $\mathbf{7 5}$ & $\mathbf{2 0}$ & $\mathbf{0 . 6 3}$ & $\mathbf{1 0}$ & 0.80 & 6.54 & 7.41 & 8.40 \\
\hline 7 & $\mathbf{7 5}$ & $\mathbf{2 0}$ & $\mathbf{0 . 6 3}$ & $\mathbf{1 4}$ & 0.47 & 6.40 & 7.29 & 8.28 \\
\hline 8 & $\mathbf{7 5}$ & $\mathbf{2 0}$ & $\mathbf{0 . 6 3}$ & $\mathbf{1 8}$ & 0.56 & 6.37 & 7.26 & 8.25 \\
\hline 9 & $\mathbf{7 5}$ & $\mathbf{2 0}$ & $\mathbf{0 . 4 1}$ & $\mathbf{6}$ & 0.66 & 6.43 & 7.31 & 8.30 \\
\hline 10 & $\mathbf{7 5}$ & $\mathbf{2 0}$ & $\mathbf{0 . 4 1}$ & $\mathbf{1 0}$ & 0.64 & 6.34 & 7.24 & 8.25 \\
\hline 11 & $\mathbf{7 5}$ & $\mathbf{2 0}$ & $\mathbf{0 . 4 1}$ & $\mathbf{1 4}$ & 0.65 & 6.25 & 7.15 & 8.15 \\
\hline 12 & $\mathbf{7 5}$ & $\mathbf{2 0}$ & $\mathbf{0 . 4 1}$ & $\mathbf{1 8}$ & 0.62 & 6.29 & 7.19 & 8.21 \\
\hline 13 & $\mathbf{7 5}$ & $\mathbf{2 0}$ & $\mathbf{0 . 2 9}$ & $\mathbf{6}$ & 0.75 & 6.42 & 7.30 & 8.29 \\
\hline 14 & $\mathbf{7 5}$ & $\mathbf{2 0}$ & $\mathbf{0 . 2 9}$ & $\mathbf{1 0}$ & 0.79 & 6.33 & 7.22 & 8.23 \\
\hline 15 & $\mathbf{7 5}$ & $\mathbf{2 0}$ & $\mathbf{0 . 2 9}$ & $\mathbf{1 4}$ & 0.93 & 6.34 & 7.23 & 8.26 \\
\hline
\end{tabular}




\begin{tabular}{|c|c|c|c|c|c|c|c|c|}
\hline 16 & 75 & 20 & 0.29 & 18 & 0.90 & 6.26 & 7.17 & 8.20 \\
\hline 17 & 75 & 25 & 0.83 & 6 & 0.59 & 7.26 & 8.05 & 8.93 \\
\hline 18 & 75 & 25 & 0.83 & 10 & 0.41 & 7.05 & 7.86 & 8.75 \\
\hline 19 & 75 & 25 & 0.83 & 14 & 0.49 & 6.96 & 7.78 & 8.68 \\
\hline 20 & 75 & 25 & 0.83 & 18 & 0.49 & 6.93 & 7.76 & 8.69 \\
\hline 21 & 75 & 25 & 0.63 & 6 & 0.86 & 7.14 & 7.95 & 8.85 \\
\hline 22 & 75 & 25 & 0.63 & 10 & 0.89 & 6.96 & 7.78 & 8.68 \\
\hline 23 & 75 & 25 & 0.63 & 14 & 0.89 & 6.90 & 7.73 & 8.65 \\
\hline 24 & 75 & 25 & 0.63 & 18 & 0.90 & 6.81 & 7.65 & 8.58 \\
\hline 25 & 75 & 25 & 0.41 & 6 & 0.76 & 6.98 & 7.80 & 8.73 \\
\hline 26 & 75 & 25 & 0.41 & 10 & 0.99 & 6.92 & 7.75 & 8.68 \\
\hline 27 & 75 & 25 & 0.41 & 14 & 1.33 & 6.73 & 7.58 & 8.50 \\
\hline 28 & 75 & 25 & 0.41 & 18 & 1.14 & 6.68 & 7.53 & 8.48 \\
\hline 29 & 75 & 25 & 0.29 & 6 & 1.06 & 6.78 & 7.62 & 8.55 \\
\hline 30 & 75 & 25 & 0.29 & 10 & 0.84 & 6.68 & 7.53 & 8.49 \\
\hline 31 & 75 & 25 & 0.29 & 14 & 0.94 & 6.58 & 7.45 & 8.40 \\
\hline 32 & 75 & 25 & 0.29 & 18 & 1.24 & 6.55 & 7.41 & 8.41 \\
\hline 33 & 75 & 30 & 0.83 & 6 & 0.69 & 7.83 & 8.57 & 9.33 \\
\hline 34 & 75 & 30 & 0.83 & 10 & 0.64 & 7.58 & 8.34 & 9.12 \\
\hline 35 & 75 & 30 & 0.83 & 14 & 1.05 & 7.53 & 8.29 & 9.12 \\
\hline 36 & 75 & 30 & 0.83 & 18 & 0.84 & 7.42 & 8.20 & 9.03 \\
\hline 37 & 75 & 30 & 0.63 & 6 & 0.64 & 7.69 & 8.44 & 9.19 \\
\hline 38 & 75 & 30 & 0.63 & 10 & 0.77 & 7.50 & 8.26 & 9.04 \\
\hline
\end{tabular}




\begin{tabular}{|c|c|c|c|c|c|c|c|c|}
\hline 39 & 75 & 30 & 0.63 & 14 & 1.02 & 7.29 & 8.08 & 8.90 \\
\hline 40 & 75 & 30 & 0.63 & 18 & 1.11 & 7.25 & 8.04 & 8.86 \\
\hline 41 & 75 & 30 & 0.41 & 6 & 0.65 & 7.32 & 8.11 & 8.93 \\
\hline 42 & 75 & 30 & 0.41 & 10 & 1.10 & 7.36 & 8.14 & 8.97 \\
\hline 43 & 75 & 30 & 0.41 & 14 & 0.72 & 7.32 & 8.10 & 8.93 \\
\hline 44 & 75 & 30 & 0.41 & 18 & 0.84 & 6.89 & 7.72 & 8.59 \\
\hline 45 & 75 & 30 & 0.29 & 6 & 1.67 & 7.49 & 8.26 & 9.11 \\
\hline 46 & 75 & 30 & 0.29 & 10 & 1.65 & 7.30 & 8.08 & 8.91 \\
\hline 47 & 75 & 30 & 0.29 & 14 & 2.26 & 7.53 & 8.29 & 9.14 \\
\hline 48 & 75 & 30 & 0.29 & 18 & 1.66 & 7.25 & 8.04 & 8.90 \\
\hline 49 & 75 & 35 & 0.83 & 6 & 0.95 & 8.68 & 9.35 & 9.99 \\
\hline 50 & 75 & 35 & 0.83 & 10 & 0.69 & 8.49 & 9.18 & 9.83 \\
\hline 51 & 75 & 35 & 0.83 & 14 & 0.73 & 8.16 & 8.87 & 9.56 \\
\hline 52 & 75 & 35 & 0.83 & 18 & 0.77 & 8.10 & 8.81 & 9.53 \\
\hline 53 & 75 & 35 & 0.63 & 6 & 0.67 & 8.20 & 8.91 & 9.60 \\
\hline 54 & 75 & 35 & 0.63 & 10 & 1.30 & 8.22 & 8.92 & 9.65 \\
\hline 55 & 75 & 35 & 0.63 & 14 & 0.76 & 8.08 & 8.80 & 9.48 \\
\hline 56 & 75 & 35 & 0.63 & 18 & 1.01 & 7.79 & 8.53 & 9.25 \\
\hline 57 & 75 & 35 & 0.41 & 6 & 1.36 & 7.91 & 8.64 & 9.33 \\
\hline 58 & 75 & 35 & 0.41 & 10 & 0.88 & 7.78 & 8.52 & 9.27 \\
\hline 59 & 75 & 35 & 0.41 & 14 & 1.58 & 7.88 & 8.61 & 9.36 \\
\hline 60 & 75 & 35 & 0.41 & 18 & 1.18 & 7.73 & 8.47 & 9.21 \\
\hline 61 & 75 & 35 & 0.29 & 6 & 1.29 & 7.96 & 8.68 & 9.39 \\
\hline 62 & 75 & 35 & 0.29 & 10 & 1.50 & 7.88 & 8.61 & 9.36 \\
\hline
\end{tabular}


Study of Motor Oil Cooling at Low Reynolds Number in Multi-Port Narrow Channels

\begin{tabular}{|c|c|c|c|c|c|c|c|c|}
\hline 63 & 75 & 35 & 0.29 & 14 & 0.91 & 7.60 & 8.36 & 9.07 \\
\hline 64 & 75 & 35 & 0.29 & 18 & 1.52 & 7.77 & 8.52 & 9.24 \\
\hline 65 & 75 & 40 & 0.83 & 6 & 0.57 & 9.69 & 10.30 & 11.00 \\
\hline 66 & 75 & 40 & 0.83 & 10 & 0.91 & 9.32 & 9.95 & 10.62 \\
\hline 67 & 75 & 40 & 0.83 & 14 & 1.06 & 9.30 & 9.93 & 10.60 \\
\hline 68 & 75 & 40 & 0.83 & 18 & 0.90 & 9.10 & 9.74 & 10.40 \\
\hline 69 & 75 & 40 & 0.63 & 6 & 1.25 & 9.30 & 9.93 & 10.57 \\
\hline 70 & 75 & 40 & 0.63 & 10 & 1.16 & 9.00 & 9.65 & 10.25 \\
\hline 71 & 75 & 40 & 0.63 & 14 & 1.20 & 8.70 & 9.37 & 10.03 \\
\hline 72 & 75 & 40 & 0.63 & 18 & 1.24 & 8.68 & 9.36 & 10.01 \\
\hline 73 & 75 & 40 & 0.41 & 6 & 0.82 & 8.96 & 9.61 & 10.21 \\
\hline 74 & 75 & 40 & 0.41 & 10 & 1.04 & 8.79 & 9.45 & 10.08 \\
\hline 75 & 75 & 40 & 0.41 & 14 & 1.72 & 9.23 & 9.87 & 10.54 \\
\hline 76 & 75 & 40 & 0.41 & 18 & 1.64 & 8.64 & 9.31 & 9.96 \\
\hline 77 & 75 & 40 & 0.29 & 6 & 1.96 & 8.99 & 9.64 & 10.24 \\
\hline 78 & 75 & 40 & 0.29 & 10 & 1.69 & 8.74 & 9.40 & 10.06 \\
\hline 79 & 75 & 40 & 0.29 & 14 & 2.51 & 8.75 & 9.42 & 10.10 \\
\hline 80 & 75 & 40 & 0.29 & 18 & 2.49 & 8.76 & 9.43 & 10.10 \\
\hline
\end{tabular}




\section{APPENDIX (C) TEST SPECIMEN GEOMETRICAL PARAMETERS}

Table C.1: Important Dimensions of the Test Specimen

\begin{tabular}{|c|c|c|c|}
\hline $\begin{array}{l}\text { Geometrical } \\
\text { Parameter }\end{array}$ & Description and Formula & Value & $\begin{array}{l}\text { Uncertainty } \\
\qquad \%)\end{array}$ \\
\hline$D_{i}$ & Channel Inside Diameter, (m) & 0.001 & \pm 3.48 \\
\hline$D_{o}$ & Channel Outside Diameter, (m) & 0.002 & \pm 0.5 \\
\hline$D_{h}$ & Channel Hydraulic Diameter, (m) & 0.001 & \pm 3.48 \\
\hline$D_{c}$ & Serpentine Curvature Diameter, (m) & 0.022 & \\
\hline$L$ & Individual Channel Length in One Slab, (m) & 0.304 & \pm 0.15 \\
\hline$A_{C S, M C}$ & Cross-Sectional Area of an Individual Channel, $\left(\mathrm{m}^{2}\right)$ & $7.85 \times 10^{-7}$ & \pm 6.96 \\
\hline$A_{S, M C}$ & $\begin{array}{l}\text { Inner Heat Transfer Surface Area of an Individual } \\
\text { minichannel, }\left(\mathrm{m}^{2}\right)\end{array}$ & $9.67 \times 10^{-4}$ & \pm 3.49 \\
\hline$A_{s, \text { oil side }}$ & $\begin{array}{l}\text { Total Inner Heat Transfer Surface Area of all } \\
\text { minichannels, }\left(\mathrm{m}^{2}\right)\end{array}$ & 0.975 & \pm 3.49 \\
\hline$A_{\text {frontal }}$ & $\begin{array}{l}\text { Frontal Area of the Minichannel Heat Exchanger, } \\
\qquad\left(\mathrm{m}^{2}\right)\end{array}$ & 0.08748 & \pm 0.29 \\
\hline
\end{tabular}




\section{APPENDIX (D) SIMPLIFICATION OF AXIAL HEAT CONDUCTION PARAMETER}

$$
M=\frac{Q_{\text {cond }}}{Q_{\text {conv }}}=\frac{k_{\text {wall }} A_{\text {wall }} \frac{\Delta T_{\text {wall }}}{L}}{\dot{m} c_{p} \Delta T_{\text {futa }}}
$$

Adding the $\left(\frac{R e}{R e}\right)\left(\frac{P r}{P r}\right)$

$$
M=\frac{k_{\text {wall }} A_{\text {wall }}}{\dot{m} c_{p} L}\left(\frac{R e}{R e}\right)\left(\frac{P r}{P r}\right)
$$

Where $\quad \operatorname{Pr}=\frac{\mu c_{p}}{k_{\text {fluid }}}, \operatorname{Re}=\frac{\rho V D_{i}}{\mu}$ and $\dot{m}=\rho V A_{c s, M C}$

$$
\begin{gathered}
M=\frac{k_{\text {wall }} A_{\text {wall }}}{\rho V A_{c s} c_{p} L}\left(\frac{1}{R e}\right)\left(\frac{1}{\text { Pr }}\right) \cdot\left(\frac{\mu c_{p}}{k_{\text {fluid }}}\right) \cdot\left(\frac{\rho V D_{i}}{\mu}\right) \\
M=\left(\frac{k_{\text {wall }}}{k_{\text {fluid }}}\right) \cdot\left(\frac{D_{i}}{L}\right) \cdot\left(\frac{A_{\text {wall }}}{A_{c s}}\right) \cdot\left(\frac{1}{\operatorname{RePr}}\right)
\end{gathered}
$$

Where $\quad A_{c s}=\frac{\pi}{4}\left(D_{i}^{2}\right) \quad$ and $\quad A_{\text {wall }}=\frac{\pi}{4}\left(D_{o}^{2}-D_{i}^{2}\right)$

$$
M=\left(\frac{k_{\text {wall }}}{k_{\text {fluid }}}\right) \cdot\left(\frac{D_{i}}{L}\right) \cdot\left(\frac{\frac{\pi}{4}\left(D_{o}^{2}-D_{i}^{2}\right)}{\frac{\pi}{4}\left(D_{i}^{2}\right)}\right) \cdot\left(\frac{1}{\operatorname{RePr}}\right)
$$

Hence,

$$
M=\left(\frac{k_{\text {wall }}}{k_{\text {fluid }}}\right) \cdot\left(\frac{\left(D_{o}^{2}-D_{i}^{2}\right)}{\left(D_{i} L\right)}\right) \cdot\left(\frac{1}{R e P r}\right)
$$




\section{REFERENCES}

Arici, M.E., and O. Aydin. "Conjugate Heat Transfer in Thermally Developing Laminar Flow with Viscous Dissipation Effects." Heat and Mass Transfer. 45.9 (2009): 1199-1203.

"Air cooled heat exchangers. An American National Standard, Performance Test Code (PTC) 30." American Society of Mechanical Engineers (ASME). NY, USA, 1991.

Can-Am Instruments Limited, 2851 Brighton Road, Oakville, Ontario, L6H 6C9. Çengel, Yunus A. Heat and Mass Transfer: A practical Approach. Third Edition. New York: McGraw Hill, 2007.

Çengel, Yunus A, and Michael A. Boles. Thermodynamics:An Engineering Approach. Fourth Edition. New York: McGraw Hill, 2002

Cetin, Barbaros, Almila Guvenc Yazicioglu, and Sadık Kakac. "Fluid Flow in Microtubes with Axial Conduction Including Rarefaction and Viscous Dissipation." International Communications in Heat and Mass Transfer. 35.5 (2008): 535-544.

Çetin, Barbaros , Almila Güvenç Yaziciog̃lu, et al. "Slip-Flow Heat Ttransfer in Microtubes with Axial Conduction and Viscous Dissipation - An Extended Graetz Problem." International Journal of Thermal Sciences. 48.9 (2009): 16731678.

Choi, S.B., R.R. Barren, and R.Q. Warrington. "Fluid Flow and Heat Transfer in Microtubes." Micromechanical Sensors, Actuators, and systems, ASME DSC. 32. (1991): 89-90. 
Cole, Kevin D., and Barbaros Çetin. "The Effect of Axial Conduction on Heat Transfer in a Liquid Microchannel Flow." International Journal of Heat and Mass Transfer. 54.11-12 (2011): 2542-2549.

Cui, Hai-hang, and Zhan-hua Silber-Li. "Flow Characteristics of Liquids in Microtubes Driven by a High Pressure." Physics of Fluids. 16.5 (2004): 1803-1810.

Dasgupta, E.S. "Experimental Study on Heat Transfer and Flow Characteristics of Air Cooling through Cross-Flow Microchannel Heat Exchanger." M.A.Sc. Thesis, University of Windsor, Canada, 2011.

Deissler, Robert G. "Analytical Investigation of Fully Developed Laminar Flow in Tubes with Heat Transfer with Fluid Properties Variable along the Radius." NACA, Washington (July, 1951).

Fox, Robert W., Alan T. Mcdonald, and Philip J. Pritchard. Introduction to Fluid Mechanics. Sixth. John Wiley \& Sons, Inc., 2004. 273-309.

Gan, Yunhua, Zeliang Yang, et al. "Effect of Axial Heat Conduction on Heat Transfer in Triangular Silicon Microchannels." Micro/Nanoscale Heat Transfer International Conference. (2008): 859-866.

Gamrat, Gabriel, Michel Favre-Marinet, and Dariusz Asendrych. "Conduction and Entrance Effects on Laminar Liquid Flow and Heat Transfer in Rectangular Microchannels." International Journal of Heat and Mass Transfer. 48.14 (2005): 2943-2954.

Gui, Fulin, and Roperto P. Scaringe. "Enhanced heat transfer in the entrance region of microchannels." Energy technologies for a sustainable future; proceedings of the 30th Intersociety Energy Conversion Engineering Conference. (1995): 289-294. 
Heisler, Heinz. Vehicle and Engine Technology. Second Edition. London, UK: Elsevier, 1999.

Herwig, H. "Flow and Heat Transfer in Micro Systems: Is Everything Different or Just Smaller." Journal of Applied Mathematics and Mechanics. 82.9 (2002): 579-586.

Herwig, H., and O. Hausner. "Critical View on "New Results in Micro-Fluid Mechanics": an example." International Journal of Heat and Mass Transfer. 46.5 (2003): 935-937.

Hetsroni, G., M. Gurevich, et al. "Drag Reduction and Heat Transfer of Surfactants Flowing in a Capillary Tube." International Journal of Heat and Mass Transfer. 47.17-18 (2004): 3797-3809.

Hetsroni, G., A. Mosyak, et al. "Fluid Flow in Microchannels." International Journal of Heat and Mass Transfer. 48.10 (2005): 1982-1998.

Iyengar, M. , and S. Garimella. "Design and Optimization of Microchannel Cooling Systems ." Tenth Intersociety Conference on Thermal and Thermomechanical Phenomena in Electronics Systems. (2006): 54 - 62.

Jeong, Ho-Eyoul, and Jae-Tack Jeong. "Extended Graetz Problem Including Streamwise Conduction and Viscous Dissipation in Microchannel." International Journal of Heat and Mass Transfer. 49.13-14 (2006): 2151-2157.

JiangFeng, Guo, Xu MingTian, et al. "The Influence of Viscous Heating on the Entransy in Two-Fluid Heat Exchangers." Science China Technological Sciences. 54.5 (2011): 1267-1274. 
Jiang, X.N., Z.Y. Zhou, et al. "Micro-Fluid Flow in Microchannels." 8th International Conference on Solid-State Sensors and Actuators, and Eurosensors IX. (1995): $317-320$.

Kandlikar, Satish G. "Microchannels and Minichannels-History, Terminology, Classification and Current Research Needs." First International Conference on Microchannels and Minichannels, NY, USA. (2003)

Kandlikar, Satish, Shailesh Joshi, and Shurong Tian. "Effect of Surface Roughness on Heat Transfer and Fluid Flow Characteristics at Low Reynolds Numbers in Small Diameter Tubes." Heat Transfer Engineering. 24.3 (2003): 4-16.

Kandlikar, S. G., and W. J. Grande. "Evaluation of Single Phase Flow in Microchannels for High Heat Flux Chip Cooling-Thermohydraulic Performance Enhancement and Fabrication Technology." Heat Transfer Engineering . 25.8 (2004): 5-16.

Kandlikar, S. G., and Michael R. King. Heat Transfer and Fluid Flow in Minichannels and Microchannels . First Edition. Amsterdam ; Boston : Elsevier, 2006.

Khan, Mesbah G., and Amir Fartaj. "A Review on Microchannel Heat Exchangers and Potential Applications." International Journal of Energy Research. 35.7 (2011): $553-582$.

Khan, Mesbah. "Experimental Investigation of Heat Transfer and Pressure Drop Characteristics of Water and Glycol-Water Mixture in Multi-Port Serpentine Microchannel Slab Heat Exchangers." Ph.D. Thesis, University of Windsor, Ontario, Canada, 2011. 
Koo, J., and C. Kleinstreuer. "Viscous Dissipation Effects in Microtubes and Microchannels." International Journal of Heat and Mass Transfer. 47.14-16 (2004): 3159-3169.

Li, J., G.P. Peterson, et al. "Three-Dimensional Analysis of Heat Transfer in a MicroHeat Sink with Single Phase Flow." International Journal of Heat and Mass Transfer. 47.19-20 (2004): 4215-4231.

Li, Zhuo, Ya-Ling He, et al. "Experimental and Numerical Studies of Liquid Flow and Heat Transfer in Microtubes." International Journal of Heat and Mass Transfer. 50.17-18 (2007): 3447-3460.

Maranzana, Gaël, Isabelle Perry, and Denis Maillet. "Mini- and Micro-Channels: Influence of Axial Conduction in the Walls." International Journal of Heat and Mass Transfer. 47.17-18 (2004): 3993-4004.

Medendale, S. S., A. M. Jacobi, et al. "Fluid Flow and Heat Transfer at Micro- and MesoScales With Application to Heat Exchanger Design." Applied Mechanics Reviews. 53.7 (2000): 175-193.

Morini, Gian Luca. "Viscous Heating in Liquid Flows in Micro-Channels." International Journal of Heat and Mass Transfer. 48.17 (2005): 3637-3647.

Morini, Gian Luca. "Scaling Effects for Liquid Flows in Microchannels." Heat Transfer Engineering. 27.4 (2006): 64-73.

Nonino, C. , S. Savino, et al. "Conjugate Forced Convection and Heat Conduction in Circular Microchannels." International Journal of Heat and Fluid Flow. 30.5 (2009): 823-830. 
Park, Ho Joon, Sang Young Son, et al. "Temperature-Dependent Property Effects on Laminar Flow Characteristics in a Rectangular Microchannel ." Proceedings of 2001 ASME International Mechanical Engineering Congress and Exposition. (2001)

Peterson, R. B. "Numerical Modeling of Conduction Effects in Microscale Counterflow Heat Exchangers." Microscale Thermophysical Engineering. 3.1 (1999): 17-30. Phillips, Richard J. "Forced-Convection, Liquid-Cooled, Microchannel Heat Sinks." M.A.Sc. Thesis, Massachusetts Institute of Technology, US, 1987.

"Physical and Chemical Properties of Engine Oils." SAE Fuels and Lubricants Technical Committee. J375. (2006)

Qu, Weilin, Gh. Mohiuddin Mala, and Dongqing Li. "Heat Transfer for Water Flow in Trapezoidal Silicon Microchannels." International Journal of Heat and Mass Transfer. 43.21 (2000): 3925-3936

Qu, Weilin, and Issam Mudawar. "Experimental and Numerical Study of Pressure Drop and Heat Transfer in a Single-Phase Micro-Channel Heat Sink." International Journal of Heat and Mass Transfer . 45.12 (2002): 2549-2565.

Quaiyum, Md Abdul. "Experimental Investigation of Automatic Transmission Fluid $(A T F)$ in an Air Cooled Minichannel Heat Exchanger." M.A.Sc. Thesis, University of Windsor, Canada, 2012.

Shah, R.K., and A.L. London. Laminar Flow Forced Convection in Ducts: A source Book for Compact Heat Exchangers Analytical Data. New York: Academic Press, Inc, 1978. 
Shah, Ramesh K., and Dušan P. Sekulić. Fundamentals of Heat Exchanger Design . New Jersey: John Wiley \& Sons, Inc, 2003.

Shannon, R. L., and C. A. Depew. "Forced Laminar Flow Convection in a Horizontal Tube with Variable Viscosity and Free Convection Effects." Journal of Heat Transfer. 91.2 (1962): 251-258.

Shin, Sehyun S, and Young Cho. "Improved Heat Transfer Design of a Liquid Cooling Module: the Use of Variable Viscosity Liquids in a 2:1 Rectangular Duct ." ASME International Electronics Packaging Conference. (1993): 641-648.

Siddiqui, Faisal. "A Study of Cross-Flow Air Heating via a Multiport Serpentine Microchannel Heat Exchanger." M.A.Sc. Thesis, University of Windsor, Canada, 2011.

Sieder, E. N. , and G. E. Tate. "Heat Transfer and Pressure Drop of Liquids in Tubes." Industrial and Engineering Chemistry. 28.12 (1936): 1429-1435.

Steinke ${ }^{1}$, Mark E., Satish G. Kandlikar, et al. "Development of an Experimental Facility for Investigating Single-Phase Liquid Flow in Microchannels." Heat Transfer Engineering. 27.4 (2006): 41-52.

Steinke $^{2}$, Mark E., and Satish G. Kandlikar. "Single-Phase Liquid Friction Factors in Microchannels." International Journal of Thermal Sciences. 45.11 (2006): 10731083.

Tiselj, I, G. Hetsroni, et al. "Effect of Axial Conduction on the Heat Transfer in MicroChannels." International Journal of Heat and Mass Transfer. 47.12-13 (2004): 2551-2565. 
Tso, C.P., and S.P. Mahulikar. "The Use of the Brinkman Number for Single Phase Forced Convective Heat Transfer in Microchannels." International Journal of Heat and Mass Transfer. 41.12 (1998): 1759-1769.

Tso, C.P., and S.P. Mahulikar. "Experimental Verification of the Role of Brinkman Number in Microchannel Using Local Parameters." International Journal of Heat and Mass Transfer. 43.10 (2000): 1837 - 1849.

Tuckerman, D.B., and R.F.W. Pease. "High-Performance Heat Sinking for VLSI." IEEE Electron Device Letters. EDL-2.5 (1981): 126-129.

Tunc, Gokturk , and Yildiz Bayazitoglu. "Heat Transfer in Microtubes with Viscous Dissipation." International Journal of Heat and Mass Transfer. 44.13 (2001): 2395-2403.

Vashisth, Subhashini, Vimal Kumar, and Krishna D. P. Nigam. "A Review on the Potential Applications of Curved Geometries in Process Industry." Industrial \& Engineering Chemistry Research. 47.10 (2008): 3291-3337.

Wu, H.Y., and Ping Cheng. "An Experimental Study of Convective Heat Transfer in Silicon Microchannels with Different Surface Conditions." International Journal of Heat and Mass Transfer. 46.14 (2003): 2547-2556.

Xie, C., and J.P. Hartnett. "Influence of Variable Viscosity of Mineral Oil on Laminar Heat Transfer in a 2:1 Rectangular Duct." International Journal of Heat and Mass Transfer. 35.3 (1992): 641-648.

Xu, B., K.T. Ooi, et al. "Viscous Dissipation Effects for Liquids Flow in Microchannels." (2002): 100-103. 
Yataghene, Mourad, , et al. "Experimental and Numerical Analysis of Heat Transfer Including Viscous Dissipation in a Scraped Surface Heat Exchanger." Chemical Engineering and Processing: Process Intensification. 48.10 (2009): 1447-1458. 


\section{VITA AUCTORIS}

Name:

Place of Birth:

Year of Birth:
Mohammed Sami Saadi

Logan, Utah State, United States of America

In 2007, Mohammed completed Bachelor's Degree in Applied Mechanical Engineering from the King Fahd University of Petroleum and Minerals (KFUPM) in Dhahran, Saudi Arabia. In 2008, he was hired by Saudi Aramco, a global oil company located in Saudi Arabia, as a maintenance Engineer. Then, he moved to Canada in 2010 to pursue higher educational degree. He is currently a candidate for Master Degree in Applied Science in Mechannical Engineering at the University of Windsor, Windsor, Ontario, Canada. 